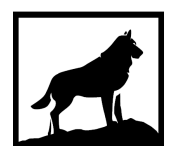

Michigan

Technological

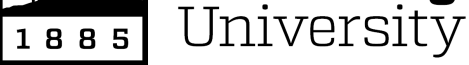

Michigan Technological University

Digital Commons @ Michigan Tech

2016

INTEGRATED COMPUTATIONAL AND EXPERIMENTAL

EVALUATION OF ELECTROMAGNETIC ENERGY-INDUCED SELFHEALING PERFORMANCE OF ASPHALT COMPOSITES

Zigeng Wang

Michigan Technological University, zigengw@mtu.edu

Copyright 2016 Zigeng Wang

Recommended Citation

Wang, Zigeng, "INTEGRATED COMPUTATIONAL AND EXPERIMENTAL EVALUATION OF

ELECTROMAGNETIC ENERGY-INDUCED SELF-HEALING PERFORMANCE OF ASPHALT COMPOSITES",

Open Access Dissertation, Michigan Technological University, 2016.

https://doi.org/10.37099/mtu.dc.etdr/220

Follow this and additional works at: https://digitalcommons.mtu.edu/etdr

Part of the Civil Engineering Commons 


\title{
INTEGRATED COMPUTATIONAL AND EXPERIMENTAL EVALUATION OF ELECTROMAGNETIC ENERGY-INDUCED SELF-HEALING PERFORMANCE OF ASPHALT COMPOSITES
}

\author{
By \\ Zigeng Wang
}

\begin{abstract}
A DISSERTATION
Submitted in partial fulfillment of the requirements for the degree of DOCTOR OF PHILOSOPHY

In Civil Engineering
\end{abstract}

MICHIGAN TECHNOLOGICAL UNIVERSITY

2016

(C) 2016 Zigeng Wang 
This dissertation has been approved in partial fulfillment of the requirements for the Degree of DOCTOR OF PHILOSOPHY in Civil Engineering.

Department of Civil and Environmental Engineering

Dissertation Advisor: $\quad$ Qingli Dai

Committee Member: Zhanping You

Committee Member: Jacob Hiller

Committee Member: Patricia A. Heiden

Department Chair: $\quad$ David W. Hand 


\section{TABLE OF CONTENTS}

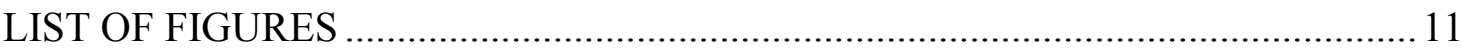

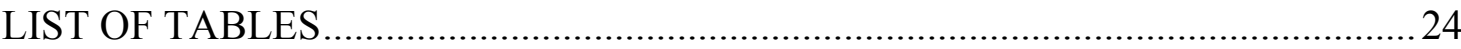

PREFACE

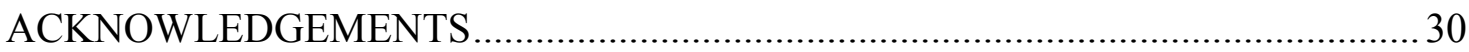

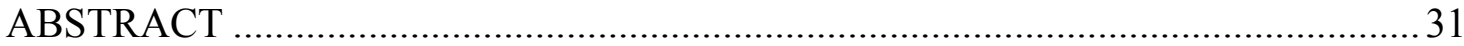

CHAPTER 1 INTRODUCTION AND LITERATURE REVIEW …................................ 33

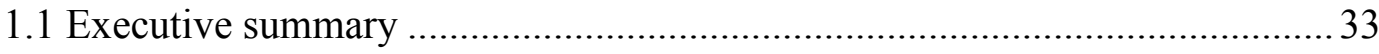

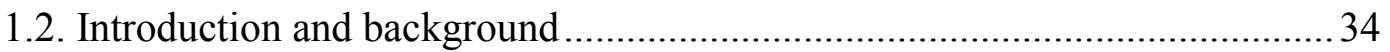

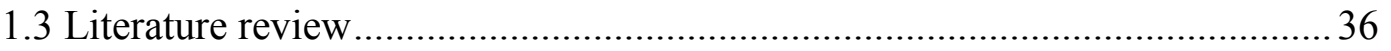

1.3.1 Performance tests of asphalt binder and mixture............................................36

1.3.2 Self-healing of asphalt and asphalt mixture........................................... 38

1.3.3 Accelerated self-healing of asphalt mixture ...................................... 42

1.4 Objectives and scopes of research ................................................................... 44

1.4.1 Research Methodology and Tasks ....................................................... 45

CHAPTER 2 EXPERIMENTAL TESTS ON ASPHALT MIXTURE SAMPLES

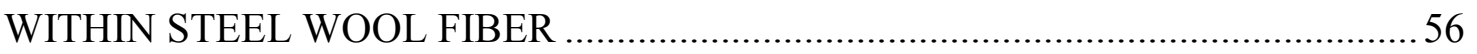

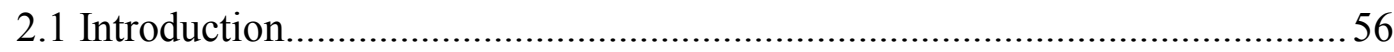

2.2 Mixture design and sample preparation.....................................................5

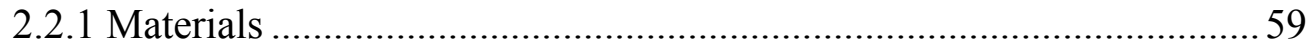

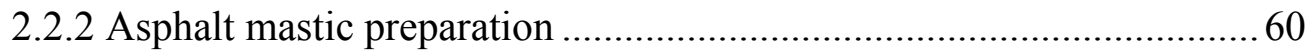

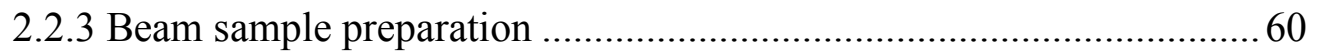


2.3 Mechanism of induction heating of asphalt materials 61

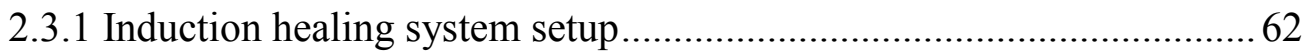

2.3.2 Resistivity measurement of prepared samples.......................................63

2.3.3 Temperature distribution of induction heated concrete samples ...........66

2.4 Fracture-healing cyclic study of asphalt mastic samples with three-point beam

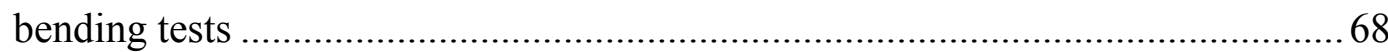

2.4.1 Fracture-healing tests of asphalt mastic samples....................................68

2.4.2 Fracture-healing test results with asphalt mastic samples .....................69

2.5 Fracture-healing investigation of asphalt concrete samples using beam

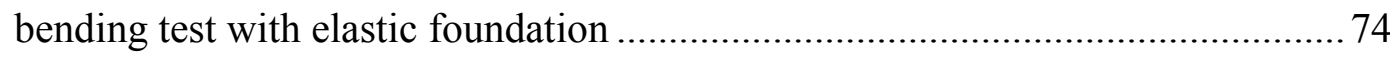

2.5.1 Fracture-healing tests of asphalt concrete samples............................... 74

2.5.2 Fracture-healing test results on asphalt concrete samples .................... 75

2.5.3 Changes of electrical resistivity during fracture-healing cycles............81

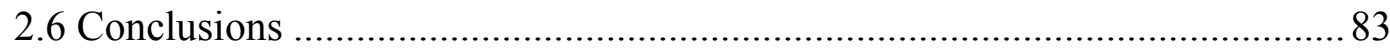

CHAPTER 3 COHESIVE ZONE MODEL DEVELOPMENT FOR ASPHALT

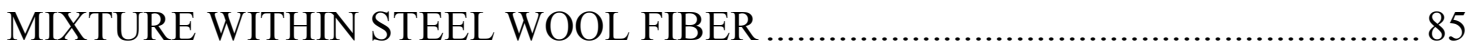

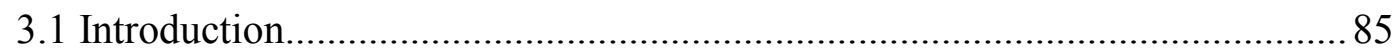

3.2 Fracture-induction healing test results of asphalt concrete samples..................8 88

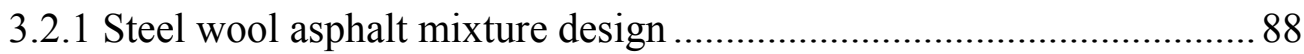

3.2.2 Cyclic fracture-induction healing test of asphalt concrete material .....89

3.3 Cohesive fracture model and numerical implementation ................................ 91

3.3.1 Bilinear cohesive zone model ............................................................ 91 
3.3.2 Numerical implementation of bilinear cohesive zone model .95

3.4 Cohesive fracture simulation and comparison of three-point bending tests....97

3.4.1 Measurement of fracture parameters for sample simulation 97

3.4.2 Comparison of simulation and experimental data of three-point beam

bending tests

3.5 Fracture simulation of samples with measured fracture energy 104

3.5.1 Fracture simulation of original samples with defined crack path....... 104

3.5.2 Comparison of simulated and measured fracture peak load of original beam samples 107

3.6 Fracture simulation of recovered fracture strength of healed samples with calibrated fracture energy 108

3.6.1 Calibration of fracture energy of healed samples based on peak load ratios 108

3.6.2 Detailed comparison of simulation and experiment of one healed beam sample 110

3.6.3 Comparison of predicted and measured recovered fracture strength for

all tested samples

3.7 Conclusions

CHAPTER 4 EXPERIMENTAL TESTS ON CARBON FIBER MODIFIED

ASPHALT MIXTURE BEAM SAMPLES 122

4.1 Introduction 122

4.2 Asphalt mixture design and sample preparation. 124 
4.2.1 Control and carbon fiber modified mixture design

4.2.2 Mixture beam sample preparation 126

4.3 Mechanism of microwave healing and properties measurement of asphalt mixture. 126

4.3.1 Mechanism of microwave healing of asphalt mixture. 126

4.3.2 Thermal conductivity of asphalt mixture beams 128

4.3.3 Electrical conductivity of asphalt mixture beams 131

4.4 Fracture-microwave healing investigation of asphalt mixture samples with elastic foundation modified beam bending test

4.4.1 Fracture-microwave healing tests of asphalt mixture samples

4.4.2 Fracture-microwave healing test results of asphalt mixture samples . 134

4.5 Summary and conclusions

\section{CHAPTER 5 EXPERIMENTAL TESTS ON GRAPHITE MODIFIED ASPHALT}

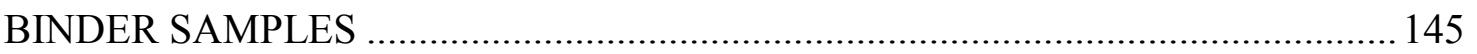

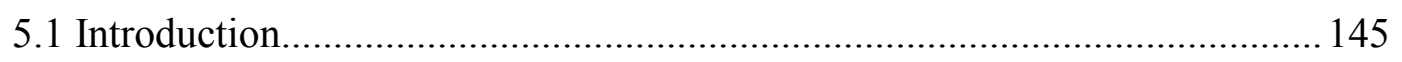

5.2 Control and graphite modified asphalt binder preparation ............................. 148

5.3 Asphalt binder tests and property measurement ........................................... 149

5.3.1 Viscosity measurement and activation energy calculation .................. 149

5.3.2 Light absorbance measurement ..................................................... 152

5.3.3 Bending beam rheometer test ...................................................... 155

5.3.4 Complex shear modulus test ............................................................ 158

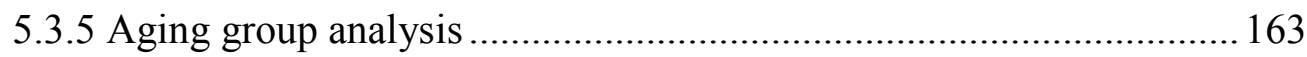


5.3.6 Thermal conductivity measurement

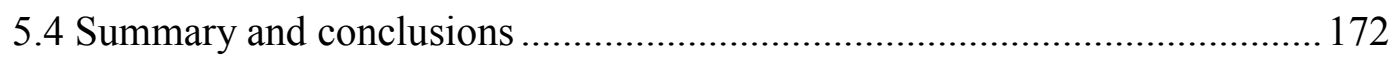

\section{CHAPTER 6 PERFORMANCE TESTS ON GRAPHITE MODIFIED ASPHALT}

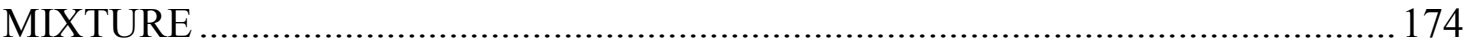

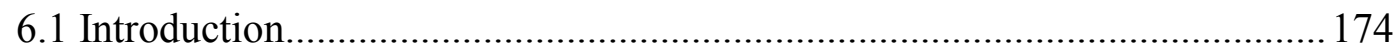

6.2 Asphalt mixture design and sample preparation...........................................176

6.2.1 Control and graphite modified asphalt mixture design........................176

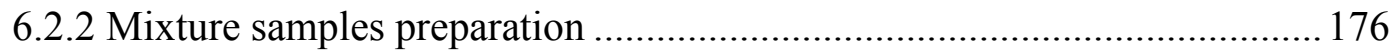

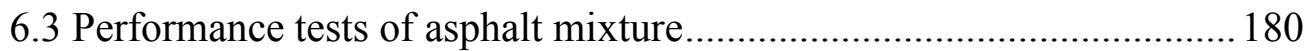

6.3.1 Electrical resistivity measurement of asphalt mixture beams............. 181

6.3.2 Thermal conductivity of asphalt mixture beams ................................ 183

6.3.3 Hamburg wheel tracking device (HWTD) test of asphalt mixture

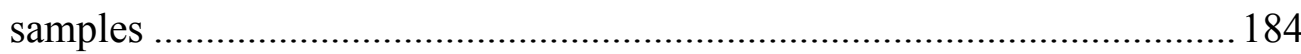

6.3.4 Dynamic modulus measurement of asphalt mixture samples..............186

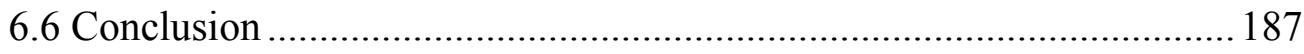

CHAPTER 7 FRACTURE-LIGHT HEALING TESTS ON GRAPHITE MODIFIED

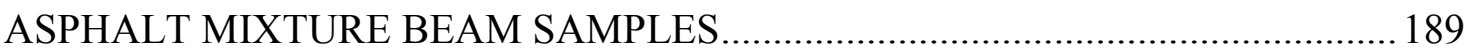

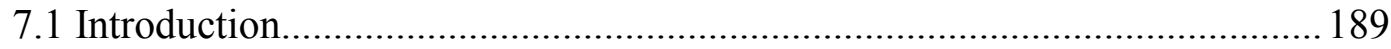

7.2 Asphalt mixture design and sample preparation............................................. 190

7.2.1 Control asphalt mixture design...................................................... 190

7.2.2 Flake graphite modified asphalt mixture design.................................. 191 
7.2.3 Exfoliated graphite nanoplatelet (xGNP) asphalt modified mixture design 192

7.2.4 Mixture beam sample preparation 193

7.3 Fracture-light healing investigation of asphalt mixture samples 194

7.3.1 Accelerated light healing mechanism...... 194

7.3.2 Cyclic fracture-light healing test of asphalt mixture samples 195

7.3.3 Temperature distribution of light-heated asphalt mixture samples

7.3.4 DIC evaluation of the local healing strains changes with healing cycles 202

7.4 Cyclic fracture-light healing test results of asphalt mixture samples . 210

7.5 Summary and conclusions 215

CHAPTER 8 FRACTURE MODEL DEVELOPMENT FOR GRAPHITE MODIFIED MIXTURE SAMPLES WITH DIGITAL IMAGE CORRELATION ANALYSIS ...217

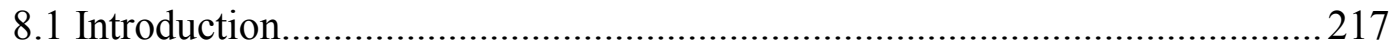

8.2 Asphalt mixture sample preparation and fracture-light healing tests results. 220

8.2.1 Asphalt mixture beam preparation ...............................................2220

8.2.2 Results of cyclic fracture-light healing tests................................ 223

8.3 Fracture simulation of original asphalt mixture samples..........................226

8.3.1 Determination of measured fracture energy of asphalt mixture samples 226

8.3.2 Bilinear cohesive fracture modeling 227 
8.3.3 Fracture simulation of original asphalt mixture beam with digital imaging analysis

8.4 Fracture simulation of recovered strength healed beam samples with DIC analysis 232

8.4.1 DIC analysis of cyclic fracture-light healing processes 232

8.4.2 Fracture simulation of strength recovered asphalt mixture samples ..241 8.5 Comparison of predicted and measured fracture strength of original and healed beam samples 244

8.6 Conclusions 252

\section{CHAPTER 9 CYCLIC FRACTURE-MICROWAVE HEALING TESTS ON}

GRAPHITE MODIFIED MIXTURE DISK-SHAPED COMPACT TENSION (DCT)

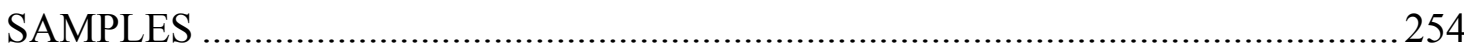

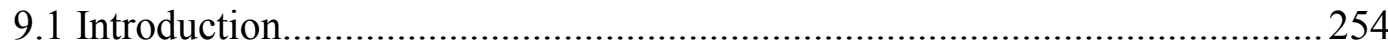

9.2 Asphalt mixture design and DCT sample preparation..............................255

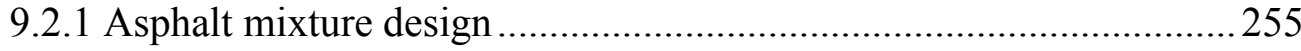

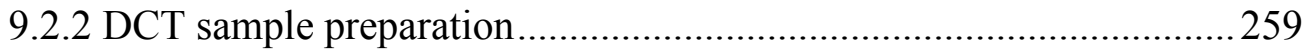

9.3 Fracture-microwave healing investigation of asphalt mixture samples ........260

9.3.1 Accelerated microwave healing mechanism ................................260

9.3.2 Determination of measured fracture energy of asphalt mixture samples 261

9.3.3 Cyclic fracture-microwave healing tests of asphalt mixture samples 263

9.3.4 Fracture-microwave healing test results of asphalt mixture samples .265 
9.4 Summary and conclusions ............................................................. 271

CHAPTER 10 SUMMARY AND CONCLUSION ...............................................2 273

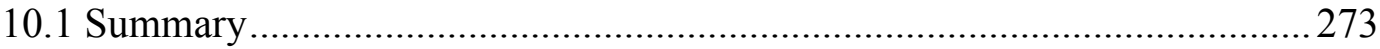

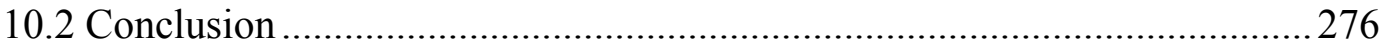

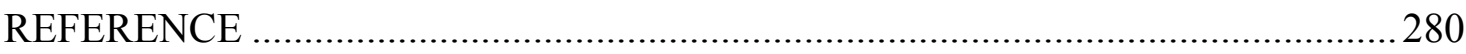

APPENDIX: COPYRIGHT CLEARANCE.......................................................2290 


\section{LIST OF FIGURES}

FIGURE 1. 1 SCHEMATIC FLOW DIAGRAM OF PROPOSED STUDY ON INVESTIGATING THE HEALING OF ASPHALT MIXTURE. ................................4 45

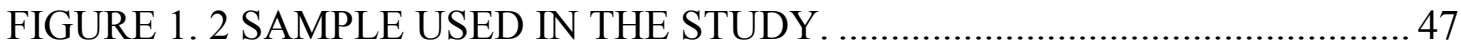

FIGURE 1. 3 1864 MEGOHMMETER FOR ELECTRICAL RESISTANCE MEASUREMENT. 48

FIGURE 1. 4 BEAM BENDING TEST OF ASPHALT MIXTURE WITH ELASTIC FOUNDATION. 49

FIGURE 2. 1 SCHEMATIC DEMONSTRATION OF INDUCTION HEALING MECHANISM FOR THERMOPLASTIC ASPHALT MATERIALS. 62

FIGURE 2. 2 INDUCTION HEALING SYSTEM WITH HEATING GENERATOR AND INDUCTION COILS: (A) ASPHALT CONCRETE SAMPLE HEALING AND; (B) ASPHALT MASTIC SAMPLE HEALING. 63

FIGURE 2. 3 ELECTRICAL RESISTIVITY MEASUREMENT OF PREPARED SAMPLES: (A) ASPHALT MASTIC SAMPLES; (B) ASPHALT CONCRETE SAMPLES 64

FIGURE 2. 4 ELECTRICAL RESISTIVITY VALUES OF PREPARED SAMPLES BEFORE LOADING: (A) ASPHALT MASTIC SAMPLES; (B) ASPHALT CONCRETE SAMPLES.

FIGURE 2. 5 INFRARED IMAGES OF INDUCTION HEATING TEMPERATURE DISTRIBUTION WITH ASPHALT CONCRETE SAMPLES UNDER HEATING TEMPERATURE OF (A) $60^{\circ} \mathrm{C}$; (B) $80^{\circ} \mathrm{C}$ AND; (C) $100{ }^{\circ} \mathrm{C}$ 
FIGURE 2. 6 DEMONSTRATION OF THE TEST SETUP: A) THREE-POINT BEAM BENDING TEST OF MASTIC BEAM AND; B) MODIFIED BENDING TEST OF ASPHALT CONCRETE BEAM WITH ELASTIC FOUNDATION 69

FIGURE 2. 7 FRACTURE-HEALING TEST DATA OF ASPHALT MASTIC SAMPLES AT HEATING TEMPERATURE OF $60^{\circ} \mathrm{C}$. 72

FIGURE 2. 8 FRACTURE-HEALING TEST DATA OF ASPHALT MASTIC SAMPLES AT HEATING TEMPERATURE OF $80^{\circ} \mathrm{C}$ 73

FIGURE 2. 9 FRACTURE-HEALING TEST DATA OF ASPHALT MASTIC

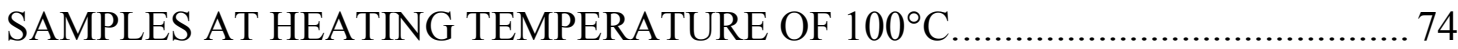

FIGURE 2. 10 FRACTURE-HEALING TEST DATA OF ASPHALT CONCRETE

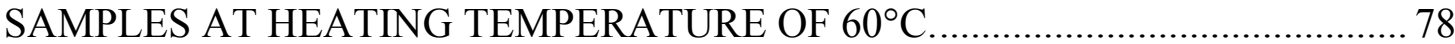

FIGURE 2. 11 FRACTURE-HEALING TEST DATA OF ASPHALT CONCRETE SAMPLES AT HEATING TEMPERATURE OF $80^{\circ} \mathrm{C}$ 79

FIGURE 2. 12 FRACTURE-HEALING TEST DATA OF ASPHALT CONCRETE SAMPLES AT HEATING TEMPERATURE OF $100^{\circ} \mathrm{C}$ 80

FIGURE 2. 13 CHANGE OF ELECTRICAL RESISTIVITY OF ONE ASPHALT CONCRETE SAMPLE DURING SEVERAL FRACTURE-HEALING CYCLES.... 82 FIGURE 3. 1 DEMONSTRATION OF THE FRACTURE-INDUCTION HEALING TEST: (A) MODIFIED BENDING TEST OF ASPHALT CONCRETE BEAM WITH ELASTIC FOUNDATION AND; (B) ASPHALT CONCRETE BEAM HEALING. 92 
FIGURE 3. 2 A COHESIVE LAW IN ACCORDANCE WITH NORMALIZED TRACTION AND NORMALIZED DISPLACEMENT JUMP FOR DIFFERENT RATIOS OF SHEAR SLIDING TO CRITICAL DISPLACEMENT. 93

FIGURE 3. 3 SCHEMATIC DRAWING OF A 4-NODE LINEAR COHESIVE ELEMENT. X AND Y INDICATE GLOBAL COORDINATES, WHILE S AND N INDICATE LOCAL COORDINATES. THE VARIABLES $\underline{u_{\mathrm{x}}^{2}}$ AND $\underline{\mathrm{u}_{\mathrm{Y}}^{2}}$ DENOTE THE DISPLACEMENT OF NODE 2 IN GLOBAL COORDINATES. THE VARIABLES $\underline{\delta_{\mathrm{X}}^{(2,3)}}$ AND $\underline{\delta_{\mathrm{Y}}^{(2,3)}}$ REPRESENT THE RELATIVE OPENING DISPLACEMENT OF NODE 2 AND 3. THE VARIABLES $\triangle \mathrm{S}$ AND $\triangle \mathrm{N}$ ARE THE SHEAR SLIDING AND NORMAL DISPLACEMENT IN THE LOCAL COORDINATES, RESPECTIVELY. 96

FIGURE 3. 4 DEMONSTRATION OF THREE-POINT BEAM BENDING TEST, INCLUDING CROSS HEAD, ANVIL AND CLIP-ON GAUGE. 99

FIGURE 3. 5 SCHEMATIC SIMULATION OF CRACK PATH OF ASPHALT CONCRETE SPECIMEN ON THREE-POINT BEAM BENDING TEST (A) CRACK PATH ON ASPHALT CONCRETE SPECIMEN; (B) SIMULATION INCLUDING THE GEOMETRY AND THE MESH, AND; (C) MAGNIFIED MESH WITH DETAILED CRACK PATH (LIGHT GREY-AGGREGATES AND DARK GREYMASTIC). 101

FIGURE 3. 6 COMPARISON BETWEEN NUMERICAL AND EXPERIMENTAL RESULTS FOR THREE-POINT BENDING TEST OF ASPHALT CONCRETE SPECIMENS. 
FIGURE 3. 7 SCHEMATIC SIMULATION OF CRACK PATH OF ASPHALT CONCRETE SAMPLE ON FRACTURE-HEALING TEST: (A) GLOBAL CRACK PATH AREA; (B) SCALED LOCAL CRACK PATH AREA (SCALE FACTOR, 0.2); (C) CRACKING MESH CONFIGURATION AND MESH DETAIL OF CRACK PATH; (D) MAGNIFIED MESH WITH DETAILED CRACK PATH AND INDICATED MATERIAL PHASES (LIGHT GREY-AGGREGATE AND DARK GREY-MASTIC) 106

FIGURE 3. 8 COMPARISON BETWEEN NUMERICAL AND EXPERIMENTAL RESULTS FOR MODIFIED BENDING TEST OF ASPHALT CONCRETE SAMPLE NO. 1 ON THE FIRST LOADING. 107

FIGURE 3. 9 ILLUSTRATION OF RELATION BETWEEN TRACTION AND DISPLACEMENT ON FOUR-TIME LOADING. 110

FIGURE 3. 10 NUMERICAL RESULTS OF ASPHALT CONCRETE BEAM ON HEALING TEMPERATURE 60 OC: (A) SAMPLE NO. 1; (B) SAMPLE NO. 2; (C)

SAMPLE NO. 3 115

FIGURE 3. 11 NUMERICAL RESULTS OF ASPHALT CONCRETE BEAM ON HEALING TEMPERATURE 80 OC: (A) SAMPLE NO. 4; (B) SAMPLE NO. 5; (C) SAMPLE NO. 6 117

FIGURE 3. 12 NUMERICAL RESULTS OF ASPHALT CONCRETE BEAM ON HEALING TEMPERATURE 100 OC: (A) SAMPLE NO. 7; (B) SAMPLE NO. 8; (C) SAMPLE NO. 9. 119 
FIGURE 4. 1 SCHEMATIC DEMONSTRATION OF MICROWAVE HEALING MECHANISM FOR CARBON FIBERS MODIFIED ASPHALT MIXTURE......... 128

FIGURE 4. 2 THERMAL CONDUCTIVITY MEASUREMENT OF NON-

FRACTURED ASPHALT MIXTURE BEAMS: (A) SAMPLE AND DEVICE; (B) THERMAL CONDUCTIVITY DATA OF TESTED SAMPLES

FIGURE 4. 3 ELECTRICAL RESISTIVITY MEASUREMENT OF NON-

FRACTURED ASPHALT MIXTURE BEAMS: (A) SAMPLE AND DEVICE; (B)

ELECTRICAL RESISTIVITY DATA OF TESTED SAMPLES. 132

FIGURE 4. 4 DEMONSTRATION OF MODIFIED BENDING TEST OF ASPHALT MIXTURE BEAM WITH ELASTIC FOUNDATION. 133

FIGURE 4. 5 MICROWAVE HEALING OF ASPHALT MIXTURE BEAM SAMPLE. 134

FIGURE 4. 6 FRACTURE-MICROWAVE HEALING TEST DATA OF CONTROL ASPHALT MIXTURE BEAMS. 139

FIGURE 4. 7 FRACTURE-MICROWAVE HEALING TEST DATA OF 2\% IM8 MODIFIED ASPHALT MIXTURE BEAMS. 140

FIGURE 4. 8 FRACTURE-MICROWAVE HEALING TEST DATA OF 4\% IM8 MODIFIED ASPHALT MIXTURE BEAMS.

FIGURE 4. 9 FRACTURE-MICROWAVE HEALING TEST DATA OF 1.5\% AS4 MODIFIED ASPHALT MIXTURE BEAMS. 142 FIGURE 4. 10 FRACTURE-MICROWAVE HEALING TEST DATA OF 1.5\% AS4 MODIFIED ASPHALT MIXTURE BEAMS. 143 
FIGURE 5. 1 VISCOSITIES AND ACTIVATION ENERGIES OF CONTROL ASPHALT, FLAKE GRAPHITE MODIFIED ASPHALT AND XGNP MODIFIED ASPHALT: (A) VISCOSITIES; (B) REGRESSION BETWEEN LN H AND 1/T; (C) ACTIVATION ENERGIES. 151

FIGURE 5. 2 DEMONSTRATION OF LIGHT ABSORBANCE TEST OF ASPHALT BINDER ON GLASS SUBSTRATE. 154

FIGURE 5. 3 LIGHT ABSORPTION OF CONTROL ASPHALT, FLAKE GRAPHITE MODIFIED ASPHALT AND XGNP MODIFIED ASPHALT. 154

FIGURE 5. 4 BENDING BEAM RHEOMETER TEST DATA OF CONTROL, 5\% FLAKE GRAPHITE MODIFIED AND 7\% FLAKE GRAPHITE MODIFIED ASPHALT.

FIGURE 5. 5 BENDING BEAM RHEOMETER TEST DATA OF CONTROL, 2\% XGNP MODIFIED AND 4\% XGNP MODIFIED ASPHALT. 157

FIGURE 5. 6 COMPLEX SHEAR MODULUS MASTER CURVES OF VIRGIN CONTROL AND FLAKE GRAPHITE MODIFIED ASPHALT 159

FIGURE 5. 7 COMPLEX SHEAR MODULUS MASTER CURVES OF RTFO CONTROL AND FLAKE GRAPHITE MODIFIED ASPHALT 160

FIGURE 5. 8 COMPLEX SHEAR MODULUS MASTER CURVES OF PAV CONTROL AND FLAKE GRAPHITE MODIFIED ASPHALT

FIGURE 5. 9 COMPLEX SHEAR MODULUS MASTER CURVES OF VIRGIN CONTROL AND XGNP MODIFIED ASPHALT. 
FIGURE 5. 10 COMPLEX SHEAR MODULUS MASTER CURVES OF RTFO CONTROL AND XGNP MODIFIED ASPHALT. 162

FIGURE 5. 11 COMPLEX SHEAR MODULUS MASTER CURVES OF PAV CONTROL AND XGNP MODIFIED ASPHALT. 163

FIGURE 5. 12 FTIR RESULTS OF VIRGIN CONTROL AND FLAKE GRAPHITE MODIFIED ASPHALT. 164

FIGURE 5. 13 FTIR RESULTS OF RTFO CONTROL AND FLAKE GRAPHITE MODIFIED ASPHALT. 165

FIGURE 5. 14 FTIR RESULTS OF PAV CONTROL AND FLAKE GRAPHITE MODIFIED ASPHALT. 165

FIGURE 5. 15 FTIR RESULTS OF UNAGED CONTROL AND XGNP MODIFIED ASPHALT. 166

FIGURE 5. 16 FTIR RESULTS OF RTFO CONTROL AND XGNP MODIFIED ASPHALT. 166

FIGURE 5. 17 FTIR RESULTS OF PAV CONTROL AND XGNP MODIFIED ASPHALT 167

FIGURE 5. 18 THE AVERAGE RATIOS OF SULFOXIDE GROUPS IN CONTROL AND FLAKE GRAPHITE MODIFIED ASPHALT. 169 FIGURE 5. 19 THE AVERAGE RATIOS OF CARBONYL GROUPS IN CONTROL AND FLAKE GRAPHITE MODIFIED ASPHALT. 169 FIGURE 5. 20 THE AVERAGE RATIOS OF SULFOXIDE GROUPS IN CONTROL AND XGNP MODIFIED ASPHALT. 170 
FIGURE 5. 21 THE AVERAGE RATIOS OF CARBONYL GROUPS IN CONTROL AND XGNP MODIFIED ASPHALT. 170

FIGURE 5. 22 THERMAL CONDUCTIVITY OF CONTROL ASPHALT, FLAKE GRAPHITE MODIFIED (5\% AND 7\%) ASPHALT AND XGNP MODIFIED (2\% AND 4\%) ASPHALT

FIGURE 6. 1 ELECTRICAL RESISTIVITY DATA OF NON-FRACTURED ASPHALT MIXTURE BEAMS.

FIGURE 6. 2 THERMAL CONDUCTIVITY DATA OF NON-FRACTURED ASPHALT MIXTURE BEAMS. 184

FIGURE 6. 3 HAMBURG WHEEL TRACKING DEVICE TEST DATA OF CONTROL, 5\% FLAKE GRAPHITE AND 2\% XGNP MODIFIED ASPHALT MIXTURE SAMPLES. 185

FIGURE 6. 4 DYNAMIC MODULUS MASTER CURVES OF CONTROL, 5\% FLAKE GRAPHITE AND 2\% XGNP MODIFIED ASPHALT MIXTURE.

FIGURE 7. 1 SCHEMATIC DEMONSTRATION OF LIGHT HEALING MECHANISM FOR ASPHALT MIXTURE WITHIN GRAPHITE MATERIAL... 195 FIGURE 7. 2 DEMONSTRATION OF MODIFIED BENDING TEST OF ASPHALT MIXTURE BEAM WITH ELASTIC FOUNDATION. 198

FIGURE 7. 3 LIGHT HEALING SYSTEM WITH 300 W LAMP. 199 FIGURE 7. 4 INFRARED IMAGES OF TEMPERATURE DISTRIBUTION IN ASPHALT MIXTURE SAMPLES AFTER 8 MINUTES OF LIGHT HEALING: (A) CONTROL ASPHALT MIXTURE BEAM; (B) FLAKE GRAPHITE MODIFIED 
ASPHALT MIXTURE BEAM; (C) XGNP MODIFIED ASPHALT MIXTURE BEAM.

FIGURE 7. 5 DEMONSTRATION OF DIC ANALYSIS OF LOCAL NO.1

CONTROL ASPHALT MIXTURE SAMPLE ON CYCLIC FRACTURE-LIGHT

HEALING TESTS, BEFORE LIGHT HEALING (REFERENCE IMAGE), AFTER

LIGHT HEALING (DEFORMED IMAGE) AND A VECTOR PLOT OF THE

DISPLACEMENT FIELD FOR EACH SET OF IMAGES: (A) FIRST LIGHT

HEALING PROCESS; (B) SECOND LIGHT HEALING PROCESS; (C) THIRD

LIGHT HEALING PROCESS.

206

FIGURE 7. 6 DEMONSTRATION OF DIC ANALYSIS OF LOCAL NO.1 FLAKE

GRAPHITE MODIFIED MIXTURE SAMPLE ON CYCLIC FRACTURE-LIGHT

HEALING TESTS, BEFORE LIGHT HEALING (REFERENCE IMAGE), AFTER

LIGHT HEALING (DEFORMED IMAGE) AND A VECTOR PLOT OF THE

DISPLACEMENT FIELD FOR EACH SET OF IMAGES: (A) FIRST LIGHT

HEALING PROCESS; (B) SECOND LIGHT HEALING PROCESS; (C) THIRD

LIGHT HEALING PROCESS.

208

FIGURE 7. 7 DEMONSTRATION OF DIC ANALYSIS OF LOCAL NO.1 XGNP

MODIFIED MIXTURE SAMPLE ON CYCLIC FRACTURE-LIGHT HEALING

TESTS, BEFORE LIGHT HEALING (REFERENCE IMAGE), AFTER LIGHT

HEALING (DEFORMED IMAGE) AND A VECTOR PLOT OF THE

DISPLACEMENT FIELD FOR EACH SET OF IMAGES: (A) FIRST LIGHT 
HEALING PROCESS; (B) SECOND LIGHT HEALING PROCESS; (C) THIRD LIGHT HEALING PROCESS. 210

FIGURE 7. 8 FRACTURE-LIGHT HEALING TEST DATA OF CONTROL

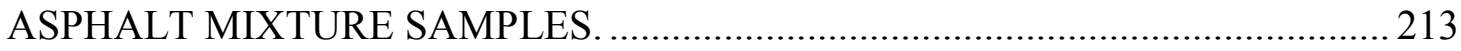

FIGURE 7. 9 FRACTURE-LIGHT HEALING TEST DATA OF ASPHALT

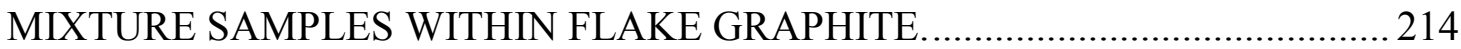
FIGURE 7. 10 FRACTURE-LIGHT HEALING TEST DATA OF ASPHALT MIXTURE SAMPLES WITHIN XGNP. 215 FIGURE 8. 1 DEMONSTRATION OF FRACTURE-LIGHT HEALING TEST: (A) MODIFIED BENDING TEST OF ASPHALT MIXTURE. 225

FIGURE 8. 2 A COHESIVE LAW IN ACCORDANCE WITH NORMALIZED TRACTION AND NORMALIZED DISPLACEMENT JUMP WITH OR WITHOUT SHEAR SLIDING. 229

FIGURE 8. 3 SCHEMATIC FRACTURE SIMULATION OF ORIGINAL NO.1 CONTROL ASPHALT MIXTURE BEAM: (A) GLOBAL CRACK PATH AREA; (B)LOCAL CRACK PATH; (C) CRACKING MESH CONFIGURATION AND MESH DETAIL OF CRACK PATH; (D) MAGNIFIED MESH WITH DETAILED CRACK PATH AND INDICATED MATERIAL PHASES (DARK GREYAGGREGATE AND LIGHT GREY-MASTIC); (E) NUMERICAL AND EXPERIMENTAL CTOD-LOAD CURVES. 231 FIGURE 8. 4 DEMONSTRATION OF DIC ANALYSIS OF NO.2 CONTROL ASPHALT MIXTURE BEAM ON CYCLIC FRACTURE-LIGHT HEALING TESTS: 
(A) CRACK VARIATION AT THE FIRST LOADING; (B) CRACK VARIATION AT THE SECOND LOADING; (C) CRACK VARIATION AT THE THIRD LOADING; (D) CRACK VARIATION AT THE FORTH LOADING. (THE RED POINTS INDICATE THE CRACK LOCATIONS FOR DIC ANALYSIS. THE BLUE POINTS DISPLAY THE LOCATIONS FOR STRAIN RATIO CALCULATION.) 235

FIGURE 8. 5 DEMONSTRATION OF DIC ANALYSIS OF NO.2 FLAKE GRAPHITE MODIFIED ASPHALT MIXTURE BEAM ON CYCLIC FRACTURELIGHT HEALING TESTS: (A) CRACK VARIATION AT THE FIRST LOADING; (B) CRACK VARIATION AT THE SECOND LOADING; (C) CRACK VARIATION AT THE THIRD LOADING; (D) CRACK VARIATION AT THE FORTH LOADING. (THE RED POINTS INDICATE THE CRACK LOCATIONS FOR DIC ANALYSIS. THE BLUE POINTS DISPLAY THE LOCATIONS FOR STRAIN RATIO CALCULATION.) 239

FIGURE 8. 6 DEMONSTRATION OF DIC ANALYSIS OF NO.2 XGNP MODIFIED ASPHALT MIXTURE BEAM ON CYCLIC FRACTURE-LIGHT HEALING TESTS: (A) CRACK VARIATION AT THE FIRST LOADING; (B) CRACK VARIATION AT THE SECOND LOADING; (C) CRACK VARIATION AT THE THIRD LOADING; (D) CRACK VARIATION AT THE FORTH LOADING. (THE RED POINTS INDICATE THE CRACK LOCATIONS FOR DIC ANALYSIS. THE BLUE POINTS DISPLAY THE LOCATIONS FOR STRAIN RATIO CALCULATION.) 
FIGURE 8. 7 ILLUSTRATION OF RELATION BETWEEN TRACTION AND DISPLACEMENT ON FOUR TIMES LOADING OF CONTROL ASPHALT MIXTURE SAMPLE. 244

FIGURE 8. 8 NUMERICAL RESULTS OF CONTROL ASPHALT MIXTURE SAMPLES: (A) SAMPLE NO.1; (B) SAMPLE NO.2; AND (C) SAMPLE NO.3. . 248 FIGURE 8. 9 NUMERICAL RESULTS OF FLAKE GRAPHITE MODIFIED ASPHALT MIXTURE SAMPLES: (A) SAMPLE NO.1; (B) SAMPLE NO.2; AND (C) SAMPLE NO.3. 250

FIGURE 8. 10 NUMERICAL RESULTS OF XGNP MODIFIED ASPHALT MIXTURE SAMPLES: (A) SAMPLE NO.1; (B) SAMPLE NO.2; AND (C) SAMPLE NO.3 252

FIGURE 9. 1 GEOMETRY (UNIT: MM) OF ASPHALT MIXTURE DCT SAMPLES. 260

FIGURE 9. 2 SCHEMATIC DEMONSTRATION OF MICROWAVE HEALING MECHANISM FOR GRAPHITE MODIFIED ASPHALT MIXTURE. 261

FIGURE 9. 3 DEMONSTRATION OF DISK-SHAPED COMPACT TENSION TEST OF ASPHALT MIXTURE SAMPLE. 263

FIGURE 9. 4 MICROWAVE HEALING OF ASPHALT MIXTURE SAMPLE..... 265 FIGURE 9. 5 FRACTURE-MICROWAVE HEALING TEST DATA OF CONTROL ASPHALT MIXTURE DCT SAMPLES. 268

FIGURE 9. 6 FRACTURE-MICROWAVE HEALING TEST DATA OF FLAKE GRAPHITE MODIFIED ASPHALT MIXTURE DCT SAMPLES 269 
FIGURE 9. 7 FRACTURE-NON MICROWAVE HEALING TEST DATA OF ASPHALT MIXTURE DCT SAMPLES WITHOUT FLAKE GRAPHITE...............2271 


\section{LIST OF TABLES}

TABLE 2. 1 AGGREGATE GRADATION OF SAND MASTIC SAMPLES. 60

TABLE 2. 2 AGGREGATE GRADATION OF ASPHALT CONCRETE MIXTURE

TABLE 2. 3 PEAK LOAD OF VIRGINAL MASTIC SAMPLES. 70

TABLE 2. 4 PERCENTAGE OF RECOVERED PEAK LOADS AFTER EACH

FRACTURE-HEALING CYCLE FOR MASTIC SAMPLES. .71

TABLE 2. 5 PEAK LOAD OF ORIGINAL ASPHALT CONCRETE SAMPLES. .....76

TABLE 2. 6 PERCENTAGE OF RECOVERED PEAK LOADS AFTER EACH

FRACTURE-HEALING CYCLE FOR ASPHALT CONCRETE SAMPLES.. . .77

TABLE 3. 1 AGGREGATE GRADATION OF ASPHALT CONCRETE MIXTURE

TABLE 3. 2 EXPERIMENTAL PEAK LOAD OF ASPHALT CONCRETE

SAMPLES. .90

TABLE 3. 3 NUMERICAL RESULTS OF ASPHALT CONCRETE SAMPLES. ....112

TABLE 3. 4 RELATIVE DIFFERENCE BETWEEN EXPERIMENTAL RESULTS

AND NUMERICAL RESULTS.

TABLE 4. 1 AGGREGATE GRADATION OF ASPHALT MIXTURE.

TABLE 4. 2 PEAK LOADS (N) OF ASPHALT MIXTURE BEAMS DURING

CYCLIC FRACTURE-MICROWAVE HEALING TESTS.

TABLE 4. 3 RATIO (\%) OF RECOVERED PEAK LOADS OF ASPHALT

MIXTURE BEAMS DURING CYCLIC FRACTURE-MICROWAVE HEALING

TESTS. 
TABLE 5. 1 STIFFNESS AND M-VALUE OF CONTROL 58-28, FLAKE

GRAPHITE MODIFIED ASPHALT AT 60S.

TABLE 6. 1 AGGREGATE GRADATION OF ASPHALT MIXTURE BEAM

SAMPLES.

TABLE 6. 2 AGGREGATE GRADATION OF ASPHALT MIXTURE SAMPLES

FOR HWTD TEST.

TABLE 6. 3 AGGREGATE GRADATION OF ASPHALT MIXTURE DYNAMIC MODULUS SAMPLES.

TABLE 7. 1 AGGREGATE GRADATION OF CONTROL ASPHALT

MIXTURE

TABLE 7. 2 AGGREGATE GRADATION OF FLAKE GRAPHITE MODIFIED ASPHALT MIXTURE.

TABLE 7. 3 AGGREGATE GRADATION OF XGNP MODIFIED ASPHALT MIXTURE.

TABLE 7. 4 PEAK LOADS (N) OF CONTROL SAMPLES, FLAKE GRAPHITE MODIFIED BEAMS AND XGNP MODIFIED BEAMS UNDER FRACTURELIGHT HEALING CYCLES.

TABLE 7. 5 AVERAGE, MAXIMUM, AND MEDIAN DISPLACEMENTS

(PIXELS) OF CONTROL ASPHALT MIXTURE SAMPLE, FLAKE GRAPHITE MODIFIED ASPHALT MIXTURE SAMPLE AND XGNP MODIFIED ASPHALT MIXTURE SAMPLE UNDER CYCLIC LIGHT HEALING PROCESS BY DIC ANALYSIS. 
TABLE 7. 6 RATIO (\%) OF RECOVERED PEAK LOADS (RPL) OF CONTROL SAMPLES, FLAKE GRAPHITE MODIFIED BEAMS AND XGNP MODIFIED BEAMS.

TABLE 8. 1 AGGREGATE GRADATION OF CONTROL, FLAKE GRAPHITE MODIFIED AND XGNP MODIFIED ASPHALT MIXTURE. 222

TABLE 8. 2 PEAK LOADS (N) OF CONTROL SAMPLES, FLAKE GRAPHITE SAMPLES AND XGNP SAMPLES UNDER FRACTURE-LIGHT HEALING CYCLES.

TABLE 8. 3 PEAK SEPARATION STRESS (MPA) OF ASPHALT MIXTURE SAMPLES 226

TABLE 8. 4 INPUT MEASURED FRACTURE ENERGY (J/M2) AND RECOVERED FRACTURE ENERGY (J/M2) FOR SIMULATION MODEL OF ASPHALT MIXTURE SAMPLES. 243

TABLE 8. 5 RELATIVE DIFFERENCE (\%) BETWEEN EXPERIMENTAL RESULTS AND NUMERICAL RESULTS. .246

TABLE 9. 1 AGGREGATE GRADATION OF CONTROL ASPHALT MIXTURE DCT SAMPLES 256

TABLE 9. 2 AGGREGATE GRADATION OF FLAKE GRAPHITE MODIFIED ASPHALT MIXTURE DCT SAMPLES.

TABLE 9. 3 AGGREGATE GRADATION OF XGNP MODIFIED ASPHALT MIXTURE DCT SAMPLES. 
TABLE 9. 4 PEAK LOADS (KN) OF CONTROL SAMPLES AND FLAKE GRAPHITE MODIFIED SAMPLES UNDER FRACTURE-MICROWAVE HEALING CYCLES. .266

TABLE 9. 5 RATIOS (\%) OF RECOVERED PEAK LOADS (RPL) OF CONTROL SAMPLES, FLAKE GRAPHITE MODIFIED SAMPLES. 267

TABLE 9. 6 PEAK LOADS (KN) OF ASPHALT MIXTURE SAMPLES WITHOUT FLAKE GRAPHITE UNDER THE CYCLEIC FRACTURE-NON MICROWAVE HEALING TESTS. 270 


\section{PREFACE}

This dissertation is partly organized as a collection of journal articles. Some chapters have been published by journals. Part contents of some chapters have been accepted by journals. A chapter has been submitted to a journal. Followed is the basic information of those articles including journal names, article titles, authorship.

Chapter 2 of this dissertation is from an article published by Construction and Building Materials, Vol 12, December 2013, Pages 729-737. The title of this paper is "Investigation of Induction Healing Effects on Electrically Conductive Asphalt Mastic and Asphalt Concrete Beams through Fracture-healing Tests". The dissertation author conducted the test data, and wrote this article with Dr. Qingli Dai. Dr. Mohd Rosli Mohd Hasan manufactured the specimens for the study.

Chapter 3 of this dissertation is from an article published by Construction and Building Materials, Vol. 106, March 2016, Pages 700-710. The title of this paper is "Integrated Computational-Experimental Approach for Evaluating Recovered Fracture Strength after Induction Healing of Asphalt Concrete Beam Samples". The dissertation author developed the programming codes, collected the simulation data, analyzed the data, and wrote this article with Dr. Qingli Dai and Dr. Xu Yang.

Part content of Chapter 5, Chapter 6, and Chapter 7 of this dissertation was accepted in Construction and Building materials_-Wang, Z., Dai, Q., Guo, S. Wang, R., Ye, M., Yap, Y. The title of this paper is "Experimental Investigation of Physical Properties 
and Accelerated Sunlight-Healing Performance of Flake Graphite and Exfoliated Graphite Nanoplatelet Modified Asphalt Materials". The dissertation author conducted the tests, wrote this article with Dr. Qingli Dai, Dr. Ronghua Wang, and Shuaicheng Guo. Dr. Yoke Khin Yap, and Mingxiao Ye helped the dissertation author implement part of the tests.

Chapter 8 of this dissertation was submitted to Journal of Materials in Civil Engineering. The title of this paper is "Evaluation of Recovered Fracture Strength after Light Healing of Graphite Modified Asphalt Mixtures with Integrated ComputationalExperimental Approach". The dissertation author developed the programming codes, method, collected the simulation data, analyzed the data, and wrote this article with Dr. Qingli Dai, Dr. Ronghua Wang, and Dr. Xu Yang. 


\section{ACKNOWLEDGEMENTS}

I would like to acknowledge my advisor, Dr. Qingli Dai, who gave me the chance to study on this challenging project and brought me an endless motivation, positive attitude and strong support. I also would like to appreciate her guidance, friendly attitude and patience and financial support provided me the inspiration and confidence to finish my research goal. I express the deepest respect and sincere admiration for her.

I wish to extend my sincere thanks to Dr. Zhanping You, Dr. Jacob Hiller, and Dr. Patricia A. Heiden for serving as committee members and providing me good suggestions during my Ph.D. study. I would like to acknowledge the Michigan tech research excellence fund, Michigan Tech transportation research institute, and Michigan department of environmental quality for financial support.

Finally, I wish to appreciate the unflinching support, endless love and encouragement of my family and my fiancee. One special thankful note will go with my colleges, Xiao Sun and Shuaicheng Guo who have supported and helped me throughout my research study. 


\begin{abstract}
INTEGRATED COMPUTATIONAL AND EXPERIMENTAL EVALUATION OF ELECTROMAGNETIC ENERGY-INDUCED SELF-HEALING PERFORMANCE OF ASPHALT COMPOSITES
\end{abstract}

By Zigeng Wang

The objective of this doctoral research is to investigate the electromagnetic energy induced self-healing effect of modified asphalt mixture material by developing computational and experimental characterization tools. More than $90 \%$ of the pavements in United States are constructed by asphalt mixture. The durability of pavement decreased by distresses has significant impact on maintenance costs. The asphalt mixture has self-healing capability because the asphalt could flow and fill the microcracks if enough external energy can be transmitted to the asphalt mixture system. However, the self-healing capability of asphalt is limited based on the climatic condition and traffic volume. Therefore, it is necessary that a new method named electromagnetic-induced healing needs to be used to accelerate the self-healing process of the asphalt mixture. In this research, different materials were added into asphalt to produce the modified asphalt binder samples and modified asphalt mixture samples, including steel wool, carbon fiber, graphite flake and exfoliated graphite nanoplatelets (xGNP). Some relative asphalt binder tests were conducted to evaluate the performance of modified asphalt, including rotational viscosity, light absorbance, aging and thermal conductivity. Some other tests were employed to evaluate the performance of the asphalt mixture, including disk-shaped compact tension test, dynamic modulus test, 
and rutting test. Three EM-induced healing approaches were utilized to investigate the induction healing effect of the asphalt mixture material, including the longwave radiation, visible/near-infrared light and microwave healing, respectively. In addition, a multi-phase triangle-shaped finite element bilinear cohesive zone model (CZM) was developed to simulate the fracture behavior of the original and strength recovered asphalt mixture samples during the cyclic fracture-induction healing tests. The digital image correlation (DIC) method was used to analyze the crack displacement variation of the fracture samples. The relative strain ratio was incorporated to determine the recovered fracture energy for the simulation model. The experimental results indicated that three added materials all could increase the healing effect of the asphalt mixture samples. The favorable numerical results compared with the experimental results indicated that the finite element bilinear CZM with defined crack path can be used to predict the recovered fracture strength after fracture-induction healing cycles. 


\section{CHAPTER 1 INTRODUCTION AND LITERATURE REVIEW}

\subsection{Executive summary}

Crack is one of the main reasons of forming pavement distress. It can be generated by a lot of factors, for instance, temperature, traffic load and water. Highway loses its function with crack accumulation during the service life. Therefore, it is necessary to develop methods to reduce the cracking rate or even to heal the crack. In this study, steel wool fiber, carbon fiber, graphite (flake graphite and exfoliated graphite nanoplatelets (xGNP)) were mixed with asphalt and aggregates to make the mixture, respectively. Based on the Faraday's law, the steel wool fibers which is metal generate electric current as long as in the electromagnetic (longwave radiation) field. Then temperature of the fiber increases due to the electric resistance described by the Joule effect. The asphalt in the mixture flows when its temperature rises up to a certain degree. The crack can be filled by the asphalt fluid partially or entirely which recover the mixture strength. The process described above is called induction healing. The carbon fibers modified asphalt mixture were heated by the microwave energy to heal the crack inside. In addition, the graphites modified asphalt mixture were heated by microwave and visible/near-infrared light to recover the strength of the asphalt mixture as well. The visible-near light and microwave were two types of electromagnetic wave. To sum up, the electromagnetic (EM) energy was utilized to accelerate the self-healing process of asphalt material.

The primary objective of this study is to investigate the damage-resistant asphalt composites with induction healing and to quantify the thermal-induced healing effects 
through the integrated computational and experimental analysis. It can be divided into three sub-objectives: 1). Understand the mechanism of thermal-induced healing process by involving binder capillary flow through cracks; 2).Predict the asphalt mixture specimen cracking and healing process with micromechanical model by finite element method; 3). Validate the model and quantify the healing effects under a speciallydesigned experimental procedure.

At the elevated temperatures, binder Capillary flow, behaving as Newtonian fluid is the main mechanism for the induction healing. A series of thermal, electrical and mechanical tests were conducted to evaluate the performance tests of the modified asphalt binder and mixture. Cohesive zone model with defined crack path was established to simulate the original and healed fracture behaviors of asphalt mixture based on finite element analysis. The cyclic fracture-healing tests were implemented to examine the healing performance of the samples. The results were employed as the input parameters to simulate fracture strength of healed samples. The comparison of the numerical results and experimental results indicated that the cohesive zone model with defined crack path could predict the fracture behavior of the asphalt mixture samples favorably.

\subsection{Introduction and background}

Asphalt mixtures are used on the surface for over $94 \%$ of all pavement in United States [1]. It consists of asphalt, graded aggregates and air voids [2]. Mineral aggregates have a wide size distribution (from as large as $37.5 \mathrm{~mm}$ to as small as several microns), shapes (angularity and elongation), roughness, friction and other 
characteristics[3]. The asphalt binder, regarded as a temperature-dependent material, behaves as viscoelastic solid at low temperature and viscous fluid at high temperature [4]. In addition, the air void has an important impact on the properties of asphalt mixtures, for instance, the moisture susceptibility, dynamic modulus, fatigue cracking and rutting $[5,6]$. The mechanism of the appearance of many pavement distresses are believed that the microcracks are formed in the asphalt mixtures by traffic loads, temperature and improper construction, for example, the fatigue cracking, moisture damage and rutting issue.

Self-healing materials exist in nature widely [7]. They have the ability of repairing themselves when mechanical or thermal damage is induced and the healing procedure happens spontaneously and simultaneously [8]. It is well known that asphalt is one typical self-healing material which links to temperature and rest period $[9,10]$. Thus, it can be classified as a thermal-related self-healing material. Many researchers have conducted a lot of tests to ascertain the mechanism of asphalt self-healing. Qiu et al. implemented a fracture-healing-re-fracture experiment to test the asphalt strength property during the fracture- healing process [11]. Shen introduced a methodology to quantify the healing using dissipated energy approach and dynamic shear rheometer (DSR) test [12]. The fatigue-healing behavior was studied from the DSR test. Castro established a distinct fatigue test with or without rest periods to study healing [13]. On the other hand, some computational simulation about the asphalt crack-healing procedure has been investigated such as $[14,15]$. 
As mentioned above, asphalt is one type of self-healing material. If it can obtain enough energy and rest periods to make the asphalt molecules flow, the crack could be healed eventually. However, in situ field, there are many factors which would affect the asphalt self-healed process, such as, continuous traffic loads, severe temperature difference and drainage issue. Thus, the self-healing process and pavement distress happen simultaneously. As known, the speed of asphalt self-healing is not enough to improve the pavement distress timely. So, it is necessary to find a method to accelerate that process. The energy of electromagnetic wave is able to satisfy the requirements. Currently, the direct way to accelerate the self-healing process is to add some conductive components into the mixture, for instance, conductive graphite powders or steel wool. Based on this, when they are placed in the electromagnetic field, the additive could observe the EM energy. At the same time, the temperature of the added materials increases. The asphalt observing enough energy is capable of flowing through the micro-crack in the asphalt mixture. It was believed that the main mechanism of induction healing is capillary flow through air voids or cracks driven by the surface tension stress of the liquid asphalt $[11,16]$.

\subsection{Literature review}

\subsubsection{Performance tests of asphalt binder and mixture}

The performance tests of asphalt binder usually include the rotational viscometer (RV), dynamic shear rheometer (DSR), rolling thin-film oven (RTFO), pressure aging vessel (PAV), direct tension tester (DTT), bending beam rheometer (BBR), ductility and so on. These tests are used to investigate the properties of asphalt binder. Many 
researchers conducted a series of performance tests of asphalt binder. Akisetty et al. [17] found that the additives for the warm mix asphalt reduced the viscosity of the binder and the viscosity of rubberized binder with Aspha-min increased by using the rotational viscometer test. Bommavaram et al. [18] utilized the dynamic shear rheometer to estimate the parameters of the intrinsic healing function of asphalt binders in order to develop a predictive model. Xiao et al. [19] conducted a series of rheological characteristic tests, such as failure temperature, performance grade, creep and creep recovery, viscous flow and frequency and amplitude sweep, of the RTFO asphalt binders. Yu et al. [20] proposed that the ductility retention rate of the organomontmorillonite modified asphalt after PAV was higher than that of the pristine asphalt. You et al. [21] studied that nanoclay reduced the strain failure rate of the asphalt by DTT test. The BBR was conducted to investigate the creep tests of asphalt mixture beam by Velasquez [22]. The crumb rubber, as a modifier, could improve the lowtemperature ductility, proposed by Xiang et al. [23]. The performance tests of asphalt mixture contain permanent deformation (rutting), static creep test, repeated load test, dynamic modulus tests, figure life, tensile strength, stiffness test, moisture susceptibility and so on. For example, the rutting level of the asphalt mixture is usually evaluated by the asphalt pavement analyzer (APA) and Hamburg wheel tracking device (HWTD) [24]. Zhao et al. [25] used HWTD tests to investigate the rut depths of the warm mix asphalt hand hot mix asphalt containing reclaimed asphalt pavement (RAP). In addition, the dynamic modulus measurement is often conducted to investigate the mechanical property of asphalt mixture. Clyne et al. [26] reported the dynamic 
modulus of the mixture with stiffer asphalt was higher than that with softer asphalt. The gradation of the aggregates affected the dynamic modulus significantly [27].

\subsubsection{Self-healing of asphalt and asphalt mixture}

Crack is considered as one of the main reason that causes pavement distress. It may develop as a result of multiple factors, such as freeze-thaw cycles, amount of precipitation or repeated traffic loads [28]. In order to improve the properties of the pavement, a lot of researches have tired to explain the self-healing mechanism of asphalt, thereby using the highway materials in a more economical way [29-31]. Different authors proposed that healing behavior which existed in asphalt mixture can be categorized into two types: first, adhesive healing at interface of asphalt and aggregate, second, cohesive healing inside asphalt binder [32-35]. Some researchers believed that when the surfaces of the crack contacted to each other due to the Van der Waals forces, the molecules diffused from one side to the other until the cracks were repaired completely and the strength recovered to the original level [31]. It is needed to explore the healing mechanism of asphalt mixtures and to quantify its impact by investigating that healing processes and the related crack surface energy of materials. In the physics of solids, the molecules on the surface have more energy than the ones do in the bulk of the material. Therefore, those high energy molecules from one surface have possibility to move to the other if the surface energy is relatively low in order to balance the system's energy. This process is called wetting [36]. However, if the crack space is too wide, the wetting cannot occur because molecules do not have sufficient 
energy to move through a long distance. In other word, the healing process continues if the system can be offered adequate energy and rest periods.

Many investigations have been implemented to measure the self-healing effect of asphalt mixture. Some papers revealed the self-healing mechanism of the asphalt binder. For example, Qiu et al. evaluated the self-healing capability of bituminous mastic which was a mixture of bituminous binder and limestone sands [11]. An approach called fracture-healing-re-fracture test (FHR) was introduced to experimentally investigate the asphalt self-healing property [37, 38]. Fluorescence microscopy was used to watch the specimen deformation during the healing period. After healing, the strength of asphalt mastic specimen recovered and it increased with increasing healing time and healing temperature.

Another method which can investigate the asphalt self-healing property was using dynamic shear rheometer to conduct the two-piece healing (TPH) test (Qiu et al [39, 40]). Two pieces of bitumen were pressed together using a $25 \mathrm{~mm}$ parallel-plate. The normal force was applied on the bottom plate. The TPH test investigated two different phases about self-healing of asphalt, including initial healing phase due to gap closure and time dependent healing phase. The initial healing phase has a three-stage complex. Time dependent healing phase indicated that compressive normal force promoted the healing effect.

Garcia proposed that the rate change of asphalt self-healing can be related to the Arrhenius equation and the activation energy was calculated using a series of asphalt mastic beams [41]. They were healed at different temperatures and times and were 
examined through CT-Scan tests. It turned out that activation energy could be an index to reflect the capillary flow of the asphalt and its relation with the capillary diameter.

Influence of aging and temperature for self-healing of asphalt binder was considered by Bhasin and Palvadi [36]. They believed that healing can be defined as a two-step process, referring to instantaneous crack wetting and time-dependent strength gain [31]. Dynamic shear rehometer was adopted to measure the rate of self-healing of asphalt binder at different temperatures and aging conditions. The experimental data demonstrated that healing increased with an increase of temperature and decrease of aging of asphalt binder.

Dissipated energy approach as a methodology was introduced to quantify the healing effect of asphalt binders by Shen [12]. Healing rate was defined as the rate of dissipated energy recovery. The results indicated that binder, strain level and temperature all have impact on healing effect. Kim adopted four different asphalt mixtures to conduct the repeated loading test and periodic resilient modulus tests to evaluate the dissipated creep strain energy [42]. Their results indicated that healing rates increased dramatically by $10{ }^{\circ} \mathrm{C}$ and were also affected by aggregate structure.

Additionally, some researchers proposed to use the self-diffusion of molecules across the crack interface to explain the asphalt self-healing behavior. Bhasin utilized molecular simulation techniques to investigate the relationship between chain length, chain branching and self-diffusion of binder molecules [14]. In the study, the author defined average molecular structure and then chose three types of molecules to represent binder molecules including asphaltenes, naphthene aromatics and saturates. 
After that, representative volume element of asphalt binder and crack interface were created. Through setting up some parameters, such as atomic configuration, velocities, and energy state, self-diffusion rate of binder molecules was determined. The results demonstrated that molecular simulation demonstrates that the molecular chain length, branching and molecular self-diffusion rate all influences the healing rate of asphalt binder.

Healing can be thought as a combination of wetting and intrinsic process that occurs across the interface of asphalt mixture crack. Wetting is the process that two sides of the interface combine into contact. Intrinsic healing is the strength obtained by the wetting process over time[36]. Kim et al. found that the relationship between the rate of healing for asphalt mixtures and the molecular characteristics of the asphalt binder in the mixture [43]. They quantified healing by an index based on the change of the dissipated pseudo-strain energy before and after the rest period. Then the healing indexes of different asphalt mixtures, in which asphalt had varied molecular structures were measured. For the sake of simplicity, a hypothesis was proposed that longer chains with fewer branches moved more freely across a crack interface and promoted healing process more easily. Thus, molecular dynamics simulation was utilized to determine the effect of asphalt molecular self-diffusivity [44].

To sum up, the important part of asphalt which has capability to heal the cracks of the mixture is that energy should be input into the system, thereby making the asphalt flow. Increasing the temperature, applying force are both the methods which can heal the asphalt mixture and recover the strength. Fatigue test and fracture test was 
implemented to examine the effect of asphalt self-healing. Meanwhile, molecular dynamics simulation was considered as a method to investigate the asphalt molecules kinetics, but it was still on the initial phase.

\subsubsection{Accelerated self-healing of asphalt mixture}

The accelerated self-healing process has a remarkably different characteristic than the self-healing of asphalt. The energy is input into asphalt, assisting to finish the selfhealing process with relatively high speed. As known, although asphalt has the selfhealing property which can decrease the crack level, the speed of self-healing is much lower than that of damage in the most cases $[45,46]$. That means it is not possible the asphalt material can heal the micro-crack totally by itself. Thus, it is necessary to find a method to increase the speed of asphalt self-healing. Through adding some conductive fibers or fillers into the asphalt mixture to accelerate self-healing process, the temperature of asphalt mixtures could increase in a relatively shorter time to accomplish the crack healed using certain equipment. Some studies added graphite and steel wool fiber into the asphalt mastic and proved that it can be healed with induction energy [47]. It was found that electrically conductive fibers had better effect than fillers [48]. There was an optimum content of fibers, above which it was very hard to make the mixtures and the electrical resistivity of the asphalt mixture decreased. Besides, once the maximum conductivity was reached, it did not change with increasing the content of fibers. After determining the type and optimum content of the additive, accelerated self-healing process was implemented. The shortwave accelerated selfhealing system includes alternating power generator, induction coils, and electrical 
conductive steel fibers in asphalt concrete sample [49]. Under alternating electrical power supply, the copper coil generated the electromagnetic field with the same frequency. The heat was generated with dominant Joule effect, dielectric hysteresis and contact resistance heating between fibers.

In order to evaluate the effect of accelerated self-healing, some tests were conducted to investigate the properties of asphalt mixtures by incorporating the healing procedure such as indirect tensile test (IDT) and fatigue life test. Liu et al. [50] found that steel wool fiber can increase the fracture strength of asphalt mixture since it reinforced the inside structure of the asphalt beam. However, too much fiber decreased the strength because it led to bad adhesion between asphalt and aggregates. Hence, it is necessary to determine the optimum fiber content. The optimization amount of steel fibers added into the asphalt mixture was based on the electrical resistivity, heating velocity and particle loss resistance [51]. The results indicated that the longer, thinner steel fiber had better induction healing effects. It was also observed that long rest period would heal the crack of the asphalt mixture if the deformation was relatively small. The fatigue life extension test was considered to estimate the effect of accelerated self-healing process as well [50]. Liu and Schlangen [35] investigated the induction healing effect on fatigue performance of porous asphalt concrete using fourpoint bending test. Fatigue life extension ratio and flexural stiffness recovery were measured to assess the healing effect. It was found that induction healing has capability to improve the mechanical properties of asphalt pavement. 
Further research has been studied to complete accelerated self-healing mechanisms. Alvaro [41] proposed a simple model (equivalent circuit) to define the induction healing effect. Capillary flow was considered as the main cause of healing [41]. The author proposed that activation energy can be utilized to calculate the healing time based on the Arrhenius equation which means a connection of healing time and healing temperature can be established. The capillary flow through the crack could be the main cause for healing. It was concluded that the model could predict the exact healing time to obtain a full strength recovery of asphalt mastic.

Therefore, adding fibers into the asphalt mixtures healed by electromagnetic energy was an effective method to improve the mechanical properties. More researches are needed to investigate the electromagnetic energy induced accelerated self-healing effect and mechanism so that the pavement service life can be extended.

\subsection{Objectives and scopes of research}

The main objective of this study is to investigate the damage-resistant asphalt composites with electromagnetic energy-induced self-healing and to quantify the thermal-induced healing performance through the integrated computational and experimental analysis. The study has been accomplished through four tasks that

involve cyclic fracture-healing test, performance tests of asphalt and mixture, and cohesive zone model simulation. 


\subsubsection{Research Methodology and Tasks}

\subsubsection{Methodology}

In this doctoral study, both experimental and numerical works were performed to evaluate the electromagnetic energy induced self-healing of asphalt mixture. The cohesive zone model for simulating the original and healed fracture of asphalt mixture samples was established. The flow diagram for this proposed study is as follows:

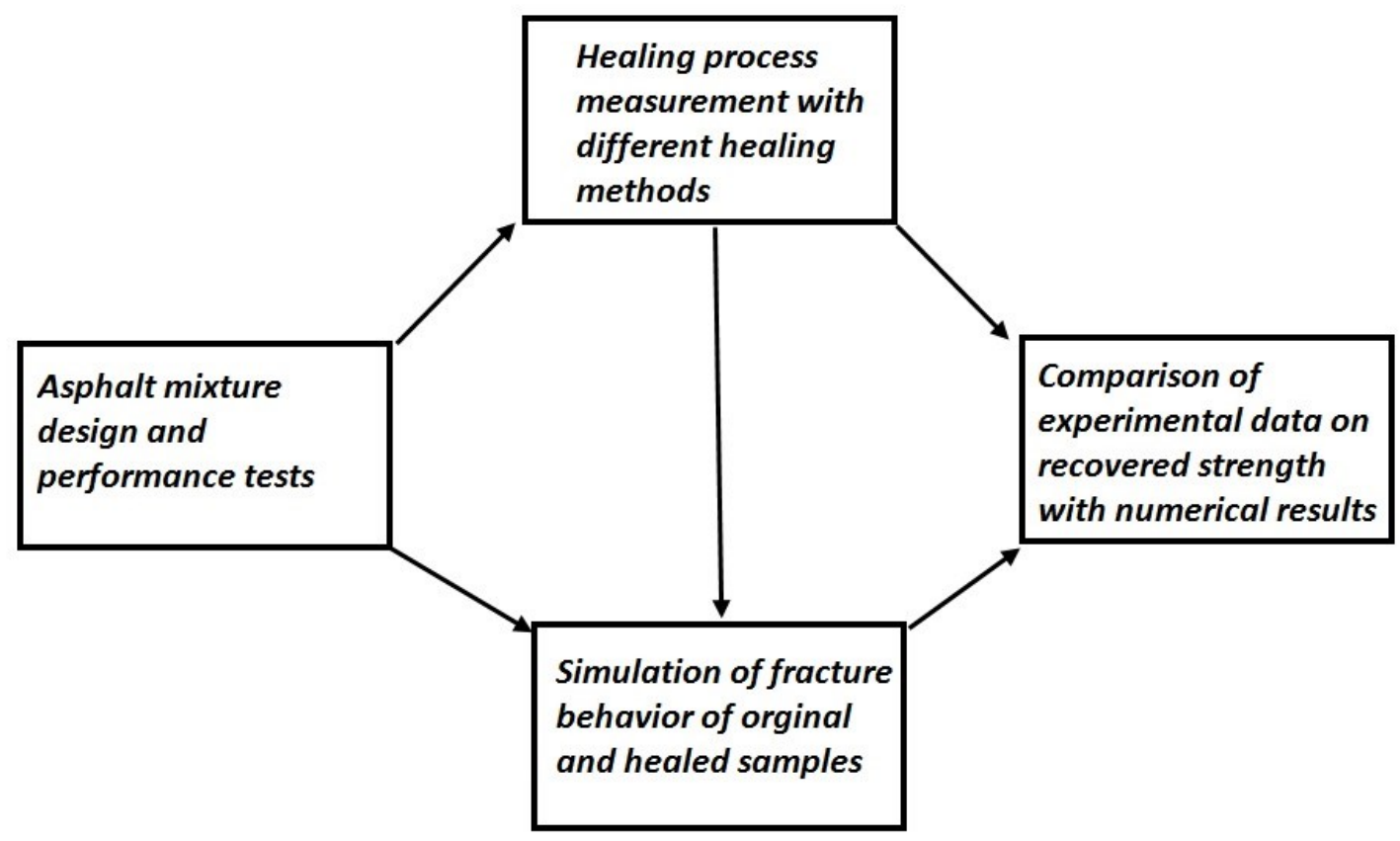

Figure 1. 1 Schematic flow diagram of proposed study on investigating the healing of asphalt mixture.

\subsubsection{Specific goals and related tasks}

Task 1: Specimen mixture design and performance tests.

Task 2: Experimental measurement for fracture strength with different healing methods.

Task 3: Finite element cohesion-based analysis of asphalt cracking and healing. 
Task 4: Comparison of recovered fracture strength with computational analysis after healing cycles.

\subsubsection{Research Tasks}

1.4.2.1 Task 1: Specimen mixture design and performance tests

Subtask 1.1 Prepare regular samples containing additives

The materials used in this study included asphalt binder, aggregates and steel wool fibers, carbon fibers, flake graphite, exfoliated graphite nanoplatelet (xGNP). The aggregates have been obtained from a local company in Hancock, Michigan, containing natural sand and crushed aggregate, with an average density of $2.72 \mathrm{~g} / \mathrm{cm}^{3}$. The asphalt binder is PG 58-28 with the density of $1.024 \mathrm{~g} / \mathrm{cm}^{3}$. The type 1 steel wool fiber will be used with length of $6.5 \mathrm{~mm}$, diameter in the range from $0.0296 \mathrm{~mm}$ to $0.1911 \mathrm{~mm}$, and density of $7.6 \mathrm{~g} / \mathrm{cm}^{3}$. The carbon fibers used were HexTow IM8 and AS4, from Hexcel Co.. IM8 carbon fiber is a continuous, high performance, intermediate modulus, PAN based fiber in 12,000 filament count tows. The tensile strength is $6067 \mathrm{MPa}$. The tensile modulus (Chord 6000-1000) is $310 \mathrm{GPa}$. The ultimate elongation at failure is $1.8 \%$. The density is $1.78 \mathrm{~g} / \mathrm{cm}^{3}$. The filament diameter is 5.2 microns. AS4 carbon fiber is a continuous, high strength, high strain, PAN based fiber in 3000 filament count tows. The tensile strength is $4619 \mathrm{MPa}$. The tensile modulus (Chord 6000-1000) is $231 \mathrm{GPa}$. The ultimate elongation at failure is $1.8 \%$. The density is $1.79 \mathrm{~g} / \mathrm{cm}^{3}$. The filament diameter is 7.1 microns. The flake graphite

was obtained from Asbury Carbons with a density of $2.25 \mathrm{~g} / \mathrm{cm}^{3}$. The particle sizes of flake graphite focus on two meshes, No.100 (75\%) and No.200 (25\%). The minimum 
layer thickness is $0.11 \mathrm{~mm}$. The $\mathrm{xGNP}$ was manufactured by XG Sciences with a bulk density of $0.03-0.1 \mathrm{~g} / \mathrm{cm}^{3}$, particle diameter of 25 microns and an average thickness of approximately 15 nanometers.

The samples, asphalt mixture beams, were produced using the materials mentioned above. Beam samples were prepared for the three-point beam bending tests. The plain samples were also prepared and tested to compared with fiber samples. The mixture was compacted by a slab kneading compactor. After that, it was cut into beams with the dimensions of $69 \mathrm{~mm} \times 50 \mathrm{~mm} \times 190 \mathrm{~mm}$. A notch with $3 \mathrm{~mm}$ width, $23 \mathrm{~mm}$ depth (one third of the sample's height) was sawn in the middle of the samples as shown in Figure 1.2. The air void ratio was controlled about 4\%. Compacting temperature and numbers were adjusted to assure samples with different content of fibers to obtain the similar air void ratios.

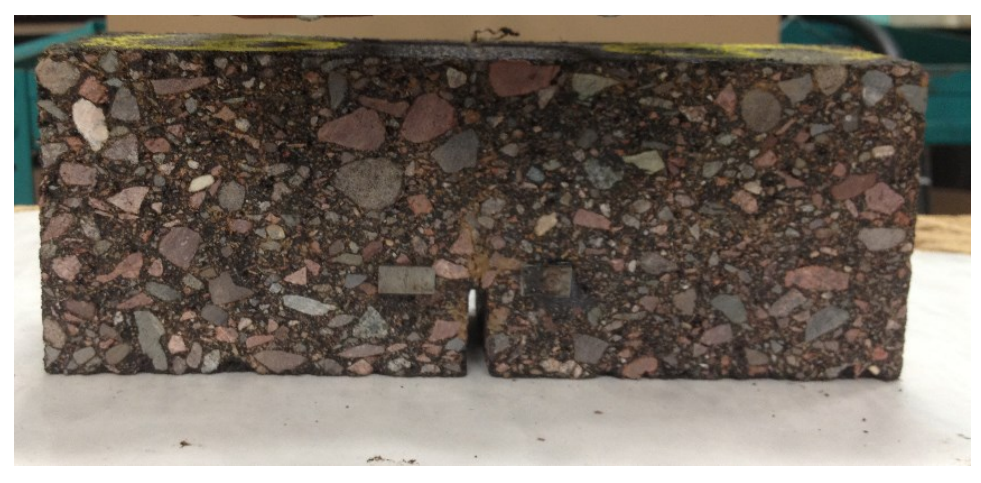

Figure 1. 2 Sample used in the study.

The electrical resistivity was measured by using 1864 Megohmmeter in order to examine if the fiber distributes uniformly in the specimens as shown in Figure 1.3. It is known that when the mount of additive reaches up to some levels, the electrical resistivity will keep constant. Besides, it is difficult to mix excessive fiber with asphalt 
and aggregates. If the electrical resistivity of samples in one group is not very close, it means many clusters still exist in the asphalt mixtures. Therefore, the mixing time needs to be adjusted to make the electrical resistance quite low. Then the optimum content of fiber was determined by performance tests and volumetric electicity measurements. In addition, the induction healing process was conducted to evaluate the heating rate and uniformity of samples for fiber content determination.

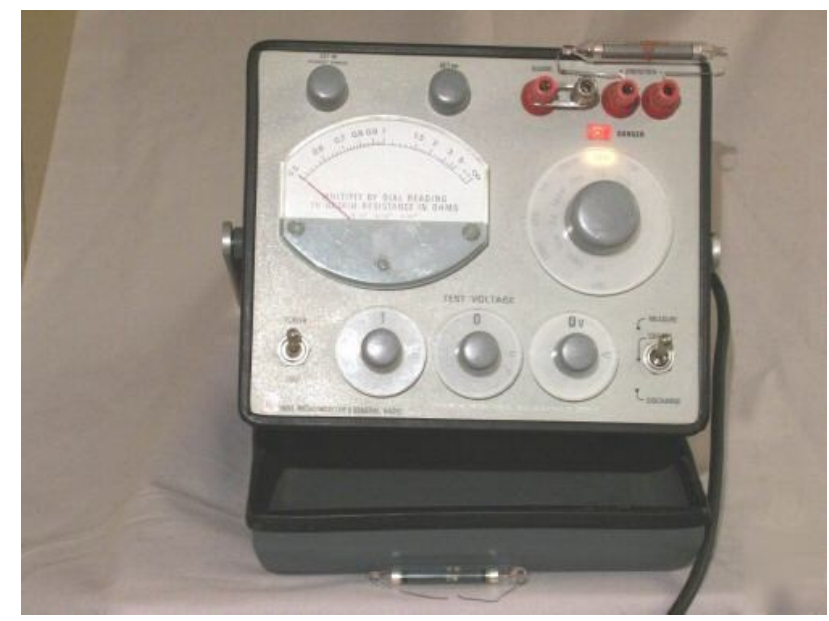

Figure 1. 31864 megohmmeter for electrical resistance measurement.

Subtask 1.2 Measure fracture performance with beam bending test

Three-point bending test was conducted to investigate how the additive affected the mechanical properties of asphalt mixture beams. The beams were applied a load at a deformation rate of $5 \mathrm{~mm} / \mathrm{min}$ using test fixture, $-20{ }^{\circ} \mathrm{C}$. Then the fracture energy of tested samples were calculated from the load-CTOD curves.

\subsubsection{Task 2: Experimental measurement for healing process}

Subtask 2.1 Investigate fracture behavior of samples during tests, and crack repair process under induction healing with digital camera images 
In this subtask, the fracture behavior of asphalt beams was investigated using a beam bending test with elastic foundation. It can prevent the beam fracturing completely, in which case the beam strength recovers by dealing with induction healing method shown in Figure 1.4. The beams with additives were tested using this beam bending test. All the samples were applied by loading with a rate of $0.5 \mathrm{~mm} / \mathrm{min}$ until the maximum loading value appeared. The test temperature was $-20{ }^{\circ} \mathrm{C}$ to limit viscoelastic or viscoplastic deformation. The process of forming crack at the middle of the specimen was recorded by taking digital camera images.

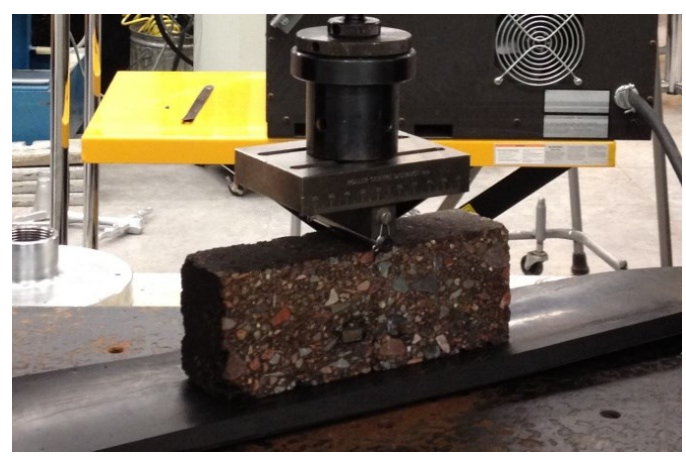

Figure 1. 4 Beam bending test of asphalt mixture with elastic foundation.

After the fracture test, the beams were healed through the induction heater, visible/near-infrared light and microwave. Before the healing process, the specimens were rested in the lab at least for 1 hour until the temperature of them reaches up to the room temperature. The reason is that if a specimen is heated at a very low temperature and its temperature rises up extremely fast, the healing process may generate some non-uniform thermal deformation and leads to some crack behaviors. During the healing process, the crack healed process in the beam samples was recorded by the 
digital camera and the infrared camera. This imaging data were used to simulate the fracture and re-fracture behavior of samples.

1.4.2.3 Task 3: Finite element cohesion-based analysis of fracture behavior of original and healed samples

Subtask 3.1 Apply cohesive zone model to simulate the crack formation and propagation during tests

Cohesive zone model has been used to simulate the fracture of materials for years including homogeneous and heterogeneous materials. It provides an effective way to simulate the damage occurring in a zone ahead of crack tip. In this study, nonlinear constitutive laws and corresponding traction were utilized to simulate fracture behavior such as crack nucleation, initiation, and propagation. The crack tip indicates the point where traction is zero and cohesive zone tip means the traction is a maximum. The cohesive zone is defined as the area between the crack tip and cohesive zone tip where fracture behavior occurs. The cohesive surfaces are joined together by cohesive traction due to the displacement jump across the crack. When displacement jump increases resulting from an external force or compliance inside the material, the traction increases until maximum and then decreases to zero monotonically. Material strength, critical displacement and cohesive fracture energy represent the cohesive parameters.

The virtual cohesive element work is given as

$W_{c o h}^{*}=\int_{s}\left(T_{n} \delta_{n}^{*}+T_{s} \delta_{s}^{*}\right) d S$ 
where subscript coh represents cohesive, $T_{n}$ and $T_{s}$ are normal and shear tractions, respectively, $\delta_{n}^{*}$ and $\delta_{s}^{*}$ are virtual normal and shear displacement, respectively. They can be expressed as

$\delta_{n}^{*}=N \bar{\delta}_{n}^{*}, \delta_{s}^{*}=N \bar{\delta}_{s}^{*}$

where $\mathrm{N}$ is shape function relating quantities at nodal points to those at Gauss points, $\bar{\delta}_{n}^{*}$ and $\bar{\delta}_{s}^{*}$ are virtual normal and shear displacement jump at nodal points, respectively. Thus, the force vector due to cohesive elements can be obtained as:

$F_{c o h}=\int_{s}\left(T_{n} N+T_{s} N\right) d S$

The cohesive material Jacobian [C] gives the relationship between traction and displacement jump as follows:

$\left\{\begin{array}{l}d T_{n} \\ d T_{s}\end{array}\right\}=[C]\left\{\begin{array}{l}d \delta_{n} \\ d \delta_{s}\end{array}\right\}$

where $[C]$ is

$\left\{\begin{array}{ll}\partial T_{n} / \partial \delta_{n} & \partial T_{n} / \partial \delta_{s} \\ \partial T_{s} / \partial \delta_{n} & \partial T_{s} / \partial \delta_{s}\end{array}\right\}$

Therefore, the tangent matrix is

$[K]=\int_{S}[B]^{T}[C][B] d S$

where $[\mathrm{B}]$ is matrix of shape function.

The equations aforementioned are the base of finite element scheme which will be used to analyze the cohesive zone model, such as force vector and tangent matrix.

The cohesive law (insert citation) which was used for the interface elements can be summarized as follows: 
$t=\frac{\partial \phi}{\partial \delta_{n}}\left(\delta_{n}, \delta_{s}, \mathrm{q}\right) \mathrm{n}+\frac{\partial \phi}{\partial \delta_{s}}\left(\delta_{n}, \delta_{s}, \mathrm{q}\right) \mathrm{s}$

where $\mathrm{n}$ and $\mathrm{s}$ represent normal and tangential directions, $\mathrm{t}$ is traction, $\phi$ is free energy potential, $\delta_{\mathrm{n}}$ is normal displacement jump, $\delta_{\mathrm{s}}$ is shear sliding, $\mathrm{n}$ is unit normal of the interface elements, and $\mathrm{q}$ is vector of internal variables. Figure 1.5 shows the relationship between the traction and displacement jump follows equation 18:

$t=\frac{\partial \phi}{\partial \delta}=e \sigma_{c} \frac{\delta}{\delta_{c}} \exp \left(-\frac{\delta}{\delta_{c}}\right)$

And the cohesive fracture energy is defined as

$G_{c}=\int_{0}^{\infty} t d \delta=e \sigma_{c} \delta_{c}$

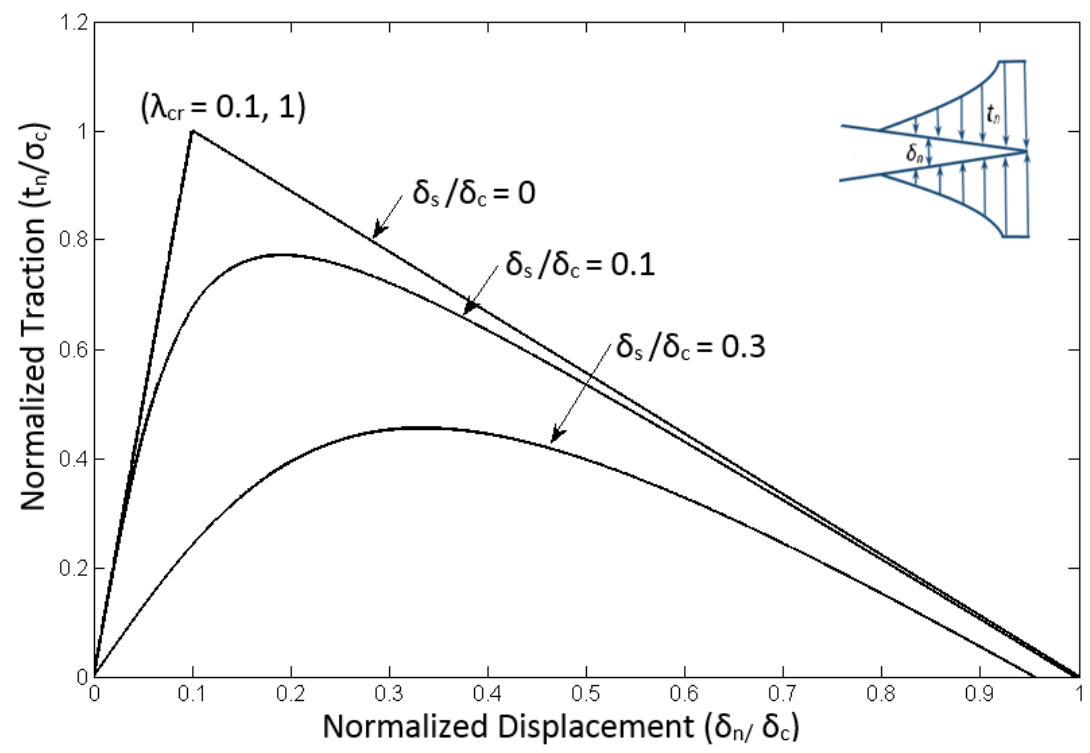

Figure 1.5 Schematic representation of loading and unloading in terms of traction and displacement-jump. 
Experiments were conducted to measure the peak separation stress and fracture energy. They were treated as the material input parameters to set up the cohesive zone model. The peak separation stress was measured by modified beam bending test. And the material strength was measured by three-point bending beam test. Then sensitivity analysis was implemented to fracture energy and material strength to explore the influence of cohesive parameters.

In this part, cohesive zone model were used to simulate the recovered strength of asphalt mixture after the induction healing process. As known, cohesive zone model has been used to investigate the fracture properties of materials for years. However, this was the first time to use the CZM to study the asphalt self-healing. The crack in the middle of the specimen can be healed to some extends. In fracture simulation which is the crack developing process, the material in cohesive zone is the asphalt mixture. Then the sample was healed and part of the crack was filled with asphalt or asphalt mastic.

1.4.2.4 Task 4: Experimental investigation of fracture strength with EM-induced selfhealing and comparison of recovered fracture strength with computational analysis after healing cycles

Subtask 4.1 Implement fracture-healing cyclic beam bending tests to measure the original strength and recovered strength of samples after each cycle.

This fracture-healing cyclic beam bending test includes two parts. One is the beam bending fracture test. The specimen was put on an elastic rubber foundation in order to prevent the beam broken completely. Then a load was applied on the specimen at a rate 
of $0.5 \mathrm{~mm} / \mathrm{min}$ until the maximum value appears then the load will decrease immediately. Therefore, the loading machine stopped manually before load decreased. Otherwise, the crack in the middle of the specimen developed too fast to be healed. The temperature of the specimen was $-20{ }^{\circ} \mathrm{C}$ to avoid creeping. After the fracture test, it was necessary to wait for at least one hour until the temperature of specimen increased to room temperature. Then the sample was placed under electromagnetic field to heal, including induction heater, visible/near-infrared light and microwave. Then the specimen was put into a freezer for at least 6 hours to keep its temperature around -20 ${ }^{\circ} \mathrm{C}$. This process can be called one cycle of fracture-healing beam bending test. After sample was conditioned in the freezer for about 6 hours, the samples were tested again to measure the fracture strengths, neamly the peak loads through the loading test. The peak loading values were recorded as well. The healing performance was investigated by comparing the original fracture strength value with the recovered strength values from each cycle [49].

Subtask 4.2 Compare the analytical results with the experimental results on recovered fracture strength

The objective of this part is to compare the analytic results with the experimental results of recovered fracture strength. The results form simulating the facture of original sample and healed sample using cohesive zone model were compared with the fracture-healing cyclic test to examine the model's suitability by relative difference. The relative difference was defined as the difference of the experimental and numerical 
results divided by the experimental resluts. Models and equations were established for calculating dissipated energy depending on the loading cycles. 


\section{CHAPTER 2 EXPERIMENTAL TESTS ON ASPHALT MIXTURE SAMPLES WITHIN STEEL WOOL FIBER*}

\subsection{Introduction}

Asphalt mixtures are used on the surface for over $94 \%$ of all pavements [1]. As an essential component of the U.S. pavement infrastructure system, the self-healing performance of asphalt mixtures has a significant impact on maintenance costs. Bitumen or asphalt binder is used in asphalt concrete mixes to bind together aggregate particles. It is typically known as a viscoelastic material which deforms at high temperatures and is brittle at low temperatures. Pavements surfaces must remain drivable for a wide range of the traffic loads under different climatic conditions for an extended period of time. In order to maintain a drivable pavement surface, asphalt concrete wearing courses should be constantly maintained and repaired. Miniature cracking on highway runways can cause the start of major forms of pavement distress[52]. The abrasive action of vehicle wheels on the pavement surface, especially on high stressed areas, can initiate raveling. Kneepkens et al. [53], described that raveling starts with the removal of the first stone, creating a gap, followed by a domino-like effect, with the loss of more aggregate particles at a higher rate. When the first stone is removed by a vehicle wheel, the remaining aggregates around the gap lack support in at least one direction, aggregates can easily plug out from the pavement, which results in uneven pavement surfaces. In the Netherlands [54], induction healing

\footnotetext{
* Text was published in Construction and Building Materials-Dai, Q., Wang, Z., Hasan, M. (2013). "Investigation of Induction Healing Effects on Electrically Conductive Asphalt Mastic and Asphalt Concrete Beams through Fracture-healing Tests." Construction and Building Materials. Doi:10.1016/j.conbuildmat.2013.08.089 
was used as a method of preventive maintenance to increase the healing rate and to prevent raveling of porous asphalt. This approach was developed at the Delft University of Technology (TU Delft) based on two intrinsic properties of asphalt concrete: 1) asphalt concrete is a self-healing material and 2) its' healing capability is better at elevated temperatures [54].

Shen et al. [55] defined the healing behavior as the self-recovery capability of asphalt materials under certain loading and/or environmental conditions, especially during the rest time. According to Alvaro [56] asphalt concrete can be classified as a thermally-induced self-healing material whereas directly linked to temperature [57] and the rest periods $[58,59]$. Healing in asphalt materials evolves complex behavior, which depend on the activation energy in asphalt binder, capillary flow through the cracks, self-diffusion of molecules across the crack interface, crack phases, material modifications and confinement [56, 60, 61]. According to a study by Qiu et al. [61], the modified bituminous mastic using Styrene-Butadiene-Styrene polymer resulted in lower healing capability compared to a bituminous mastic made with conventional binder 70/100 penetration grade. Little and Bhasin [62] affirmed that the healing process between two surfaces of a nano crack can be classified into three primary steps which is initiated by the wetting of the nano crack surfaces, followed by the diffusion of molecules from one surfaces to the other and finally randomized of the diffused molecules to attempt to reach the level of strength of the original material. This complete self-healing process will occur with sufficient rest time (no loading) and contacted crack surface. The lab test results support that the amount of healing 
increases when the asphalt materials are subjected to an elevated temperature during the rest time [63].

Based on the above findings [56-61], it is important to ensure that asphalt binder behaves as a Newtonian fluid by stimulating the activation energy at an adequate level which can be predicted through the Arrhenius equation [64]. Conductive steel fibers are added to the asphalt mixtures to generated eddy current under an alternating magnetic field in order to use induction heating to heal the micro-crack, enough to increase the asphalt binder healing rates and repair the bond between aggregates and binder. In this method, the induction generator sends alternating currents through a coil, generating an alternating electromagnetic field and induces currents through the conductive loop formed by the steel wool. Theoretically, heat was generated due to the electrical resistance in the conductive particles when connected to a power source [65]. The induction healing of asphalt composites containing conductive fibers were investigated at TU Delft $[47,52,54,65-68]$. The induction healing effects were experimentally investigated with the porous asphalt concrete specimens. García et al. [66] conducted Gel-Permeation Chromatography tests on healed specimens by evaluating induction healing and original specimens, and demonstrated the chemical properties of asphalt such as averaged molecular weight did not change. Liu et al. [54] evaluated the induction healing effect of porous asphalt concrete through the four-point bending fatigue test and found that the fatigue life of porous asphalt concrete can be extended by applying multiple induction healing cycles. Liu et al. $[65,67]$ concluded 
that the self-healing rate of porous asphalt concrete can be increased by induction heating.

The main objective of this study is to investigate the self-healing performance of conductive asphalt materials through cyclic peak-to-peak fracture and induction healing tests, and to evaluate the influence of different temperatures of induction heating on the healing capability of dense-graded asphalt materials. The mastic and concrete samples were prepared by adding Type 1 steel wool fibers with an approximate length of $6.5 \mathrm{~mm}$. These prepared samples were then tested under fracture-healing cycles by using the three-point bending loading and modified threepoint bending loading tests (with an elastic foundation support) for the asphalt mastic and concrete beam samples, respectively. The healing performances of samples were evaluated with recovered peak load under fracture-healing cycles.

\subsection{Mixture design and sample preparation}

\subsubsection{Materials}

The materials used in this study for the preparation of asphalt mastic and asphalt concrete beams were aggregates, asphalt binder and steel wool fibers. The aggregate were obtained from a local source in Hancock, Michigan that contained natural sand and crushed aggregate, with an average density of $2.72 \mathrm{~g} / \mathrm{cm}^{3}$. While the asphalt binder used was PG 58-28 with the density of $1.024 \mathrm{~g} / \mathrm{cm}^{3}$. The steel wool fibers were Type 1 with the approximate length of $6.5 \mathrm{~mm}$ and the density of $7.6 \mathrm{~g} / \mathrm{cm}^{3}$. 


\subsubsection{Asphalt mastic preparation}

Asphalt mastic samples were prepared using the sand to bitumen ratio 1.6 in volume for mixture design. As a conductive component, $5.66 \%$ steel wool by volume of asphalt binder was incorporated in the mixture to obtain a high electrical conductivity. To obtain a homogenous mixture, aggregates (gradation shown in Table 2.1) and steel wool fibers were mixed using a Hobart mixer for 10 minutes before mixing with the asphalt binder for another 5 minutes. Finally, the mixture was handcompacted in a fabricated aluminum mold as shown in Figure 2.3 (a). The dimensions of each sample were $125 \mathrm{~mm}$ x $25 \mathrm{~mm}$ x $15 \mathrm{~mm}$ with a triangular shape notch $(5.8 \mathrm{~mm}$ wide and $5 \mathrm{~mm}$ in height) at the center of sample.

Table 2. 1 Aggregate gradation of sand mastic samples.

\begin{tabular}{|l|l|l|l|}
\hline Sieve Number & Sieve Size $(\mathrm{mm})$ & \% Retained & Mass $(\mathrm{g})$ \\
\hline No.8 & 2.36 & 68.3 & 286.2 \\
\hline No.16 & 1.18 & 10.9 & 45.7 \\
\hline No.30 & 0.6 & 8.2 & 34.4 \\
\hline No.50 & 0.3 & 4.3 & 18.0 \\
\hline No.100 & 0.15 & 2.7 & 11.3 \\
\hline No.200 & 0.075 & 5.6 & 23.5 \\
\hline
\end{tabular}

\subsubsection{Beam sample preparation}

For the concrete beam preparation, the aggregate gradation in Table 2.2 was mixed with the same type of asphalt binder and steel wool used in the mastic sample 
preparation. The beam samples contained a higher percentage of steel wool which was approximately $8 \%$ of the binder volume. The mixture was first compacted using a slab kneading compactor and then cut into a beam with the dimensions of $69 \mathrm{~mm} \times 50 \mathrm{~mm}$ x $190 \mathrm{~mm}$. Additionally a small notch with $3 \mathrm{~mm}$ width and $20 \mathrm{~mm}$ depth was sawn in the center of the concrete beam samples.

Table 2. 2 Aggregate gradation of asphalt concrete mixture.

\begin{tabular}{|l|l|l|l|}
\hline Sieve Number & Sieve Size $(\mathrm{mm})$ & \% Retained & Mass $(\mathrm{g})$ \\
\hline $3 / 4$ & 19 & 1.3 & 124.0 \\
\hline $1 / 2$ & 12.5 & 12.2 & 1164.0 \\
\hline $3 / 8$ & 9.5 & 14.7 & 1402.5 \\
\hline No.4 & 4.75 & 20.4 & 1946.4 \\
\hline No.8 & 2.36 & 15.3 & 1459.8 \\
\hline No.16 & 1.18 & 10.6 & 1011.3 \\
\hline No.30 & 0.6 & 10.8 & 1030.4 \\
\hline No.50 & 0.3 & 7 & 667.9 \\
\hline No.100 & 0.15 & 2.3 & 219.4 \\
\hline No.200 & 0.075 & 5.4 & 515.2 \\
\hline
\end{tabular}

\subsection{Mechanism of induction heating of asphalt materials}

The induction heating system includes alternating power generator, induction coils, and electrical conductive steel fibers in asphalt concrete sample as shown in Figure 2.1. Under alternating electrical power supply, the copper coil generated the 
magnetic field with the same frequency. Each conductive steel fiber was induced as indicated in asphalt mixtures (Figure 2.1). The induction heat was generated with dominant Joule effect, dielectric hysteresis and contact resistance heating between fibers. The binder in the samples behaves as a Newtonian fluid, when the asphalt temperature in the range of $30^{\circ} \mathrm{C}$ to $70^{\circ} \mathrm{C}$, depending on the source and composition of the bitumen. The capillary pressure will drive the binder to flow over crack space. Thus the micro-cracks will be healed with filled binder and recovered bonding and adhesive strength[64].

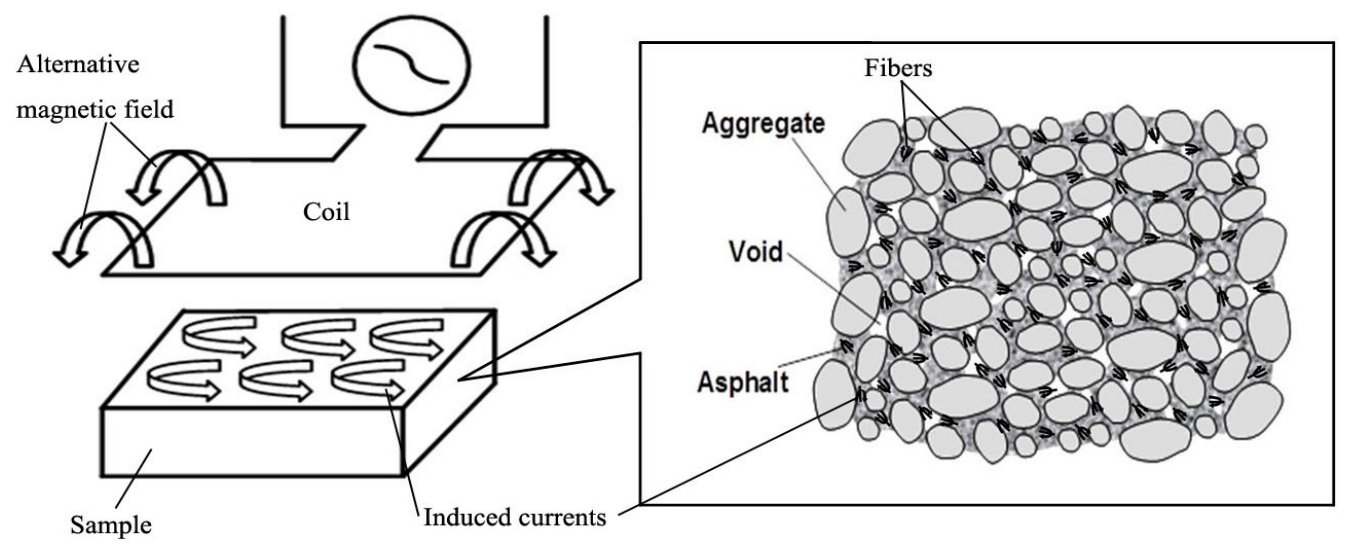

Figure 2. 1 Schematic demonstration of induction healing mechanism for thermoplastic asphalt materials.

\subsubsection{Induction healing system setup}

The induction healing systems for asphalt mastic and concrete samples were used as shown in Figure 2.2 (a) and 2 (b), respectively. As mentioned, the induction coils connected with power generator introduced magnetic field for induction healing of asphalt samples. These experiments were performed using Ameritherm Solid State induction heating equipment SP-5.0 with a capacity of $5 \mathrm{~kW}$. A $125 \mathrm{~mm}$ by $105 \mathrm{~mm}$ 
planer coil was fabricated to carry out the heating process. The coil was place over the fracture area of the sample during healing. To regulate and set the temperature being produced, a thermal couple was used in conjunction with the induction heating machine. A hand held Fluke 62 Mini IR Thermometer was used to detect the temperature changes on the surface of the sample during the healing process.

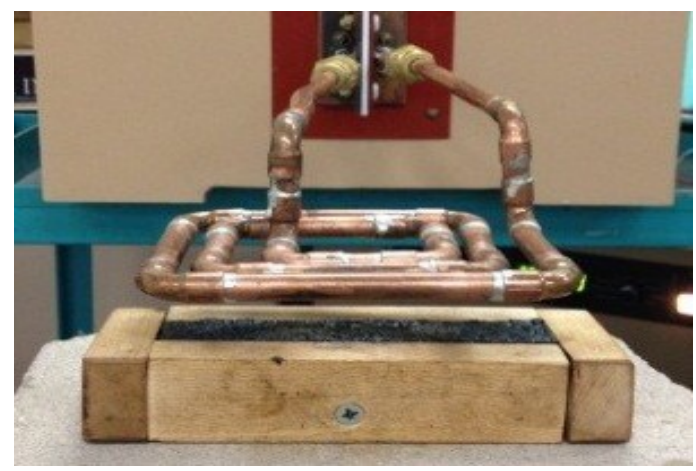

(a)

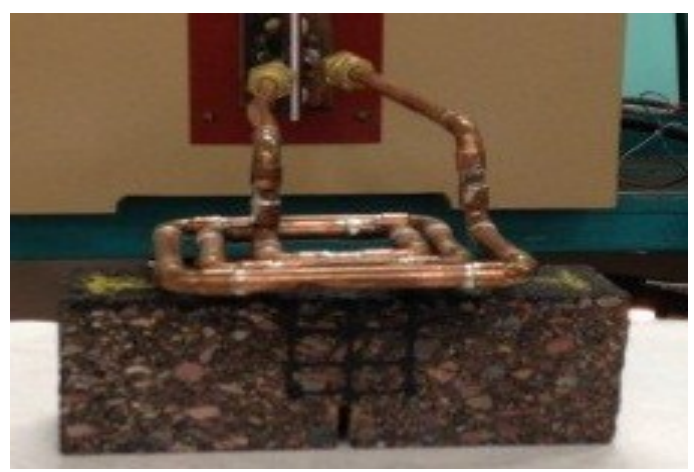

(b)

Figure 2. 2 Induction healing system with heating generator and induction coils: (a) asphalt concrete sample healing and; (b) asphalt mastic sample healing.

\subsubsection{Resistivity measurement of prepared samples}

Electrical resistivity measurements were conducted on the prepared asphalt mastic (Figure 2.3 (a)) and concrete beam specimens (Figure 2.3 (b)) at room temperature of $20^{\circ} \mathrm{C}$. Copper electrodes with the size of the short end of the samples were used to measure resistance (R). Graphite powder was used on the mastic sample to ensure full contact with the electrode. Resistivity was then calculated using Ohm's second law as shown in Equation (2-1):

$\rho=\frac{R S}{L}$ 
where R is the measured electrical resistance $(\Omega), \mathrm{S}$ is the electrode conductivity $\left(\mathrm{m}^{2}\right)$, $\mathrm{L}$ is the internal electrode distance $(\mathrm{m})$ and $\rho$ is the electrical resistivity $(\Omega \cdot \mathrm{m})$

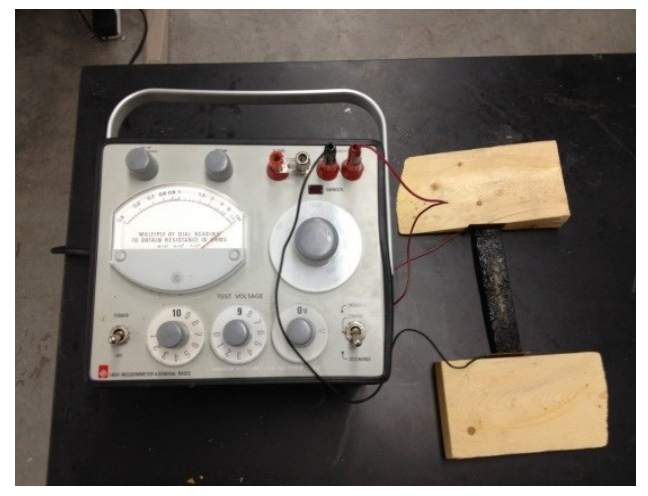

(a)

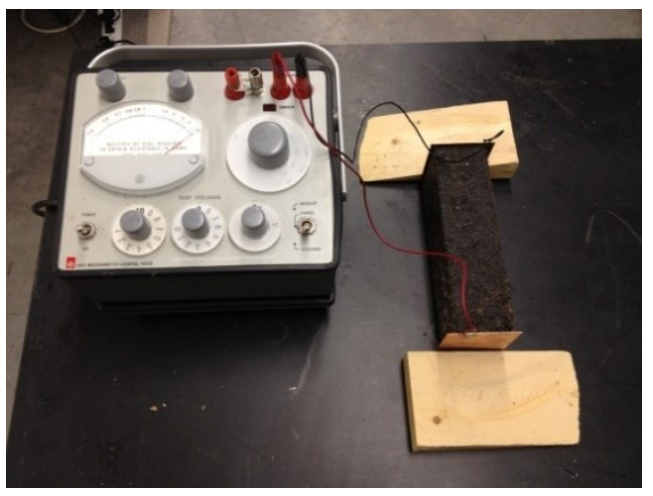

(b)

Figure 2. 3 Electrical resistivity measurement of prepared samples: (a) asphalt mastic samples; (b) asphalt concrete samples.

The measured electrical resistivity of asphalt mastic and concrete samples was plotted as logarithm values as shown in Figure 2.4 (a) and (b). Figure 2.4 (a) shows the measured volumetric resistivity of nine mastic samples used for the following fracturehealing cyclic studies. The average volume resistivity of the mastic samples was calculated about $2.4 \times 10^{11} \Omega \cdot \mathrm{m}$. The average volume resistivity $(\log (\Omega \cdot \mathrm{m}))$ was 9.7 with a standard deviation about 1.55 . Figure 2.4 (b) displays the measured volume resistivity of nine asphalt concrete beams. These concrete beam samples were also used for healing performance study. The average volumetric resistivity of these asphalt concrete beam samples was about $5.81 \times 10^{11} \Omega \cdot \mathrm{m}$. The average Logarithm value of volume resistivity $(\log (\Omega \mathrm{m}))$ was 11.2 with a standard deviation of 0.66 . The relative larger deviation values were caused due to relatively higher fiber content in asphalt mastic samples, compared with asphalt concrete samples. 


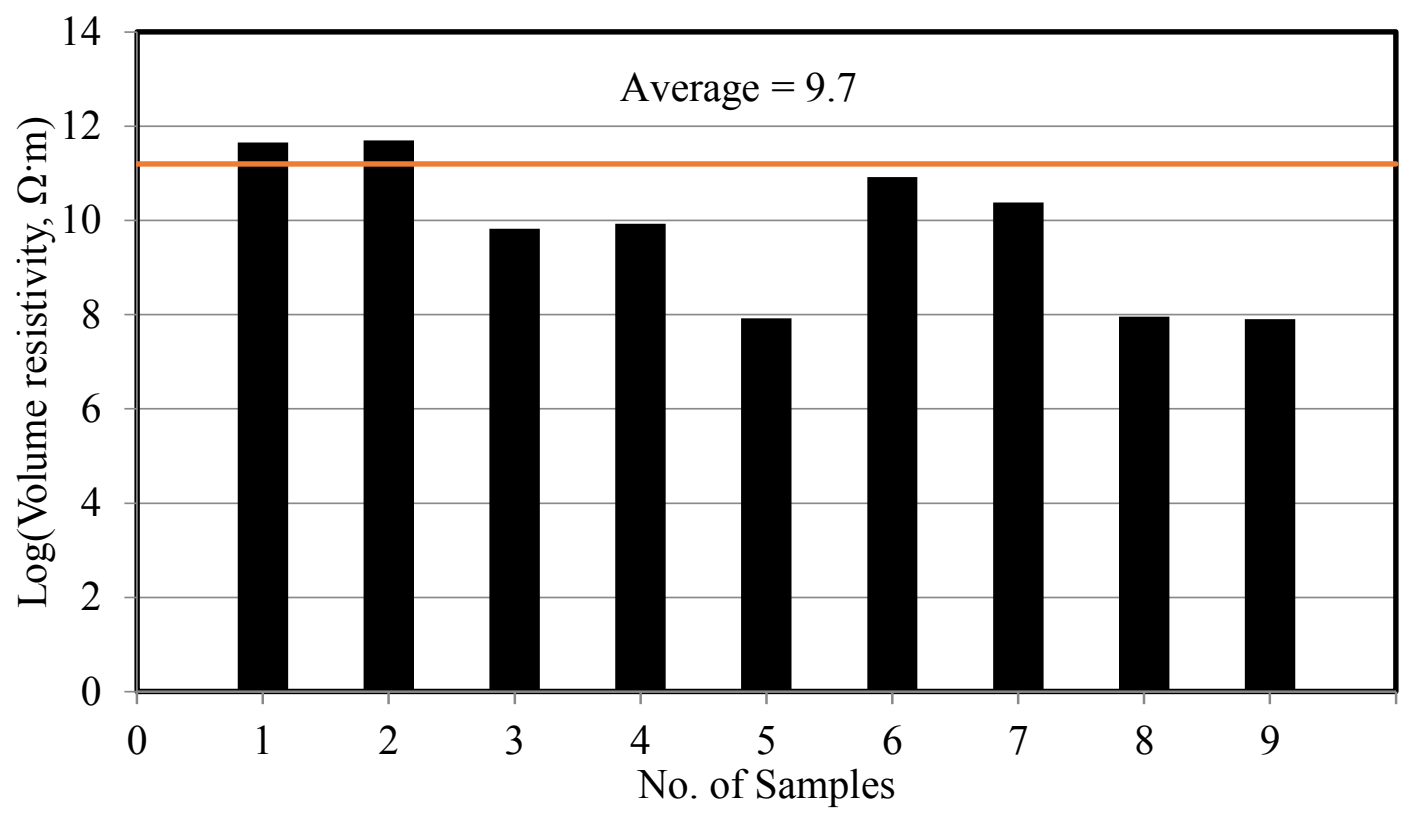

(a)

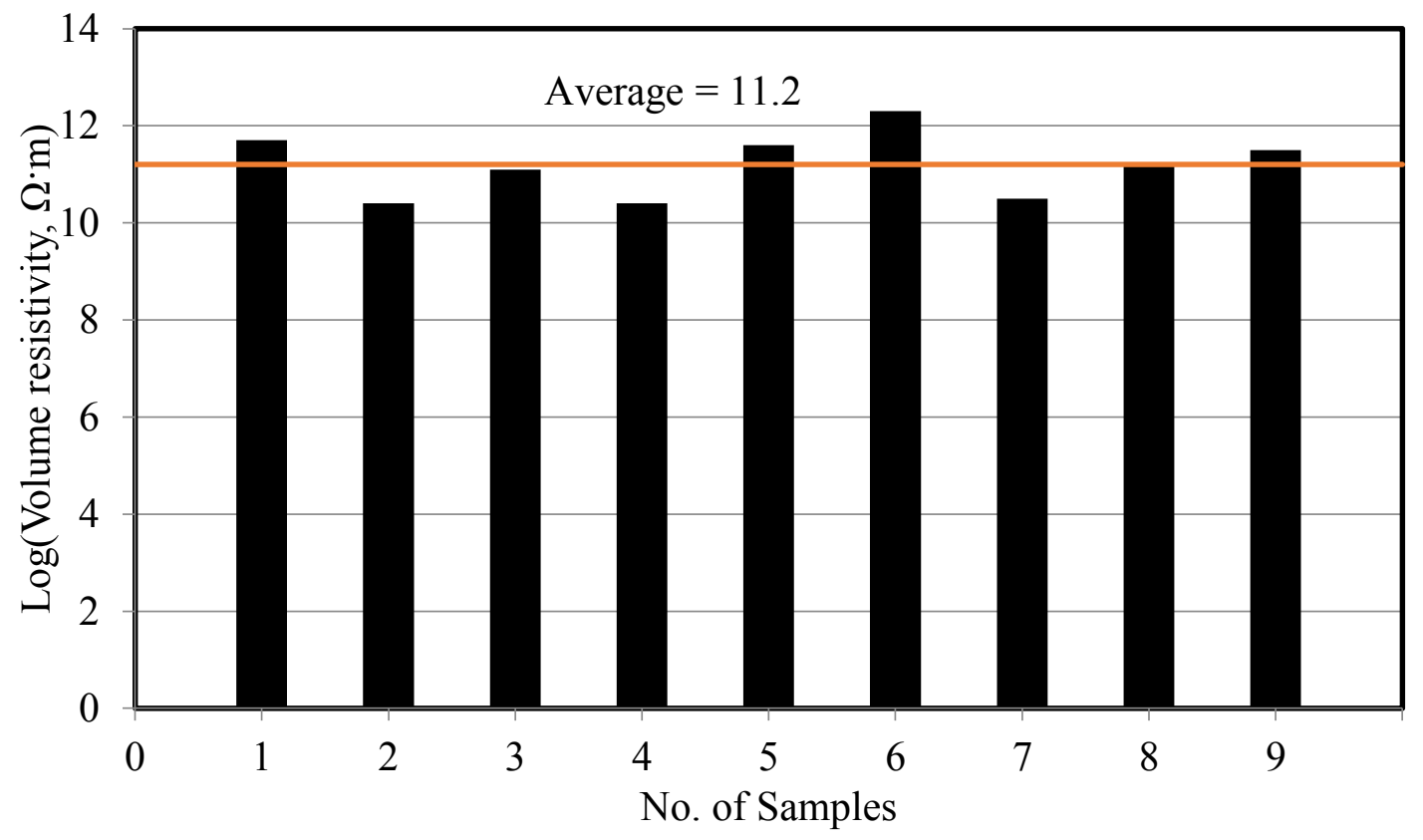

(b)

Figure 2. 4 Electrical resistivity values of prepared samples before loading: (a) asphalt mastic samples; (b) asphalt concrete samples. 


\subsubsection{Temperature distribution of induction heated concrete samples}

Type 1 steel wool fibers were incorporated into the asphalt mastic and concrete samples to induction heat the samples through different heating temperatures. During induction heating, the asphalt concrete sample was placed about $10 \mathrm{~mm}$ from the induction heating coil. Once the sample surface temperature reached the desired heating temperature $\left(60,80\right.$ and $\left.100^{\circ} \mathrm{C}\right)$, the sample was held for another two minutes. The infrared thermal camera (FLIR 8X Digital Zoom 640x480) was used to capture the temperature distribution in each sample as shown in Figure 2.5. The images were taken at the end of healing process. Figure 2.5 (a-c) shows the temperature distribution of samples at three heating temperatures. In these images, the color bar at the right side represents the temperature variation of the specimen. The bright yellow color indicates the relatively high temperature while the dark blue color represents the relatively low temperature. Even though the strength of alternating magnetic field frequency decreased from top surface to bottom surface of the samples, the induction energy and heating temperature have the same trend. The highest temperature can reach about $67.2^{\circ} \mathrm{C}, 80.4^{\circ} \mathrm{C}$ and $100^{\circ} \mathrm{C}$ in the middle of the top surface for the specimen healed at $60^{\circ} \mathrm{C}, 80^{\circ} \mathrm{C}$ and $100^{\circ} \mathrm{C}$, respectively. The figures indicate that the samples are uniformly healed during the induction healing process. 


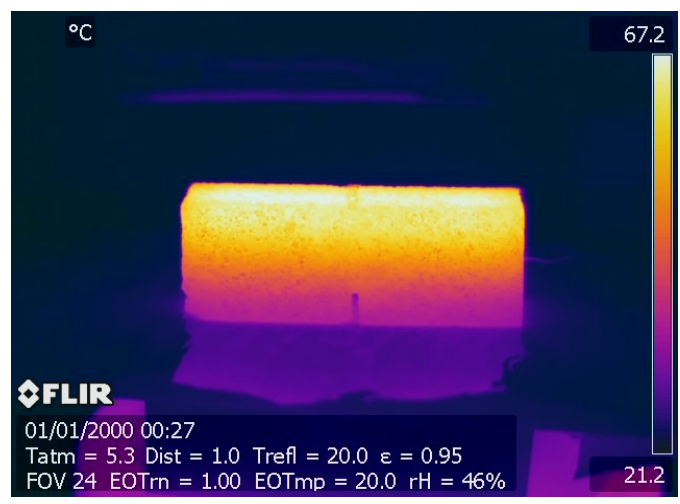

(a)

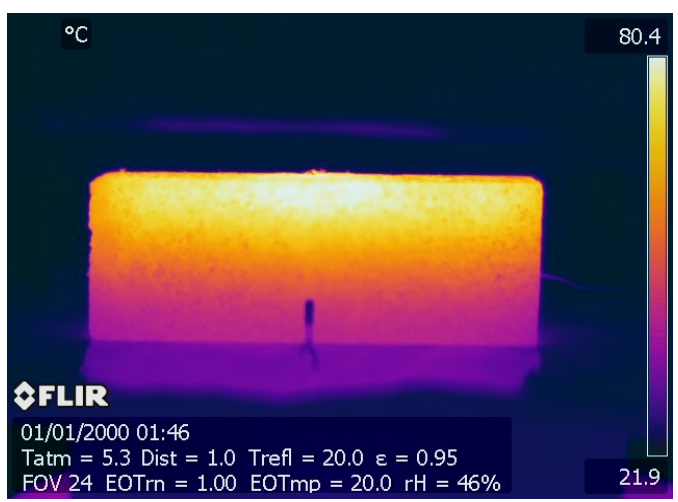

(b)

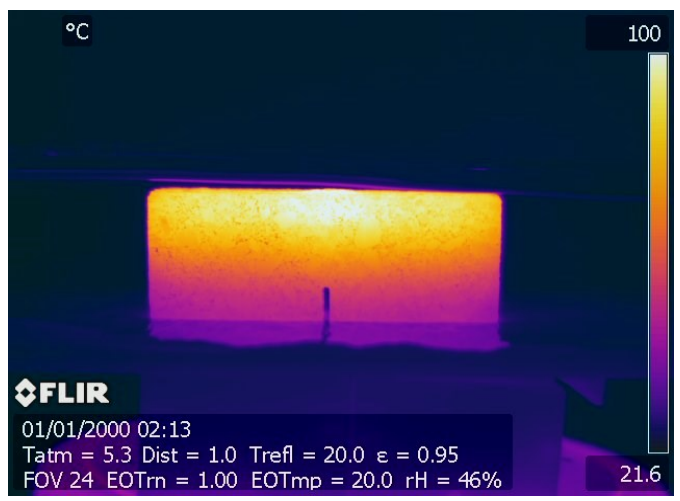

(c)

Figure 2. 5 Infrared images of induction heating temperature distribution with asphalt concrete samples under heating temperature of (a) $60^{\circ} \mathrm{C}$; (b) $80^{\circ} \mathrm{C}$ and; (c) $100{ }^{\circ} \mathrm{C}$. 


\subsection{Fracture-healing cyclic study of asphalt mastic samples with three-point beam bending tests}

\subsubsection{Fracture-healing tests of asphalt mastic samples}

The peak loads of three-point beam bending test of asphalt mastic samples were used to evaluate the healing performance after the fracture-healing cycles. A total of nine fracture-healing cycles were completed to measure the peak load values of asphalt mastic samples by following the same test procedure. The mastic samples were formerly conditioned at $-20^{\circ} \mathrm{C}$ about 6 hours before the test to limit the viscoelastic and unrecovered deformation. The samples were tested with a three-point bending setup at a loading rate of $50 \mathrm{~mm} / \mathrm{min}$ (as shown in Figure 2.6(a)). When the loading force started to decrease, the loading machine was stopped. The loading curve and peak value was recorded for healing performance analysis. After fractured, the samples were rested at least for 15 minutes until they reached the room temperature about $20^{\circ} \mathrm{C}$. For the healing process, the samples were placed in a wooden mold to help maintain the shape during healing. The samples were heated at a distance of $35 \mathrm{~mm}$ under the planar induction heating coil. Once the surface temperature reaches the desired values $(60,80$ and $100^{\circ} \mathrm{C}$ ), the sample was continue heating about one more minute. Then, the sample in the mold was placed in the freezer for 15 minutes to maintain the shapes of the samples. This allows the samples to cool down before being removed from the mold to prevent damaging the mastic samples. This process was repeated several times with rest period and conditioning time to allow the samples to reach $-20^{\circ} \mathrm{C}$, before being fractured in the next cycle. 


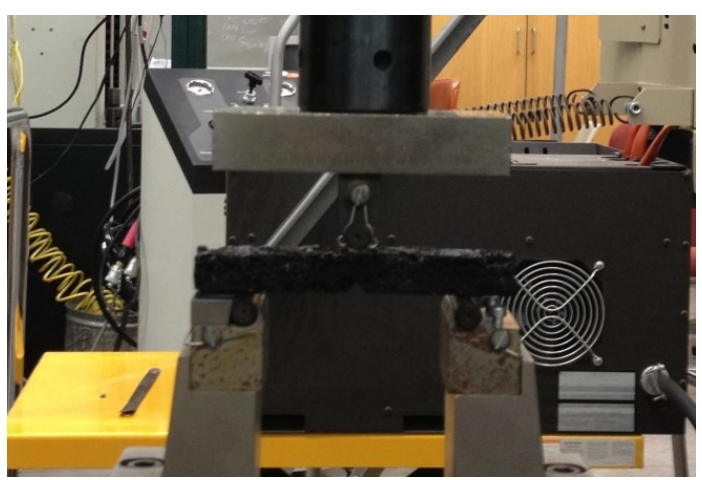

(a)

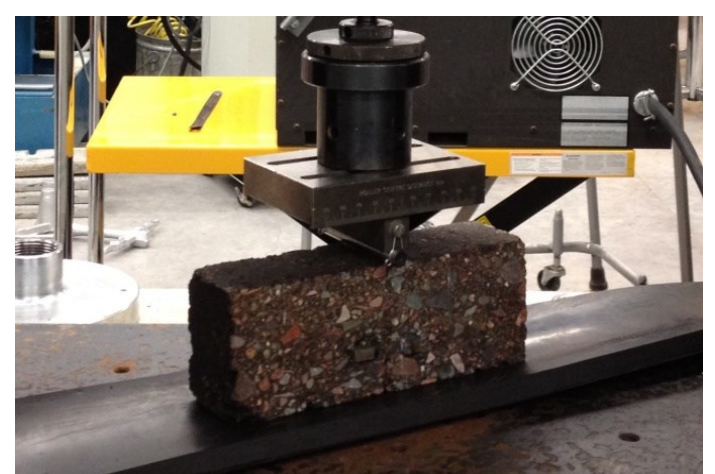

(b)

Figure 2. 6 Demonstration of the test setup: a) three-point beam bending test of mastic beam and; b) modified bending test of asphalt concrete beam with elastic foundation.

\subsubsection{Fracture-healing test results with asphalt mastic samples}

The fracture-healing tests were conducted with three samples at each heating temperature of $60^{\circ} \mathrm{C}, 80^{\circ} \mathrm{C}$ or $100^{\circ} \mathrm{C}$. During the healing process, the binder flowing into cracks was observed. Table 2.3 shows the peak load values of the original mastic samples. The peak load values were measured in the range from $50 \mathrm{~N}$ to $150 \mathrm{~N}$. The fracture-healing test curve of asphalt mastic samples (Sample 1,2 and 3) at the heating temperature of $60^{\circ} \mathrm{C}$ is shown in Figure 2.7. The figure shows that the peak loads of the samples are relatively identical after each fracture-healed cycle. The percentage of recovered peak loads after each cycle for mastic samples were listed in the Table 2.4. After nine cycles, the Sample 1 has the recovered strength about 117.8\%, while Sample 2 and 3 have increased the peak strength about $160.9 \%$ and $209.3 \%$. The increased peak strength was due to the mastic samples have relatively high binder content. And thus the notched crack in the bottom of the sample was filled with some heated binder and sands after each healing process. 
Table 2. 3 Peak load of virginal mastic samples.

\begin{tabular}{|l|l|l|l|l|l|l|l|l|}
\hline Specimen & 1 & 2 & 3 & 4 & 5 & 7 & 8 & 9 \\
\hline Peak & 126.64 & 82.56 & 61.23 & 152.05 & 154.25 & 129.16 & 151.53 & 100.38 \\
$\operatorname{load}(\mathrm{N})$ & & & & & & & & \\
\hline
\end{tabular}


Table 2. 4 Percentage of recovered peak loads after each fracture-healing cycle for mastic samples.

\begin{tabular}{|c|c|c|c|c|c|c|c|c|}
\hline Specimen & 1 & 2 & 3 & 4 & 5 & 7 & 8 & 9 \\
\hline Cycle 1 & $99.8 \%$ & $\begin{array}{l}162.3 \\
\%\end{array}$ & $\begin{array}{l}220.9 \\
\%\end{array}$ & $\begin{array}{l}108.0 \\
\%\end{array}$ & $\begin{array}{l}173.0 \\
\%\end{array}$ & $\begin{array}{l}171.0 \\
\%\end{array}$ & $\begin{array}{l}115.9 \\
\%\end{array}$ & $\begin{array}{l}128.8 \\
\%\end{array}$ \\
\hline Cycle 2 & $\begin{array}{l}117.4 \\
\%\end{array}$ & $\begin{array}{l}160.6 \\
\%\end{array}$ & $\begin{array}{l}200.1 \\
\%\end{array}$ & $85.5 \%$ & $\begin{array}{l}113.8 \\
\%\end{array}$ & $\begin{array}{l}107.8 \\
\%\end{array}$ & $\begin{array}{l}125.5 \\
\%\end{array}$ & $\begin{array}{l}151.1 \\
\%\end{array}$ \\
\hline Cycle 3 & $\begin{array}{l}114.3 \\
\%\end{array}$ & $\begin{array}{l}158.6 \\
\%\end{array}$ & $\begin{array}{l}207.4 \\
\%\end{array}$ & $\begin{array}{l}101.4 \\
\%\end{array}$ & $\begin{array}{l}113.5 \\
\%\end{array}$ & $\begin{array}{l}182.3 \\
\%\end{array}$ & $\begin{array}{l}110.0 \\
\%\end{array}$ & $\begin{array}{l}168.6 \\
\%\end{array}$ \\
\hline Cycle 4 & $\begin{array}{l}113.5 \\
\%\end{array}$ & $\begin{array}{l}149.5 \\
\%\end{array}$ & $\begin{array}{l}190.3 \\
\%\end{array}$ & $\begin{array}{l}110.2 \\
\%\end{array}$ & $\begin{array}{l}104.8 \\
\%\end{array}$ & $\begin{array}{l}195.6 \\
\%\end{array}$ & $\begin{array}{l}106.9 \\
\%\end{array}$ & $\begin{array}{l}163.3 \\
\%\end{array}$ \\
\hline Cycle 5 & $\begin{array}{l}101.9 \\
\%\end{array}$ & $\begin{array}{l}131.1 \\
\%\end{array}$ & $\begin{array}{l}205.1 \\
\%\end{array}$ & $\begin{array}{l}108.6 \\
\%\end{array}$ & $\begin{array}{l}115.1 \\
\%\end{array}$ & $\begin{array}{l}152.5 \\
\%\end{array}$ & $\begin{array}{l}122.3 \\
\%\end{array}$ & $\begin{array}{l}174.5 \\
\%\end{array}$ \\
\hline Cycle 6 & $96.8 \%$ & $\begin{array}{l}152.6 \\
\%\end{array}$ & $\begin{array}{l}195.4 \\
\%\end{array}$ & $\begin{array}{l}129.0 \\
\%\end{array}$ & $\begin{array}{l}106.6 \\
\%\end{array}$ & $\begin{array}{l}208.4 \\
\%\end{array}$ & $\begin{array}{l}133.9 \\
\%\end{array}$ & $\begin{array}{l}202.8 \\
\%\end{array}$ \\
\hline Cycle 7 & $\begin{array}{l}103.7 \\
\%\end{array}$ & $\begin{array}{l}112.5 \\
\%\end{array}$ & $\begin{array}{l}196.1 \\
\%\end{array}$ & $\begin{array}{l}143.8 \\
\%\end{array}$ & $\begin{array}{l}110.8 \\
\%\end{array}$ & $\begin{array}{l}191.4 \\
\%\end{array}$ & - & $\begin{array}{l}210.9 \\
\%\end{array}$ \\
\hline Cycle 8 & $88.2 \%$ & $\begin{array}{l}136.2 \\
\%\end{array}$ & $\begin{array}{l}205.9 \\
\%\end{array}$ & $\begin{array}{l}142.9 \\
\%\end{array}$ & $\begin{array}{l}139.4 \\
\%\end{array}$ & $\begin{array}{l}192.1 \\
\%\end{array}$ & - & $\begin{array}{l}238.0 \\
\%\end{array}$ \\
\hline Cycle 9 & $\begin{array}{l}117.8 \\
\%\end{array}$ & $\begin{array}{l}160.9 \\
\%\end{array}$ & $\begin{array}{l}209.3 \\
\%\end{array}$ & $\begin{array}{l}167.6 \\
\%\end{array}$ & $\begin{array}{l}148.7 \\
\%\end{array}$ & $\begin{array}{l}185.0 \\
\%\end{array}$ & - & $\begin{array}{l}249.9 \\
\%\end{array}$ \\
\hline
\end{tabular}




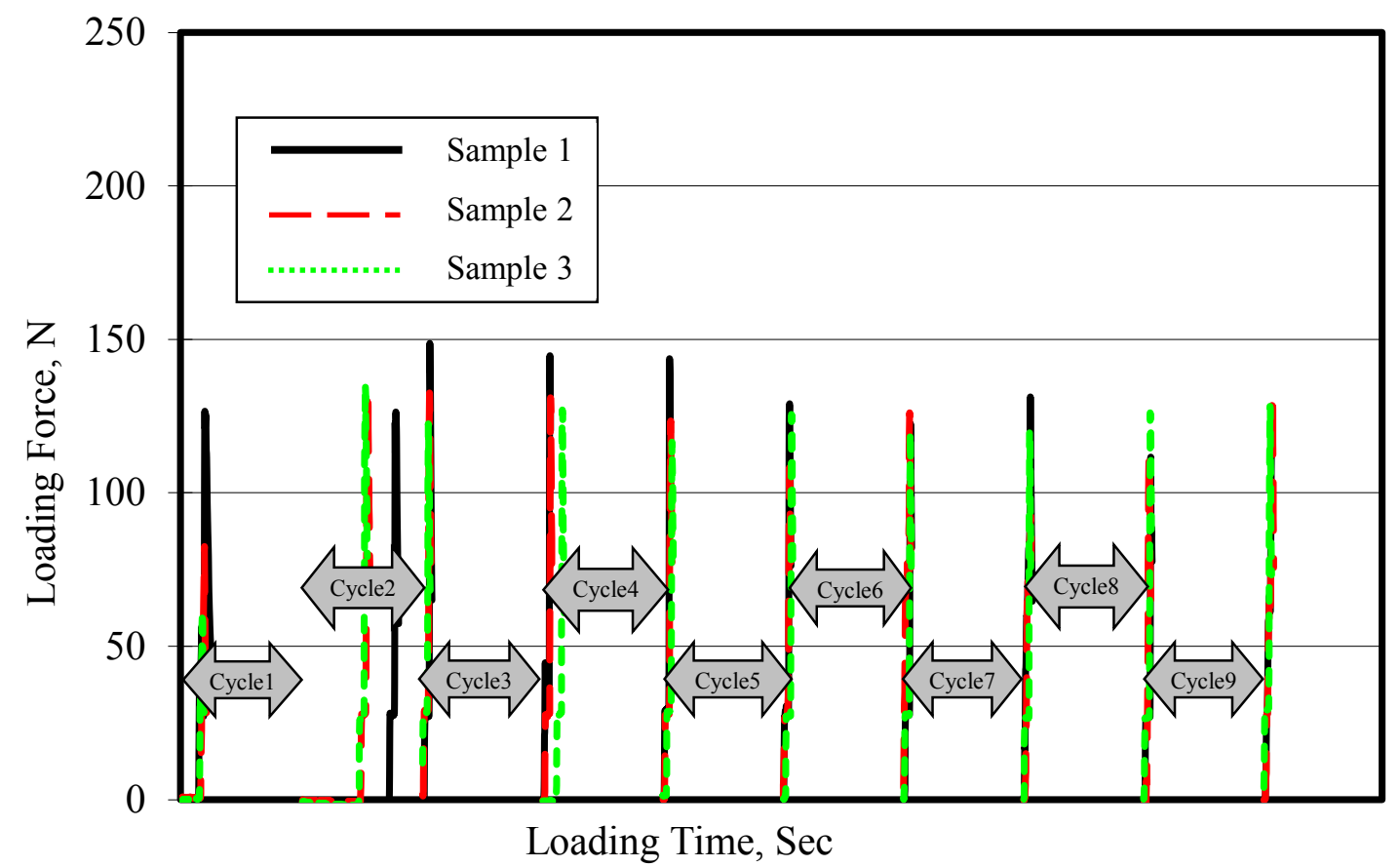

Figure 2. 7 Fracture-healing test data of asphalt mastic samples at heating temperature

$$
\text { of } 60^{\circ} \mathrm{C} \text {. }
$$

The fracture-healing test curve of asphalt mastic samples (Sample 4 and 5) at the heating temperature of $80^{\circ} \mathrm{C}$ is shown in Figure 2.8. Again, the peak load values of the original mastic samples were listed in Table 2.3. After nine cycles, Sample 4 and 5 have increased the peak strength about $160.9 \%$ and $209.3 \%$. The test data of Sample 6 was not included since the recovered peak load value of cycle 9 was very high (about three times higher than the original peak load value). This abnormal test data were probably caused by large amount binder and sands flowing into the notched crack. 


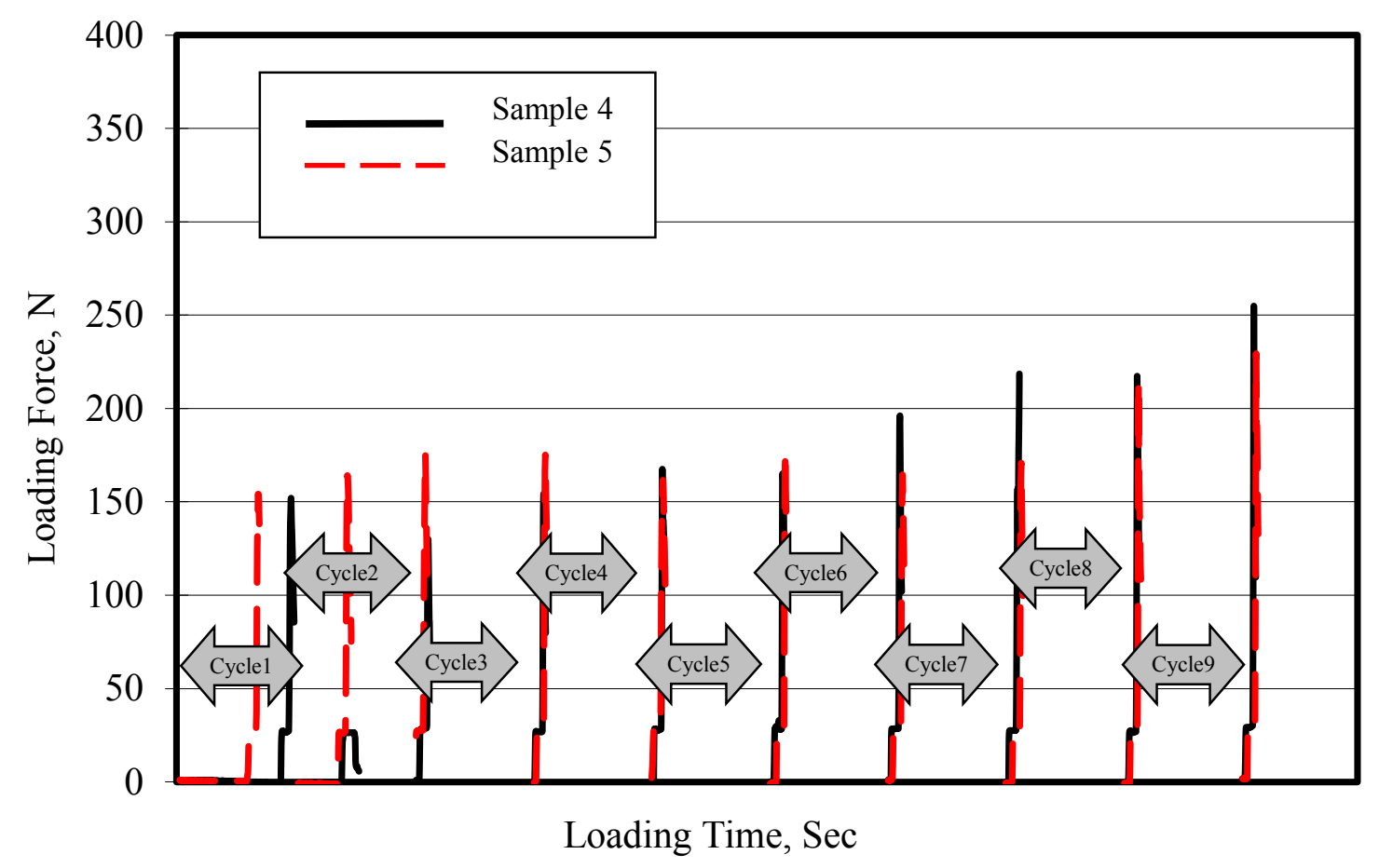

Figure 2. 8 Fracture-healing test data of asphalt mastic samples at heating temperature of $80^{\circ} \mathrm{C}$.

The fracture-healing test curve of asphalt mastic samples (Sample 7, 8 and 9) at the heating temperature of $100^{\circ} \mathrm{C}$ is shown in Figure 2.9. The peak load value of the original mastic samples is listed in Table 2.3. After nine cycles, Sample 7 and 9 have increased the peak strength about $185.0 \%$ and $249.9 \%$. Sample 8 was fractured as two pieces after cycle 6 , with the recovered peak strength about $133.9 \%$. These mastic sample test results indicated that induction healing process can fully repair cracks and also increased peak strength with cycles. The recovered peak strength has increased with heating temperatures. Where at higher heating temperatures, the viscosity of 
asphalt binder is significantly reduced, hence results in higher binder's flow rate and seals the crack opening.

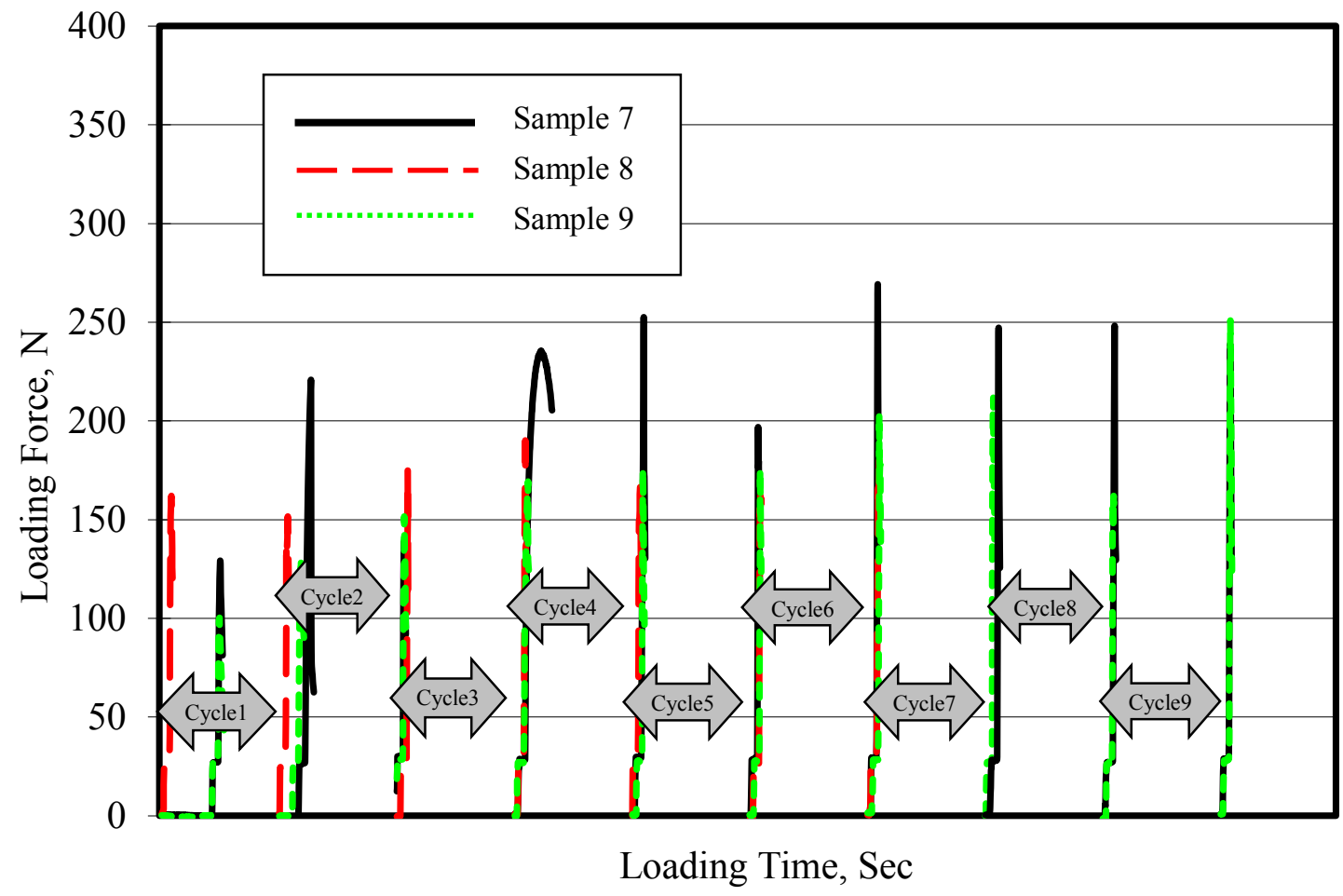

Figure 2.9 Fracture-healing test data of asphalt mastic samples at heating temperature of $100^{\circ} \mathrm{C}$.

\subsection{Fracture-healing investigation of asphalt concrete samples using beam bending test with elastic foundation}

\subsubsection{Fracture-healing tests of asphalt concrete samples}

The measured peak load of the asphalt concrete beams after fracture-healing cycles was used to determine the healing capacity of asphalt mixture samples. The tests were conducted to determine the recovered peak load of the asphalt concrete samples by following the same test procedures for the asphalt mastic test. The asphalt concrete 
samples were initially conditioned at $-20^{\circ} \mathrm{C}$. Then, the conditioned samples were fractured using a modified beam bending test with an elastic rubber foundation support as shown in Figure 2.6(b). The low loading rate of $0.5 \mathrm{~mm} / \mathrm{min}$ was applied for the beam fracture test. This test setup allowed the sample to be fractured globally by limiting local damage. When the loading started to reduce, the loading was stopped. The loading curve and peak loads were recorded for healing performance investigation. After beam bending test, the samples rested at least for an hour until they reached room temperature about $20^{\circ} \mathrm{C}$. During the induction healing process, the sample was placed about $10 \mathrm{~mm}$ below the induction heating coil. Once the surface temperature reaches to the desired temperature $\left(60,80\right.$ and $\left.100^{\circ} \mathrm{C}\right)$, the sample was prolong for another two minutes heating process. Afterward, the samples were let to cool down at the room temperature. And followed by the samples were put into the freezer for six hours to reach $-20^{\circ} \mathrm{C}$, before the next fracture-healing cycle.

\subsubsection{Fracture-healing test results on asphalt concrete samples}

As mentioned in the previous test section, the measured peak load of the asphalt concrete beams after each fracture re-healing cycle was used to determine healing performance. The peak load of the original asphalt concrete samples is listed in Table 2.5. The range of the peak values is from $3500 \mathrm{~N}$ to $5000 \mathrm{~N}$. The fracture-healing tests were conducted with three samples at each heating temperature of $60^{\circ} \mathrm{C}, 80^{\circ} \mathrm{C}$ or $100^{\circ} \mathrm{C}$. 
Table 2. 5 Peak load of original asphalt concrete samples.

\begin{tabular}{|l|l|l|l|l|l|l|l|l|l|}
\hline Specimen & 1 & 2 & 3 & 4 & 5 & 6 & 7 & 8 & 9 \\
\hline Peak & 4593. & 4512. & 5158. & 3608. & 4325. & 4961. & 4605. & 4862. & 4661. \\
Load (N) & 6 & 2 & 0 & 9 & 8 & 5 & 0 & 0 & 4 \\
\hline
\end{tabular}

Figure 2.10 shows the fracture-healing test data of asphalt concrete samples at heating temperature of $60^{\circ} \mathrm{C}$ for Sample 1, 2 and 3. The original peak loads of these asphalt concrete samples were within the range from $4500 \mathrm{~N}$ to $5000 \mathrm{~N}$, and reduced to the range from $2000 \mathrm{~N}$ to $2500 \mathrm{~N}$ after nine fractured-healed cycles. Table 2.6 lists the percentage of recovered peak loads of asphalt concrete samples after each fracturehealing cycle. Sample 1 and 2 has $35.8 \%$ and $56.8 \%$ recovered peak loads after 9 cycles respectively. Sample 3 was fractured into two pieces in the 7th beam bending loading test with $41.9 \%$ recovered fracture strength. It was found that the fracture strength reduced to half of original values after few cycles at the heating temperature of $60^{\circ} \mathrm{C}$. 
Table 2. 6 Percentage of recovered peak loads after each fracture-healing cycle for asphalt concrete samples.

\begin{tabular}{|c|c|c|c|c|c|c|c|c|c|}
\hline Specimen & 1 & 2 & 3 & 4 & 5 & 6 & 7 & 8 & 9 \\
\hline Cycle 1 & $\begin{array}{l}86.4 \\
\%\end{array}$ & $\begin{array}{l}77.0 \\
\%\end{array}$ & $\begin{array}{l}84.1 \\
\%\end{array}$ & $\begin{array}{l}102.8 \\
\%\end{array}$ & $\begin{array}{l}102.5 \\
\%\end{array}$ & $\begin{array}{l}87.5 \\
\%\end{array}$ & $\begin{array}{l}79.1 \\
\%\end{array}$ & $\begin{array}{l}91.0 \\
\%\end{array}$ & $\begin{array}{l}104.5 \\
\%\end{array}$ \\
\hline Cycle 2 & $\begin{array}{l}77.5 \\
\%\end{array}$ & $\begin{array}{l}73.9 \\
\%\end{array}$ & $\begin{array}{l}65.7 \\
\%\end{array}$ & $\begin{array}{l}75.2 \\
\%\end{array}$ & $\begin{array}{l}85.8 \\
\%\end{array}$ & $\begin{array}{l}80.1 \\
\%\end{array}$ & $\begin{array}{l}77.6 \\
\%\end{array}$ & $\begin{array}{l}91.9 \\
\%\end{array}$ & $\begin{array}{l}90.6 \\
\%\end{array}$ \\
\hline Cycle 3 & $\begin{array}{l}57.4 \\
\%\end{array}$ & $\begin{array}{l}67.9 \\
\%\end{array}$ & $\begin{array}{l}66.4 \\
\%\end{array}$ & $\begin{array}{l}70.8 \\
\%\end{array}$ & $\begin{array}{l}86.5 \\
\%\end{array}$ & $\begin{array}{l}78.4 \\
\%\end{array}$ & $\begin{array}{l}73.5 \\
\%\end{array}$ & $\begin{array}{l}81.5 \\
\%\end{array}$ & $\begin{array}{l}81.9 \\
\%\end{array}$ \\
\hline Cycle 4 & $\begin{array}{l}54.3 \\
\%\end{array}$ & $\begin{array}{l}65.5 \\
\%\end{array}$ & $\begin{array}{l}58.3 \\
\%\end{array}$ & $\begin{array}{l}64.4 \\
\%\end{array}$ & $\begin{array}{l}84.8 \\
\%\end{array}$ & $\begin{array}{l}68.8 \\
\%\end{array}$ & $\begin{array}{l}63.9 \\
\%\end{array}$ & $\begin{array}{l}74.7 \\
\%\end{array}$ & $\begin{array}{l}80.2 \\
\%\end{array}$ \\
\hline Cycle 5 & $\begin{array}{l}57.1 \\
\%\end{array}$ & $\begin{array}{l}64.9 \\
\%\end{array}$ & $\begin{array}{l}47.1 \\
\%\end{array}$ & $\begin{array}{l}61.1 \\
\%\end{array}$ & $\begin{array}{l}84.6 \\
\%\end{array}$ & $\begin{array}{l}63.9 \\
\%\end{array}$ & $\begin{array}{l}54.7 \\
\%\end{array}$ & $\begin{array}{l}70.8 \\
\%\end{array}$ & $\begin{array}{l}78.7 \\
\%\end{array}$ \\
\hline Cycle 6 & $\begin{array}{l}53.5 \\
\%\end{array}$ & $\begin{array}{l}69.5 \\
\%\end{array}$ & $\begin{array}{l}41.9 \\
\%\end{array}$ & $\begin{array}{l}60.2 \\
\%\end{array}$ & $\begin{array}{l}76.2 \\
\%\end{array}$ & $\begin{array}{l}57.7 \\
\%\end{array}$ & $\begin{array}{l}50.5 \\
\%\end{array}$ & $\begin{array}{l}67.5 \\
\%\end{array}$ & $\begin{array}{l}76.9 \\
\%\end{array}$ \\
\hline Cycle 7 & $\begin{array}{l}49.3 \\
\%\end{array}$ & $\begin{array}{l}63.5 \\
\%\end{array}$ & - & $\begin{array}{l}50.8 \\
\%\end{array}$ & $\begin{array}{l}63.2 \\
\%\end{array}$ & $\begin{array}{l}56.4 \\
\%\end{array}$ & $\begin{array}{l}\begin{array}{l}44.4 \\
\%\end{array} \\
\text { \% }\end{array}$ & $\begin{array}{l}62.8 \\
\%\end{array}$ & $\begin{array}{l}74.0 \\
\%\end{array}$ \\
\hline Cycle 8 & $\begin{array}{l}36.6 \\
\%\end{array}$ & $\begin{array}{l}59.5 \\
\%\end{array}$ & - & $\begin{array}{l}48.3 \\
\%\end{array}$ & $\begin{array}{l}57.6 \\
\%\end{array}$ & $\begin{array}{l}51.7 \\
\%\end{array}$ & $\begin{array}{l}32.7 \\
\%\end{array}$ & $\begin{array}{l}64.5 \\
\%\end{array}$ & $\begin{array}{l}75.1 \\
\%\end{array}$ \\
\hline Cycle 9 & $\begin{array}{l}35.8 \\
\%\end{array}$ & $\begin{array}{l}56.8 \\
\%\end{array}$ & - & - & $\begin{array}{l}51.8 \\
\%\end{array}$ & $\begin{array}{l}45.5 \\
\%\end{array}$ & - & $\begin{array}{l}63.2 \\
\%\end{array}$ & $\begin{array}{l}73.6 \\
\%\end{array}$ \\
\hline
\end{tabular}




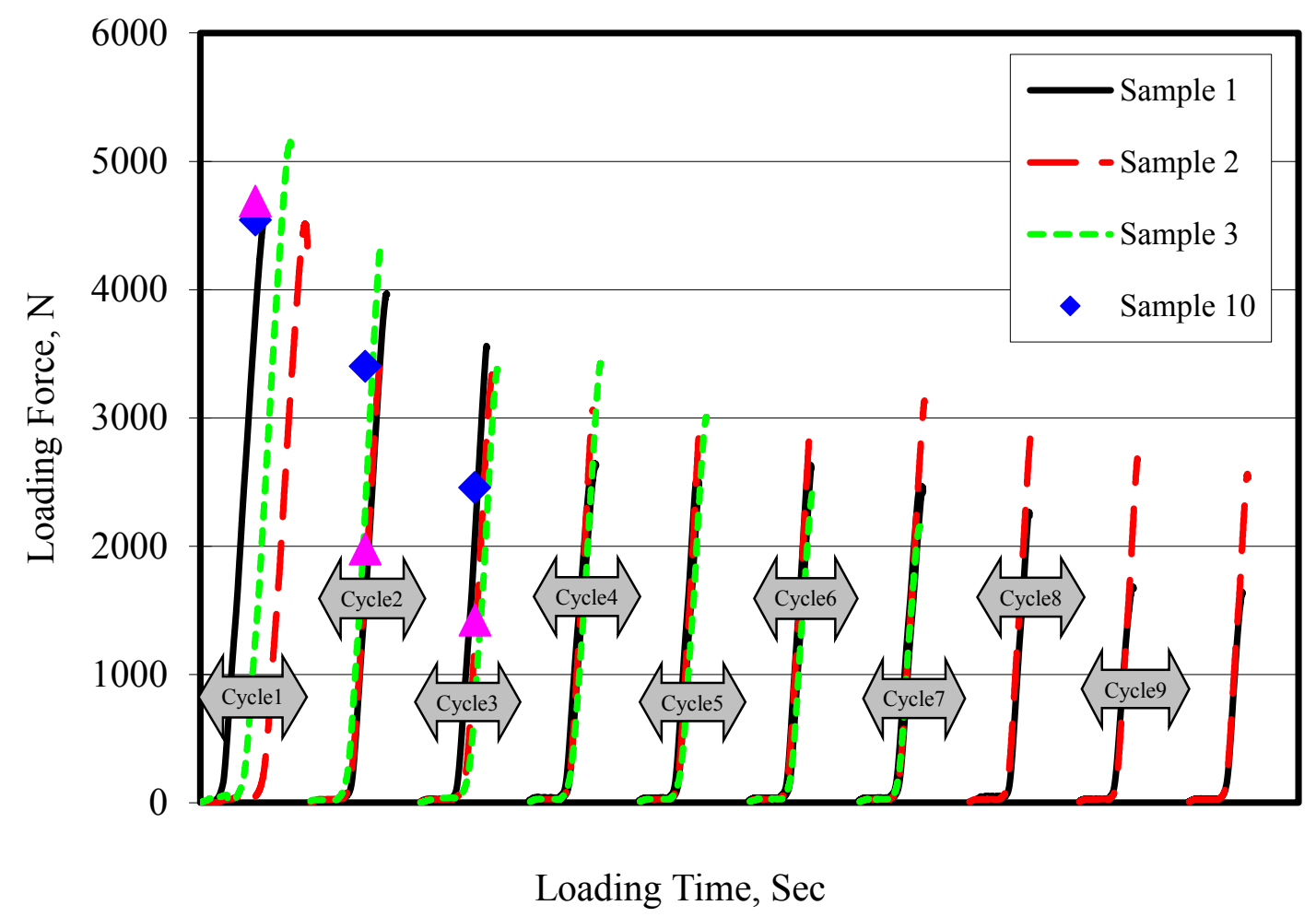

Figure 2. 10 Fracture-healing test data of asphalt concrete samples at heating temperature of $60^{\circ} \mathrm{C}$.

The fracture-healing test data of asphalt concrete Sample 4, 5 and 6 at the heating temperature of $80^{\circ} \mathrm{C}$ are plotted in Figure 2.11. The percentages of recovered peak loads of these samples after each fracture-healing cycle are also listed in Table 2.6. Sample 5 and 6 has $51.8 \%$ and $45.5 \%$ recovered peak loads after 9 cycles respectively. Sample 4 was fractured into two pieces in the 9th beam bending loading with $48.3 \%$ recovered fracture strength. Overall, the healing performance of these samples was improved at the heating temperature of $80^{\circ} \mathrm{C}$, comparing to the previous case. The test results show that the recovered fracture strength maintained about half of the original values at the end of cycles. 


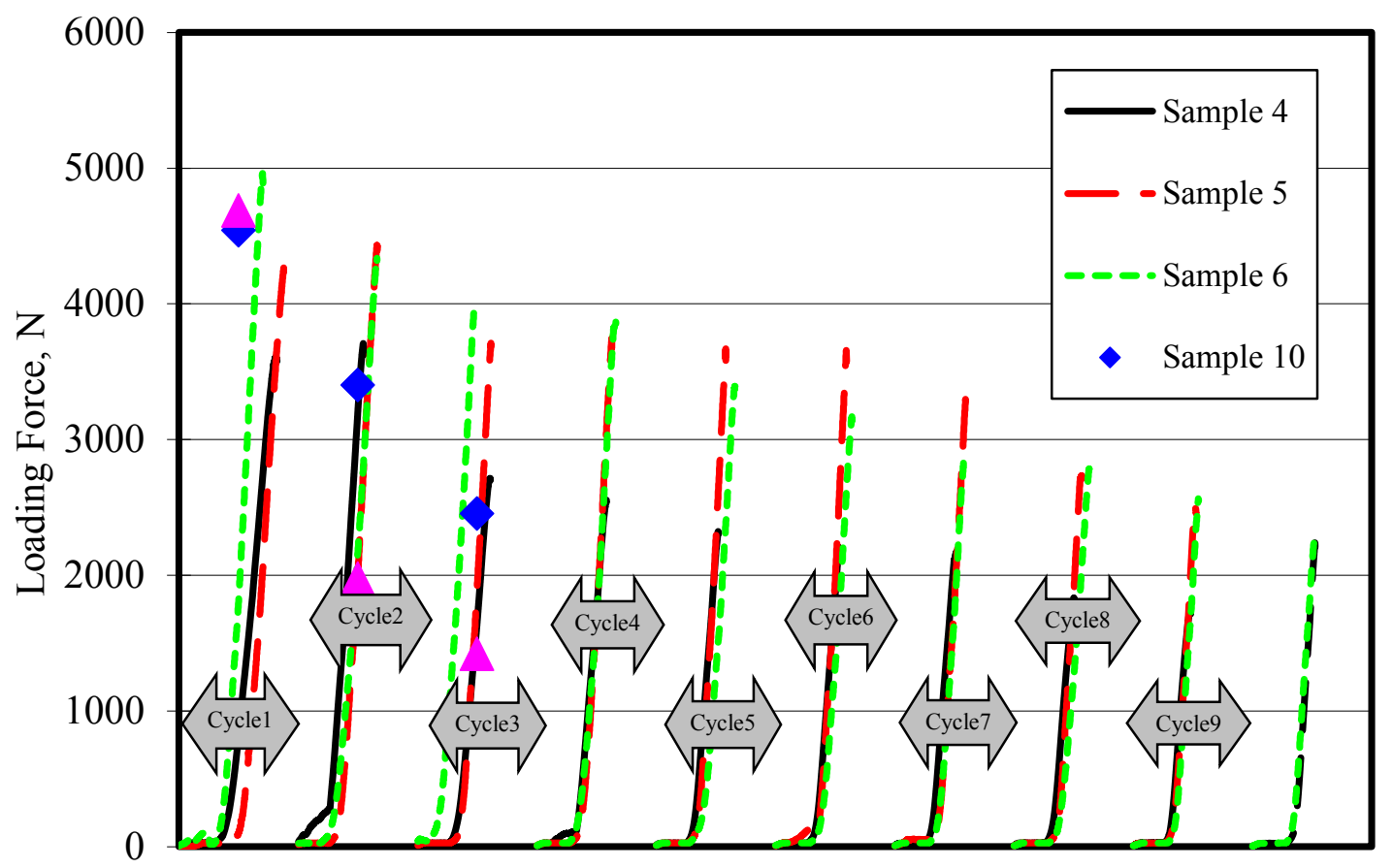

Loading Time, Sec

Figure 2. 11 Fracture-healing test data of asphalt concrete samples at heating temperature of $80^{\circ} \mathrm{C}$.

Figure 2.12 shows that the fracture-healing test data of asphalt concrete Sample 4, 5 and 6 at the heating temperature of $100^{\circ} \mathrm{C}$. From the recovered peak load percentages as listed in Table 2.6, Sample 8 and 9 maintained at $63.2 \%$ and $73.6 \%$ of original fracture strength after 9 fracture-healing cycles respectively. Sample 7 was also fractured into two pieces in the 9th beam bending loading with $32.7 \%$ recovered fracture strength. Meanwhile, the asphalt concrete beam samples (Sample 10 and Sample 11) were loaded with the same beam bending test at $-20^{\circ} \mathrm{C}$. These samples were not going through the healing process prior to make comparison. The samples were conditioned with $-20^{\circ} \mathrm{C}$ before the next fracture test. The peak loads of these two 
samples were used as the comparative test to prove the effectiveness of the induction healing. The original peak loads of these two samples were about $4500 \mathrm{~N}$. After the third-time loading, the peak loads decrease to $1500 \mathrm{~N}$ and $2500 \mathrm{~N}$ of Sample 10 and 11 , as indicated with the diamond and triangle markers in the figure. And the recovered fracture strength of these two samples reached about $55 \%$ and $33 \%$ of the original level after the third loading. Therefore, the micro-cracks in asphalt concrete samples with steel wool fibers can be effectively healed under induction healing and the fracture strength of asphalt mixes can be significantly recovered. From the test data of Sample 8 and 9 , the recovered fracture strength is still in the high level of original values after six fracture-healing cycles at the heating temperature of $100^{\circ} \mathrm{C}$.

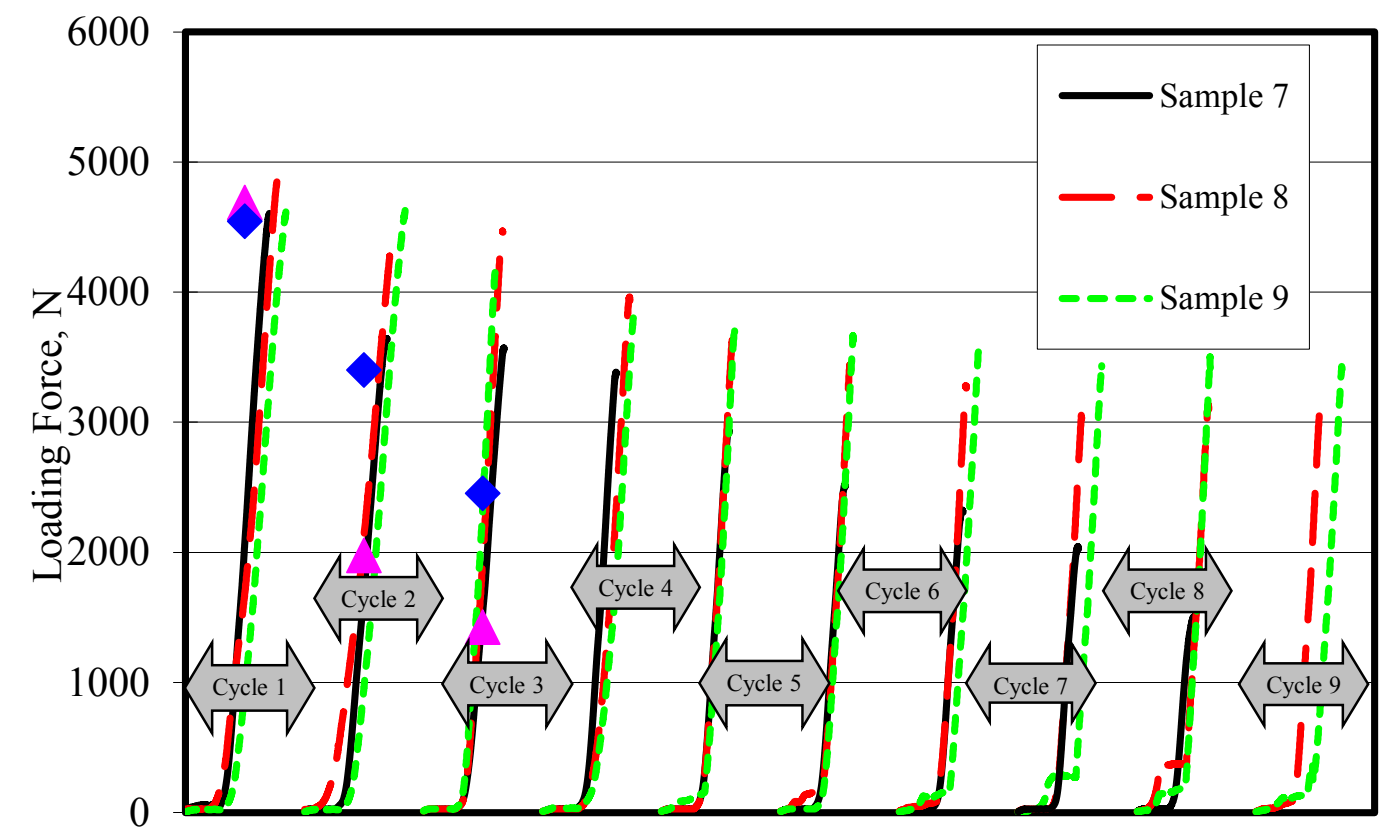

Loading Time, Sec

Figure 2. 12 Fracture-healing test data of asphalt concrete samples at heating temperature of $100^{\circ} \mathrm{C}$. 
Therefore, the healing performance of asphalt concrete beam samples was improved with the heating temperature. The heating temperature of $100^{\circ} \mathrm{C}$ can achieve optimum healing without affecting the physical properties of asphalt materials.

\subsubsection{Changes of electrical resistivity during fracture-healing cycles}

Sample 7 was chosen to evaluate the change of electrical resistivity through four fracture-healing cycles (from fifth cycle to eighth cycle) as shown in Figure 2.13. During each cycle, the electrical resistivity was measured at three different stages to investigate the potential of self-sensing ability. At the first stage, the conditioned sample was loaded after the bending beam test and then was rest until the surface temperature reached the room temperature about $20^{\circ} \mathrm{C}$. In the second stage, the induction healing process was conducted and the sample was then placed to reach the

room temperature. While at the third stage, the sample was put inside the freezer and conditioned about 6 hrs to maintain $-20^{\circ} \mathrm{C}$. 


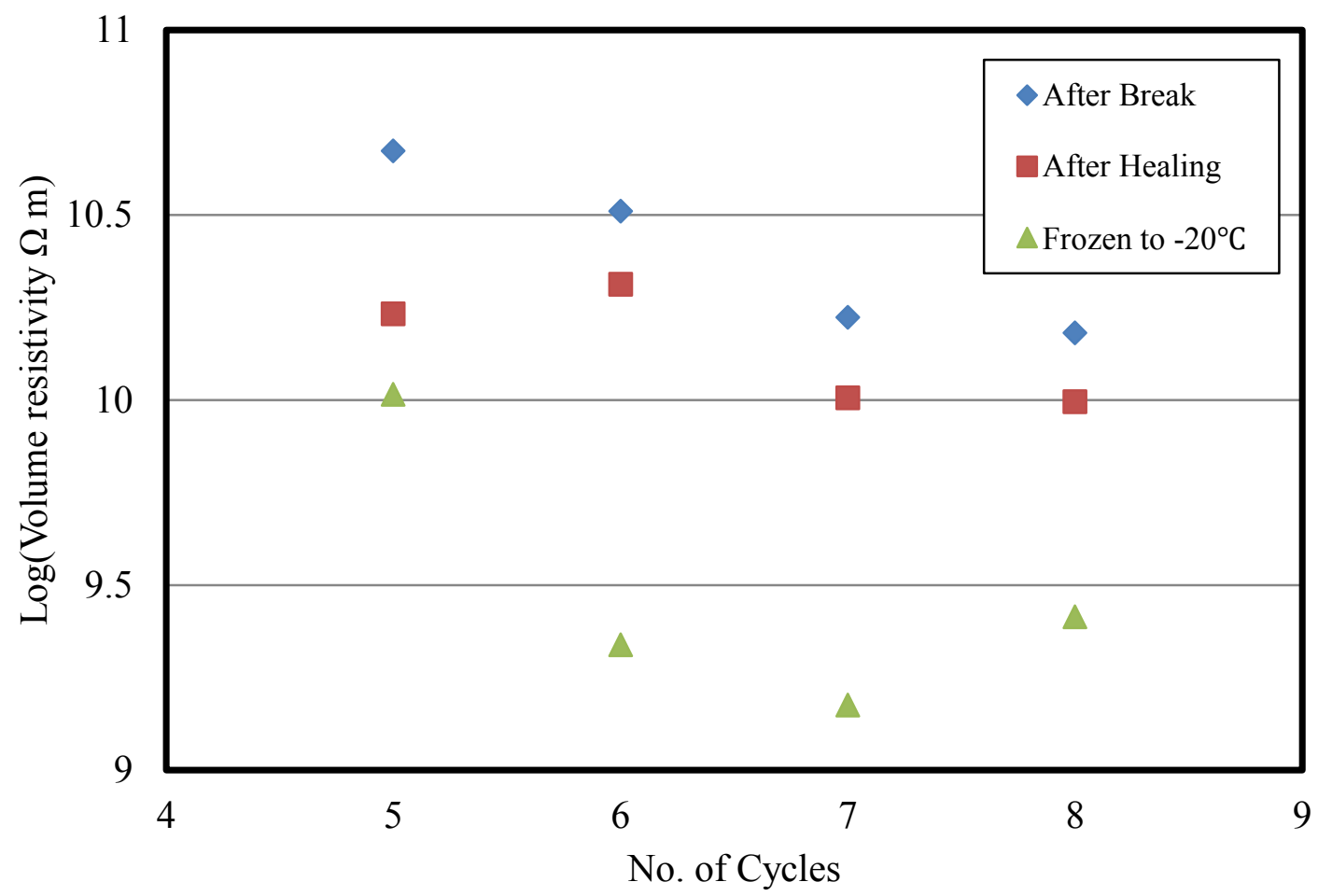

Figure 2.13 Change of electrical resistivity of one asphalt concrete sample during several fracture-healing cycles.

Comparing the first and the second stages at room temperature, the electrical resistivity of the sample was reduced after induction healing process. The value was further reduced at the stage 3 after the sample was conditioned in the freezer at subcooling temperature $-20^{\circ} \mathrm{C}$. The self-healing behavior during the freezing process contributes this resistivity reduction by further repairing the micro-cracks. And also at the subcooling temperatures, the binder generates shrinkage deformation to allow fibers to have better contacts. After the sample was loaded with beam bending test with peak loading and reach to the first stage at the next cycle, the electrical resistivity was increased significantly because the micro-crack behavior causes the fibers to separate. 
This study indicates the electro active- asphalt mixtures with conductive fibers have potentials in damage-sensing ability in structure health monitoring application. The electrical resistivity of the samples decreases with fracture-healing cycles because of the accumulated self-or induction- healing behavior in the samples.

\subsection{Conclusions}

The induction healing performance of prepared asphalt mastic and asphalt concrete samples were investigated through fracture-healing test. The test data of asphalt mastic samples indicate that micro-cracks in the mastic samples can be effectively healed at the heating temperature of $60^{\circ} \mathrm{C}$. The sample fracture strength was improved because the binder filled the notched cracks at the bottom of the samples at the heating temperatures of $80^{\circ} \mathrm{C}$ and $100^{\circ} \mathrm{C}$. From the test data of asphalt concrete samples, it was determined that the $100^{\circ} \mathrm{C}$ heating temperature could be the optimum option for the induction healing because the recovered peak load values were higher than the other two temperatures after several fracture-healing cycles. However, the heating temperature $60^{\circ} \mathrm{C}$ and $80^{\circ} \mathrm{C}$ are also acceptable since the recovered fracture strength is higher than $50 \%$ after six fracture-healing cycles. The induction healing performance on asphalt concrete samples was also validated with sample behaviors without healing process. During each fracture-healing cycle, both induction healing and self-healing behavior can decrease the electrical resistivity of the asphalt concrete samples. And the beam bending test can increase the electrical resistivity by generating the internal damage or cracks. The electrical resistivity of the samples decreases with fracture-healing cycles because of the accumulated crack opening in the samples. 
Future work will be performed to consider the healing effects with different mixture design of asphalt mastic or concrete samples, heating time-periods, and volume percentage and diameter and length dimensions of steel fibers. Especially, the micro-crack healing capacity of asphalt concrete samples will be optimized by varying these design parameters for sustainable pavement applications. It is expected that the effective induction healing system might reduce huge pavement maintenance cost and related traffic jams. The successful applications also help to reduce the $\mathrm{CO}_{2}$ emission and save energy with smooth interactions between pavement surface layer and vehicle tires. 


\section{CHAPTER 3 COHESIVE ZONE MODEL DEVELOPMENT FOR ASPHALT MIXTURE WITHIN STEEL WOOL FIBER*}

\subsection{Introduction}

Asphalt mixtures are used on the surface for over 94\% of all pavements [1]. As a significant component of the U.S. pavement infrastructure system, the self-healing performance of asphalt mixtures has an important impact on maintenance costs. Bitumen or asphalt binder is used in asphalt concrete mixes to bind together aggregate particles. It is typically known as a viscous type thermoplastic material which behaves viscously at high temperatures and is stiff at low temperatures. Pavements surfaces must remain drivable for a wide range of the traffic loads under different climatic conditions for an extended period of time. In order to maintain a drivable pavement surface, the wearing courses are necessary to be repaired constantly. Microcrack can cause the start of major forms of pavement distress [52]. The abrasive action of vehicle wheels on the pavement surface, especially on high stressed areas, can initiate raveling. In the Netherlands [54], induction healing was used as a maintaining method to increase the healing rate and to prevent raveling of porous asphalt. This approach was developed by the Delft University of Technology (TU Delft) based on two essential properties of asphalt concrete: 1) self-healing material and 2) healing capability increases at elevated temperatures [54].

* Text was published in Construction and Building Materials_-Wang, Z., Dai, Q., Yang, X. (2016). "Integrated Computational-Experimental Approach for Evaluating Recovered Fracture Strength after Induction Healing of Asphalt Concrete Beam Samples." Construction and Building Materials. Doi:10.1016/j.conbuildmat.2015.12.130 
Shen et al. [55] believed that the healing behavior was the self-recovery ability of asphalt materials affected by loading and environmental conditions. According to García work [69], asphalt concrete can be treated as a self-healing material related to temperature [57] and the rest periods directly [58, 59]. Healing in asphalt materials evolved complex behavior, which depended on the activation energy of asphalt, capillary flow through the cracks, self-diffusion of molecules, crack phases, material modifications and confinement $[60,61,69]$. In a recent work [64], the asphalt binder flow behavior regarded as Newtonian fluid was simulated through using activation energy based on the Arrhenius equation. Conductive steel fibers were added to the asphalt concrete material to generate eddy current under an alternating magnetic field in order to use induction heating to heal the micro-crack, increase the healing rates of asphalt binder and repair the bond between binder and aggregates. Theoretically, heat was generated due to the dominant Joule effects through the conductive components under induction process [65]. The induction healing of asphalt composites containing conductive fibers were investigated at TU Delft [47, 52, 54, 65-68].

Researchers used the cohesive zone modeling (CZM) techniques to simulate crack propagation for years effectively [70-72]. The CZM techniques employ the relations between crack opening displacement and surface traction [73]. In the early 1933, the idea of cohesive traction relation was applied by Prandtl [74] to predict the debonded zone length between two slender beams. Barenblatt [75] introduced the CZM to study the atoms interacting forces near crack tip of brittle materials in the $60 \mathrm{~s} . \mathrm{Xu}$ and Needleman [76] have established a potential-based cohesive zone model by combining 
exponential cohesive elements with finite element mesh in the 90s. To date, the CZM techniques have been developed to simulate the fracture behavior for both homogeneous and heterogeneous materials and also tailored to suit the application needs and constraints, such as [77-79]. These techniques have solved the singularity issue that has been encountered in many fracture mechanic studies [80]. In the last decade, many applications of civil engineering material utilized the CZM techniques $[81,82]$. The CZM techniques was used to predict concrete fracture behavior through three-point beam bending test and bilinear softening approach [71]. Fracture energy and material strength as the input parameters for the bilinear CZM model were determined by the three-point beam bending test and the correlation between fracture energy and phase properties was demonstrated [83].

The main objective of this study is to evaluate the healing performance and fracture strength recovery ratios of samples after cyclic fracture-induction healing tests. At the beginning, asphalt concrete beams with steel wool fibers and single-edged notch on the bottom were prepared. Secondly, the cyclic fracture-induction healing tests were implemented to obtain the peak load values at $-20{ }^{\circ} \mathrm{C}$ on different induction healing temperatures, $60{ }^{\circ} \mathrm{C}, 80{ }^{\circ} \mathrm{C}$ and $100{ }^{\circ} \mathrm{C}$. Moreover, the simulation model using cohesive zone theory and finite element method was adapted to simulate the crack path of asphalt concrete beam using digital imaging analysis. Then standard three-point bending test was conducted to validate the cohesive fracture model by comparing the experimental results with numerical simulation. Afterwards, the fracture properties including the peak separation stress and fracture energy were proposed for fracture- 
healing cyclic simulation to predict the loading-displacement curves for different cycles. Finally, the cohesive model simulation with proposed fracture properties have favorable prediction on the recovered fracture strength by comparing the difference between the experimental and numerical results.

\subsection{Fracture-induction healing test results of asphalt concrete samples}

\subsubsection{Steel wool asphalt mixture design}

The materials used in this study for the preparation of asphalt concrete beams were aggregates, asphalt binder and steel wool fibers. The aggregates which obtained from a local source in Hancock, Michigan contained natural sand and crushed gravel, with an average density of $2.72 \mathrm{~g} / \mathrm{cm}^{3}$, while The asphalt binder used was PG 58-28 with a density of $1.024 \mathrm{~g} / \mathrm{cm}^{3}$. The steel wool fibers were Type 1 with an approximate length of $6.5 \mathrm{~mm}$, diameter of $0.08 \mathrm{~mm}$ and density of $7.6 \mathrm{~g} / \mathrm{cm}^{3}$.

The aggregate gradation for the asphalt concrete beam preparation is shown in Table 3.1. The steel wool fiber added in the beam samples was approximately $8 \%$ of the binder by volume and the binder content is $5.5 \%$ of the mixture by weight. This percentage was determined by balancing the sample electrical resistivity, thermal effect and mixing workability. 
Table 3. 1 Aggregate gradation of asphalt concrete mixture.

\begin{tabular}{|l|l|l|l|}
\hline Sieve number & Sieve size $(\mathrm{mm})$ & Retained (\%) & Mass (g) \\
\hline $1 / 2$ & 12.5 & 6 & 714.1 \\
\hline $3 / 8$ & 9.5 & 7.7 & 916.5 \\
\hline No. 4 & 4.75 & 18.1 & 2154.3 \\
\hline No. 8 & 2.36 & 19 & 2261.4 \\
\hline No. 16 & 1.18 & 10.8 & 1285.4 \\
\hline No. 30 & 0.6 & 10.6 & 1261.6 \\
\hline No. 50 & 0.3 & 12.8 & 1523.5 \\
\hline No. 100 & 0.15 & 8.3 & 987.9 \\
\hline No. 200 & 0.075 & 2.2 & 261.8 \\
\hline Pan powder & $<0.075$ & 4.5 & 535.6 \\
\hline
\end{tabular}

\subsubsection{Cyclic fracture-induction healing test of asphalt concrete material}

The induction heating system consists of alternating magnetic field generator, induction copper coil and water chilling system. Metal material has ability to produce eddy current while locating in the magnetic field from Faraday's law. The induction heat was generated with Joule's effect. Above the binder transition temperatures $\left(40{ }^{\circ} \mathrm{C}\right.$ to $70{ }^{\circ} \mathrm{C}$, depends on the components and properties of asphalt), the asphalt behaviors as Newtonian fluid. The crack in the asphalt concrete could be filled due to binder capillary flow. 
The fracture-healing tests of asphalt concrete samples were conducted with elastic supported beam bending tests as reported in our previous paper [4]. Compared to the natural healing process of asphalt binder, induction healing can accelerate the healing rate of asphalt binder and is able to heal the micro-cracks within asphalt concrete through the capillary flow and interface wetting of asphalt binder. The measured peak load of asphalt concrete samples of original and healed samples were given in Table 32. In this fracture-healing cyclic testing research, nine asphalt concrete samples was conducted for eight fracture-healing cyclic tests.

Table 3. 2 Experimental peak load of asphalt concrete samples.

\begin{tabular}{|c|c|c|c|c|c|c|c|c|}
\hline Sample & $1^{\text {st }}$ & $2^{\text {nd }}$ & $3^{\text {rd }}$ & $4^{\text {th }}$ & $5^{\text {th }}$ & $6^{\text {th }}$ & $7^{\text {th }}$ & $8^{\text {th }}$ \\
& loadin & loadin & loadin & loadin & loadin & loadin & loadin & loadin \\
\hline No.1 & 4593.6 & 3968.1 & 3560.6 & 2634.6 & 2495.8 & 2623.3 & 2455.5 & 2264.2 \\
\hline No.2 & 4512.2 & 3472.2 & 3335.6 & 3064.4 & 2957.2 & 2929.1 & 3134.8 & 2863.3 \\
\hline No.3 & 5158.0 & 4337.7 & 3390.4 & 3425.6 & 3008.1 & 2429.8 & 2160.5 & damage \\
\hline No.4 & 3608.9 & 3708.5 & 2714.8 & 2555.1 & 2322.8 & 2203.6 & 2170.7 & 1832.9 \\
\hline No.5 & 4325.8 & 4431.7 & 3710.2 & 3742.6 & 3668.1 & 3657.6 & 3297.1 & 2733.1 \\
\hline No.6 & 4961.5 & 4341.0 & 3973.0 & 3888.4 & 3412.3 & 3168.7 & 2860.4 & 2800.1 \\
\hline No.7 & 4605.0 & 4424.4 & 3644.2 & 3571.6 & 3385.0 & 2941.5 & 2519.9 & 2324.9 \\
\hline No.8 & 4862.0 & 4652.4 & 4470.0 & 3963.2 & 3631.7 & 3442.3 & 3282.2 & 3055.3 \\
\hline No.9 & 4661.4 & 4870.3 & 4223.8 & 3819.5 & 3738.4 & 3666.8 & 3585.8 & 3450.9 \\
\hline
\end{tabular}




\subsection{Cohesive fracture model and numerical implementation}

\subsubsection{Bilinear cohesive zone model}

The CZM can simulate crack growth in the fracture zone prior to a crack tip based on the nonlinear constitutive laws. The constitutive laws can be expressed with the displacement jump, $\delta$ and traction, $t$ along interfaces for simulating fracture behavior, for instance, crack nucleation, initiation, and propagation [84]. The traction has zero value at the crack tip and maximum value at the cohesive zone tip. That is, the material crack tip is where the material experiences total failure, while the cohesive zone tip is where the crack is initiated with the highest cohesive bonding. The region between the material crack tip and the cohesive zone tip is the cohesive zone where nonlinear fracture behavior occurs. The cohesive traction existed in the cohesive surfaces due to an applied external force. As the displacement jump increases, the corresponding traction increases to peak value, and decays to zero monotonically. The cohesive parameters affecting the traction-separation responses include maximum separation stress, critical displacement, and cohesive fracture energy (see Figure 3.1). 


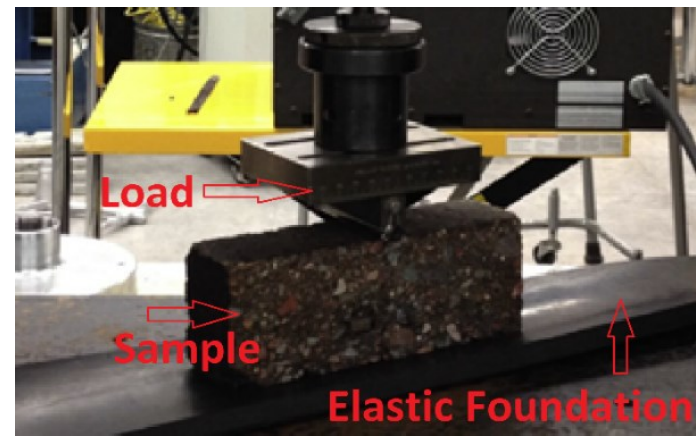

(a)

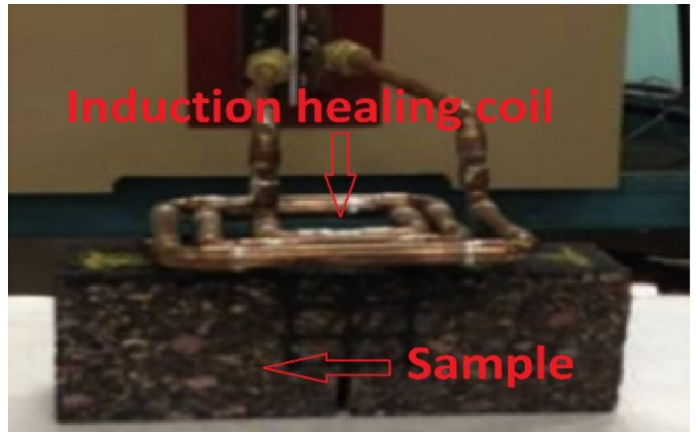

(b)

Figure 3. 1 Demonstration of the fracture-induction healing test: (a) modified bending test of asphalt concrete beam with elastic foundation and; (b) asphalt concrete beam healing.

Different cohesive laws have been proposed to develop CZM techniques such as exponential cohesive law and bilinear cohesive law $[76,84]$. The characteristic of bilinear cohesive law is the cohesive zone compliance could be reduced through adjusting initial slope before softening point [72]. Figure 3.2 demonstrates the plot of the bilinear cohesive law, showing normalized normal traction with respect to nondimensional normal opening displacement for mixed-mode fracture behavior. The plot demonstrates an elastic relationship before the peak load and a softening curve which composes of various damages in the fracture process zone after the peak load for different ratios of open and shear displacements $(0,0.1$ and 0.3$)$. When the ratio is 0 , it means the shear force is 0. When the ratio is 0.1 and 0.3 , the shear force and normal force are both considered. 


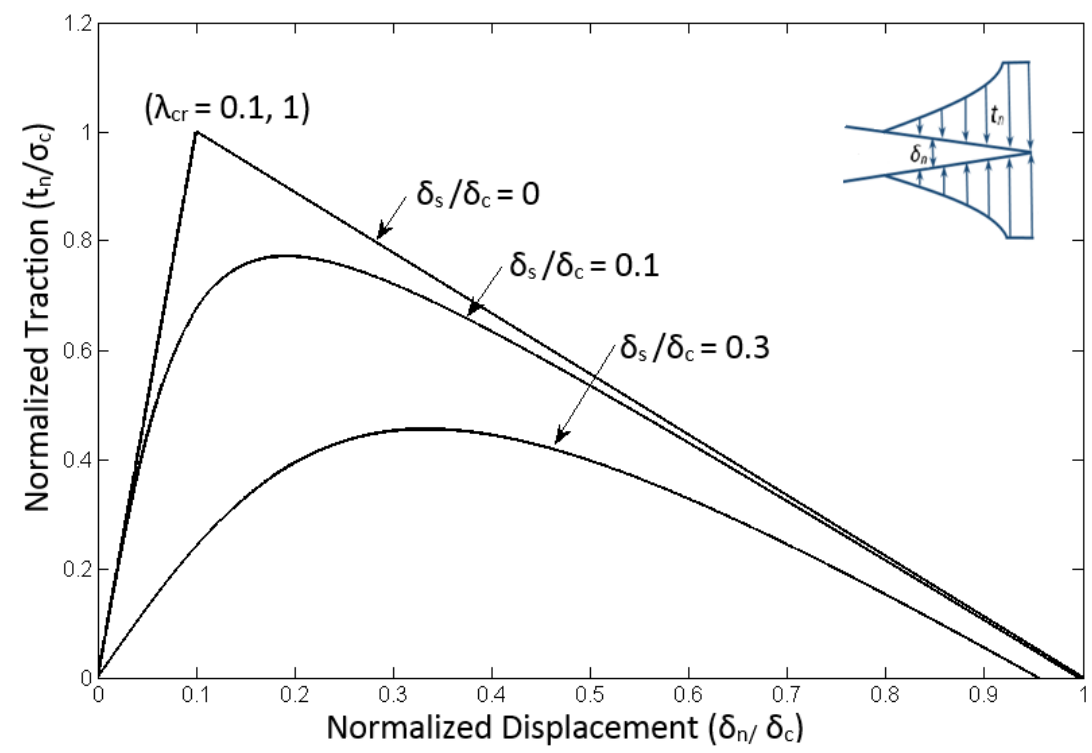

Figure 3. 2 A cohesive law in accordance with normalized traction and normalized displacement jump for different ratios of shear sliding to critical displacement. The non-dimensional effective displacement $\left(\lambda_{e}\right)$ and effective traction $\left(t_{e}\right)$ are shown as followings [72]:

$$
\begin{aligned}
& \lambda_{e}=\sqrt{\left(\frac{\delta_{n}}{\delta_{c}}\right)^{2}+\left(\frac{\delta_{s}}{\delta_{c}}\right)^{2}} \\
& t_{e}=\sqrt{t_{n}^{2}+t_{s}^{2}}
\end{aligned}
$$

where $\delta_{n}$ and $\delta_{s}$ denote the normal displacement and shear sliding on crack surface, respectively; $\delta_{c}$ is the critical displacement corresponding to zero traction; $t_{n}$ and $t_{s}$ are the normal and shear tractions, respectively. The relations of normal and shear 
tractions with respect to open and shear displacements [72] are described at pre-failure and post-failure stages as followings:

$$
\left.\begin{array}{l}
\left.\begin{array}{l}
t_{n}=\sigma_{c} \\
\frac{1}{\lambda_{c r}}\left(\frac{\delta_{n}}{\delta_{c}}\right) \\
t_{s}=\sigma_{c} \frac{1}{\lambda_{c r}}\left(\frac{\delta_{s}}{\delta_{c}}\right)
\end{array}\right\} \text { for } \lambda_{e}<\lambda_{c r} \\
\text { and } t_{s}=\sigma_{c} \frac{1-\lambda_{e}}{1-\lambda_{c r}} \frac{1}{\lambda_{e}}\left(\frac{\delta_{s}}{\delta_{c}}\right) \\
t_{n}=\sigma_{c} \frac{1-\lambda_{e}}{1-\lambda_{c r}} \frac{1}{\lambda_{e}}\left(\frac{\delta_{n}}{\delta_{c}}\right)
\end{array}\right\} \text { for } \lambda_{e}>\lambda_{c r}
$$

where $\lambda_{c r}$ denotes non-dimensional critical displacement corresponding to the maximum traction. Meanwhile, the tangent modulus matrix ( $\mathbf{C}$ ), is a result of differentiation of traction with respect to the relative displacements, as followings:

$$
\mathbf{C}=\left[\begin{array}{cc}
C_{n n} & C_{n s} \\
-C_{s n} & C_{s s}
\end{array}\right]=\left[\begin{array}{ll}
\frac{\partial t_{n}}{\partial \delta_{n}} & \frac{\partial t_{n}}{\partial \delta_{s}} \\
\frac{\partial t_{s}}{\partial \delta_{n}} & \frac{\partial t_{s}}{\partial \delta_{s}}
\end{array}\right]
$$

where the components of the tangent modulus matrix for two stages [72] are given as followings:

$$
\left.\begin{array}{l}
C_{s s}=C_{n n}=\frac{\sigma_{c}}{\lambda_{c r} \delta_{c}} \\
C_{s n}=C_{n s}=0
\end{array}\right\} \quad \text { for } \lambda_{e}<\lambda_{c r}
$$

and 


$$
\left.\begin{array}{l}
C_{s s}=-\frac{\delta_{c} \sigma_{c}}{1-\lambda_{c r}}\left(\frac{\delta_{s}}{\lambda_{e} \delta_{c}^{2}}\right)^{2}+\left(1-\lambda_{e}\right) \frac{\delta_{c} \sigma_{c}}{1-\lambda_{c r}}\left(\frac{1}{\lambda_{e} \delta_{c}^{2}}-\frac{1}{\lambda_{e}^{3}} \frac{\delta_{s}^{2}}{\delta_{c}^{4}}\right) \\
C_{s n}=C_{n s}=-\frac{\delta_{c} \sigma_{c}}{1-\lambda_{c r}}\left(\frac{\delta_{s}}{\lambda_{e} \delta_{c}^{2}}\right)\left(\frac{\delta_{n}}{\lambda_{e} \delta_{c}^{2}}\right)+\left(1-\lambda_{e}\right) \frac{\delta_{c} \sigma_{c}}{1-\lambda_{c r}}\left(-\frac{1}{\lambda_{e}^{3}} \frac{\delta_{s} \delta_{n}}{\delta_{c}^{4}}\right) \\
C_{n n}=-\frac{\delta_{c} \sigma_{c}}{1-\lambda_{c r}}\left(\frac{\delta_{n}}{\lambda_{e} \delta_{c}^{2}}\right)^{2}+\left(1-\lambda_{e}\right) \frac{\delta_{c} \sigma_{c}}{1-\lambda_{c r}}\left(\frac{1}{\lambda_{e} \delta_{c}^{2}}-\frac{1}{\lambda_{e}^{3}} \frac{\delta_{n}^{2}}{\delta_{c}^{4}}\right)
\end{array}\right\} \text { for } \lambda_{e}>\lambda_{c r}
$$

The cohesive fracture energy $\left(G_{c}\right)$ is the area under the normalized displacementtraction curve (as shown in Figure 3.2) which also equivalents to:

$$
G_{c}=\frac{1}{2} \delta_{c} \sigma_{c}
$$

\subsubsection{Numerical implementation of bilinear cohesive zone model}

The ABAQUS user-defined element (UEL) subroutine was applied to implement the CZM for material fracture behavior studies $[70,72,81,84]$. In this study, the user interface elements were developed by using the UEL subroutine. In finite element mesh, the elements along the crack path combined with cohesive elements were utilized to simulate the fracture behavior of material. Figure 3.3 demonstrates a fournode interface cohesive element in the CZM, by using the boundaries of two adjacent constitutive elements. The ordering of the node number is in counter-clockwise direction. Nodes 1 and 2 are located along one element boundary while Nodes 3 and 4 are along the boundary of the other adjacent element. The X-Y coordinate system refers to the global coordinates while n-s coordinate system refers to the local coordinates. The force vector and the tangent stiffness matrix are first defined in the local coordinate with the bilinear cohesive law. The global matrices can be obtained through the transformation matrix with $\mathbf{T}$ with the orientation angle [72]. 


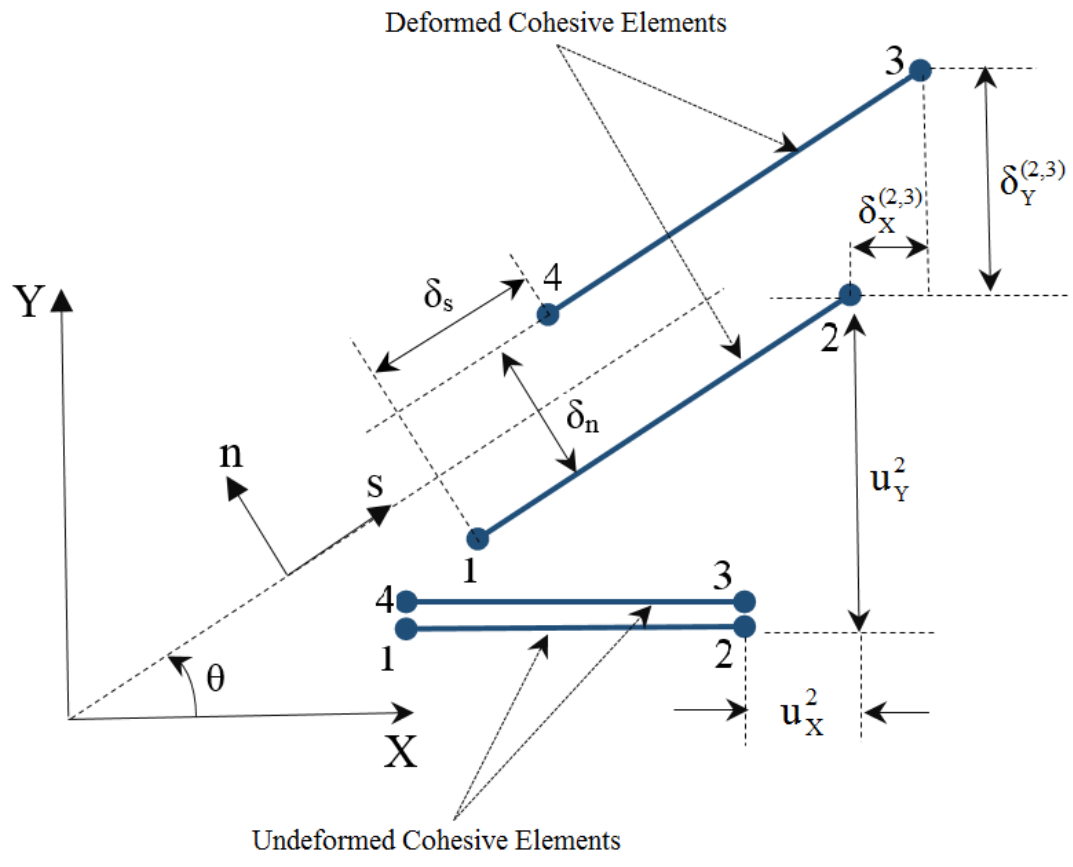

Figure 3. 3 Schematic drawing of a 4-node linear cohesive element. X and Y indicate global coordinates, while s and $n$ indicate local coordinates. The variables $u_{\mathrm{X}}^{2}$ and $u_{\mathrm{Y}}^{2}$ denote the displacement of node 2 in global coordinates. The variables $\delta_{\mathrm{X}}^{(2,3)}$ and $\delta_{\mathrm{Y}}^{(2,3)}$ represent the relative opening displacement of node 2 and 3 . The variables $\delta_{\mathrm{s}}$ and $\delta_{\mathrm{n}}$ are the shear sliding and normal displacement in the local coordinates, respectively. With two degrees of freedom at each node, the global displacement vector of the cohesive elements is given as:

$\mathbf{U}=\left[\begin{array}{llllllll}u_{1} & v_{1} & u_{2} & v_{2} & u_{3} & v_{3} & u_{4} & v_{4}\end{array}\right]^{T}$

where $u$ and $v$ denote the global displacement in the $\mathrm{X}$ and $\mathrm{Y}$ directions, respectively. The subscripts indicate the node numbers. $T$ indicates the transpose of the vector 
matrix. The relative normal and shear displacements between the Nodes 1 and 2 and Nodes 3 and 4 can be obtained from the global nodal displacement vector through $\mathbf{B}$ matrix [72].

With isoparametric finite element formulation, the global nodal force vector, $f$ and global tangent stiffness matrix, $\mathbf{k}$ of the cohesive element can be obtained as followings:

$$
\begin{aligned}
& \mathbf{f}=\int_{-1}^{1} \mathbf{B}^{T} \mathbf{t}|\mathbf{J}| d \eta \\
& \mathbf{k}=\int_{-1}^{1} \mathbf{B}^{T} \mathbf{C B}|\mathbf{J}| d \eta
\end{aligned}
$$

where $\mathbf{J}$ denotes the Jacobian matrix between reference and original coordinates, $\mathbf{C}$ is the tangent modulus matrix with Equation (3-6) and (3-7), $\mathbf{t}$ is the traction vector that can be obtained from Equation (3-4), and $\mathbf{B}$ is the operation matrix between local normal/shear relative displacement vectors with nodal global displacement vector. This numerical scheme was defined in the UEL subroutine. The bilinear CZM technique was used to predict the crack growth behavior under mechanical loadings in the following sections.

\subsection{Cohesive fracture simulation and comparison of three-point bending tests}

\subsubsection{Measurement of fracture parameters for sample simulation}

The three-point bending test was conducted to obtain the fracture energy and peak separation stress as two major input parameters for the cohesive fracture model, as shown in Figure 3.4. The crack tip opening displacement (CTOD)-controlled beam bending test was conducted with the MTS machine, with a loading speed of $5 \mathrm{~mm} / \mathrm{min}$. Fracture energy was determined by calculating the area under the load-CTOD curve 
and normalizing with the cross-sectional area of the sample [84]. Two knife edges were attached on both sides of the top notch of the beam with a distance of $20 \mathrm{~mm}$. The CTOD was measured by a clip-on gage while applying the load on the top of the beam. Before the beam bending tests, the samples were conditioned at $-10^{\circ} \mathrm{C}$ for $6 \mathrm{hrs}$. Normally, the largest crack width appears on the top of the notch. At the peak loads, the corresponding crack tip opening displacement was in the range of $0.4 \mathrm{~mm}$ to 0.7 mm. Three single-edge notched beams (Sample No. 1, No. 2 and No. 3) were experienced to the standard three-point beam bending test to obtain the fracture energy of the asphalt concrete material. The curves of Load-CTOD of samples were obtained and the areas under those curves were calculated. Then the cross-sectional areas of the three samples were calculated by using the heights and thicknesses measured with a caliper. After calculation suing the method mentioned above, three fracture energy values were obtained as 1043,1074 and $1188 \mathrm{~J} / \mathrm{m}^{2}$ for samples No.1, No.2 and No.3, respectively. The fracture energy of sample No.2, $1074 \mathrm{~J} / \mathrm{m}^{2}$, was chosen as the input fracture energy for the cohesive fracture simulation of three-point beam bending tests. 


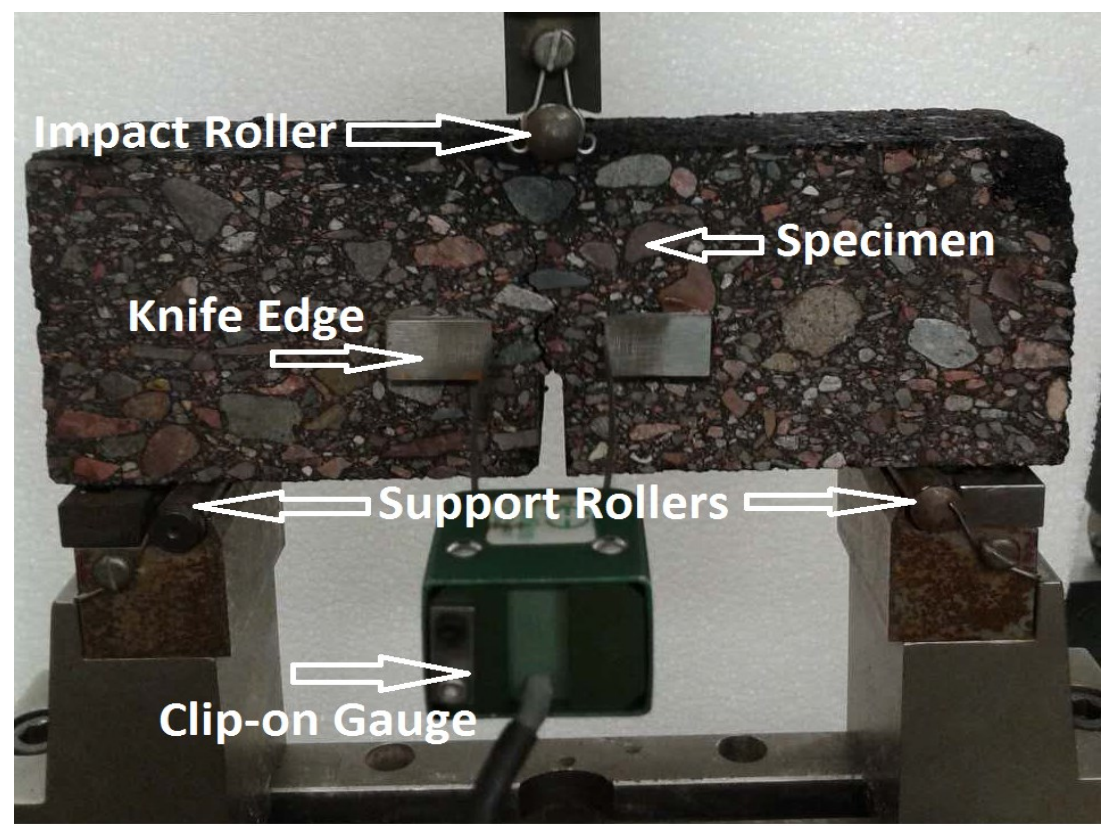

Figure 3. 4 Demonstration of three-point beam bending test, including cross head, anvil and clip-on gauge.

The peak separation stress of the sample No.2 was calculated by the equation in the below:

$\sigma_{\max }=\frac{3 \cdot F \cdot L}{2 \cdot B \cdot H^{2}}$

where $\mathrm{F}$ is the force applied on the beam, $\mathrm{L}$ is the span which is twice as the beam's height in this study, $\mathrm{H}$ is the middle sectional-area of the beam and $\mathrm{B}$ is the beam thickness. After calculation with the dimensions of the samples and the maximum loads by Equation (3-11), the maximum separation stress was calculated as $7.48 \mathrm{MPa}$. So, fracture energy $1074 \mathrm{~J} / \mathrm{m}^{2}$ and maximum separation stress $7.48 \mathrm{MPa}$ were used as the two major input parameters to prove the validity of the cohesive zone model by simulating the fracture behavior of three-point beam bending test. The details about the 
simulation of beam on three-point bending test compared with experimental results were discussed in Section 3.4.2.

\subsubsection{Comparison of simulation and experimental data of three-point beam bending tests}

The crack path simulation in this research was based on the real crack configuration located in the middle of the asphalt concrete sample. The picture of crack was processed by digital imaging analysis method. Then the pixels representing the crack was established connections with cohesive zone model by finite element method. During the cracking simulation, different boundary conditions were applied based on the types of fracture tests. Figure 3.5 (a) shows the image of cracked asphalt concrete beam conducted by the three-point beam bending test. The crack path of Sample No. 2 is located in the middle sectional-area. The pixel resolution of camera was 1024 by1280. Then a local image of the crack path was selected by Image $J$ and with pixels 160 by 640 . Afterwards, the pixels of that image were further decreased to 16 by 64 by using a scale factor 0.1 in order to decrease the computational work. 


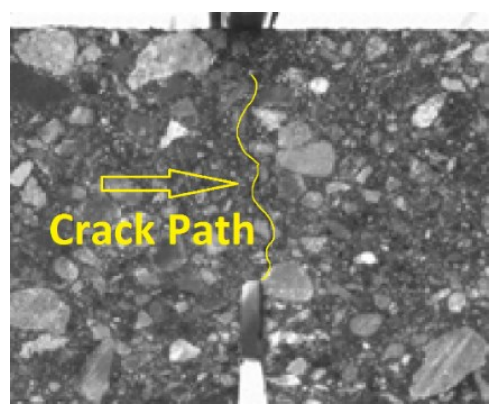

(a)

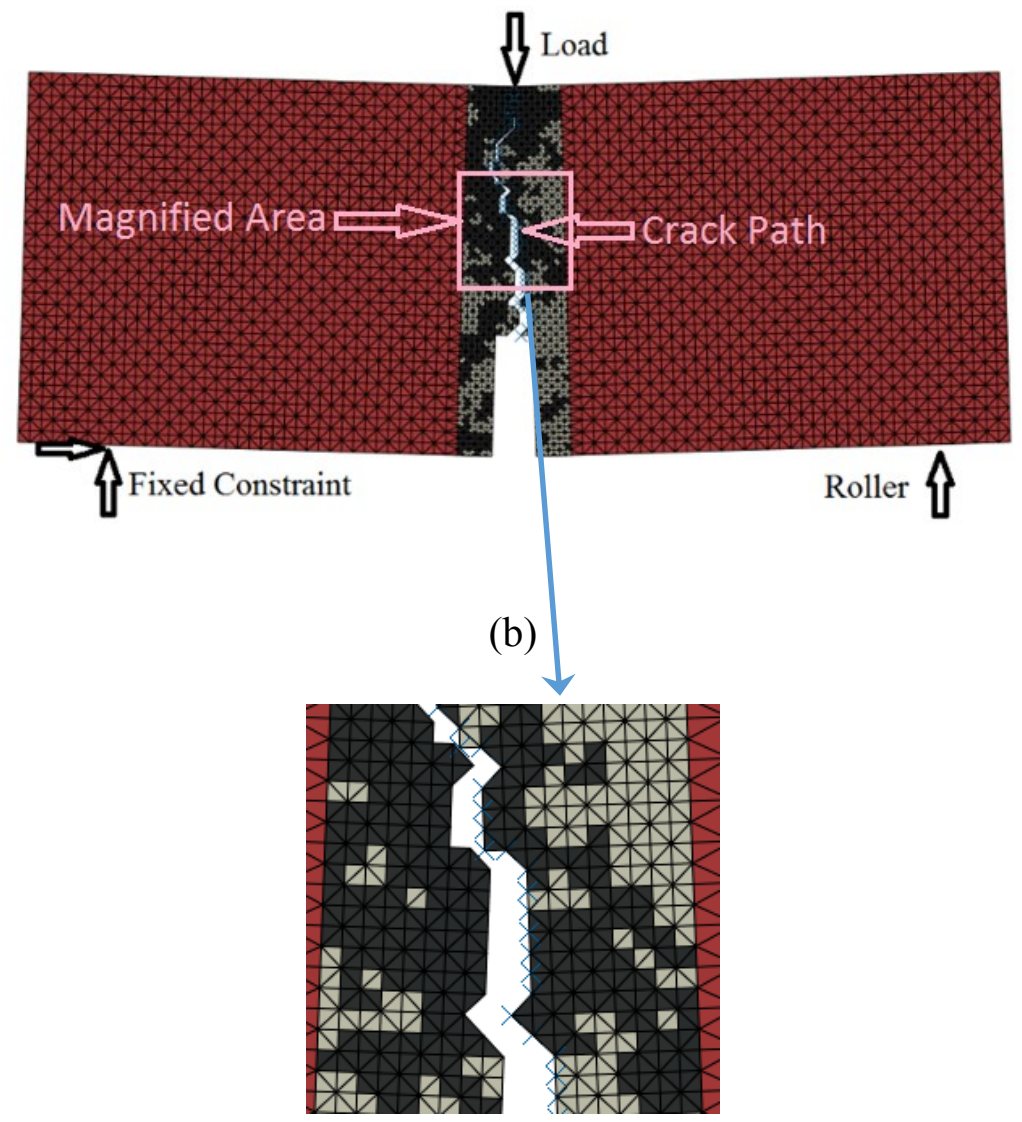

(c)

Figure 3. 5 Schematic simulation of crack path of asphalt concrete specimen on threepoint beam bending test (a) crack path on asphalt concrete specimen; (b) simulation including the geometry and the mesh, and; (c) magnified mesh with detailed crack path (light grey-aggregates and dark grey-mastic). 
The plane stress triangle-shaped elements were applied in this study. Compare to the rectangle-shaped elements, triangle-shaped elements provided more accurate results in simulating the irregular crack path inside of asphalt concrete beam. The method of defining crack path from imaging processing was explained below. Firstly, coordinates of image pixels in the real crack path were obtained by using Image J. Then, these pixels were transferred to nodes that were used to form the elements. Afterwards, crack path in the simulation was defined as the common boundaries between elements mentioned above. Finally, the bilinear cohesive zone elements were setup on the common boundaries based on image processing for simulating crack path and forcedisplacement behaviors of samples. The finished 2D asphalt concrete beam model conducted by three-point beam bending test is shown in Figure 3.5 (b). The boundary condition in the simulation was setup as fixed constraints on the left side and a roller support on the right side. Figure 3.5 (c) shows the magnified mesh detail of crack path. It can be easily identified that two different types of elements were located on both sides of the crack. The light grey elements indicated the aggregates and the dark grey elements represented the mastic. The distinguishing method was based on the greyscale intensity of image pixels. When the greyscale intensity of a pixel exceeded the value of 110, it was defined as aggregate. Likewise, pixels were defined as mastic if their greyscale intensity were below a chosen threshold value of 110 . Mesh refinement was applied in the middle portion of beam sample to better represent the irregular crack path. Then the model with calibrated fracture parameters was implemented to validate 
the model simulation by comparing the experiment and simulation results on loadingdisplacement curves.

The experimental peak loads of the three samples were 3426.4, 3763.8, and 3329.6 N, respectively, as shown in Figure 3.6. The finite element model for asphalt concrete was reconstructed based on the digital images of the sample No.2. The peak load obtained from the numerical simulation was $3649.6 \mathrm{~N}$ which is relatively $3.03 \%$ lower than the experiment results. The comparison between the simulated and tested loading-displacement curves was shown in the Figure 3.6. While the load in the simulation dropped slightly quicker than that in the experiment, the overall patterns of the curves agreed well with each other. This indicates that the bilinear cohesive zone model is capable to simulate the fracture behavior of asphalt concrete with steel wool fibers under three-point beam bending test.

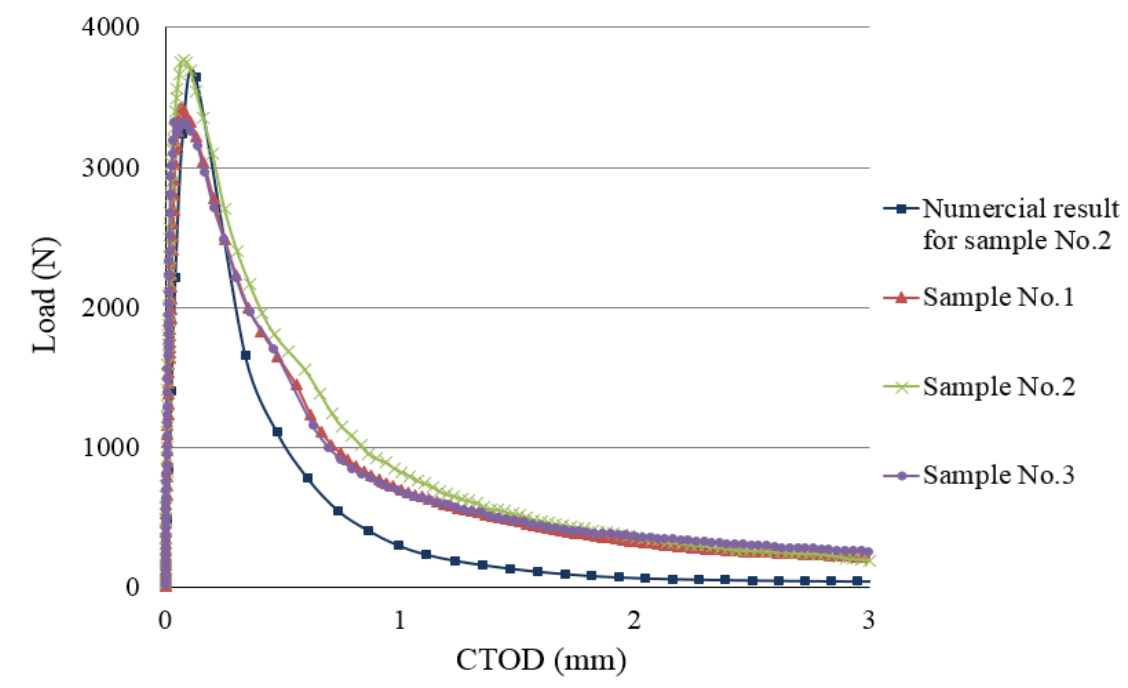

Figure 3. 6 Comparison between numerical and experimental results for three-point bending test of asphalt concrete specimens. 


\subsection{Fracture simulation of samples with measured fracture energy}

\subsubsection{Fracture simulation of original samples with defined crack path}

In this section, experimental setup of the beam bend test was modified by using an elastic foundation to replace the two rigid supports. The reason to do this is to control the crack width so that we can do the multi-cycle loading after induction healing. In the multi-cycle loading, the loading was stopped just after the peak load is reached. First, the crack path of the sample No. 1 after the first cycle loading was captured with the high resolution camera, as shown in Figure 3.7 (a). Afterward, the middle section of the image was cropped out and the resolution was rescaled to a proper pixel size of 40 by 188 , as shown in Figure 3.7 (b). Then all the pixels were transferred to nodes. The three-node triangle element mesh was subsequently generated by connecting the pixel nodes. The element refinement was furtherly applied in the middle portion of the sample to allow crack to propagate freely. The topology scheme was applied in the transition zones with different element sizes. The boundary condition in the modified bending test was different compared than that used in the three-point beam bending test. It was set up as an elastic foundation in which the bottom nodes were connected with spring elements, as illustrated in Figure 3.7 (c). The aggregate particles (light grey) and asphalt mastic (dark grey) were identified from the digital image so that a heterogeneous model was reconstructed for the middle section of the sample. The notch located on the bottom of the model was created by removing some elements according to the real notch size of sample. The elastic modulus of the rubber foundation as the input parameter was obtained in the lab. The machine applied a load 
on a steel cylinder above the rubber foundation. The loading value and the corresponding displacement of steel cylinder were recorded. After measuring the contact area between the steel cylinder and rubber foundation, the thickness of rubber foundation, the stress and strain of foundation were computed. Then the elastic modulus of the foundation, 9.28 MPa, was calculated as the stress divided by the strain. The middle section of the model was magnified in order to show the crack path clearly shown in Figure 3.7 (d). 

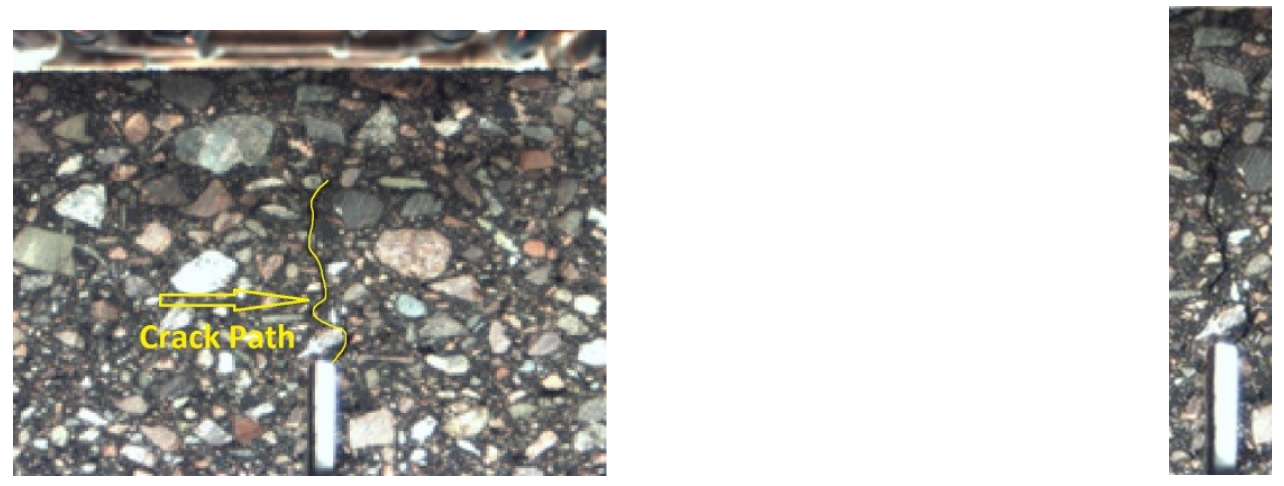

(a)

(b)

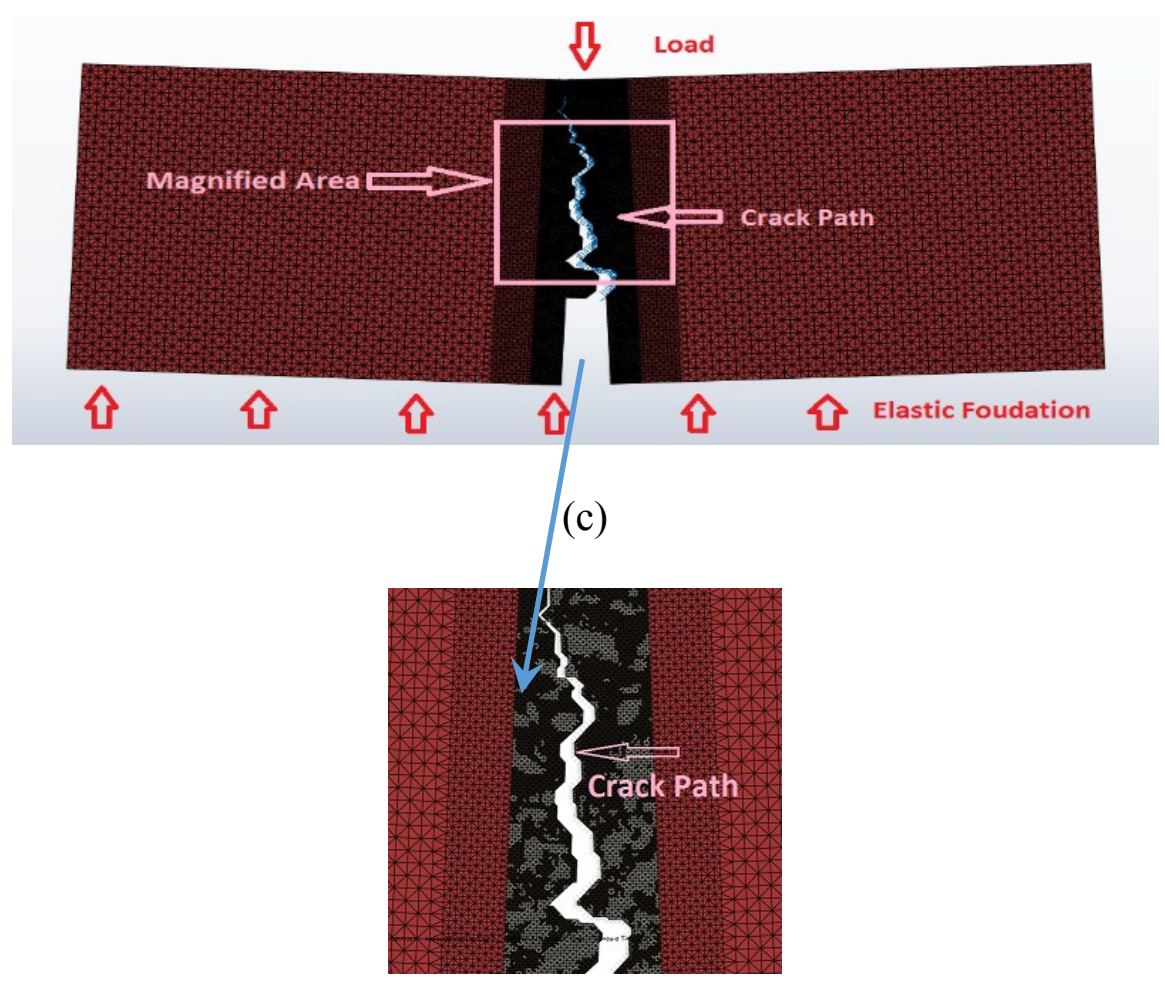

(d)

Figure 3. 7 Schematic simulation of crack path of asphalt concrete sample on fracturehealing test: (a) Global crack path area; (b) scaled local crack path area (scale factor, 0.2); (c) cracking mesh configuration and mesh detail of crack path; (d) magnified mesh with detailed crack path and indicated material phases (light grey-aggregate and dark grey-mastic). 


\subsubsection{Comparison of simulated and measured fracture peak load of original beam samples}

The simulation was also conducted with the exactly predefined crack path as the fracture samples as shown in Figure 3.7 (d). By including these microstructure features, the loading-displacement comparison between numerical and experimental results of sample No.1 on the first loading were demonstrated in Figure 3.8. In the peak to peak fracture healing tests, the loading curve only includes the recorded data up to peak loads. The computational simulation were conducted up to and beyond the peak loads. It is observed that simulation results have good agreement with experimental data (up to the peak loadings). Thus, the simulating model of asphalt concrete sample on modified beam bending test was effective.

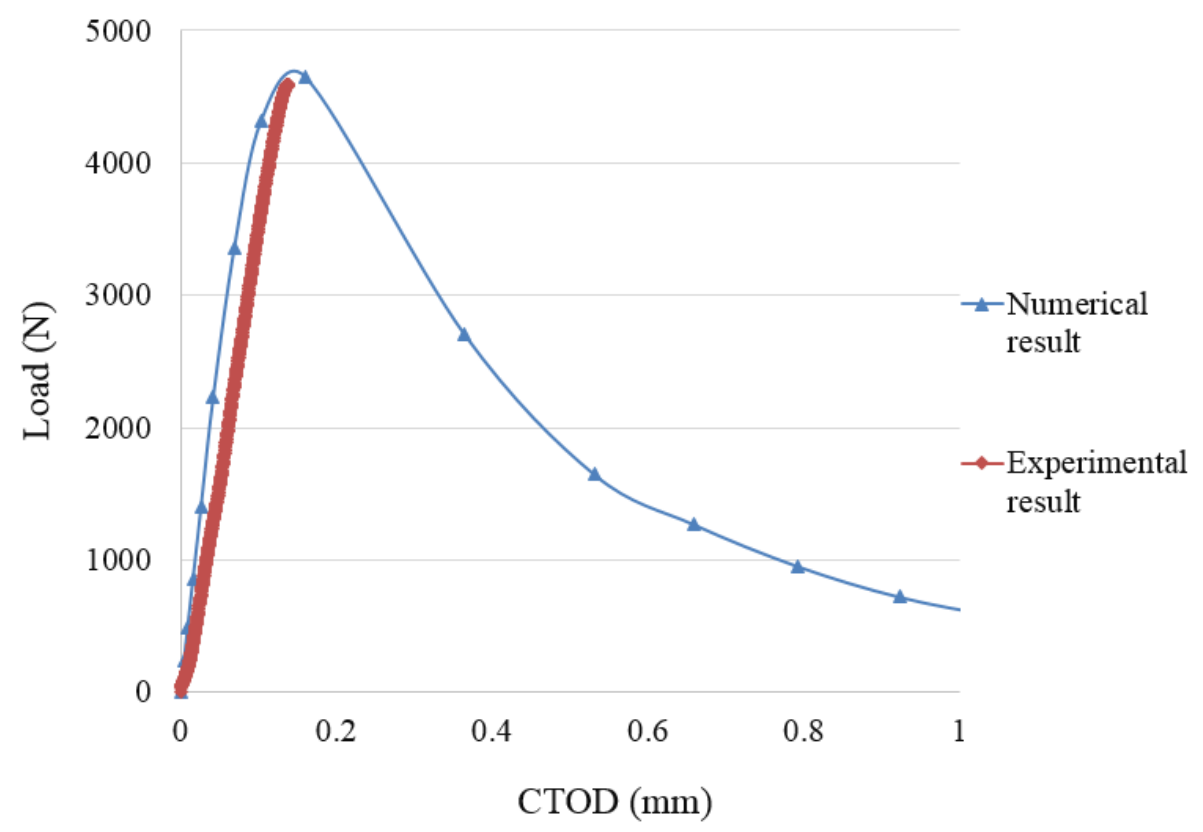

Figure 3. 8 Comparison between numerical and experimental results for modified bending test of asphalt concrete sample No. 1 on the first loading. 


\subsection{Fracture simulation of recovered fracture strength of healed samples with calibrated fracture energy}

\subsubsection{Calibration of fracture energy of healed samples based on peak load ratios}

In order to investigate the recovered peak loads of asphalt concrete beam samples, the cyclic fracture-healing test was simulated. The cohesive model was applied with two input parameters, fracture energy and peak separation stress. As observed from experimental data in Table 3-2, the fracture energy of each asphalt concrete sample decreased with fracture-healing cycles. These are caused by the partial healing due to limited binder content. According to the bilinear cohesive law (Equation (3-8)), similar trends were assumed for the peak separation stress and critical displacement. Therefore, the model parameters were selected with the following proposed rules for simulation inputs.

The cohesive fracture simulation was conducted on sample No. 1-3 (tested with healing temperature of $60{ }^{\circ} \mathrm{C}$ ). The scaling ratio was defined as the value of recovered peak load divided by the maximum peak load, $5158.0 \mathrm{~N}$ from sample No.3 on the first loading shown in Equation (3-12).

$$
R_{F i}^{j}=\frac{F_{R i}^{j}}{F_{M}}
$$

where $R_{F}$ indicates the scaling ratio, $F_{R}$ is the recovered peak load, $F_{M}$ is the maximum peak load, $5158.0 \mathrm{~N}$, subscript $i$ denotes the No. of sample $(i=1,2,3, \ldots$, 9), superscript $j$ denotes the $j$ th loading on samples $(j=1,2,3, \ldots, 8)$. Then the 
recovered maximum separation stress was determined by scaling ratio timed by original peak separation stress described in Equation (3-13).

$$
\sigma_{R M i}^{j}=R_{F i}^{j} \times \sigma_{o}
$$

where $\sigma_{R M}$ is the recovered maximum separation stress, $\sigma_{o}$ is the original peak separation stress. The Equation (3-14) represents the recovered fracture energy calculated by the original fracture energy timed by the square of scaling ratio due to the both reduction of maximum separation stress and failure displacement during the facture-healing cycles.

$$
E_{R i}^{j}=E_{o} \times\left(R_{F i}^{j}\right)^{2}
$$

where $E_{R}$ indicates the recovered fracture energy, $E_{o}$ denotes the original fracture energy, $1074 \mathrm{~J} / \mathrm{m}^{2}$. Figure 3.9 represents the reduction of fracture energy (area of the triangle) due to the decline of maximum separation stress and critical displacement for four cycles of fracture-healing test. The ratio of critical displacement (corresponding to peak load) vs. failure strain was chosen as 0.1 based on the experiments. 


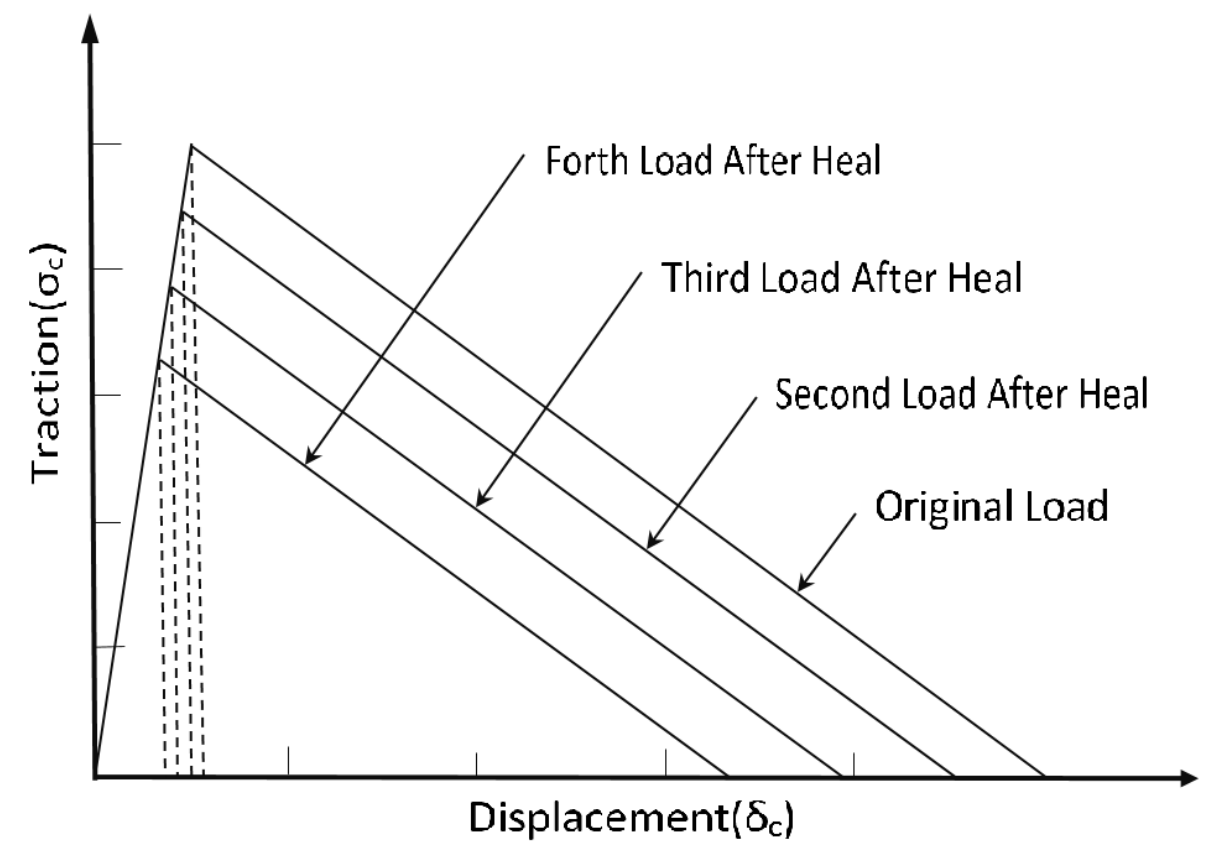

Figure 3.9 Illustration of relation between traction and displacement on four-time loading.

\subsubsection{Detailed comparison of simulation and experiment of one healed beam sample}

The fracture energy obtained from three-point bending test, $1074 \mathrm{~J} / \mathrm{m}^{2}$, was regarded as the input parameter for original 2D model of asphalt concrete samples. The peak load of sample No.3, $5158.0 \mathrm{~N}$, is the maximum value of all the samples as listed in Table 3-2. Besides, it was found that $6.2 \mathrm{MPa}$ was the maximum peak separation stress with numerical peak load, $5176.3 \mathrm{~N}$, by implementing the model with defined crack path and imposed cohesive zone elements. In other words, the simulated peak load was very close to the experimental peak load, which was determined by two input parameters, the original fracture energy, $1074 \mathrm{~J} / \mathrm{m}^{2}$ and original peak separation stress, 6.2 MPa. 
For instance, the peak load of the sample No.1 was $4593.6 \mathrm{~N}$ from initial fracture experiments. Thus, the scaling ratio for sample No. 1 on initial fracture was 0.891 from 4593.6 $\mathrm{N}$ divided by $5158.0 \mathrm{~N}$. In this simulation, this scaling ratio of recovered maximum separation stress and recovered critical displacement were assumed as the same value. So, the recovered maximum separation stress (RMSS) value of sample No. 1 on initial fracture was $5.522 \mathrm{MPa}$ from 0.891 timed by original peak separation stress, 6.2 MPa. Afterwards, the facture energy of sample No. 1 from initial fracture was $852.6 \mathrm{~J} / \mathrm{m}^{2}$ from $0.891^{2}$ timed by original fracture energy $1074 \mathrm{~J} / \mathrm{m}^{2}$. To date, fracture energy $852.6 \mathrm{~J} / \mathrm{m}^{2}$ and separation stress $5.522 \mathrm{MPa}$ were inputted for $2 \mathrm{D}$ simulation of reloading behavior. The simulating peak load was $4652.6 \mathrm{~N}$ shown in Table 3.3. 
Table 3. 3 Numerical results of asphalt concrete samples.

\begin{tabular}{|c|c|c|c|c|c|c|c|c|}
\hline Sampl & $1^{\text {st }}$ & $2^{\text {nd }}$ & $3^{\text {rd }}$ & $4^{\text {th }}$ & $5^{\text {th }}$ & $6^{\text {th }}$ & $7^{\text {th }}$ & $8^{\text {th }}$ \\
& loadin & loadin & loadin & loadin & loadin & loadin & loadin & loadin \\
\hline No.1 & 4652.6 & 4008.7 & 3588.7 & 2656.5 & 2457.6 & 2642.6 & 2386.4 & 2079.3 \\
\hline No.2 & 4552.4 & 3470.2 & 3253.8 & 3055.3 & 2982.4 & 2959.6 & 3094.3 & 2903.1 \\
\hline No.3 & 5167.3 & 4316.0 & 3347.4 & 3402.9 & 3018.6 & 2333.3 & 2050.9 & None \\
\hline No.4 & 3649.6 & 3764.8 & 2754.9 & 2550.9 & 2091.0 & 2063.6 & 2053.8 & 1860.7 \\
\hline No.5 & 4391.5 & 4446.8 & 3767.2 & 3800.0 & 3719.3 & 3707.1 & 3178.3 & 2775.3 \\
\hline No.6 & 5018.8 & 4320.4 & 4012.5 & 3939.9 & 3381.9 & 3110.2 & 2899.8 & 2844.2 \\
\hline No.7 & 4665.3 & 4436.1 & 3691.4 & 3602.4 & 3340.7 & 2969.8 & 2496.3 & 2092.0 \\
\hline No.8 & 4929.8 & 4720.1 & 4498.3 & 4004.5 & 3675.9 & 3425.7 & 3153.2 & 3050.0 \\
\hline No.9 & 4729.7 & 4937.9 & 4179.2 & 3876.4 & 3796.5 & 3718.7 & 3620.2 & 3439.7 \\
\hline
\end{tabular}

\subsubsection{Comparison of predicted and measured recovered fracture strength for all}

\section{tested samples}

Following similar procedures, the calculated maximum separation stresses and fracture energies on eight cycles of fracture test were inputted to simulate the peak cyclic fracture-healing test for sample 1-3. Figure 3.10 shows the load-CTOD simulating curve of samples No. 1, No. 2 and No. 3 at the healing temperature of $60^{\circ} \mathrm{C}$. The simulation results of peak load listed in Table 3.3 were compared with the experimental data shown in Table 3.2. The relative difference was defined as absolute 
value of experimental value subtracted by numerical value divided by experimental value, was shown in Table 3.4. It is observed that the average relative difference was $1.63 \%$ when the healing temperature is $60{ }^{\circ} \mathrm{C}$, indicating that the simulated fracture strength has a good agreement with the recovered fracture strength from experiment.

Table 3. 4 Relative difference between experimental results and numerical results.

\begin{tabular}{|c|c|c|c|c|c|c|c|c|}
\hline Sampl & $1^{\text {st }}$ & $2^{\text {nd }}$ & $3^{\text {rd }}$ & $4^{\text {th }}$ & $5^{\text {th }}$ & $6^{\text {th }}$ & $7^{\text {th }}$ & $8^{\text {th }}$ \\
& loadin & loadin & loadin & loadin & loadin & loadin & loadin & loadin \\
\hline No.1 & 1.28 & 1.02 & 0.79 & 0.83 & 1.53 & 0.73 & 2.82 & 8.17 \\
\hline No.2 & 0.89 & 0.06 & 2.45 & 0.30 & 0.85 & 1.04 & 1.29 & 1.39 \\
\hline No.3 & 0.18 & 0.50 & 1.27 & 0.66 & 0.35 & 3.97 & 5.07 & None \\
\hline No.4 & 1.13 & 1.52 & 1.48 & 0.17 & 9.98 & 6.35 & 5.38 & 1.52 \\
\hline No.5 & 1.52 & 0.34 & 1.54 & 1.53 & 1.40 & 1.35 & 3.60 & 1.55 \\
\hline No.6 & 1.15 & 0.47 & 0.99 & 1.33 & 0.89 & 1.85 & 1.38 & 1.58 \\
\hline No.7 & 1.31 & 0.27 & 1.29 & 0.86 & 1.31 & 0.96 & 0.94 & 10.02 \\
\hline No.8 & 1.40 & 1.46 & 0.63 & 1.04 & 1.22 & 0.48 & 3.93 & 0.17 \\
\hline No.9 & 1.47 & 1.39 & 1.06 & 1.49 & 1.56 & 1.41 & 0.96 & 0.32 \\
\hline
\end{tabular}




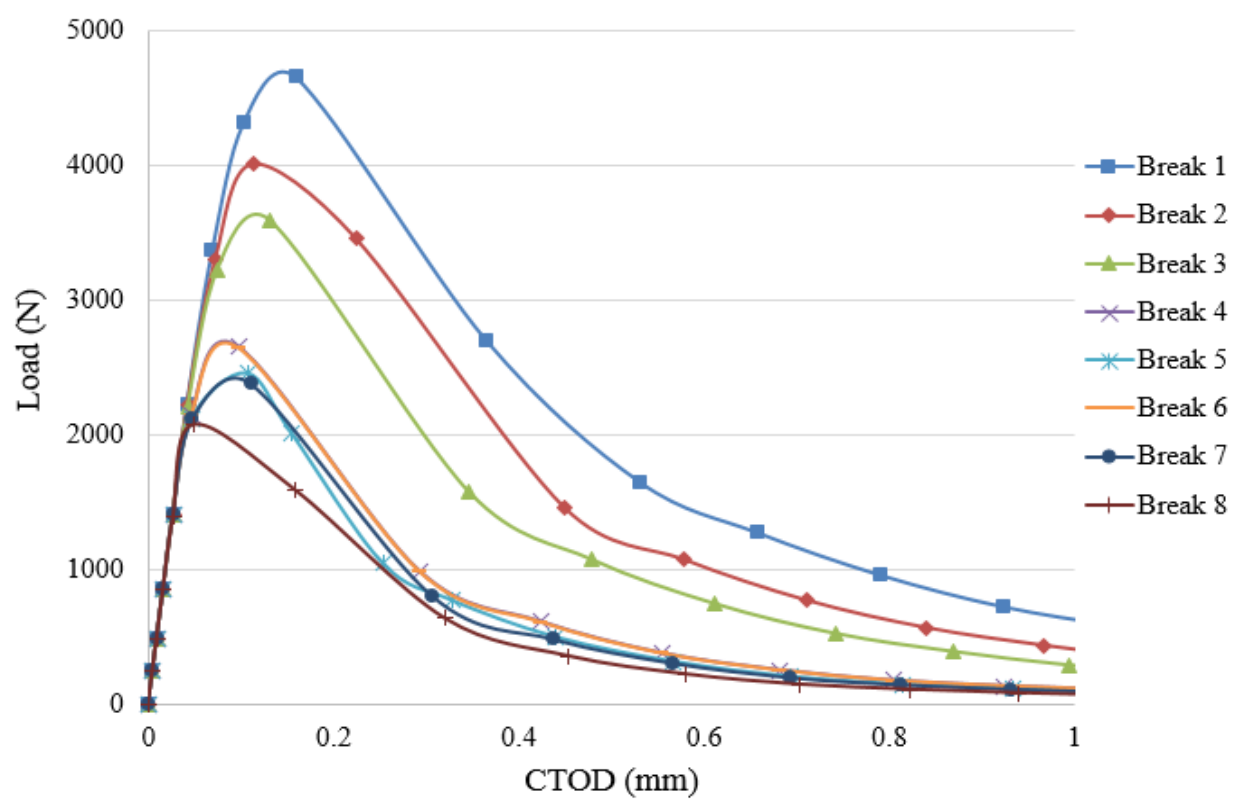

(a)

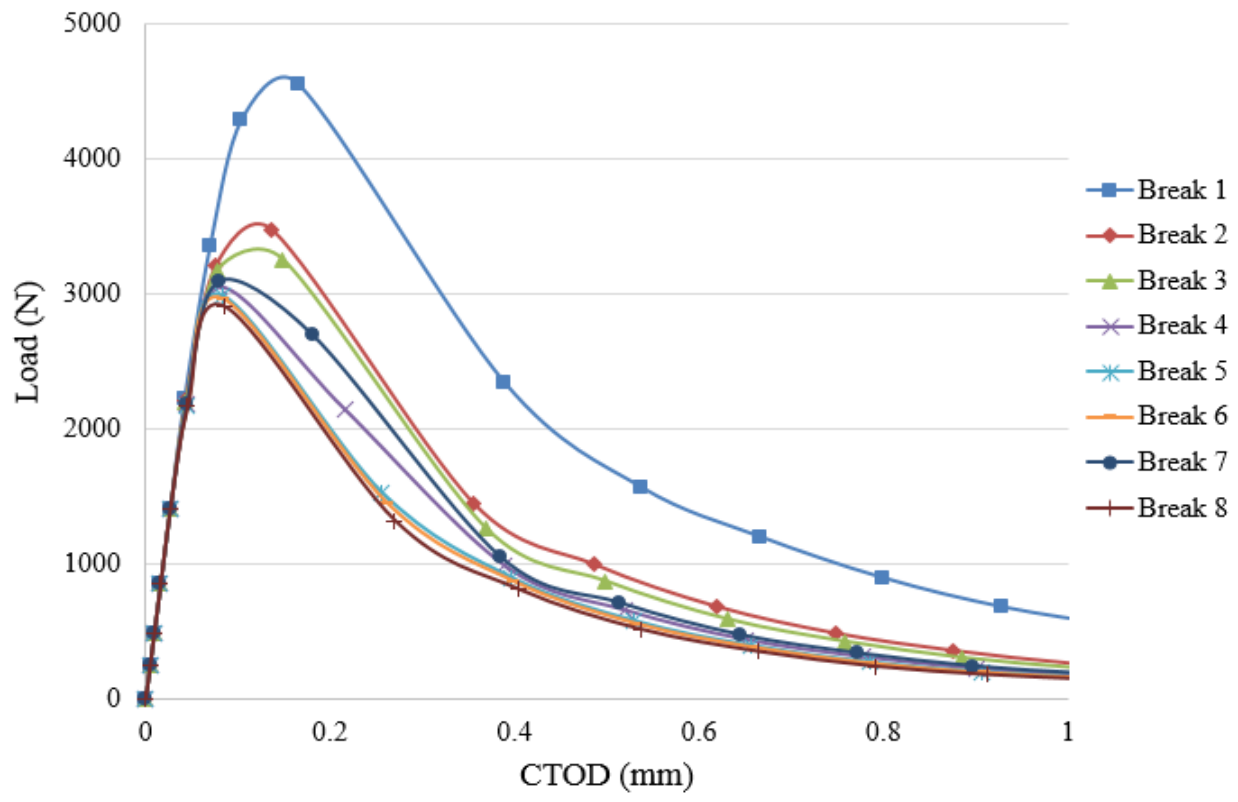

(b) 


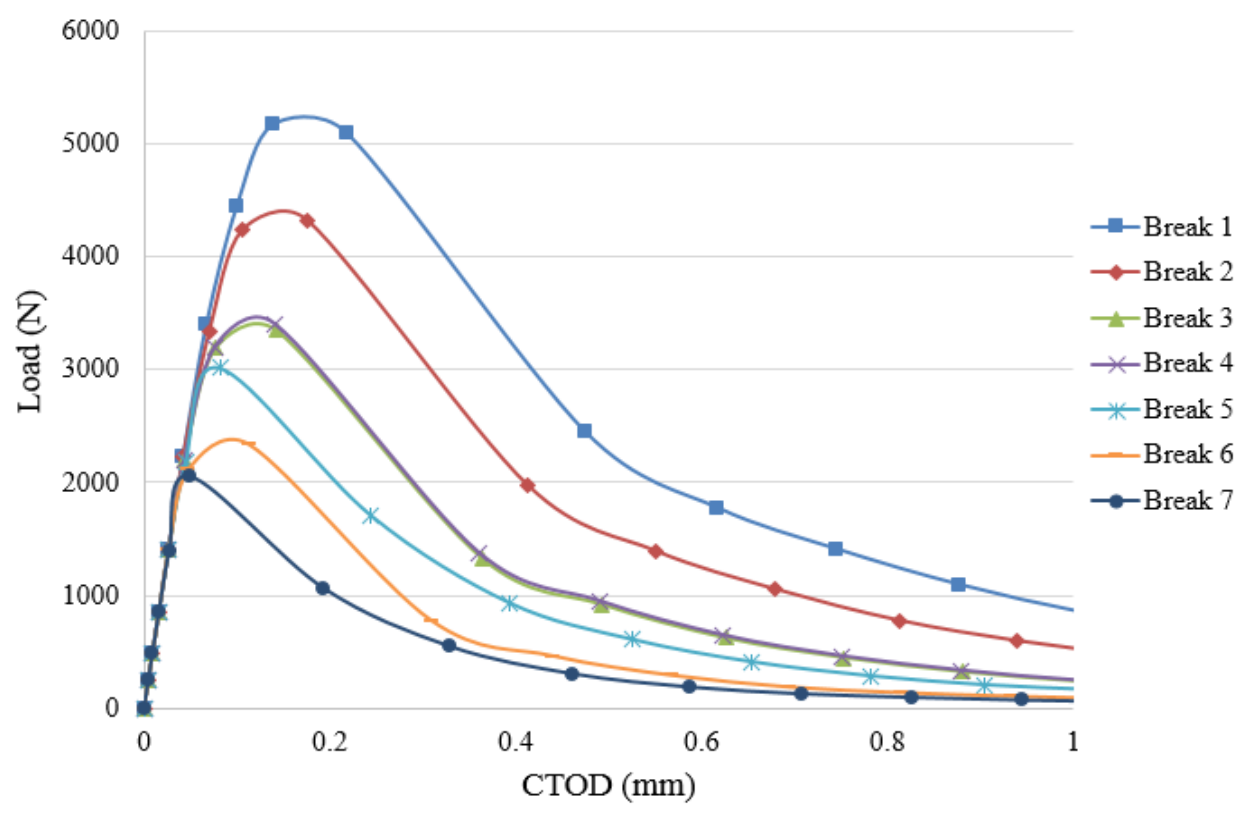

(c)

Figure 3. 10 Numerical results of asphalt concrete beam on healing temperature $60{ }^{\circ} \mathrm{C}$ :

(a) sample No. 1; (b) sample No. 2; (c) sample No. 3.

Similarly, the cohesive fracture simulation was conducted on beam sample No. 46 (tested with healing temperature of $80{ }^{\circ} \mathrm{C}$ ). Figure 3.11 presents the load-CTOD simulating curve of sample No. 4, No. 5 and No. 6 . The average relative difference was $2.08 \%$. Likewise, the cohesive fracture simulation was implemented for beam sample No. 7-9 (tested with healing temperature of $100{ }^{\circ} \mathrm{C}$ ). Fig. 12 represents the load-CTOD simulating curve of sample No. 7, No. 8, No. 9. The average relative difference was $1.54 \%$ obtained from Table 3.4. Therefore, the simulated fracture strengths have satisfactory agreements with the recovered fracture strength from experiments with healing temperatures $80{ }^{\circ} \mathrm{C}$ and $100{ }^{\circ} \mathrm{C}$. 


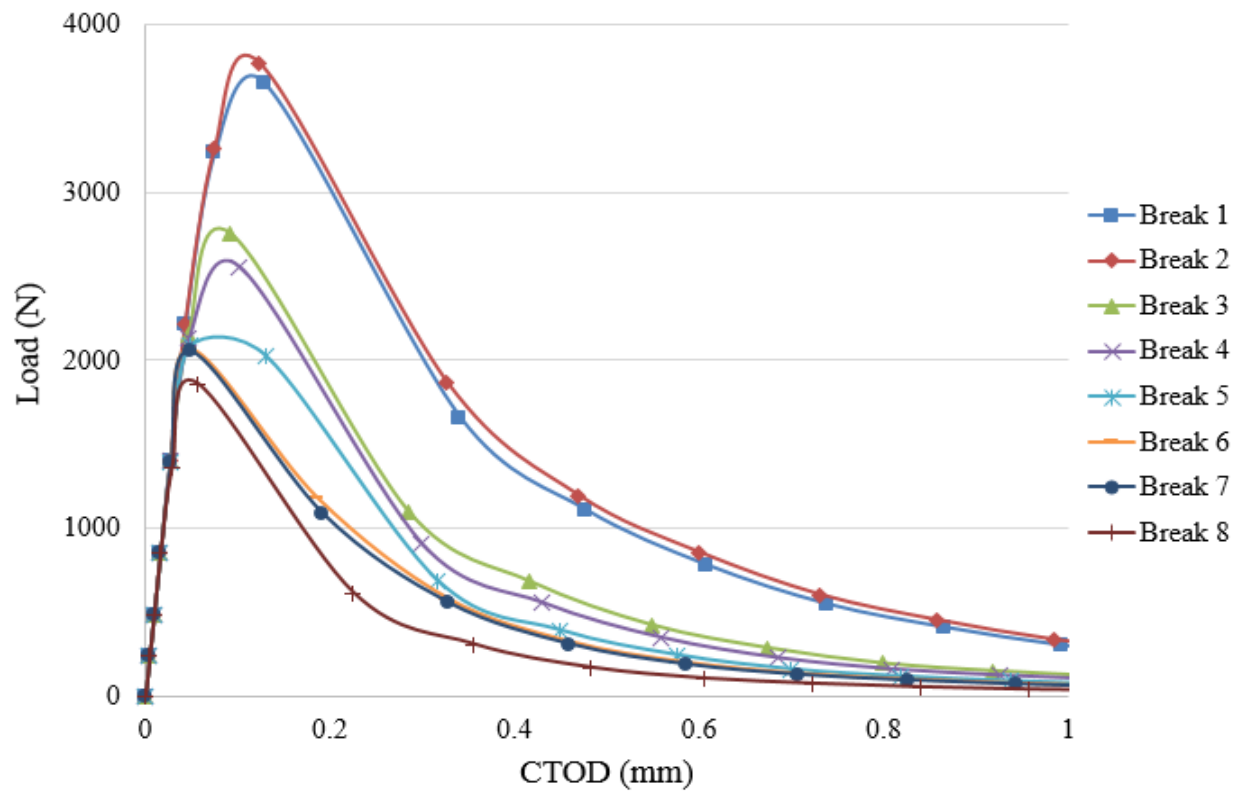

(a)

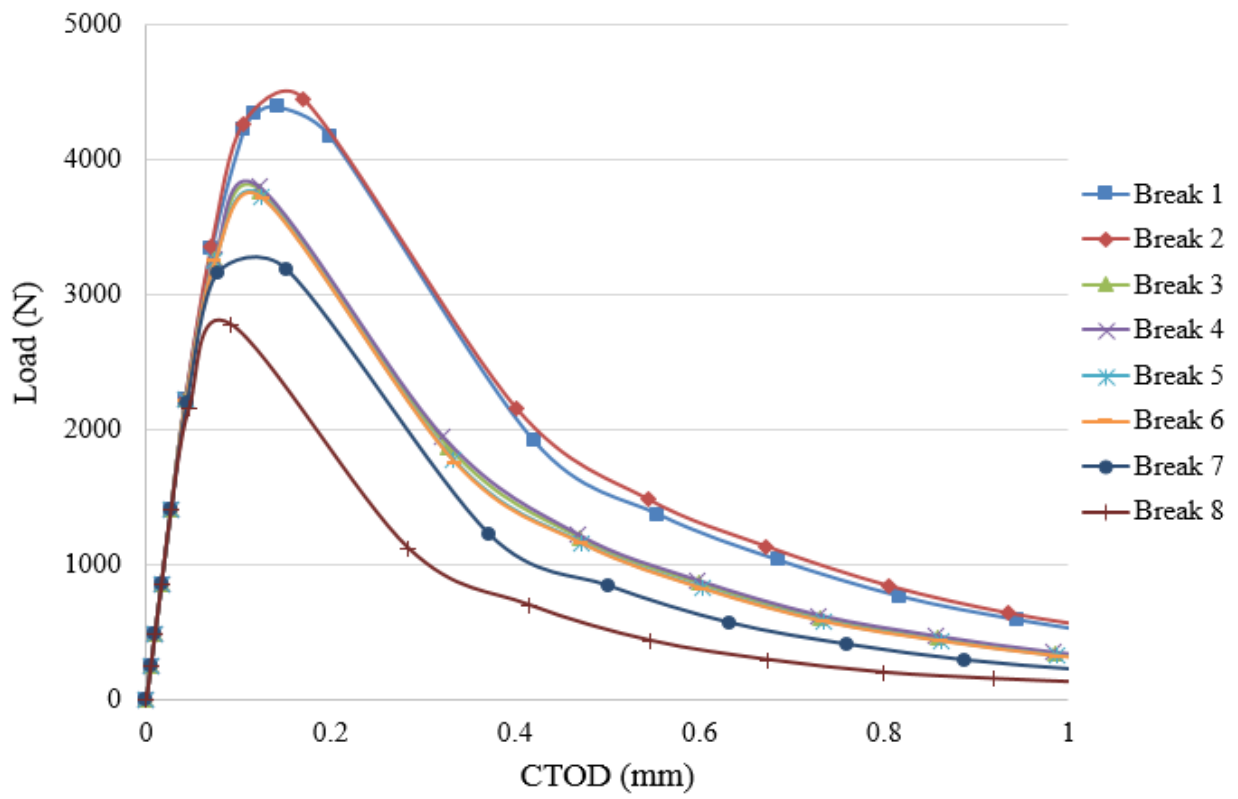

(b) 


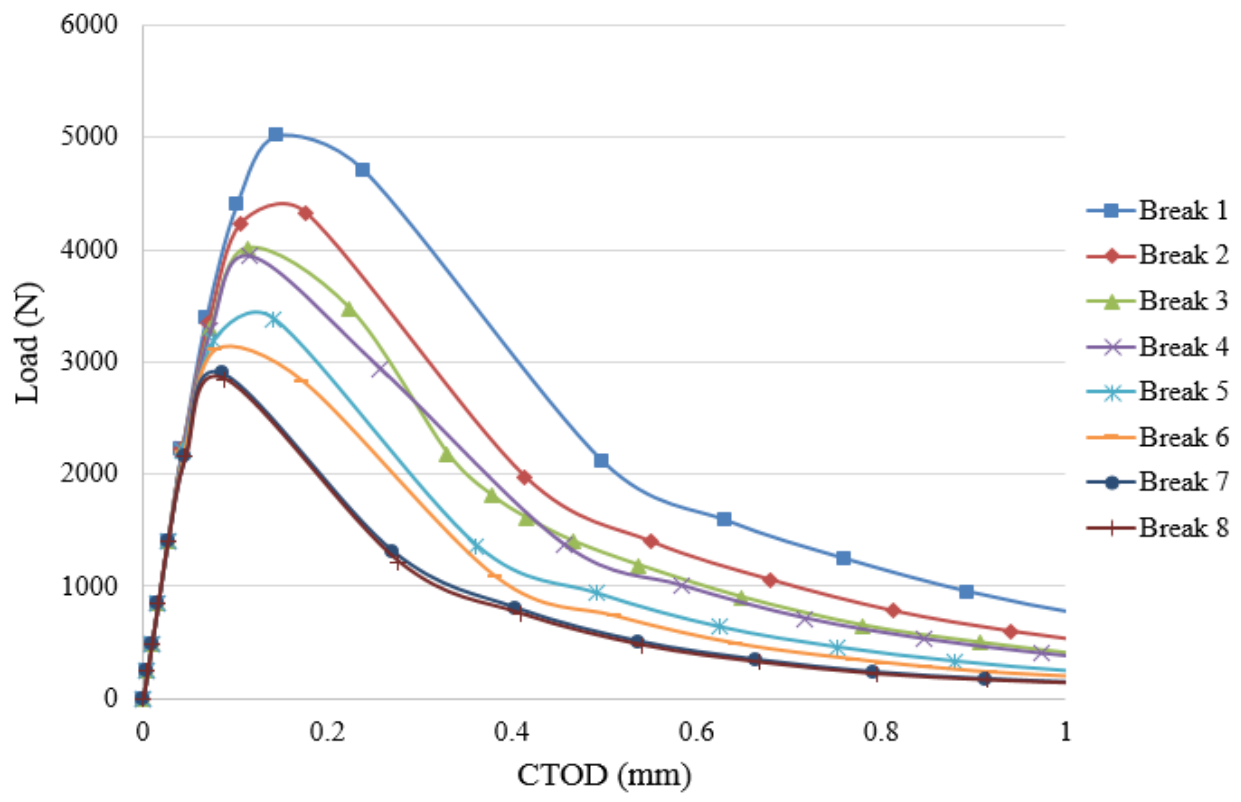

(c)

Figure 3. 11 Numerical results of asphalt concrete beam on healing temperature $80{ }^{\circ} \mathrm{C}$ :

(a) sample No. 4; (b) sample No. 5; (c) sample No. 6. 


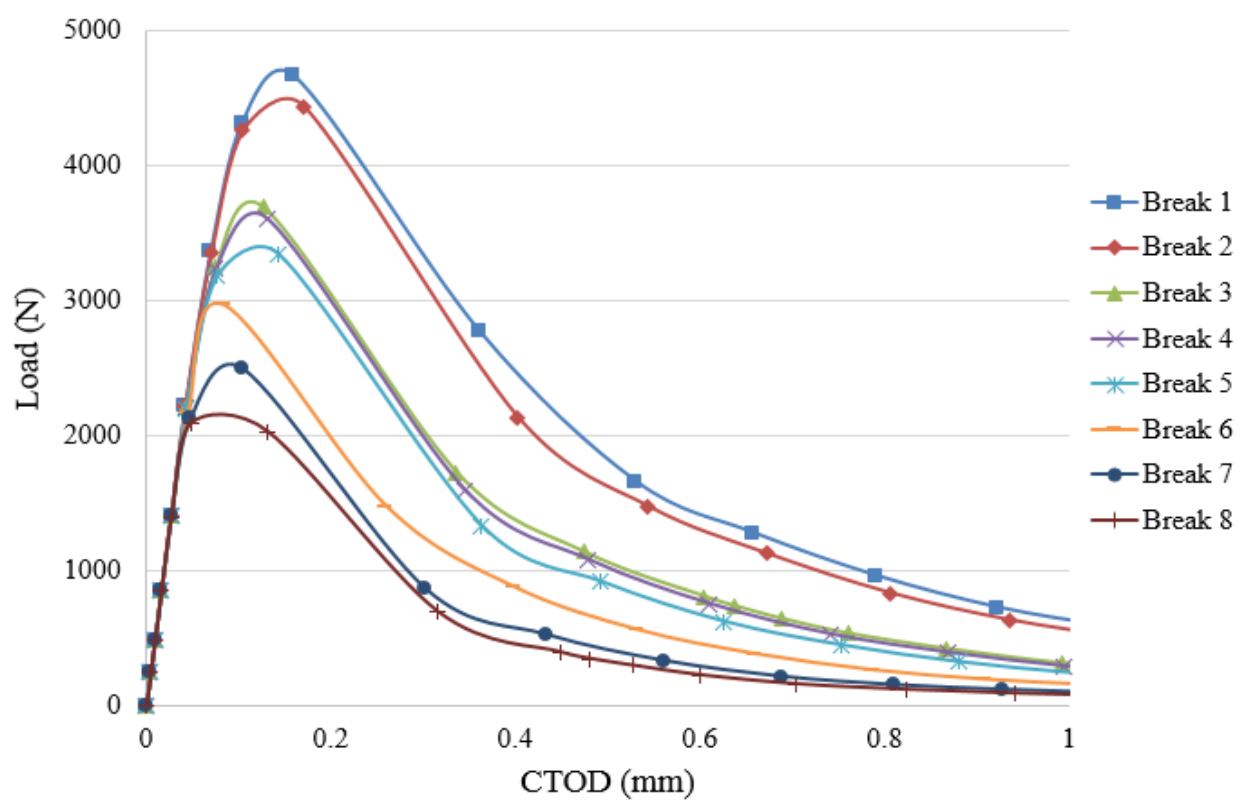

(a)

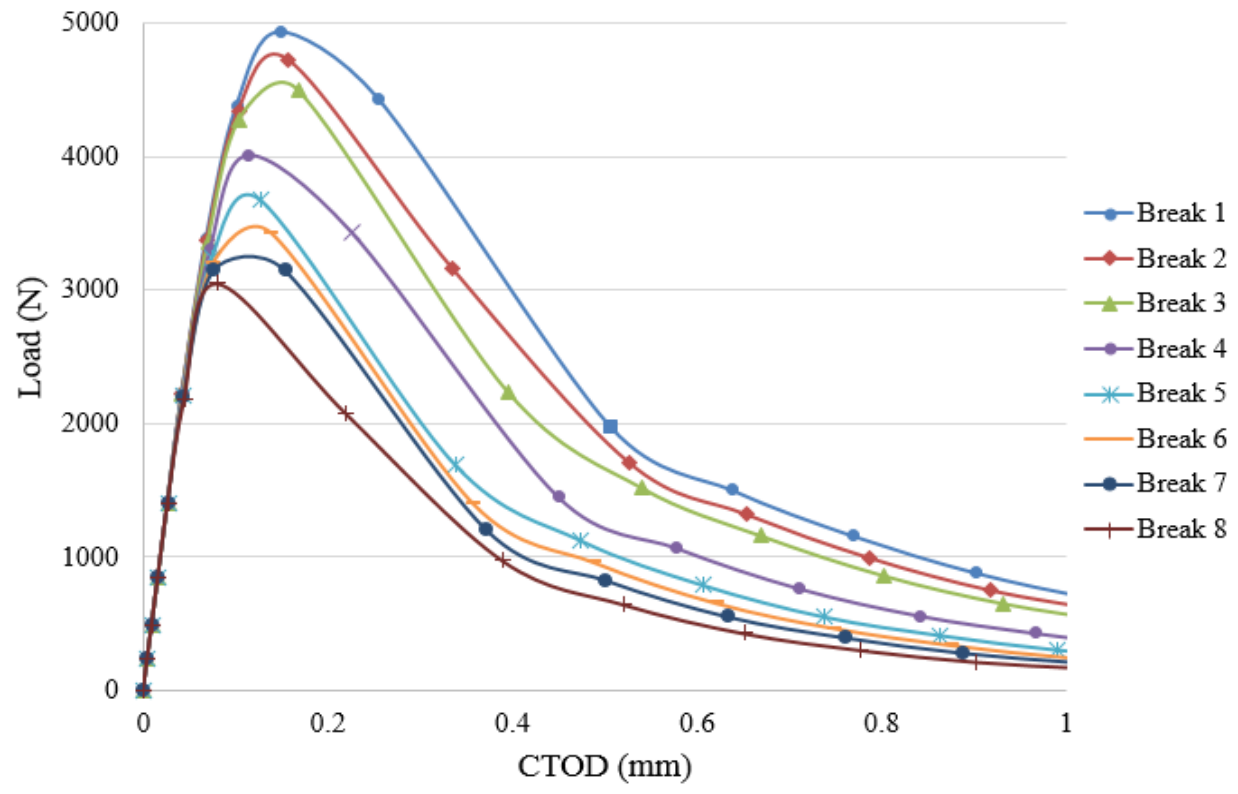

(b) 


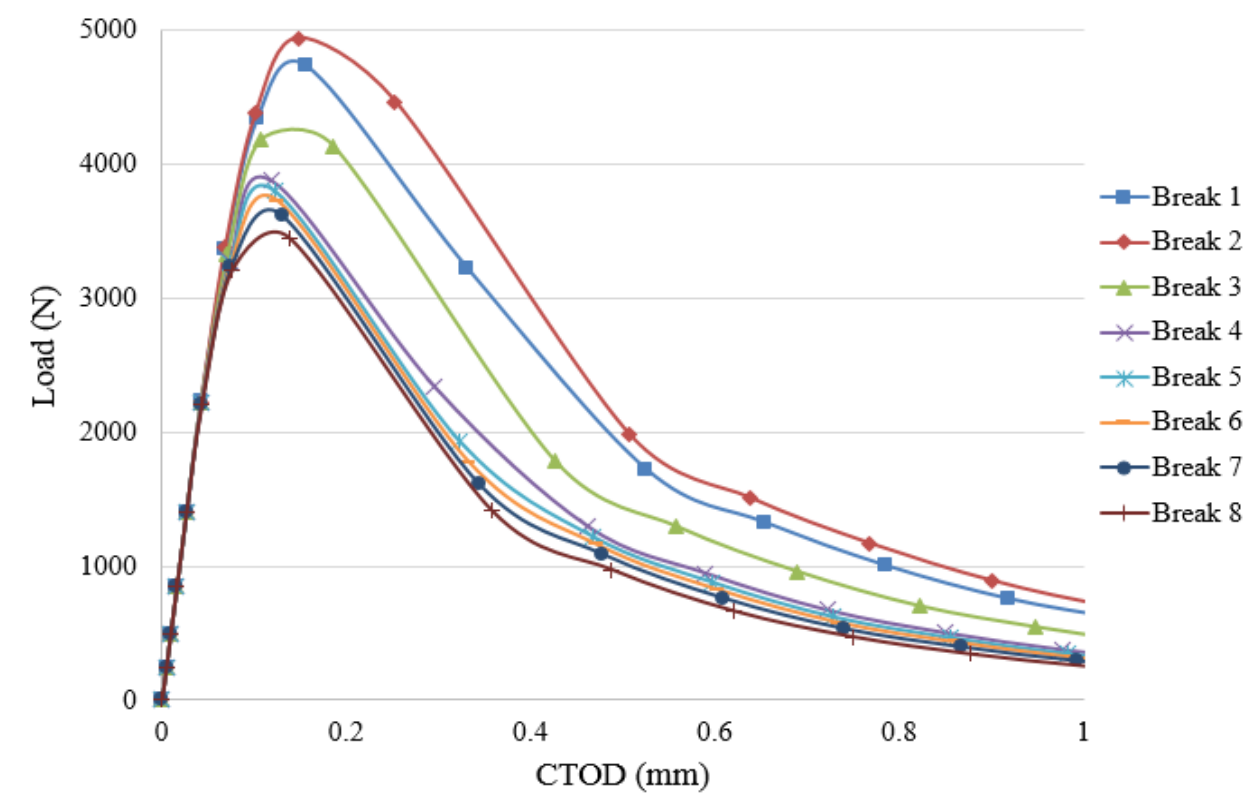

(c)

Figure 3. 12 Numerical results of asphalt concrete beam on healing temperature $100{ }^{\circ} \mathrm{C}$ :

(a) sample No. 7; (b) sample No. 8; (c) sample No. 9.

By comparing the model prediction and experimental data, the average relative difference of all these nine samples was $1.75 \%$. The results showed the relative differences among the three healing temperatures were all very low. The comparison data also indicated that implemented finite element fracture model with bilinear cohesive law was effective and reliable for predicting the recovered fracture strength after fracture-healing test cycles.

\subsection{Conclusions}

In this presented work, the cohesive zone model and finite element method were utilized to study the strength recover of asphalt concrete beam during the cyclic 
fracture-healing test. Based on the experimental and simulation results, some conclusions can be drawn.

Firstly, in the crack path simulation, it was found that finite element models with triangle-shaped elements can simulate crack path propagation more accurately than that with rectangle-shaped elements. Secondly, the bilinear cohesive zone law can effectively capture the relation between separation stress and displacement along the crack path. It was proved that the bilinear cohesive zone model could be used for threepoint beam bending test and modified beam bending test with an elastic foundation of asphalt concrete. Thirdly, the numerical results showed that the fracture energy of asphalt concrete sample decreased gradually with the fracture-healing cyclic test. At the same time, it was clear that the fracture energy decreased due to by the reduction of both maximum separation stress and critical displacement after each fracture-healing cyclic test.

The cohesive fracture simulation were conducted with scaled fracture energy and peak separation stress from experimental data to predict the recovered peak loads after each fracture-healing cycle. The predicted peak loads have a good agreement with the experimental results. The average relative difference between the predicted peak load and the experimental peak load was low as $1.75 \%$. These favorable comparison indicated that numerical simulation using finite element method and cohesive zone model is capable to predict the fracture recovered strength after fracture-healing cycles. This result could offer great help on highway maintenance if the field sample is obtained. Then the cohesive zone model with defined crack based on the sample could 
be employed to evaluate the pavement performance and to decide the maintenance method. In the future work, the fracture simulation will be extended to the displacement (CTOD) controlled fracture-healing cyclic studies with induction healing process. 


\section{CHAPTER 4 EXPERIMENTAL TESTS ON CARBON FIBER MODIFIED ASPHALT MIXTURE BEAM SAMPLES}

\subsection{Introduction}

Asphalt, graded asphalt and air voids consist of asphalt mixture [85]. As one of the critical component, asphalt binder regarded as a temperature-dependent material behaves as viscoelastic solid at low temperature and viscous flow at high temperature [4]. The durability and service life of pavement are affected by the large scale traffic loads and changeable climatic conditions [86]. In addition, the pavement performance could be weakened by the developing microcracks and other pavement distresses [52]. Therefore, the pavement surface needs to be maintained frequently.

Asphalt mixture has the ability to repair its damage during the service life called self healing [64]. The healing process is controlled by two factors, temperature and rest periods $[33,87]$. When the external energy is input to the pavement system, cracks generated by the traffic and freeze-thaw cycles could be healed [88]. The healing behavior studied by Shen et al. [12] was a complicated process combined with capillary flow, molecules wetting and intermolecular diffusion. In addition, the crack size, material type and other factors could affect the self-healing process $[11,14,41]$.

Carbon fiber, as a type of modifier, was added to asphalt material to improve the performance by many researchers. Yang et al. [89] utilized carbon fiber into the transportation system to improve the deicing technology. Liu et al. [90] proposed that the conductive asphalt concrete within graphite and carbon fiber was valid for the selfmonitoring of strain and stress. In addition, after measuring the mechanical and 
electrical properties of graphite and carbon fiber modified asphalt concrete, Liu and $\mathrm{Wu}$ [91] found the carbon fiber could increase the Marshall stability, residual stability and rutting dynamic stability. Khattak et al. [92] believed that the carbon nanofibers modified asphalt binder could increase the complex shear modulus of asphalt binder and fatigue life of asphalt mixture.

Some scientists studied the relationship between the carbon fiber and microwave. For instance, Qing et al. [93] investigated the microwave electromagnetic properties of carbon fiber as conductive absorber filled insulating epoxy/silicone resin coatings and the complex permittivity of the coatings increased when the content of carbon fiber increased. The reflection properties of the composites were affected by the element configurations of inductive activated carbon fiber felt screens, found by Zhao et al. [94]. Hashisho et al. [95] proposed that the density of functional groups by chemical treatment of activated carbon fiber cloth significantly affected its microwave and electrical regeneration properties. Cao and Song et al. [96] believed that the microwave absorption of carbon fiber/silica composites varied with the changes of thickness and temperature.

The objective of this research is to investigate the thermal property, electrical property and microwave healing effect of the carbon fiber modified asphalt mixture. First, two types of carbon fiber, HexTow IM8 and AS4 were added to the asphalt mixture to produce the beam samples. Then, the thermal conductivity and electrical resistivity of the samples were measured and calculated, respectively. Moreover, the 
cyclic fracture-microwave healing tests were implemented to evaluate the healing effect of the samples.

\subsection{Asphalt mixture design and sample preparation}

In this research, five types of asphalt mixture samples were prepared as the tested samples, including control, IM8 carbon fiber ( $2 \%$ and $4 \%$ by weight of asphalt mixture) modified and AS4 carbon fiber $(1.5 \%$ and $3 \%$ by weight of asphalt binder) modified asphalt mixture, respectively.

\subsubsection{Control and carbon fiber modified mixture design}

The asphalt binder used in the mixture was PG 58-28 with a density of 1.024 $\mathrm{g} / \mathrm{cm}^{3}$. The aggregates consisting of mixture were from Hancock, Michigan with an average density of $2.72 \mathrm{~g} / \mathrm{cm}^{3}$. The amount of asphalt used for the mixture samples was $5.7 \%$ by weight of the mixture determined by the test of the optimum asphalt content based on Superpave 5E1 mix design. The aggregate gradation of the asphalt mixture is shown in Table 4.1. 
Table 4. 1 Aggregate gradation of asphalt mixture.

\begin{tabular}{|c|c|c|c|c|c|c|}
\hline $\begin{array}{l}\text { Sieve } \\
\text { Size } \\
\text { (No.) }\end{array}$ & $\begin{array}{l}\text { Weight } \\
\text { (gram) }\end{array}$ & $3 / 4 "$ X 1/2" & $1 / 2 " \times 1 / 4 "$ & $\begin{array}{c}1 / 4 " \\
\text { minus } \\
\text { washed }\end{array}$ & $\begin{array}{c}\text { Natural } \\
\text { Sand }\end{array}$ & $\begin{array}{l}\text { Washed } \\
\text { Natural } \\
\text { Sand }\end{array}$ \\
\hline $1 / 2$ inch & 720.0 & 198.0 & & & 108.0 & 414.0 \\
\hline $3 / 8$ inch & 924.0 & & 254.1 & & 138.6 & 531.3 \\
\hline No. 4 & 2172.0 & & 367.6 & 835.4 & 200.5 & 768.6 \\
\hline No. 8 & 2280.0 & & & 1055.6 & 253.3 & 971.1 \\
\hline No. 16 & 1296.0 & & & 600.0 & 144.0 & 552.0 \\
\hline No. 30 & 1272.0 & & & 588.9 & 141.3 & 541.8 \\
\hline No. 50 & 1536.0 & & & 711.1 & 170.7 & 654.2 \\
\hline No. 100 & 996.0 & & & 461.1 & 110.7 & 424.2 \\
\hline No. 200 & 264.0 & & & 122.2 & 29.3 & 112.4 \\
\hline Pan & 540.0 & & & 250.0 & 60.0 & 230.0 \\
\hline
\end{tabular}

The carbon fibers used were HexTow IM8 and AS4, from Hexcel Co.. IM8 carbon fiber is a continuous, high performance, intermediate modulus, PAN based fiber in 12,000 filament count tows. The tensile strength is $6067 \mathrm{MPa}$. The tensile modulus (Chord 6000-1000) is $310 \mathrm{GPa}$. The ultimate elongation at failure is $1.8 \%$. The density is $1.78 \mathrm{~g} / \mathrm{cm}^{3}$. The filament diameter is 5.2 microns. All the IM8 carbon fibers were first hand cut to $1 / 4$ " then mixed with the asphalt mixture. The amount used of IM8 
was $2 \%$ and $4 \%$ of the asphalt mixture by weight. AS4 carbon fiber is a continuous, high strength, high strain, PAN based fiber in 3000 filament count tows. The tensile strength is $4619 \mathrm{MPa}$. The tensile modulus (Chord 6000-1000) is $231 \mathrm{GPa}$. The ultimate elongation at failure is $1.8 \%$. The density is $1.79 \mathrm{~g} / \mathrm{cm}^{3}$. The filament diameter is 7.1 microns. All the AS4 carbon fibers were pre-cut to $1 / 4$ " and glued in order to keep the strength. Then they were mixed with asphalt mixture. The amount used of AS4 was $1.5 \%$ and $3 \%$ of asphalt binder by weight.

\subsubsection{Mixture beam sample preparation}

In this study, the samples used were beams with a length of $190 \mathrm{~mm}$, width of 50 $\mathrm{mm}$ and height of $69 \mathrm{~mm}$. In addition, a $23 \mathrm{~mm}$ deep, $3 \mathrm{~mm}$ wide notch was sawn in the center of the beams to control the initial cracking position. For each beam sample, two knife edges were glued on the top notch for measuring the crack tip opening displacement by a clip-on gauge. Consequently, 3 beam samples were prepared for each mixture type, control, $2 \%$ and 4\% IM8 modified, $1.5 \%$ and 3\% AS4 modified asphalt mixture beam samples. Therefore, 15 beam samples were produced for the whole cyclic fracture-microwave healing tests discussed in the following sections.

\subsection{Mechanism of microwave healing and properties measurement of asphalt}

\section{mixture}

\subsubsection{Mechanism of microwave healing of asphalt mixture}

The carbon fibers have the ability to absorb the energy when locating in the microwave field. When absorbing the energy, the temperature of the carbon fibers increase. Then the heat is transferred to the asphalt and aggregate. In this transfer 
process, the temperature-dependent asphalt behaves as Newtonian flow to fill the cracks in the mixture. The crack healing process could be regarded as a combination of capillary flow induced by surface tension force, gravity of liquid asphalt and friction between aggregate particles and flowing asphalt. The recovered strength is mainly from two aspects. One is the molecules diffusion in asphalt, the other is the rebinding of asphalt and aggregates. Figure 4.1 displays the mechanism of microwave healing of asphalt mixture. In this study, the healing effect of carbon fibers modified asphalt mixture was investigated in the following sections. 


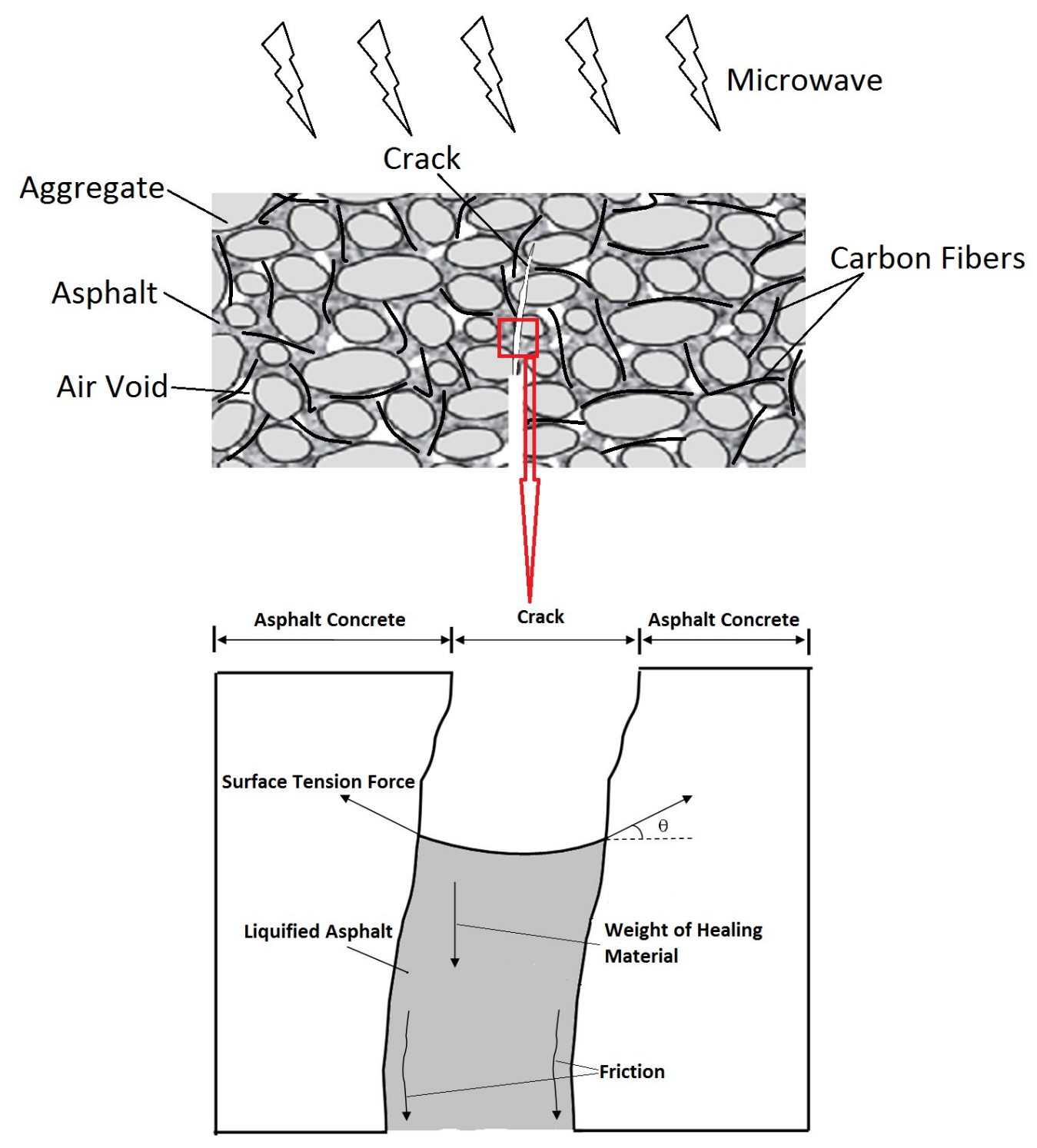

Figure 4. 1 Schematic demonstration of microwave healing mechanism for carbon fibers modified asphalt mixture.

\subsubsection{Thermal conductivity of asphalt mixture beams}

In this study, a KD2 Pro thermal property analyzer from Decagon Devices Inc. was utilized to measure the thermal conductivity of carbon fiber modified asphalt mixture samples based on transient line heal source methods, displayed in Figure 4.2 (a) 
[97, 98]. The heat generated by a needle TR-1 sensor (length of $10 \mathrm{~cm}$, diameter of 2.4 $\mathrm{mm}$ ) inside the sample formed gradient temperature. Then the sensor detected the temperature variation and recorded the data. The thermal conductivity was calculated by Equation (4-1) and (4-2):

$T=m_{0}+m_{1} t+m_{2} \ln t$

where $T$ is the recorded temperature, $m_{0}$ denotes the environmental temperature, $m_{1}$ is the varying rate of the background temperature, $m_{2}$ indicates the temperature drifting of the tested material, $t$ is the testing time.

$k=\frac{q}{4 \pi m_{2}}$

where $k$ is the thermal conductivity $(\mathrm{W} /(\mathrm{m} \cdot \mathrm{K})), q$ is the heat generated by the device. The thermal conductivity values of five types of asphalt mixture beams were measured, including the control, 2\% IM8 modified, 4\% IM8 modified, 1.5\% AS4 modified and 3\% AS4 modified asphalt mixture samples, shown in Figure 4.2 (b). It is observed that the average thermal conductivity of control asphalt mixture samples is $1.562 \mathrm{~W} /(\mathrm{m} \cdot \mathrm{K})$. The average thermal conductivities of 1.5\% AS4 modified and 3\% AS4 modified asphalt mixture samples are $1.651 \mathrm{~W} /(\mathrm{m} \cdot \mathrm{K})$ and $1.731 \mathrm{~W} /(\mathrm{m} \cdot \mathrm{K})$, respectively. The average thermal conductivities of 2\% IM8 modified and 4\% IM8 modified asphalt mixture samples are $1.886 \mathrm{~W} /(\mathrm{m} \cdot \mathrm{K})$ and $2.033 \mathrm{~W} /(\mathrm{m} \cdot \mathrm{K})$. Therefore, the carbon fibers could increase the thermal conductivity of asphalt mixture samples. Additionally, the thermal conductivity value of the asphalt mixture sample increases with raising the content of carbon fibers. 


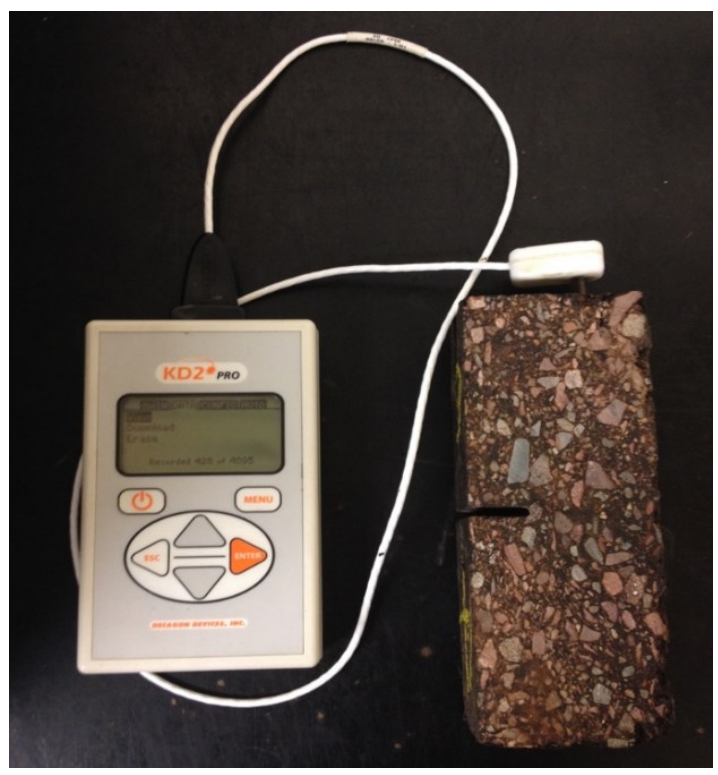

(a)

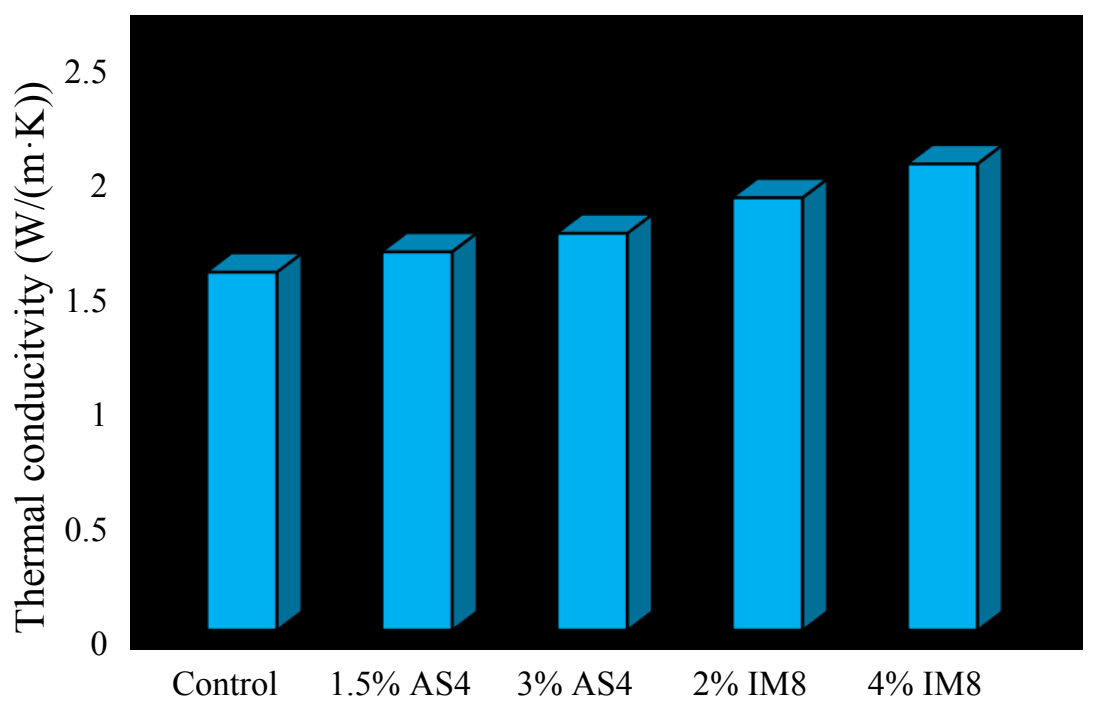

(b)

Figure 4. 2 Thermal conductivity measurement of non-fractured asphalt mixture beams:

(a) sample and device; (b) thermal conductivity data of tested samples. 


\subsubsection{Electrical conductivity of asphalt mixture beams}

The electrical resistivity measurements were conducted on five different types of prepared beam samples at room temperature, displayed in Figure 4.3 (a). Two copper electrodes were located on the two sides of the sample to measure the electrical resistance. Then the electrical resistivity of the sample was calculated by Equation (43):

$\rho=\frac{R \square}{L}$

where $\rho$ indicates the electrical resistivity $(\Omega \square$ ), $R$ denotes the measured electrical resistance ( $\Omega$ ), $S$ is the cross-sectional area and $L$ is the length of the beam samples. The measured electrical resistivity values of prepared samples are plotted in Figure 4.3 (b). It is observed that the average electrical resistivity of control samples is about 38.5 $\Omega \quad$. The average electrical resistivity of $1.5 \%$ and $3 \%$ AS4 modified asphalt mixture samples are approximately 29.8 and $26.3 \Omega \square$. In addition, the average electrical resistivity of $2 \%$ and 4\% IM8 modified asphalt mixture samples are around 19.3 and $15.4 \Omega \square$. Therefore, the carbon fiber AS4 and IM8 both could decrease the electrical resistivity of the asphalt mixture samples. 


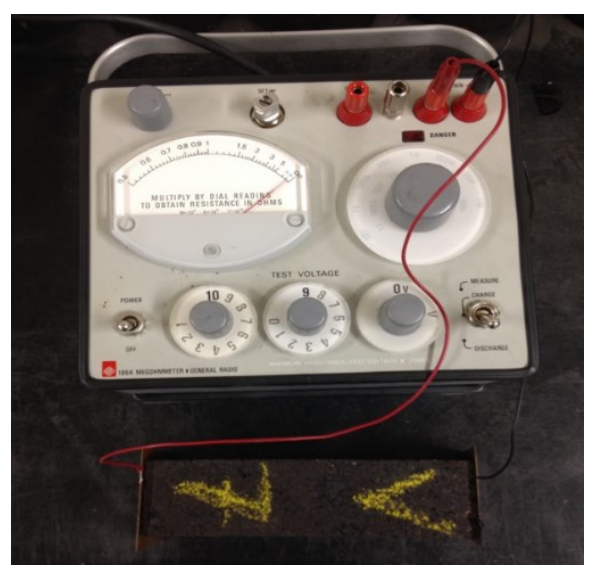

(a)

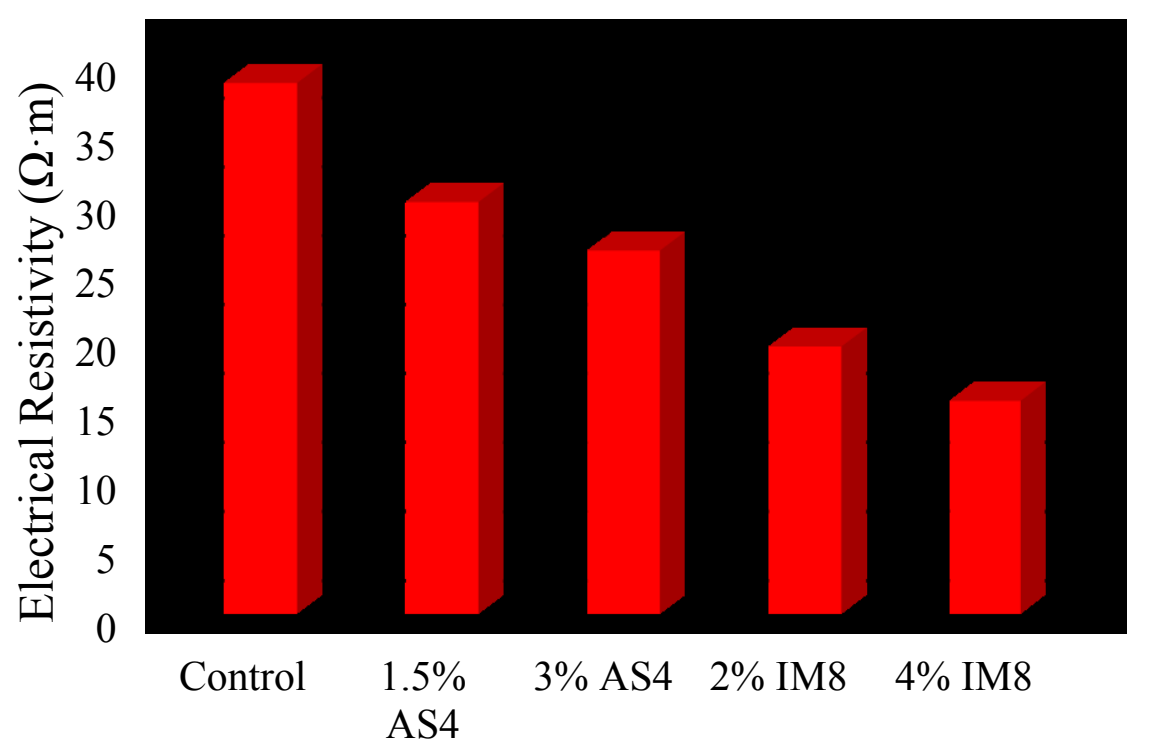

(b)

Figure 4. 3 Electrical resistivity measurement of non-fractured asphalt mixture beams:

(a) sample and device; (b) electrical resistivity data of tested samples. 


\subsection{Fracture-microwave healing investigation of asphalt mixture samples with}

\section{elastic foundation modified beam bending test}

\subsubsection{Fracture-microwave healing tests of asphalt mixture samples}

The healing effect of carbon fibers in the asphalt mixture was investigated by the cyclic fracture-microwave healing test. Briefly speaking, it contains two parts, the sample fractured test and sample microwave healed test. In the sample fractured test, the tested sample was first placed in a freezer for 6 hours to assure an internal temperature of $-10{ }^{\circ} \mathrm{C}$. Then the beam was located on a modified elastic foundation instead of the regular three-point support, shown in Figure 4.4. The crack along the vertical direction of the tested beam was generated by applying a descending load with a speed of $0.5 \mathrm{~mm} / \mathrm{min}$. During the test, the loading machine was halted manually as long as the applying load increased to the maximum value (peak load). The peak load, crack tip opening displacement (CTOD) and testing time were recorded automatically.

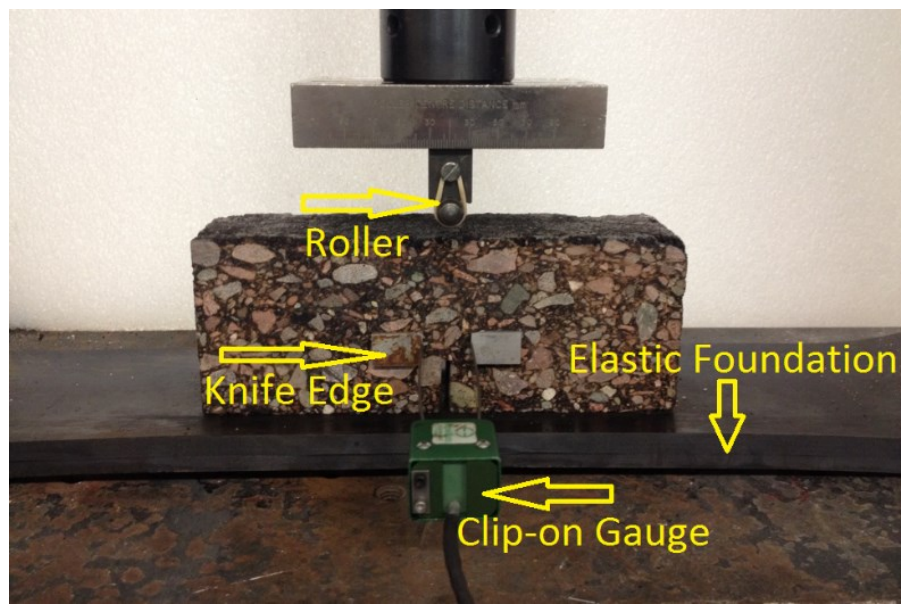

Figure 4. 4 Demonstration of modified bending test of asphalt mixture beam with elastic foundation. 
During the sample microwave healing process, the fractured sample was located into a $1100 \mathrm{w}$ microwave oven, heating for 2 minutes, shown in Figure 4.5. The carbon fiber inside the sample absorbed the microwave energy and the surface temperature went up to around $100{ }^{\circ} \mathrm{C}$ to heal the crack. Later, the sample was taken out, being healed for another 30 minutes until its temperature decreased to room temperature. Then the healed sample was placed into the freezer for 6 hours and the load was applied on the sample again. This repeated procedure was called cyclic fracturemicrowave healing tests. In this research, six cycles of fracture-microwave healing tests were conducted to investigate the healing effect of the control, IM8 and AS4 carbon fiber modified asphalt mixture samples.

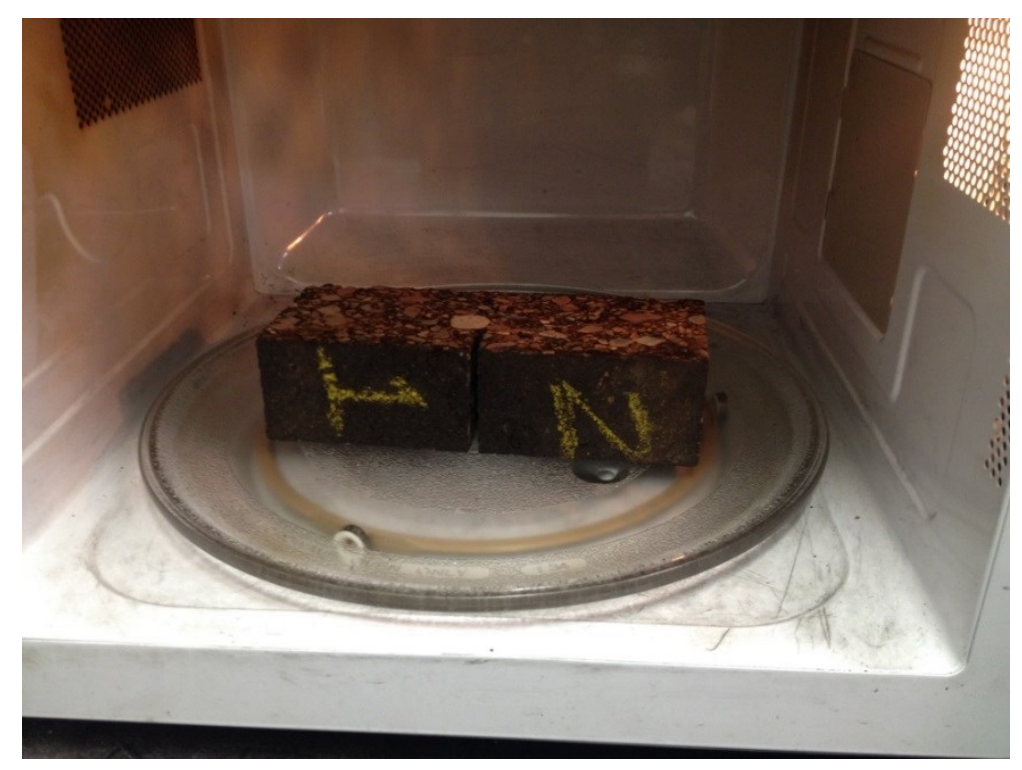

Figure 4. 5 Microwave healing of asphalt mixture beam sample.

\subsubsection{Fracture-microwave healing test results of asphalt mixture samples}

In this study, the recovered strengths (recovered peak loads) were adopted to evaluate the healing effect of the carbon fiber modified asphalt samples. Table 4.2 
exhibits the peak loads of asphalt mixture beam samples by the cyclic fracturemicrowave healing tests, including control, $2 \%$ and $4 \%$ IM8, $1.5 \%$ and $3 \%$ AS4 carbon fiber modified asphalt mixture beams, respectively. The ratios of recovered peak loads (recovered peak load divided by original peak load) of all the tested beam samples are recorded in Table 4.3. Figure 4.6 shows the fracture-microwave healing test data of control asphalt mixture beams, it is observed that the range of original peak loads is from $4300 \mathrm{~N}$ to $4600 \mathrm{~N}$, reducing to the range of $1200 \mathrm{~N}$ to $1800 \mathrm{~N}$ after five fracturemicrowave healing cycles. The average ratio of recovered peak loads after the first cycle remains $55.4 \%$, reducing to $48.9 \%, 41.8 \%, 35.0 \%$ and $31.9 \%$ cycle by cycle.

Table 4. 2 Peak loads (N) of asphalt mixture beams during cyclic fracture-microwave healing tests.

\begin{tabular}{|l|r|r|r|r|r|r|}
\hline Sample & $\begin{array}{r}1^{\text {st }} \\
\text { loading }\end{array}$ & $\begin{array}{r}2^{\text {nd }} \\
\text { loading }\end{array}$ & $\begin{array}{r}3^{\text {rd }} \\
\text { loading }\end{array}$ & $\begin{array}{r}4^{\text {th }} \\
\text { loading }\end{array}$ & $\begin{array}{r}5^{\text {th }} \\
\text { loading }\end{array}$ & $6^{\text {th }}$ \\
No.1 & 4349.5 & 2739.3 & 2103.7 & 1978.7 & 1308.0 & 1206.9 \\
\hline Control & 4799.3 & 2363.6 & 2449.7 & 1724.9 & 1610.0 & 1436.1 \\
No.2 & & & & & & \\
\hline Control & 4529.8 & 2447.1 & 2138.8 & 1990.3 & 1878.5 & 1723.5 \\
No.3 & & & & & & \\
\hline 2\% IM8 & 3554.4 & 3285.1 & 3184.5 & 3098.0 & 3068.5 & 2957.1 \\
No.1 & & & & & & \\
\hline 2\% IM8 & 3705.6 & 3370.3 & 3397.0 & 3283.4 & 3238.0 & 3234.7 \\
\hline
\end{tabular}




\begin{tabular}{|l|r|r|r|r|r|r|}
\hline No.2 & & & & & & \\
\hline No.3 $\%$ IM8 & 3773.1 & 3501.6 & 3436.7 & 3421.9 & 3356.8 & 3268.4 \\
\hline No.1 & & & & & & \\
\hline $4 \%$ IM8 & 4312.3 & 2728.9 & 2611.8 & 2538.2 & 2428.9 & 2281.4 \\
No.2 & & & & & & \\
\hline $4 \%$ IM8 & 3792.9 & 2986.7 & 2768.8 & 2754.1 & 2520.9 & 2399.7 \\
No.3 & & & & & & \\
\hline $1.5 \%$ AS4 & 4934.7 & 4063.2 & 3869.7 & 3319.1 & 2414.8 & 2010.8 \\
No.1 & & & & & & \\
\hline $1.5 \%$ AS4 & 4688.5 & 4423.4 & 4199.0 & 3784.6 & 2887.7 & 2255.8 \\
No.2 & & & & & & \\
\hline $1.5 \%$ AS4 & 4452.2 & 4352.3 & 3842.77 & 3649.7 & 2846.2 & 2113.2 \\
No.3 & & & & & & \\
\hline $3 \%$ AS4 & 3597.6 & 3106.6 & 3126.5 & 3375.1 & 3121.4 & 2875.2 \\
No.1 & & & & & & \\
\hline $3 \%$ AS4 & 3857.2 & 3634.0 & 3462.3 & 3393.6 & 3304.3 & 3188.3 \\
\hline No.2 & & & & & & \\
\hline $3 \%$ AS4 & 3931.8 & 3566.7 & 3377.6 & 3171.3 & 2846.8 & 2814.0 \\
\hline No.3 & & & & & & \\
\hline & & & & & & \\
\hline
\end{tabular}


Table 4. 3 Ratio (\%) of recovered peak loads of asphalt mixture beams during cyclic fracture-microwave healing tests.

\begin{tabular}{|c|c|c|c|c|c|}
\hline Sample & $\begin{array}{l}\text { 2nd } \\
\text { loading } \\
\text { after } 1 \\
\text { cycle }\end{array}$ & $\begin{array}{r}\text { 3rd loading } \\
\text { after } 2 \\
\text { cycles }\end{array}$ & $\begin{array}{r}\text { 4th loading } \\
\text { after } 3 \\
\text { cycles }\end{array}$ & $\begin{array}{r}\text { 5th loading } \\
\text { after } 4 \\
\text { cycles }\end{array}$ & $\begin{array}{r}\text { 6th loading } \\
\text { after } 5 \\
\text { cycle }\end{array}$ \\
\hline $\begin{array}{l}\text { Control } \\
\text { No.1 }\end{array}$ & $63.0 \%$ & $48.4 \%$ & $45.5 \%$ & $30.1 \%$ & $27.7 \%$ \\
\hline $\begin{array}{l}\text { Control } \\
\text { No. } 2\end{array}$ & $49.2 \%$ & $51.0 \%$ & $35.9 \%$ & $33.5 \%$ & $29.9 \%$ \\
\hline $\begin{array}{l}\text { Control } \\
\text { No.3 }\end{array}$ & $54.0 \%$ & $47.2 \%$ & $43.9 \%$ & $41.5 \%$ & $38.0 \%$ \\
\hline $\begin{array}{l}\text { Average } \\
\text { of control } \\
\text { samples }\end{array}$ & $55.4 \%$ & $48.9 \%$ & $41.8 \%$ & $35.0 \%$ & $31.9 \%$ \\
\hline $\begin{array}{l}\text { 2\% IM8 } \\
\text { No.1 }\end{array}$ & $92.4 \%$ & $89.6 \%$ & $87.2 \%$ & $86.3 \%$ & $83.2 \%$ \\
\hline $\begin{array}{l}\text { 2\% IM8 } \\
\text { No.2 }\end{array}$ & $91.0 \%$ & $91.7 \%$ & $88.6 \%$ & $87.4 \%$ & $87.3 \%$ \\
\hline $\begin{array}{l}\text { 2\% IM8 } \\
\text { No.3 }\end{array}$ & $92.8 \%$ & $91.1 \%$ & $90.7 \%$ & $89.0 \%$ & $86.6 \%$ \\
\hline Average & $92.0 \%$ & $90.8 \%$ & $88.8 \%$ & $87.6 \%$ & $85.7 \%$ \\
\hline
\end{tabular}




\begin{tabular}{|c|c|c|c|c|c|}
\hline $\begin{array}{l}\text { of } 2 \% \text { IM8 } \\
\text { samples }\end{array}$ & & & & & \\
\hline $\begin{array}{l}\text { 4\% IM8 } \\
\text { No.1 }\end{array}$ & $63.3 \%$ & $60.6 \%$ & $58.9 \%$ & $56.3 \%$ & $52.9 \%$ \\
\hline $\begin{array}{l}\text { 4\% IM8 } \\
\text { No. } 2\end{array}$ & $59.5 \%$ & $55.7 \%$ & $52.9 \%$ & $47.3 \%$ & $46.9 \%$ \\
\hline $\begin{array}{l}\text { 4\% IM8 } \\
\text { No.3 }\end{array}$ & $78.7 \%$ & $73.0 \%$ & $72.6 \%$ & $66.5 \%$ & $63.3 \%$ \\
\hline $\begin{array}{l}\text { Average } \\
\text { of } 4 \% \text { IM8 } \\
\text { samples }\end{array}$ & $67.2 \%$ & $63.1 \%$ & $61.5 \%$ & $56.7 \%$ & $54.4 \%$ \\
\hline $\begin{array}{l}1.5 \% \text { AS4 } \\
\text { No. } 1\end{array}$ & $82.3 \%$ & $78.4 \%$ & $67.3 \%$ & $48.9 \%$ & $40.7 \%$ \\
\hline $\begin{array}{l}1.5 \% \text { AS4 } \\
\text { No. } 2\end{array}$ & $94.3 \%$ & $89.6 \%$ & $80.7 \%$ & $61.6 \%$ & $48.1 \%$ \\
\hline $\begin{array}{l}1.5 \% \text { AS4 } \\
\text { No.3 }\end{array}$ & $97.8 \%$ & $86.3 \%$ & $82.0 \%$ & $63.9 \%$ & $47.5 \%$ \\
\hline $\begin{array}{l}\text { Average } \\
\text { of } 1.5 \% \\
\text { AS4 } \\
\text { samples }\end{array}$ & $91.5 \%$ & $84.8 \%$ & $76.7 \%$ & $58.1 \%$ & $45.4 \%$ \\
\hline $3 \%$ AS4 & $86.4 \%$ & $86.9 \%$ & $93.8 \%$ & $86.8 \%$ & $79.9 \%$ \\
\hline
\end{tabular}




\begin{tabular}{|l|r|r|r|r|r|}
\hline No.1 & & & & & \\
\hline No.2 & & & & & \\
\hline $3 \%$ AS4 4 & $90.7 \%$ & $85.9 \%$ & $80.7 \%$ & $72.4 \%$ & $71.6 \%$ \\
No.3 & & & & & \\
\hline Average & $90.4 \%$ & $87.5 \%$ & $87.5 \%$ & $81.6 \%$ & $78.1 \%$ \\
of 3\% & & & & & \\
AS4 & & & & & \\
samples & & & & & \\
\hline
\end{tabular}

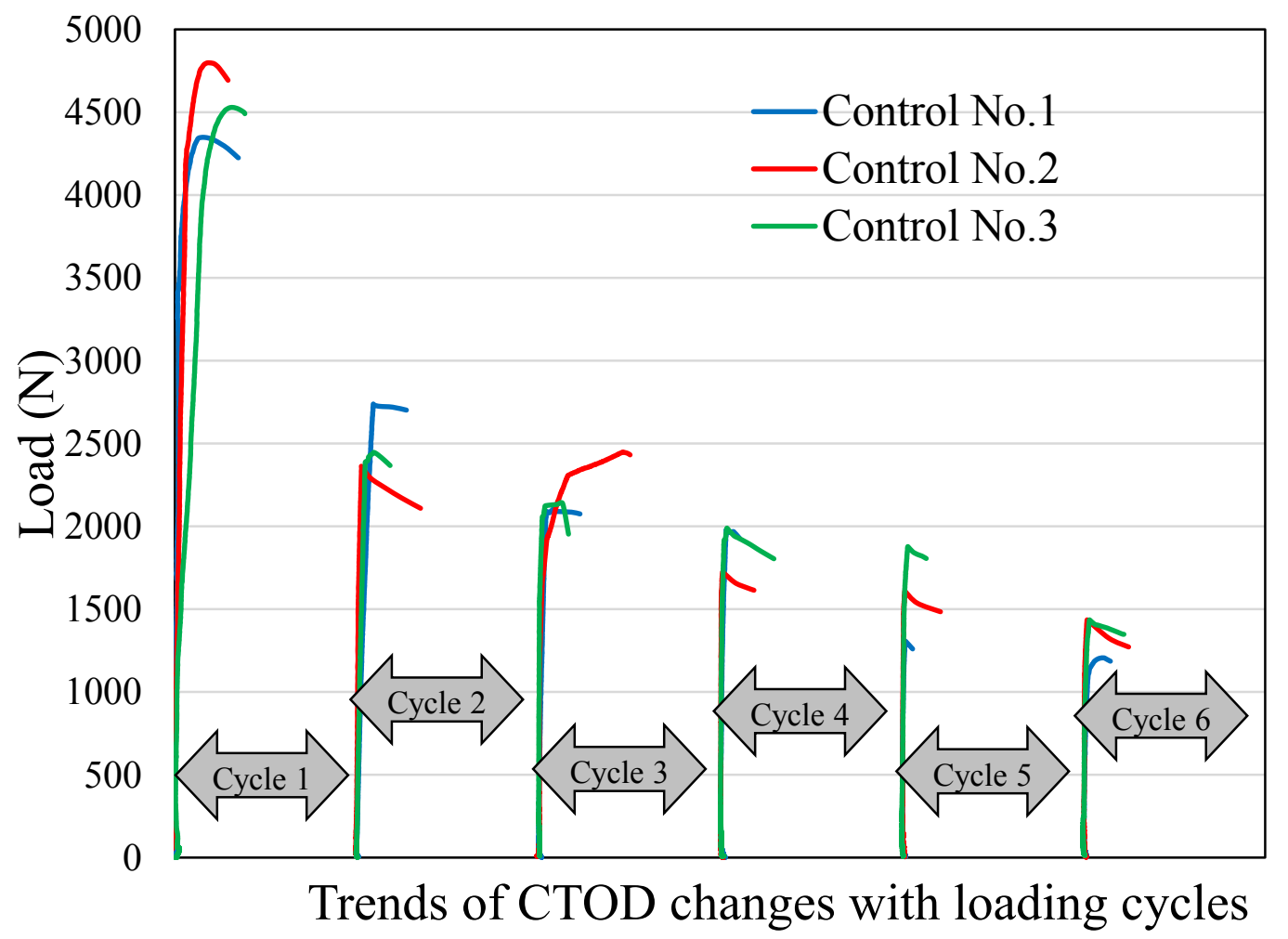

Figure 4. 6 Fracture-microwave healing test data of control asphalt mixture beams. 
Figure 4.7 displays the fracture-microwave healing test data of 2\% IM8 modified asphalt mixture beams. The peak loads are in the range of $3500 \mathrm{~N}$ to $3800 \mathrm{~N}$ at the first loading, decreasing to the range of $2900 \mathrm{~N}$ to $3300 \mathrm{~N}$ at the sixth loading. The average ratios of recovered peak loads decrease from $92.0 \%, 90.8 \%, 88.8 \%, 87.6 \%$ to $85.7 \%$ during five cycles. Figure 4.8 shows the fracture-microwave healing test data of $4 \%$ IM8 modified asphalt mixture beams, the scope of original peak loads is from $3700 \mathrm{~N}$ to $4400 \mathrm{~N}$. After five cycles of loading, the recovered peak loads float from $2200 \mathrm{~N}$ to $2400 \mathrm{~N}$. The average ratios of recovered peak loads reduce from $67.2 \%$ to $54.4 \%$ in the five cycles.

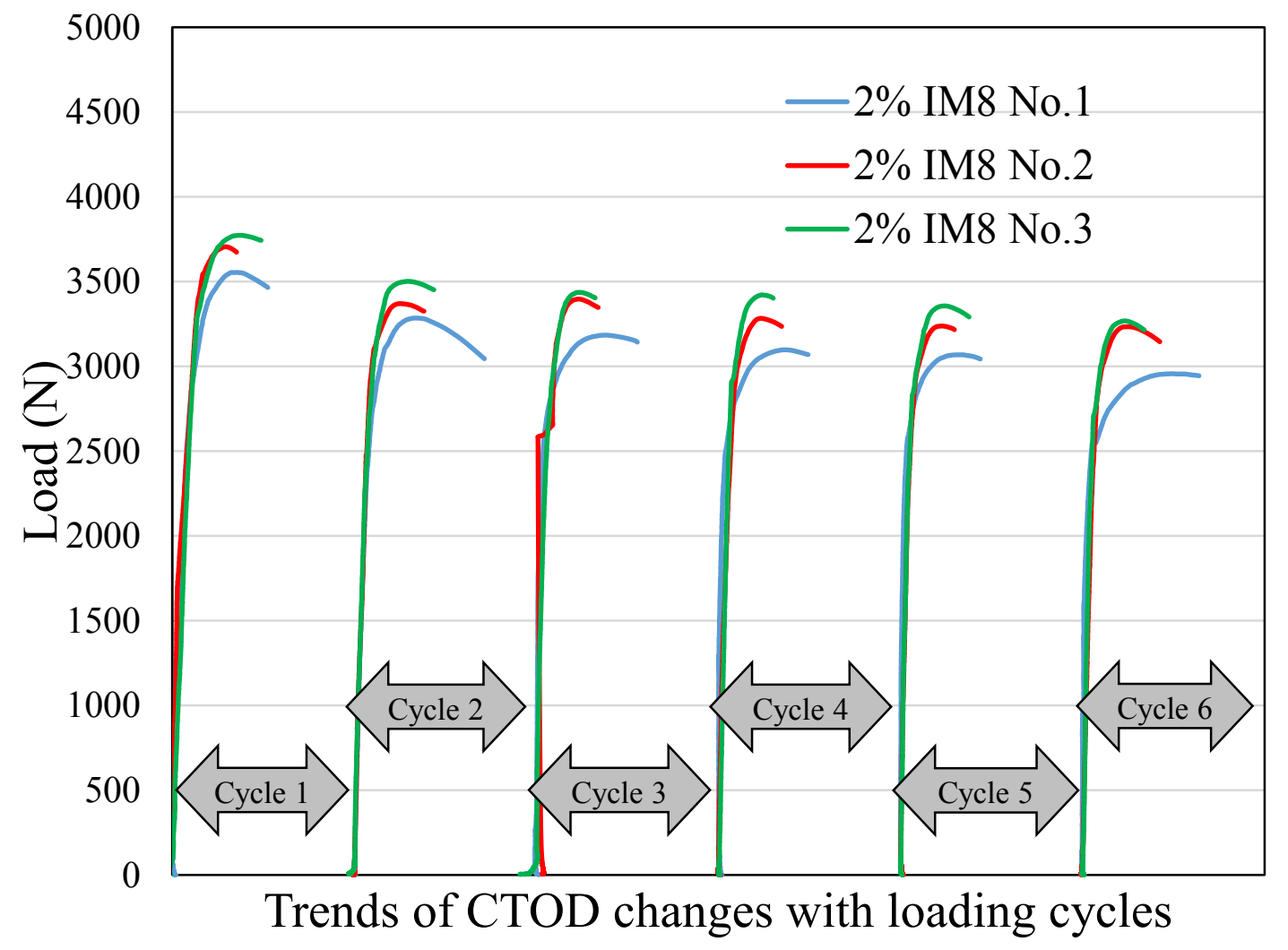

Figure 4. 7 Fracture-microwave healing test data of 2\% IM8 modified asphalt mixture beams. 


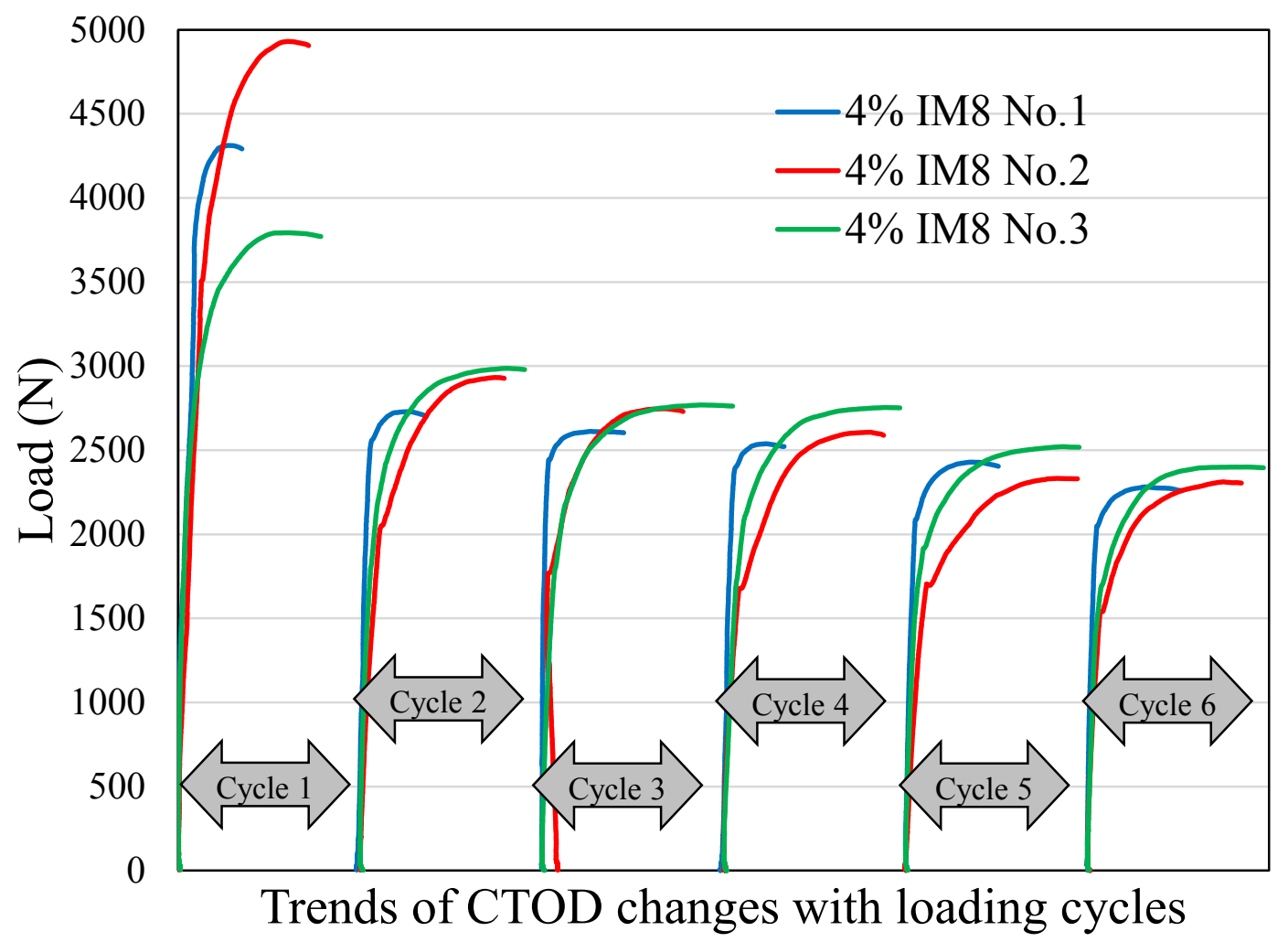

Figure 4. 8 Fracture-microwave healing test data of 4\% IM8 modified asphalt mixture beams.

Figure 4.9 exhibits the fracture-microwave healing test data of $1.5 \%$ AS4 modified asphalt mixture samples, the range of original peak loads is from $4400 \mathrm{~N}$ to $5000 \mathrm{~N}$, lowering to about $2200 \mathrm{~N}$ at the sixth loading. The average ratios of recovered peak loads are $91.5 \%$ after the first cycle and $45.5 \%$ after the fifth cycle. Figure 4.10 shows the fracture-microwave healing test data of 3\% AS4 modified asphalt mixture samples, the original peak loads are in the scope of $3500 \mathrm{~N}$ to $4000 \mathrm{~N}$ while the recovered peak loads are between $2800 \mathrm{~N}$ and $3200 \mathrm{~N}$ at the sixth loading. In addition, the average ratios of recovered peak loads decrease from $90.4 \%$ to $78.1 \%$ after the fifth cycle. The experimental results showed that both the added IM8 and AS4 could 
improve the microwave healing performance of asphalt mixture material. However, the microwave healing effect of $2 \%$ IM8 modified asphalt mixture was better than the $4 \%$ IM8 modified asphalt mixture. It is concluded that two many carbon fibers may have negative impact on the Newtonian flow of the asphalt during the microwave healing process. This study demonstrates a promising microwave healing technique with carbon fiber modified asphalt mixtures.

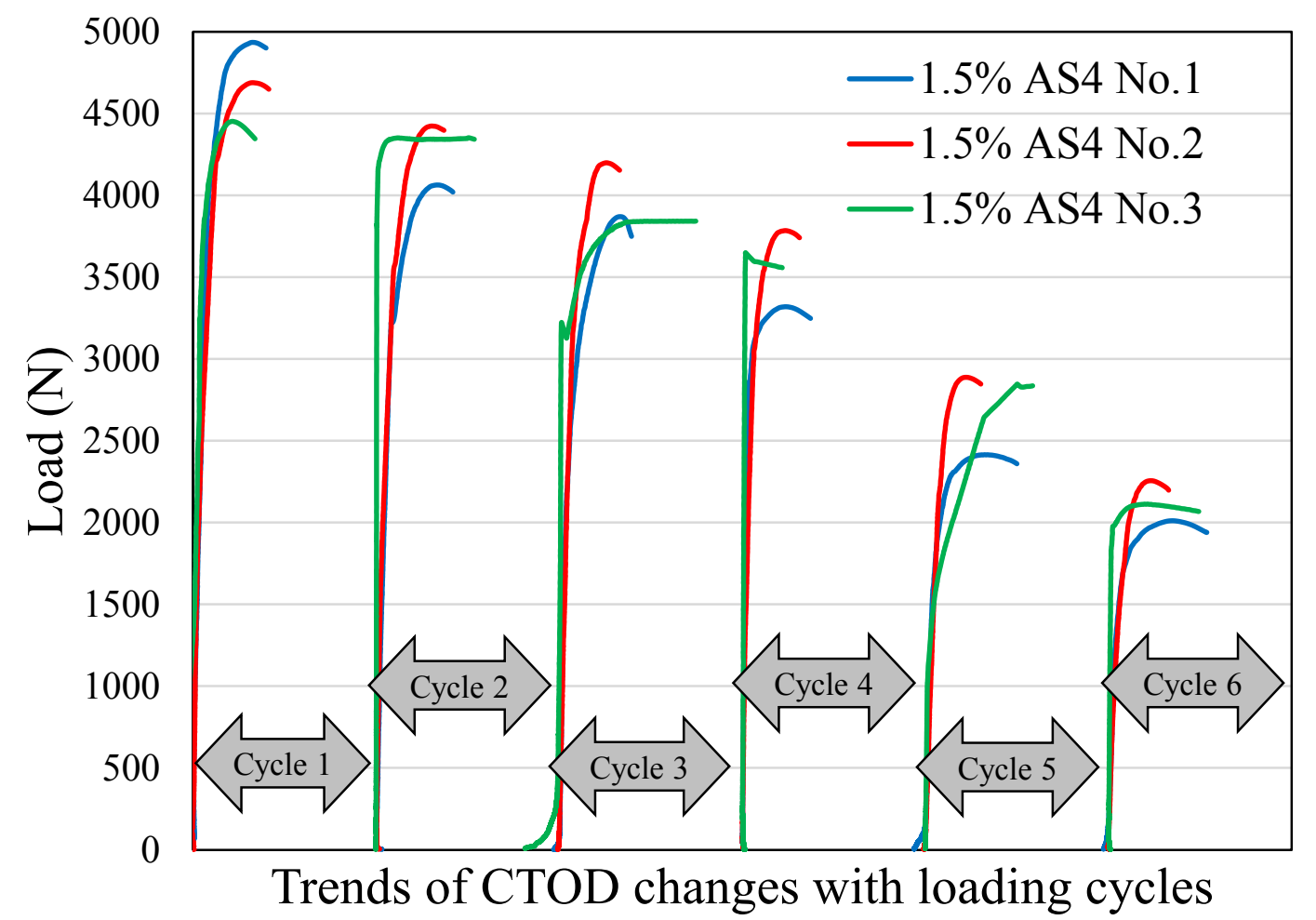

Figure 4. 9 Fracture-microwave healing test data of 1.5\% AS4 modified asphalt mixture beams. 


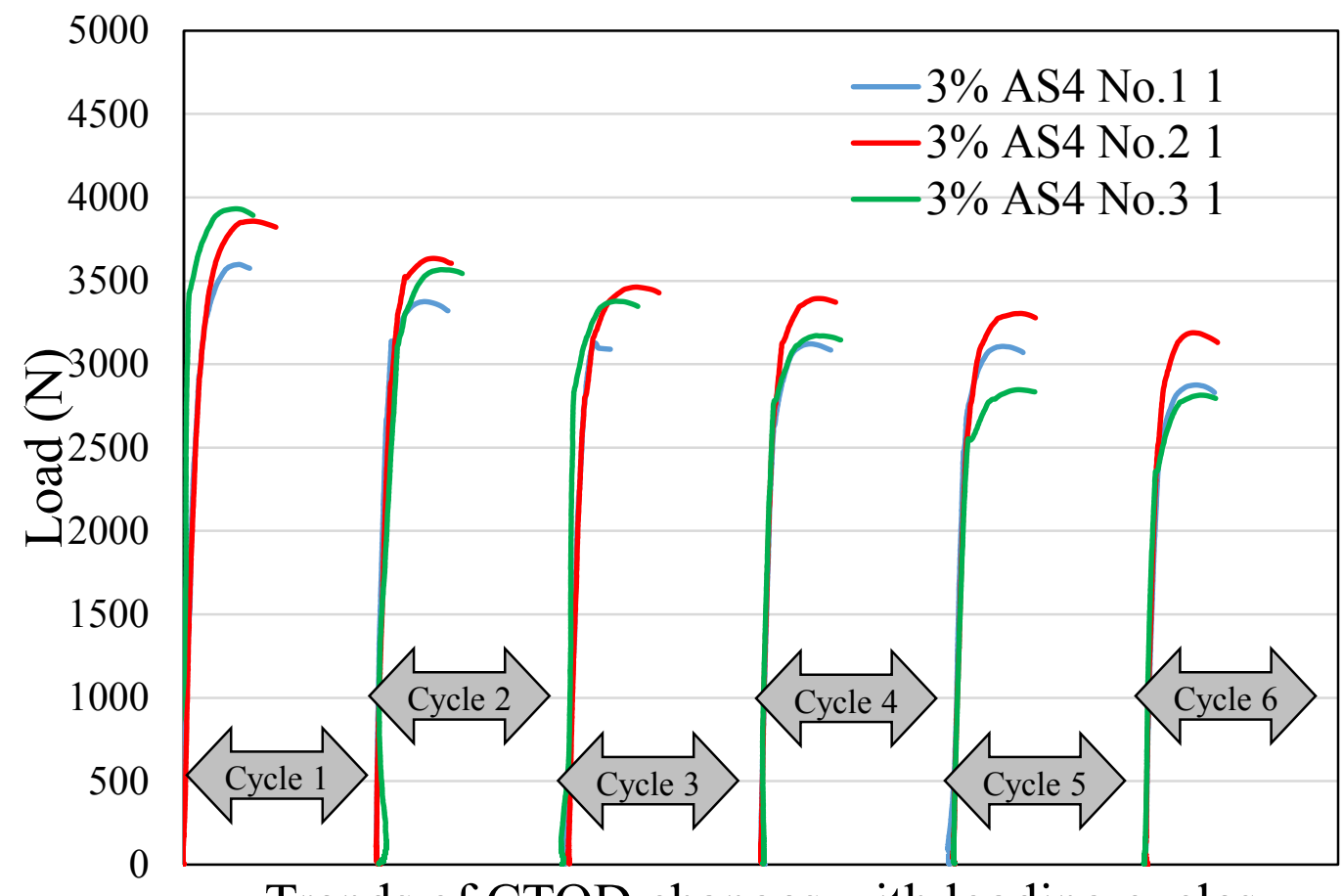

Figure 4. 10 Fracture-microwave healing test data of 1.5\% AS4 modified asphalt mixture beams.

\subsection{Summary and conclusions}

In this research, two carbon fibers, IM8 and AS4, were added into the asphalt mixture. The thermal conductivity and electrical resistivity of the control and carbon fiber modified asphalt mixture samples were measured. In addition, the cyclic fracturelight healing tests were implemented to evaluate the microwave healing effect of samples, including control, $2 \%$ and 4\% IM modified, $1.5 \%$ and 3\% AS4 modified asphalt mixture.

On the one hand, the measurement results of the thermal conductivity of the samples indicated that the carbon fiber, as a modifier, could increase the thermal conductivity of the asphalt mixture. On the other hand, the carbon fiber has the ability 
to decrease the electrical resistivity. Finally, the results of the cyclic fracturemicrowave healing test indicated that the carbon fibers, containing IM8 and AS4, could increase the microwave healing effect. However, too many carbon fibers may affect the Newtonian flow of asphalt and the microwave healing effect could be decreased. 


\section{CHAPTER 5 EXPERIMENTAL TESTS ON GRAPHITE MODIFIED}

\section{ASPHALT BINDER SAMPLES*}

\subsection{Introduction}

In the United States, 94\% of the pavement's surface was constructed using an asphalt mixture material [1]. Asphalt mixture consists of asphalt, graded aggregates and air voids [85]. The temperature-dependent asphalt binder behaves as viscous flow at high temperatures and as viscoelastic solid at low temperatures [4]. Increasing traffic loads and changing climatic conditions impose challenges to the pavement's durability and service life. In addition, the pavement performance can be quickly weakened with microcrack developments and combined pavement distresses [52]. For instance, raveling can be initiated by the abrasive action of vehicle wheels on the pavement surface. The moisture transport or freeze-thaw cycles can greatly increase further damage development, and lead to removal and loss of stones due to weaker bonding [99]. With all the combined damage factors, the wearing courses need to be maintained and repaired frequently.

Asphalt mixture, as a self-healing material, has limited ability to repair its own damage after placed in service [64]. There are two key factors that impact the healing process, temperature and test periods [33, 87]. Cracks developing in the asphalt mixture due to factors such as traffic loads or freeze-thaw cycles can be healed when the external activation energy is input into the system. If the energy or time is sufficient

\footnotetext{
* Part of the text was accepted in Construction and Building materials-Wang, Z., Dai, Q., Guo, S. Wang, R., Ye, M., Yap, Y. "Experimental Investigation of Physical Properties and Accelerated Sunlight-Healing Performance of Flake Graphite and Exfoliated Graphite Nanoplatelet Modified Asphalt Materials.” (2016).
} 
to complete this process, cracks could almost disappear [64]. It is concluded that the crack healing was mainly related to the Newtonian binder flow or the related creep flow of asphalt mastic through the cracks at elevated temperatures [41]. To initiate this process, the asphalt's temperature needs to be heated higher than the transition one. Then the binder behaves as a Newtonian fluid. The transition temperature level depends on the types and components of asphalt, normally in the range of $30{ }^{\circ} \mathrm{C}$ to 70 ${ }^{\circ} \mathrm{C}$ [100-103]. According to the study of Shen et al. [12], the healing behavior was a self-recovery capability of the asphalt binder which involved loading and environmental conditions. Self-healing can be considered a complex behavior, involving activation energy and capillary flow of asphalt at the micro or meso scale, and intermolecular diffusion and wetting of asphalt molecules at crack surfaces. The healing behavior is affected by the crack size, material mixture types and modification $[11,14,41]$. For example, Qiu et al. [11] showed that the healing ability of asphalt mastic modified by Styrene-Butadiene-Styrene polymer has been weakened compared to the unmodified control asphalt mastic.

The visible/near-field infrared lights are considered to be a type of easily obtained solar energy. The energy could be potentially used to heat and heal microcracks in the surface layer of pavement. However, the light absorption and thermal conductivity of asphalt mixture are relatively low $[104,105]$. Currently there is no effective method to employ the light energy (specifically the near-field infrared light energy) directly. Therefore, graphite materials that have the ability to increase the light absorbance and thermal conductivity of composites are necessary to be combined with asphalt mixture. 
Kim et al. [106] found that exfoliated graphite nanoplatelets (xGNP) can be used to improve the thermal conductivity of the material as an effective heat-diffusion promoter. In a study by Liu et al. [107], it was concluded that the manufactured flake graphite has high thermal conductivity through the graphite layers. Luo and Lloyd [108] found that the thermal energy transport in graphite-polymer was affected by graphite particle size and the graphite-matrix, interfacial bonding strength.

Graphite, as a super thermal conductor that can be applied in an asphalt mixture and pavement study, has attracted the interest of many researchers. Wu et al. [109] utilized asphalt mixtures within microcrystal graphite powders to collect solar energy for the heating and cooling of buildings and to keep the pavements ice-free. A study by Chen et al. [110] found that graphite powders could improve the thermal conductivity of asphalt mixtures and be a better method to counteract problems that arise from snow. Wang et al. [111] employed a finite element model to predict the thermal response of asphalt pavements with added graphite conductive media. Pan et al. [112] concluded that the thermal conductivity and diffusivity of graphite asphalt increased with the added graphite. In this research, two types of graphite materials, flake graphite and exfoliated graphite nanoplatelets were used as mixture modifiers to improve the visible/near-field infrared light healing effects.

The digital image correlation (DIC) is an effective optical technique that measures the full-field surface deformation of sample [113]. Essentially, two digital images are compared by DIC, one is the reference image regarded as an undeformed case and the other is the deformed image. The DIC algorithm could detect the two locations of one 
selected point (pixel) in the reference image and in the deformed image by matching the gray value of that point. Afterwards, the displacement (pixels) of the selected point can be calculated [114]. Some researchers have put efforts to use the DIC techniques in civil engineering, e.g., Kuntz et al. [115] utilized digital image cross-correlation to measure the displacement of a shear crack in a reinforced concrete beam during a bridge load test. Chehab et al. [116] studied the fracture process zone strains of asphalt mixtures by DIC. Rastiello et al. [117] established the relationship between the crack surface and the mid-height crack opening displacement using DIC techniques.

This research aims to evaluate the sunlight heating and accelerated self-healing performance of graphite modified asphalt binder. In the first place, flake graphite and exfoliated graphite nanoplatelets (xGNP) were added into asphalt with weight percentages for preparing the graphite modified asphalt binder. Then asphalt binder tests were conducted to evaluate the performance of graphite modified asphalt, including rotational viscosity, light absorbance, low temperature property, complex shear modulus, aging group analysis and thermal conductivity.

\subsection{Control and graphite modified asphalt binder preparation}

In this research, five types of asphalt samples were prepared, including the control asphalt (PG 58-28), exfoliated graphite nanoplatelets (xGNP) modified asphalt (2\% and $4 \%$ by binder weight) and flake graphite modified asphalt (5\% and $7 \%$ by binder weight), respectively. The flake graphite was obtained from Asbury Carbons with a density of $2.25 \mathrm{~g} / \mathrm{cm}^{3}$. The particle sizes of flake graphite focus on two meshes, No.100 (75\%) and No.200 (25\%). The minimum layer thickness is $0.11 \mathrm{~mm}$. The xGNP was 
manufactured by XG Sciences with a bulk density of $0.03-0.1 \mathrm{~g} / \mathrm{cm}^{3}$, particle diameter of 25 microns and an average thickness of approximately 15 nanometers. The flake graphite or xGNP graphite modifiers were added into control asphalt based on selected weight percentages and mixed by a high speed mixer at $120{ }^{\circ} \mathrm{C}$ for about $1 \mathrm{hr}$. The prepared and control asphalt binder were used for following binder performance tests.

\subsection{Asphalt binder tests and property measurement}

\subsubsection{Viscosity measurement and activation energy calculation}

The viscosity as a basic rheological property of control and graphite modified asphalt samples was measured by a BROOKFIELD MODEL DV-II viscometer. The measured viscosity results of control, $5 \%$ flake graphite modified and $2 \%$ xGNP modified asphalt are exhibited in Figure 5.1 (a). The testing temperatures were selected as $100{ }^{\circ} \mathrm{C}, 125^{\circ} \mathrm{C}, 135^{\circ} \mathrm{C}, 150^{\circ} \mathrm{C}$, and $175^{\circ} \mathrm{C}$, separately. It can be observed that the $2 \%$ xGNP modified asphalt has a higher viscosity than the $5 \%$ flake graphite modified asphalt. The viscosity of the control asphalt is lower than those of the $2 \%$ xGNP and $5 \%$ flake graphite modified asphalt. 


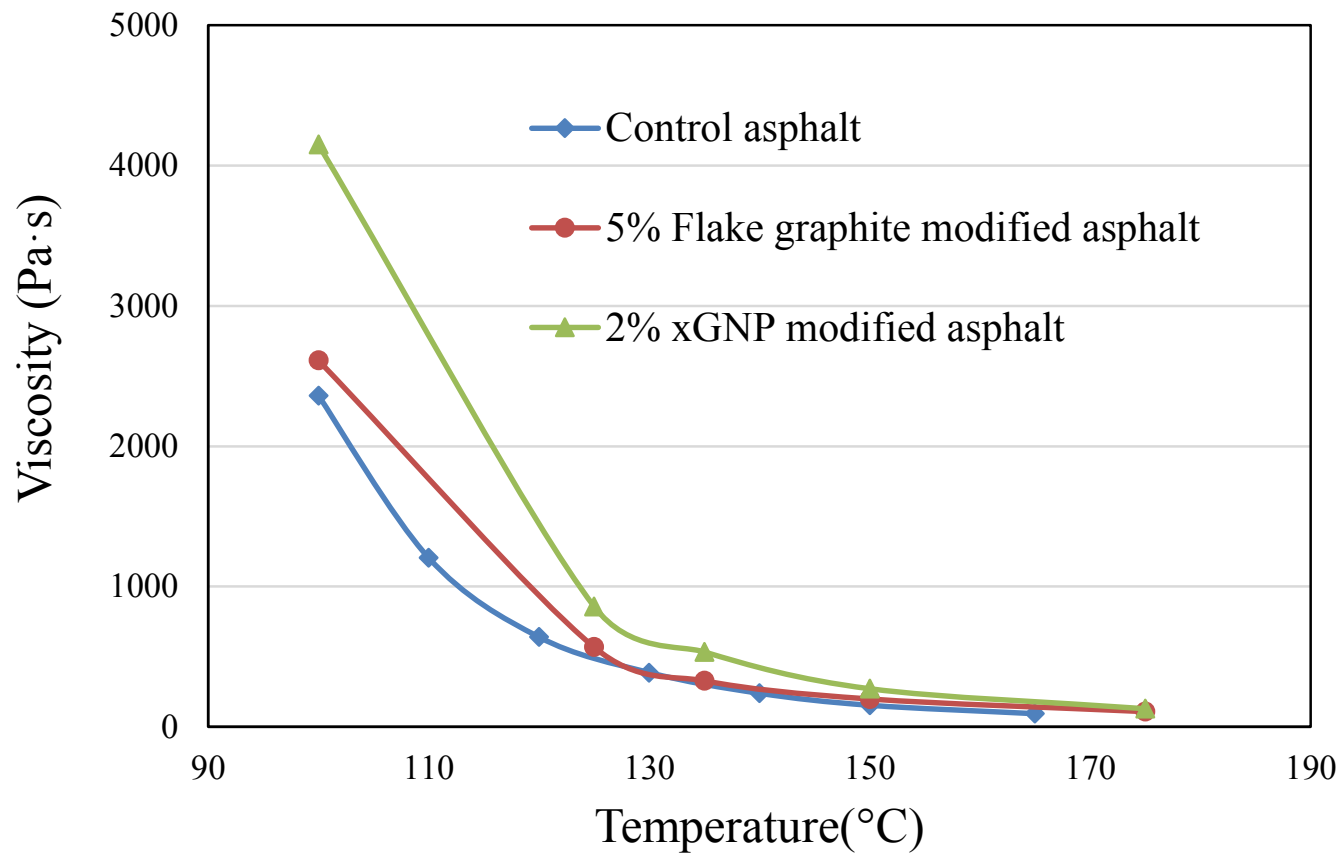

(a)

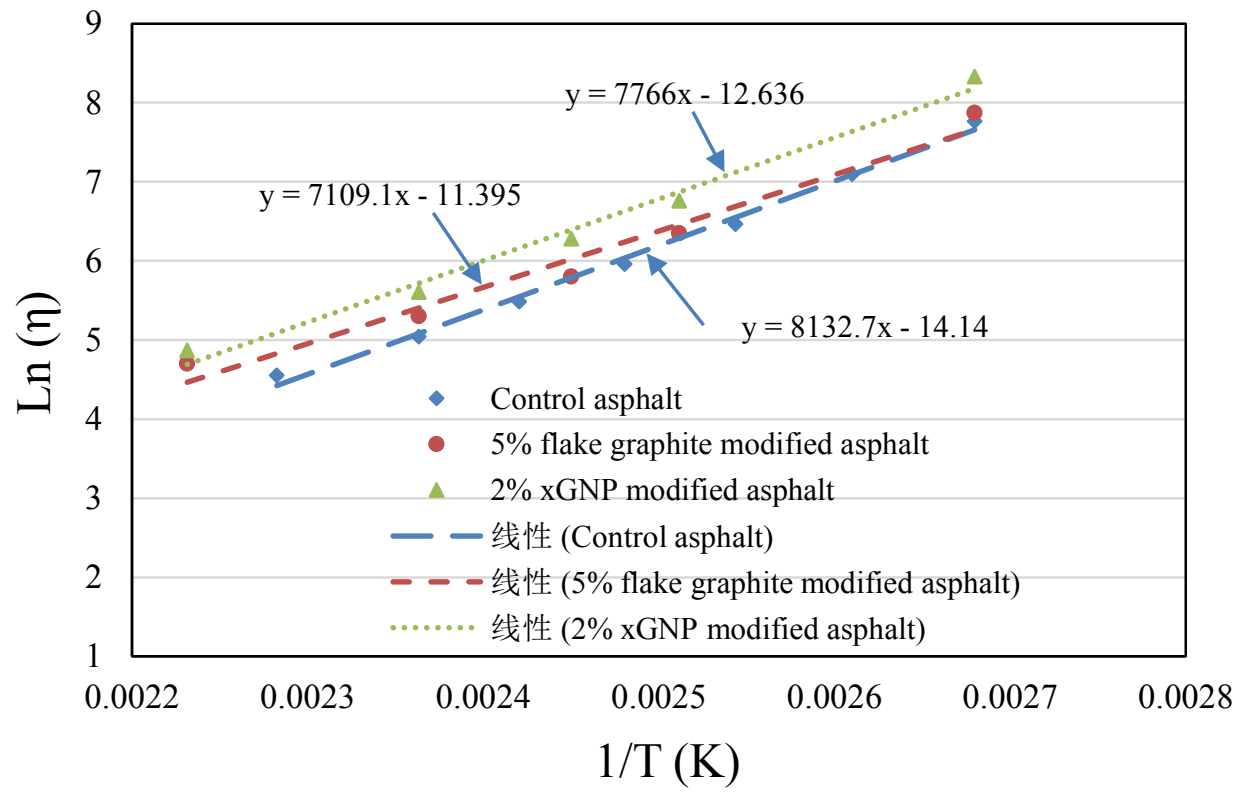

(b) 


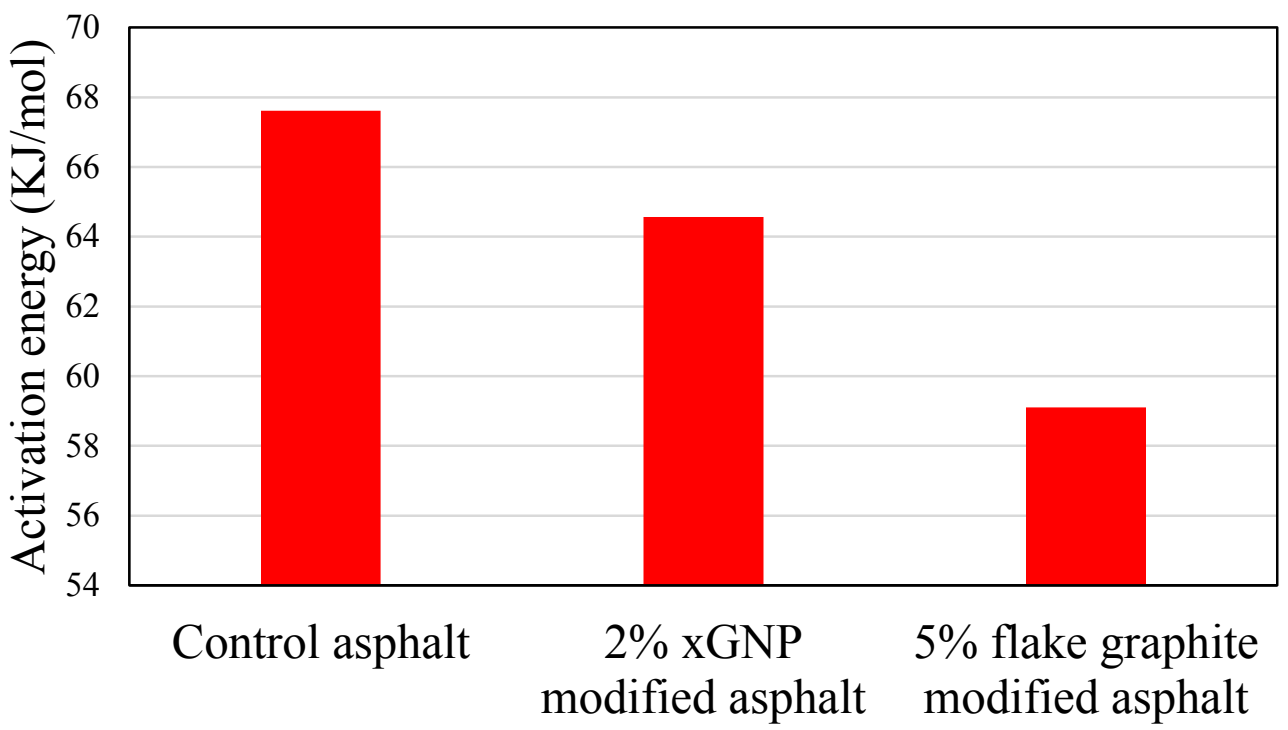

(c)

Figure 5. 1 Viscosities and activation energies of control asphalt, flake graphite modified asphalt and xGNP modified asphalt: (a) viscosities; (b) regression between $\ln$ $\eta$ and $1 / \mathrm{T} ;(\mathrm{c})$ activation energies.

The concept of an activation energy barrier for starting viscous liquid flow was used [118]. The viscous flow process can be considered as a thermal process where atoms, molecules and groups of molecules should overcome an energy barrier to move [119]. The asphalt self-healing process was regarded as a viscous Newtonian flow process in this study. Therefore, the activation energy was used to evaluate the healing performance of control asphalt, 5\% flake graphite modified asphalt and 2\% xGNP modified asphalt. It was calculated by the Arrhenius equation [120] shown in Equation $(5-1)$

$\eta=A e^{\frac{E_{f}}{R T}}$ 
where $\eta$ is the viscosity of asphalt, $A$ is a constant, $E_{f}$ indicates the activation energy, $T$ is the temperature in $K$, and $R$ denotes the universal gas constant (8.314 $\mathrm{J} /(\mathrm{mol} \cdot \mathrm{K}))$. Normally, the Arrhenius equation is written as Equation (5-2) to simplify the calculation

$$
\ln \eta=E_{f} / R T+\ln A
$$

The relation between $\ln \eta$ and $1 / T$ is displayed in Figure 5.1 (b). Then the discrete test data was regressed linearly to obtain the slope for each line. It was observed that the slope of the control asphalt line is 8477.4 , the slopes of the $5 \%$ flake graphite modified asphalt line and 2\% xGNP modified asphalt line are 7109.1 and 7766 , respectively. The activation energy was calculated with the multiplication of the regression slope and the universal gas constant as in Equation (5-2). Hence, the activation energies of the control asphalt, 5\% flake graphite modified asphalt and 2\% $\mathrm{xGNP}$ modified asphalt are calculated as $67.6 \mathrm{KJ} / \mathrm{mol}, 59.1 \mathrm{KJ} / \mathrm{mol}$, and $64.6 \mathrm{KJ} / \mathrm{mol}$ respectively. Compared with the control asphalt, the activation energy of the flake graphite modified asphalt and the xGNP modified asphalt both decreased. Thus, it is concluded that the graphite modified asphalt can generate viscous flow with less energy absorption.

\subsubsection{Light absorbance measurement}

Since infrared light accounts for $50 \%$ of sunlight and is reflected back to the atmosphere as a contributor of global warming effects, the absorption of infrared light by graphite modified asphalt can accelerate self-healing of pavement materials with renewable solar energy inputs. It can also potentially reduce the heat island through 
surface to base layers of pavement by transferring more heat. Therefore, the visible/infrared light absorption test was implemented to evaluate the light energy absorption and accelerated self-healing performance of control and graphite modified asphalt. The light absorbance was calculated using Equation (5-3)

$$
A=\log _{10}\left(\frac{\phi_{e}^{i}}{\phi_{e}^{t}}\right)=-\log _{10} T
$$

where $A$ indicates the absorbance (a.u.), $\phi_{e}^{i}$ is the radiant flux received by the sample, $\phi_{e}^{t}$ is the radiant flux transmitted by the sample, $T$ denotes the transmittance of the sample. Figure 5.2 exhibits the schematic demonstration of the light absorbance test of the asphalt binder. First of all, the control asphalt, 5\% flake graphite modified asphalt and $2 \% \times$ GNP modified asphalt were daubed on glass substrates to prepare the samples. Then the samples were placed inside the test machine, UV-1800 Spectrophotometer. Figure 5.3 displays the test results of three different samples. It is observed that the wavelength range of testing light is from $300 \mathrm{~nm}$ to $1100 \mathrm{~nm}$ (visible spectrum: $300 \mathrm{~nm}$ $\sim 750 \mathrm{~nm}$, infrared spectrum: $750 \mathrm{~nm} \sim 1100 \mathrm{~nm}$ ). When the wavelength of the testing light exceeds $670 \mathrm{~nm}$, the light absorbance of control asphalt decreases to $0.512 \mathrm{a}$.u. monotonously corresponding to the wavelength of $1100 \mathrm{~nm}$. Similarly, the light absorbance of 2\% xGNP modified asphalt starts to decrease from 4.0 a.u. to 1.364 a.u. when the wavelength of testing light exceeds $700 \mathrm{~nm}$. The light absorbance of $5 \%$ flake graphite modified asphalt declines from 4.0 a.u. to 1.903 a.u. while the wavelength of testing light exceeds $860 \mathrm{~nm}$. 


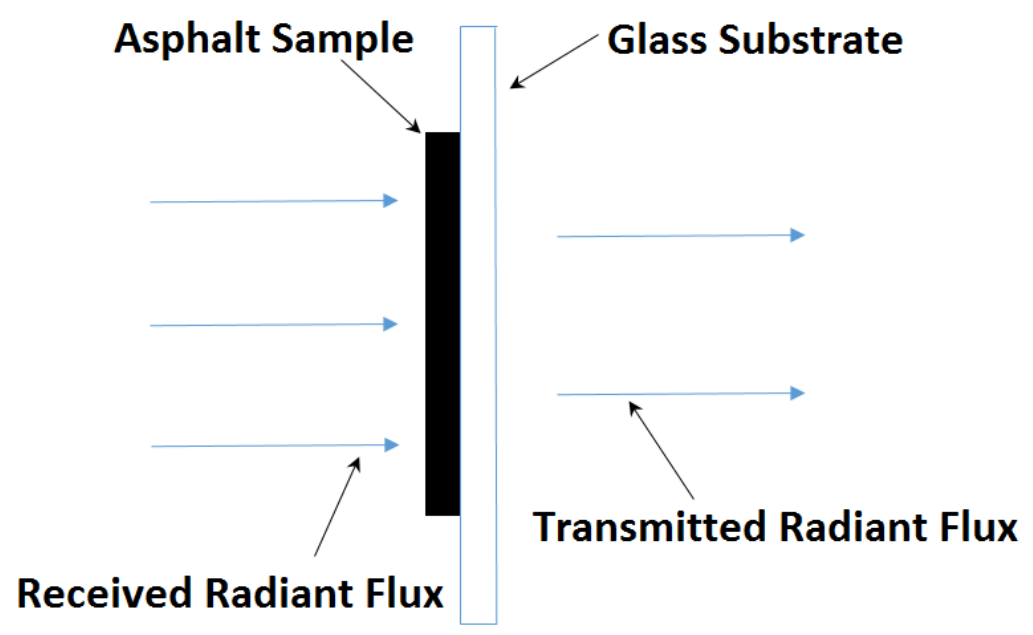

Figure 5. 2 Demonstration of light absorbance test of asphalt binder on glass substrate.

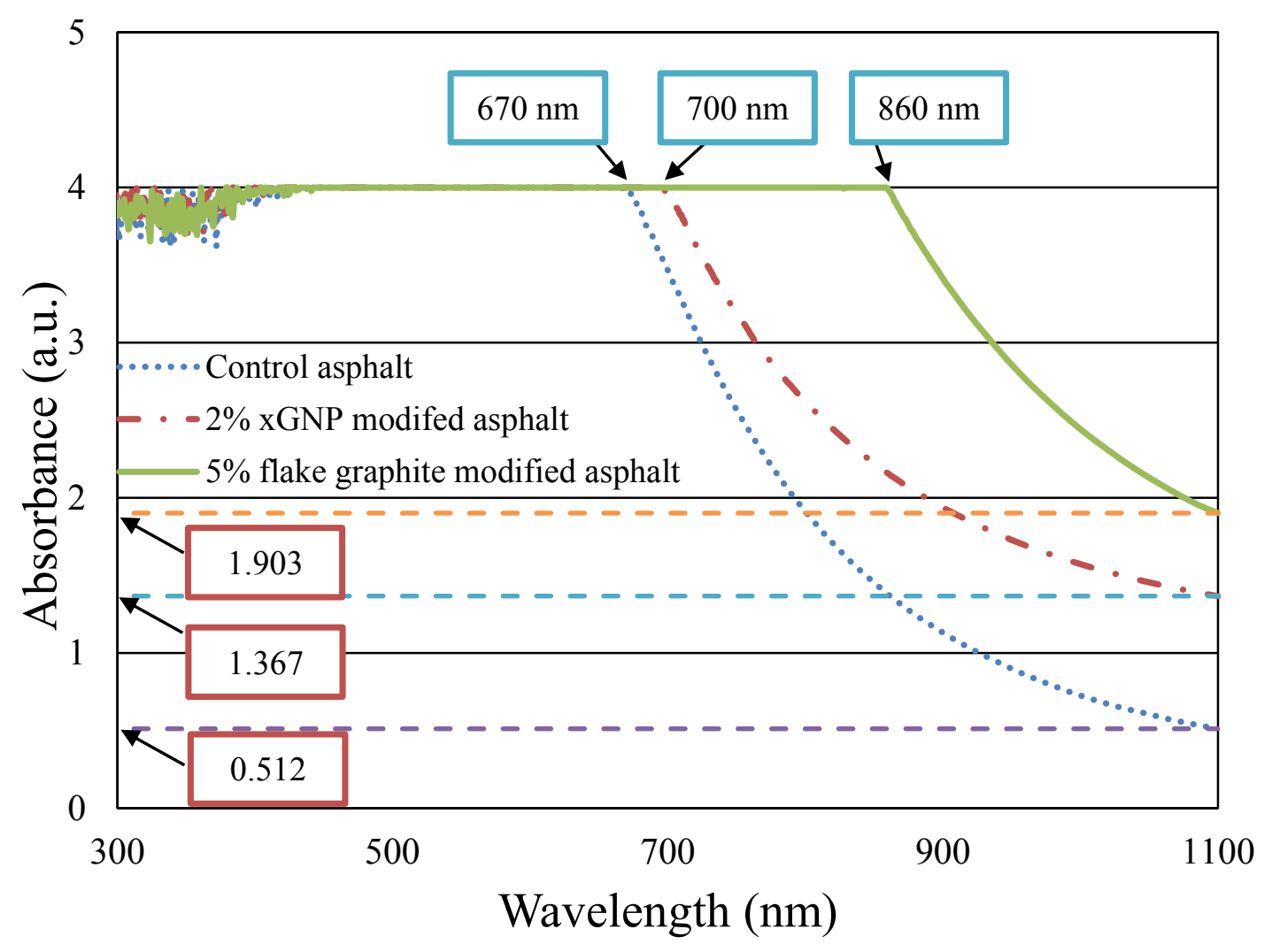

Figure 5. 3 Light absorption of control asphalt, flake graphite modified asphalt and xGNP modified asphalt. 
The ratio of absorbed radiant flux is defined as the difference of the received radiant flux and transmitted radiant flux divided by the received radiant flux, displayed in Equation (5-4)

$$
R_{a}=\frac{\phi_{e}^{i}-\phi_{e}^{t}}{\phi_{e}^{i}}
$$

where $R_{a}$ is the ratio of the absorbed radiant flux Consequently, the ratio of the absorbed radiant flux of the control asphalt is $69.2 \%$ when the wavelength of testing light is $1100 \mathrm{~nm}$ calculated by Equation (4). Likewise, the ratios of absorbed radiant flux of 5\% flake graphite modified asphalt and 2\% xGNP modified asphalt are $98.7 \%$ and $95.7 \%$ respectively. Therefore, the graphite materials can greatly enhance the light absorption ability of asphalt, especially the infrared light absorption ability of asphalt. In addition, the $5 \%$ flake graphite modified asphalt has better light absorbance than $2 \%$ xGNP modified asphalt.

\subsubsection{Bending beam rheometer test}

The low temperature property of graphite modified asphalt binder was evaluated by bending beam rheometer (BBR) test. The control, flake graphite modified (5\% and $7 \%$ by binder weight), xGNP modified ( $2 \%$ and $4 \%$ by binder weight) after the rolling thin-film oven (RTFO) testand pressure aging vessel (PAV) test were cast into a mold to make asphalt binder beams with a dimension of $101.6 \mathrm{~mm} \times 12.7 \mathrm{~mm} \times 6.35 \mathrm{~mm}$. The stiffness and $\mathrm{m}$-value of the beam were measured by applying a loading on the top center with testing temperature of $-18{ }^{\circ} \mathrm{C}$. Figure 5.4 and Figure 5.5 display the relationship between the testing time and stiffness of control, $5 \%$ and $7 \%$ flake graphite 
modified, $2 \%$ and 4\% xGNP modified asphalt binders, respectively. It is observed that the graphite materials could increase the stiffness of asphalt binder. The stiffness increases with the rising up of content of graphite materials. The obtained stiffnesses and m-values of the control and graphite modified asphalt binder at $60 \mathrm{~s}$ during the test are listed in Table 5.1 based on Superpave standard. It is seen that all the stiffnesses of graphite modified binders increase compared with control asphalt binder. In addition, all the m-values of graphite modified binders decrease compared with control asphalt binder. Based on the Superpave standard, the stiffness value should not exceed 300 $\mathrm{MPa}$ and the minimum m-value is 0.3 . Therefore, the graphite materials could decrease the low temperature property of asphalt. The content of xGNP can not go up to $4 \%$ of the asphalt by weight.

Table 5. 1 Stiffness and m-value of control 58-28, flake graphite modified asphalt at $60 \mathrm{~s}$.

\begin{tabular}{|l|l|l|l|l|l|}
\hline Asphalt & Control & $5 \%$ flake & $7 \%$ flake & $2 \%$ xGNP & $4 \%$ xGNP \\
& $58-28$ & graphite & graphite & modified & modified \\
& & modified & modified & & \\
\hline Stiffness(MPa) & 117 & 244 & 275 & 223 & 324 \\
\hline m-value & 0.481 & 0.332 & 0.310 & 0.325 & 0.305 \\
\hline
\end{tabular}




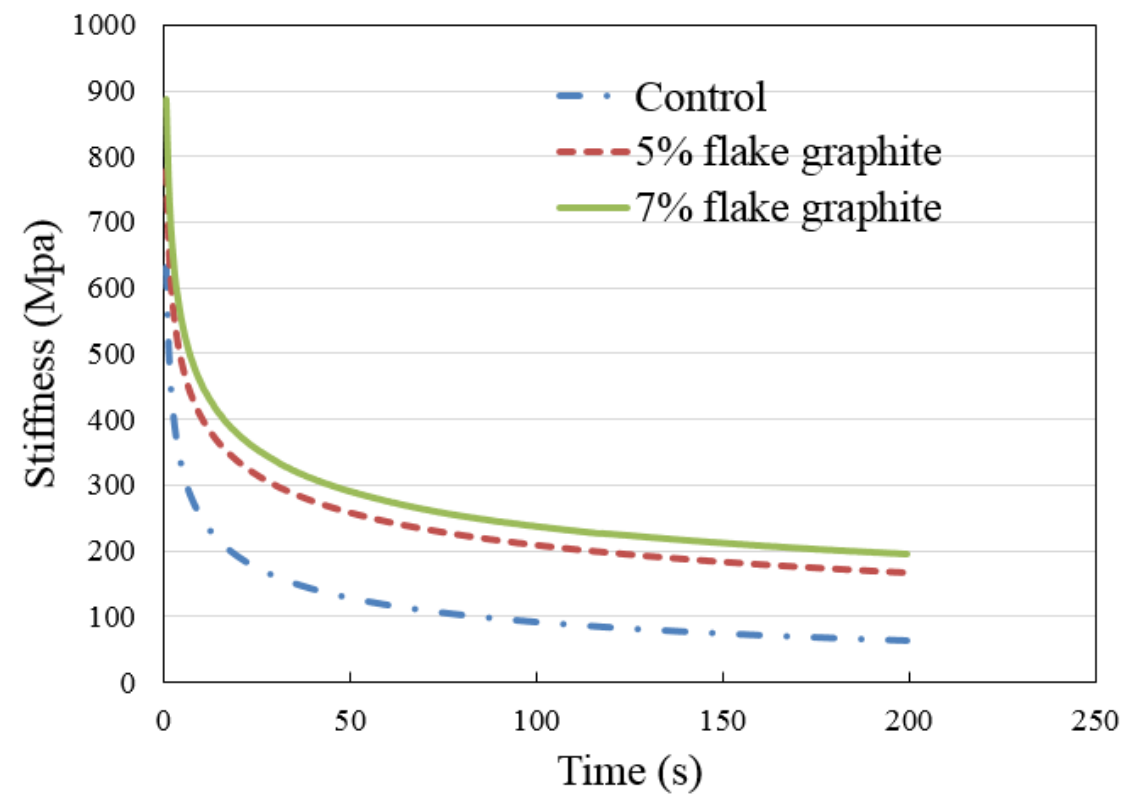

Figure 5. 4 Bending beam rheometer test data of control, 5\% flake graphite modified and $7 \%$ flake graphite modified asphalt.

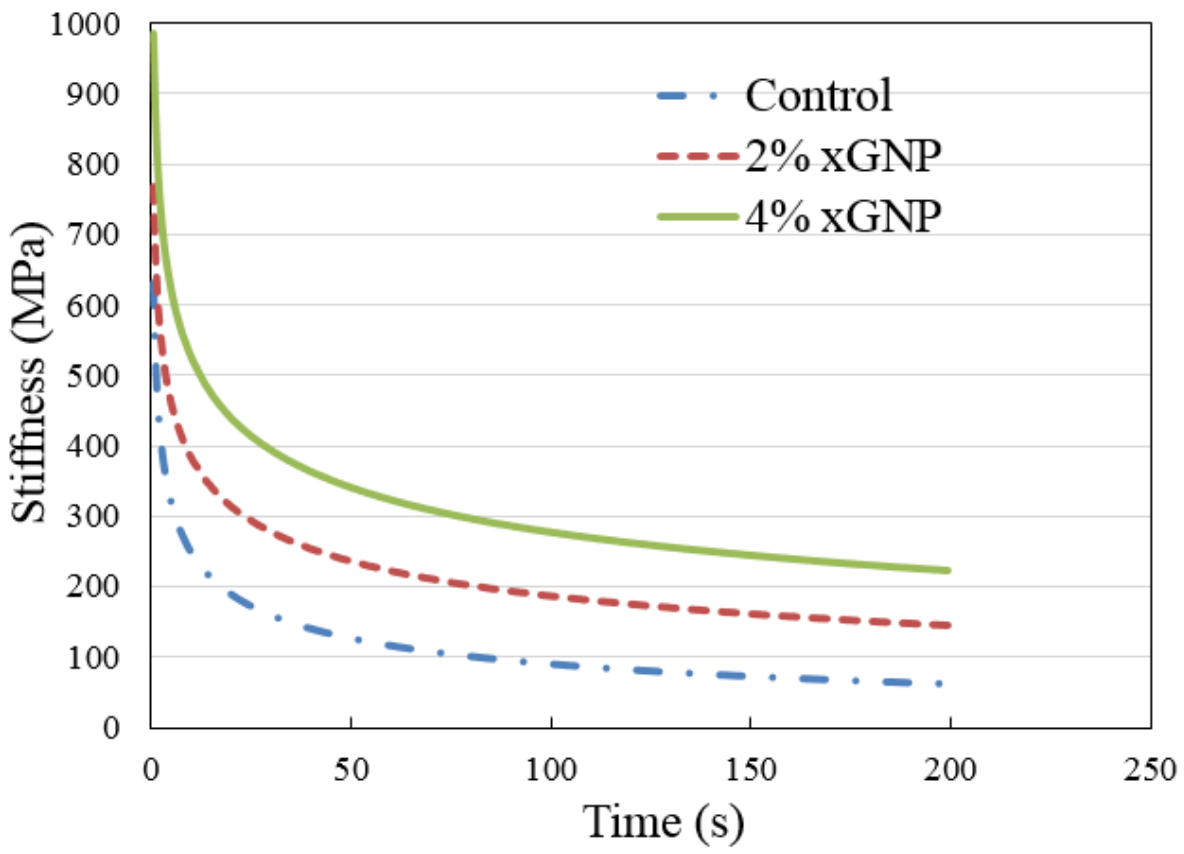

Figure 5. 5 Bending beam rheometer test data of control, $2 \% x G N P$ modified and $4 \%$ xGNP modified asphalt. 


\subsubsection{Complex shear modulus test}

A dynamic shear rheometer (DSR) was used to investigate the complex shear modulus of the control and graphite modified asphalt binders. The complex shear modulus described the resistance of the tested asphalt binder to the deformation induced by the shear force. In this study, all the tested asphalt binders were divided to three groups, including virgin asphalt binder, RTFO asphalt binder and PAV asphalt binder. In each group, it has the control and graphite modified asphalt binders. The test temperatures were selected as $46{ }^{\circ} \mathrm{C}, 52{ }^{\circ} \mathrm{C}, 58{ }^{\circ} \mathrm{C}, 64^{\circ} \mathrm{C}$, and $70{ }^{\circ} \mathrm{C}$, respectively. The test frequencies were $0.01 \mathrm{~Hz}, 0.1 \mathrm{~Hz}, 1 \mathrm{~Hz}, 5 \mathrm{~Hz}, 10 \mathrm{~Hz}$, and $25 \mathrm{~Hz}$, separately. Figure 5.6 to 5.11 show the master curves of control and graphite modified asphalt, describing the relationships between the complex shear modulus and reduced frequency. Figure 5.6 shows the master curves of complex shear moduli of virgin control, $5 \%$ flake graphite modified and $7 \%$ flake graphite modified asphalt. It is observed that the graphite could increase the shear resistance of asphalt slightly and the $7 \%$ of flake graphite could increase the shear modulus better than the $5 \%$ of flake graphite. 


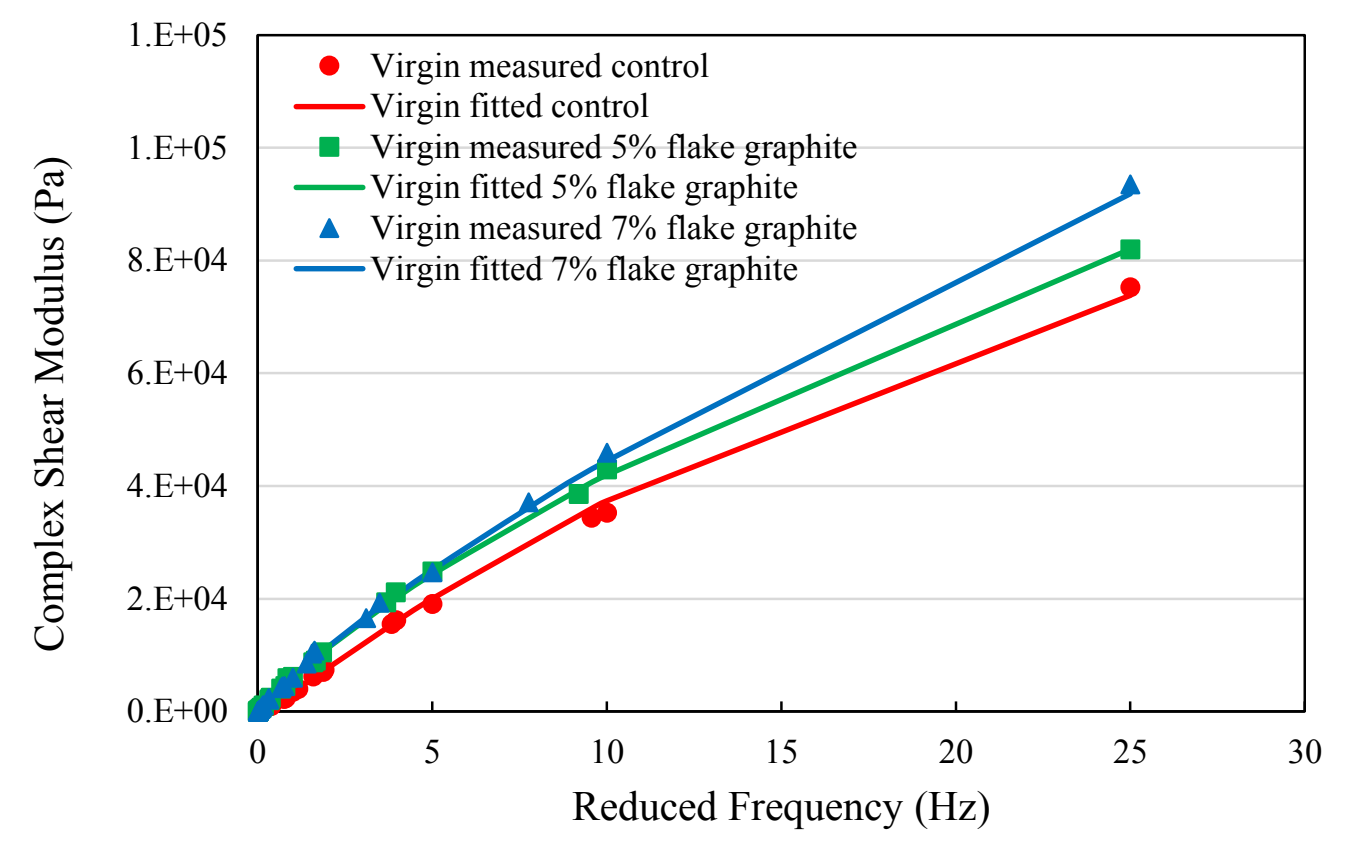

Figure 5. 6 Complex shear modulus master curves of virgin control and flake graphite modified asphalt.

Figure 5.7 displays the complex shear modulus master curves of control, $5 \%$ flake graphite modified, 7\% flake graphite modified asphalt after RTFO test. It is seen that the flake graphite could increase the shear modulus of RTFO asphalt. However, the shear modulus of 5\% flake graphite modified RTFO asphalt is higher than that of 7\% flake graphite modified RTFO asphalt. It is concluded that two much flake graphite has a negative effect on modifying the RTFO asphalt shear resistance property. The shear modulus of flake graphite modified asphalt binder is contributed to the shear force between the asphalt molecules and the flake graphite. If the content of flake graphite is too high, the effect of shear forces between the flake graphites increase so that the shear modulus of the modified asphalt binder decrease. Figure 5.8 shows the complex shear modulus master curves of control, $5 \%$ flake graphite modified, $7 \%$ flake graphite 
modified asphalt after PAV test. The flake graphite could increase the shear modulus of PAV asphalt as well. In addition, the shear modulus of $5 \%$ flake graphite modified PAV asphalt is higher than that of $7 \%$ flake graphite modified PAV asphalt with the same trend of flake graphite modified RTFO asphalt.

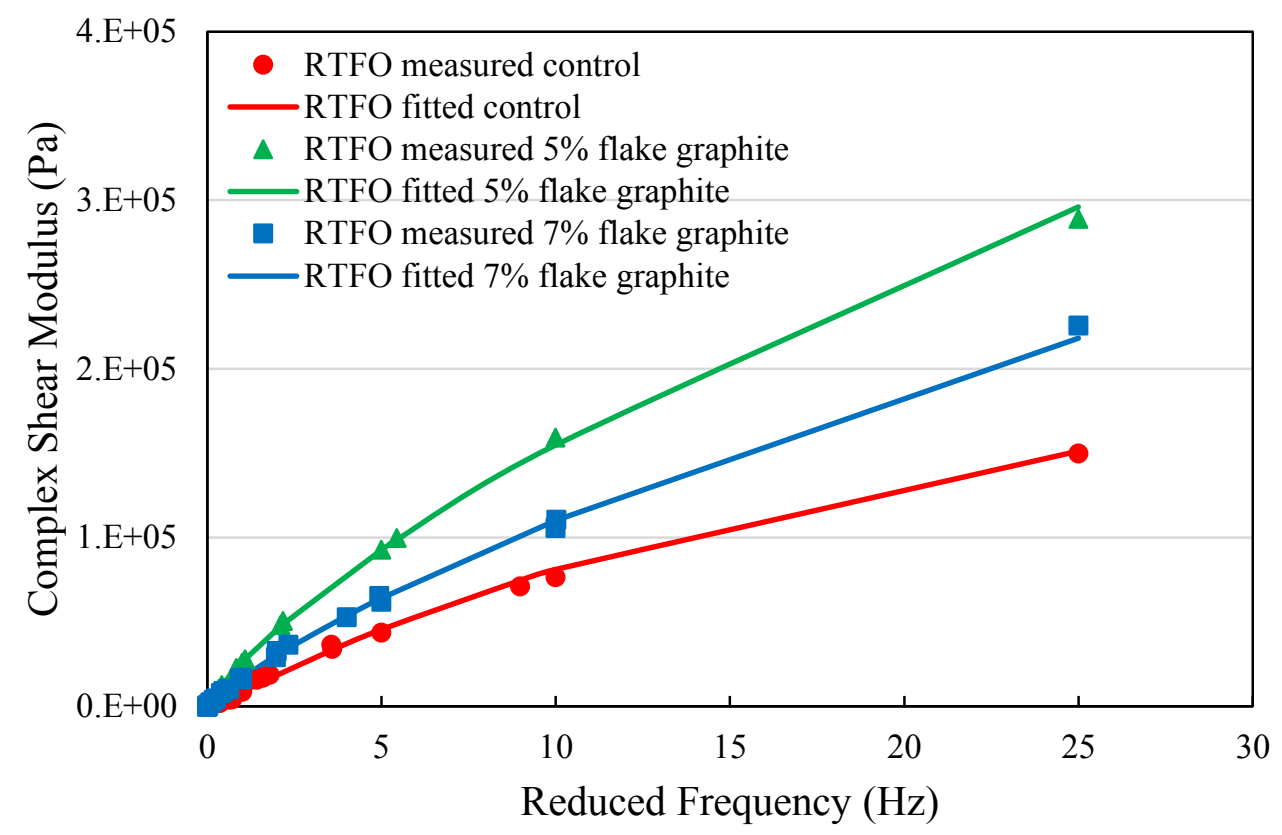

Figure 5. 7 Complex shear modulus master curves of RTFO control and flake graphite modified asphalt. 


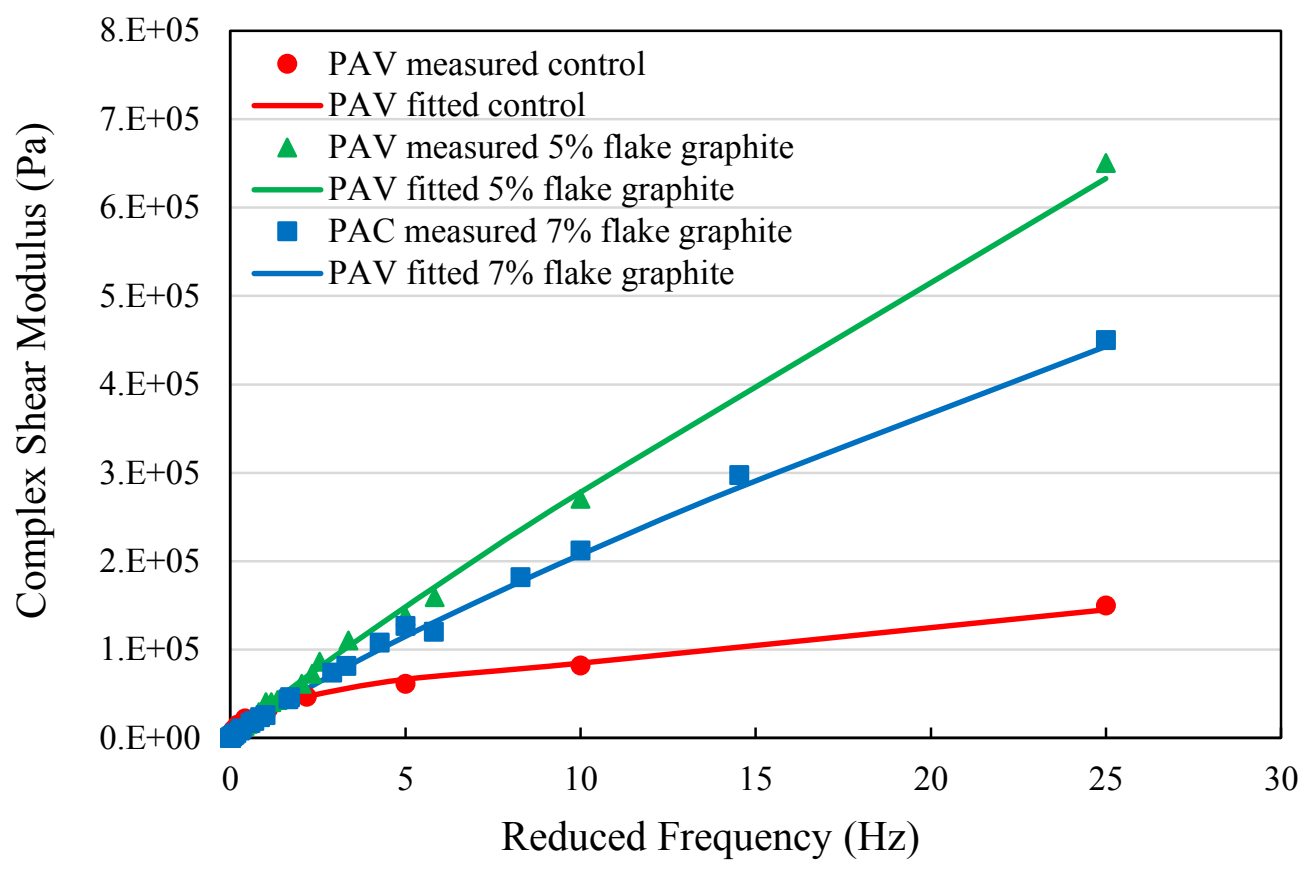

Figure 5. 8 Complex shear modulus master curves of PAV control and flake graphite modified asphalt.

Figure 5.9 exhibits the complex shear modulus mater curves of virgin control, 2\% xGNP modified and 4\% xGNP modified asphalt. It can be observed that the xGNP has the ability to increase the shear resistance of virgin asphalt. The shear modulus of $4 \%$ xGNP modified virgin asphalt is higher than that of $2 \% x$ GNP modified virgin asphalt. Therefore, the xGNP could increase the shear modulus of virgin asphalt. Figure 5.10 and 5.11 show the complex shear modulus master curves of RTFO and PAV control, 2\% xGNP modified and 4\% xGNP modified asphalt binders. It is seen that xGNP could increase the shear force resistance of RTFO and PAV asphalt binders. The complex shear modulus of $4 \% \mathrm{xGNP}$ modified virgin asphalt is higher than that of $2 \% \mathrm{xGNP}$ modified virgin asphalt. 


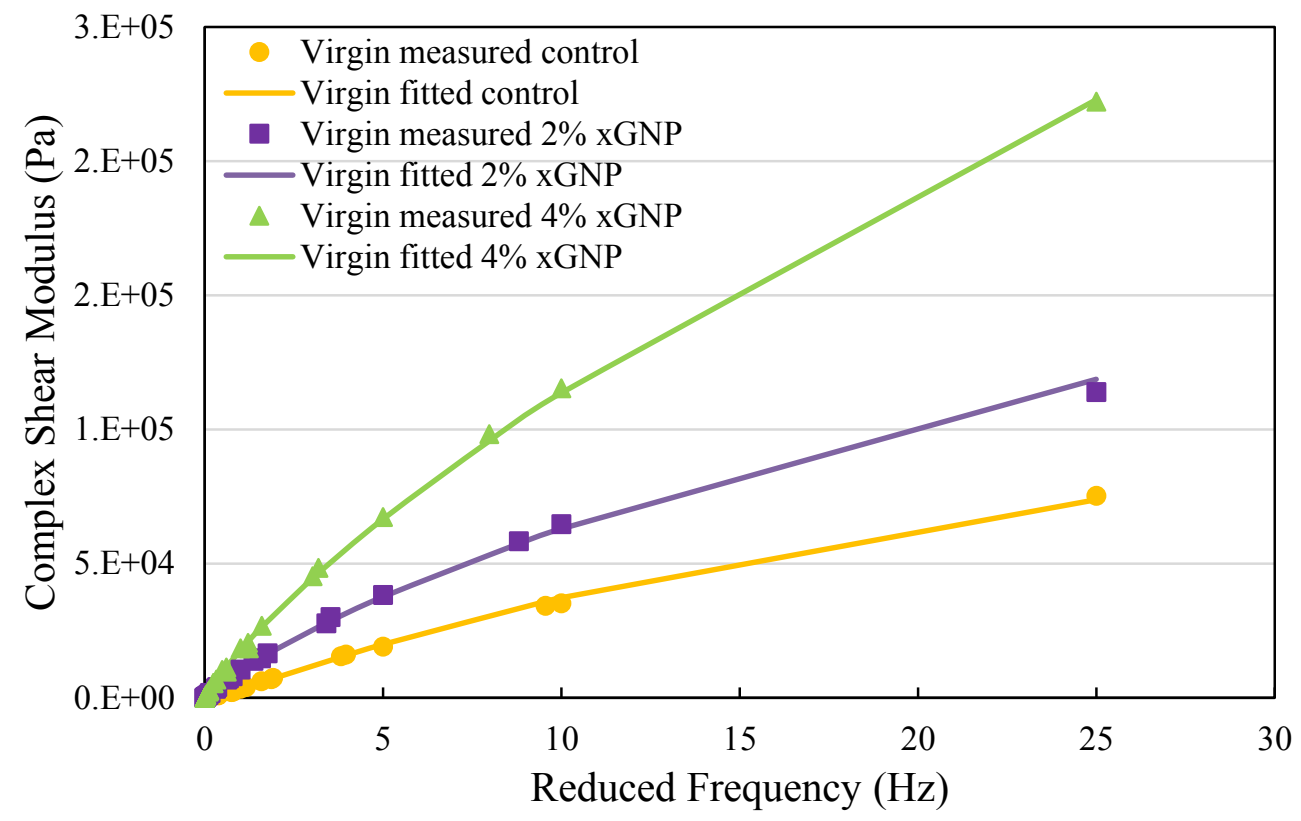

Figure 5.9 Complex shear modulus master curves of virgin control and xGNP modified asphalt.

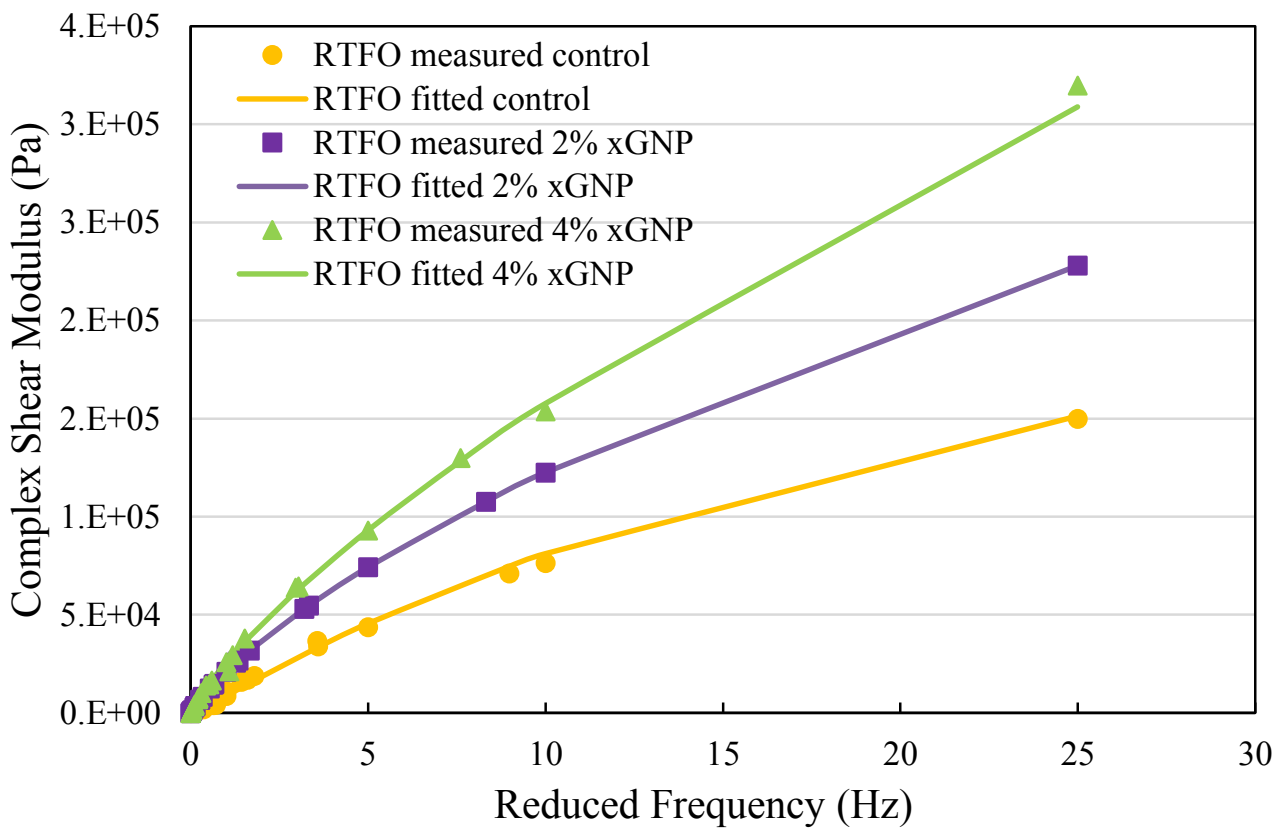

Figure 5. 10 Complex shear modulus master curves of RTFO control and xGNP modified asphalt. 


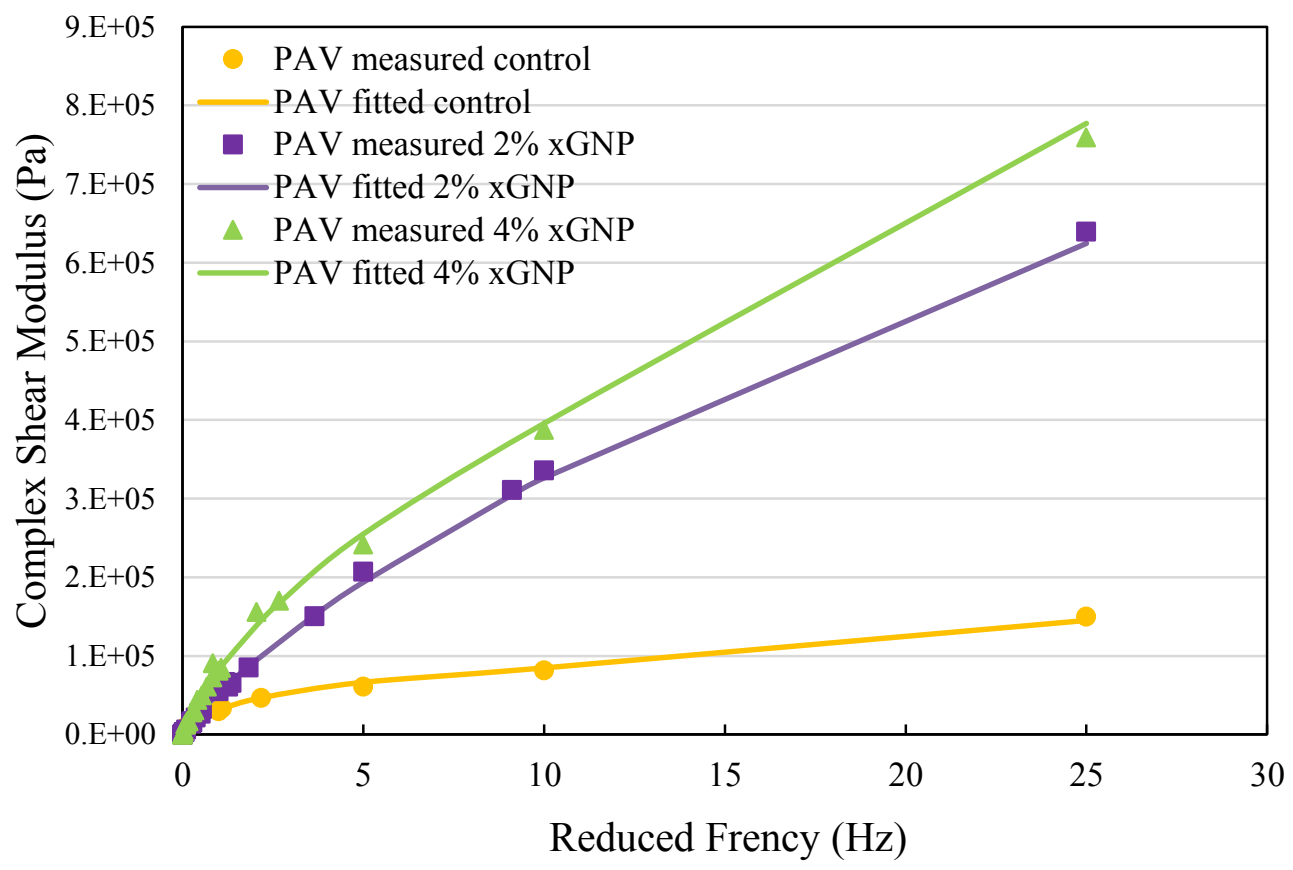

Figure 5. 11 Complex shear modulus master curves of PAV control and xGNP modified asphalt.

\subsubsection{Aging group analysis}

The aging behavior of asphalt is a very important index to reflect the resistance to the moisture sensitivity and rutting $[121,122]$. Hence, it is necessary to study how the graphite materials affect the aging level of asphalt binder. In this research, the Fourier transform infrared spectroscopy (FTIR) was utilized to obtain the spectrum of light absorption of control and graphite modified asphalt binders. First, all the tested asphalt samples were daubed on glass substrates. Then they were scanned with a resolution of $4 \mathrm{~cm}^{-1}$. Afterward, the raw data were processed by Fourier transform to obtain the final spectrum, displaying the relationship of wavenumber and absorbance. Figure 5.12 shows the FTIR results of the virgin control and virgin flake graphite modified asphalt binders. The main aging groups in asphalt are carbonyl $(\mathrm{C}=\mathrm{O})$ bond and sulfoxide 
$(\mathrm{S}=\mathrm{O})$ bond. The wavenumber peaks of $1700 \mathrm{~cm}-1$ and $1030 \mathrm{~cm}-1$ represent the carbonyl and sulfoxide bonds[2, 123], respectively.

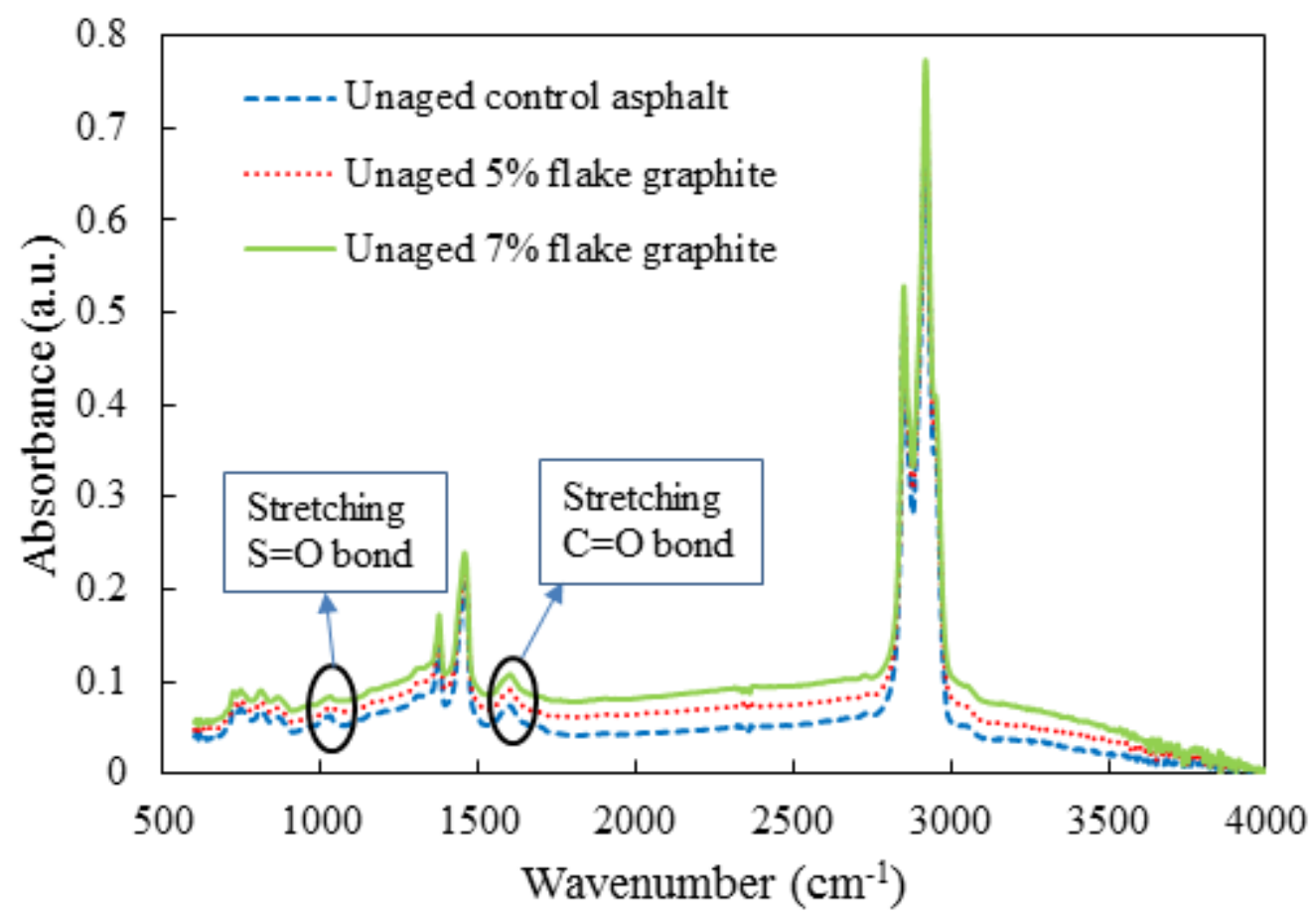

Figure 5.12 FTIR results of virgin control and flake graphite modified asphalt.

In this research, the carbonyl bond and sulfoxide bond of control and graphite modified asphalt were both tested by FTIR. Figure 5.13 and Figure 5.14 show the FTIR results of control and flake graphite modified RTFO and PAV asphalt, respectively. Figure 5.15, Figure 5.16 and Figure 5.17 exhibit the FTIR results of control and xGNP modified virgin, RTFO and PAV asphalt, respectively. 


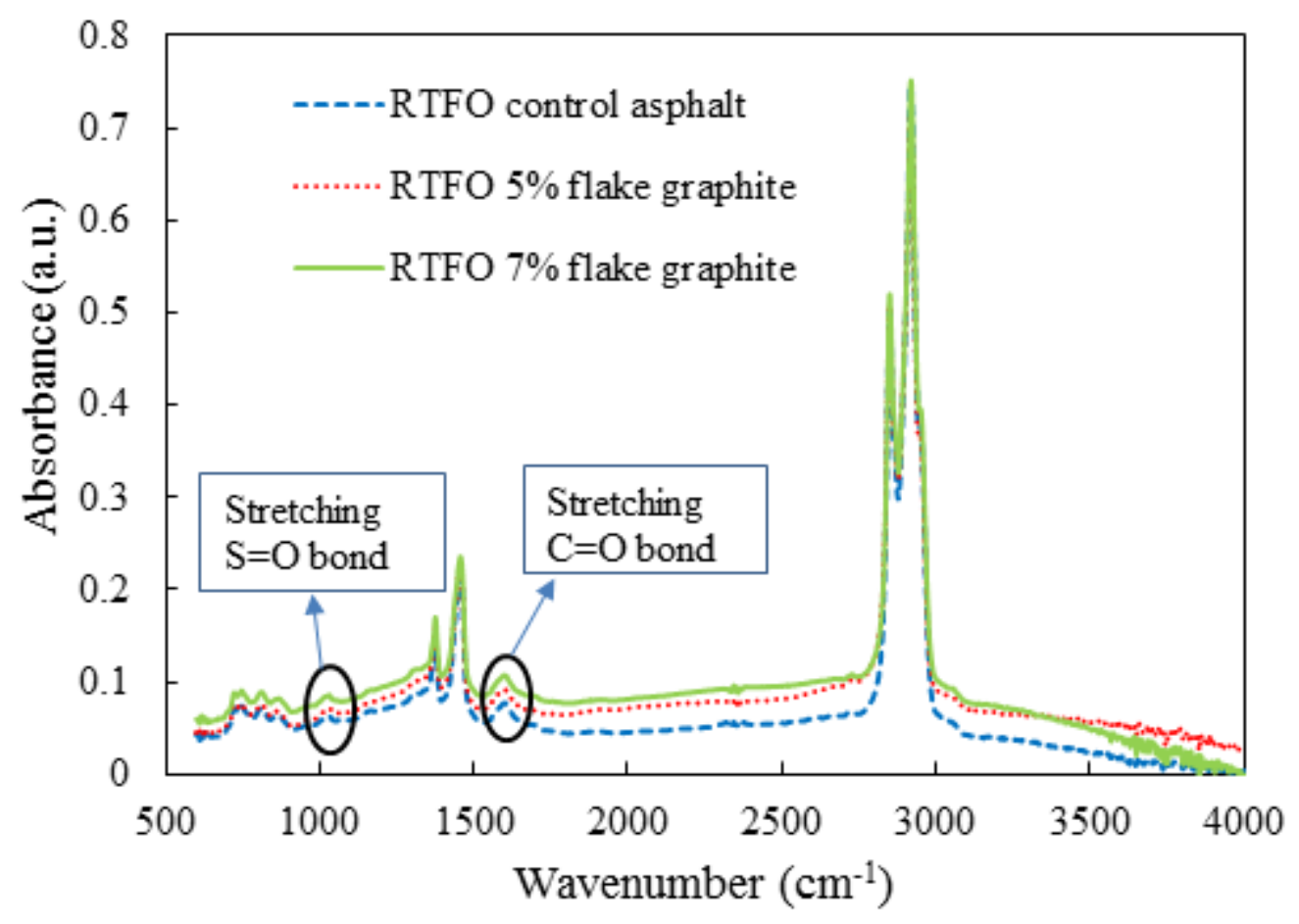

Figure 5. 13 FTIR results of RTFO control and flake graphite modified asphalt.

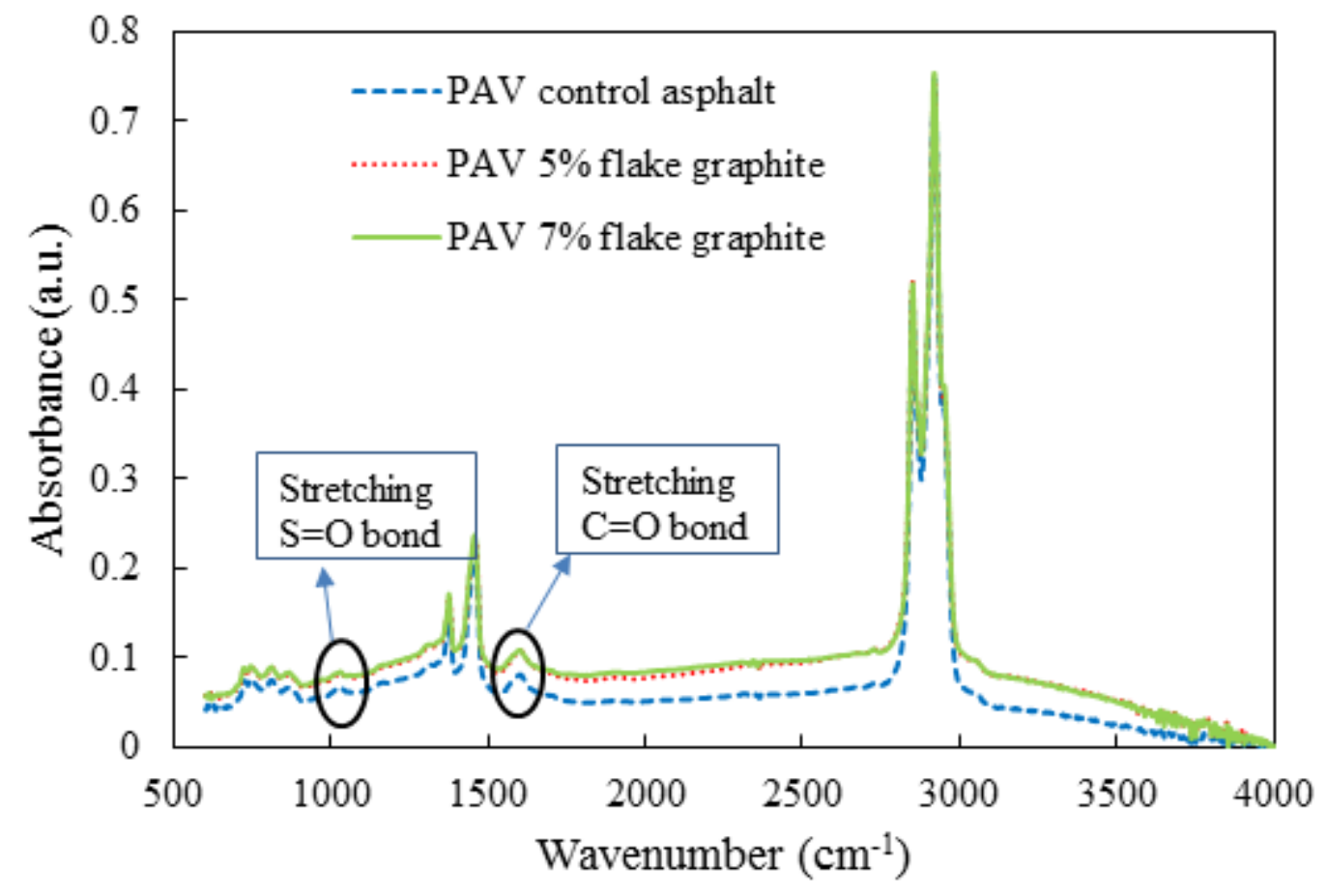

Figure 5. 14 FTIR results of PAV control and flake graphite modified asphalt. 


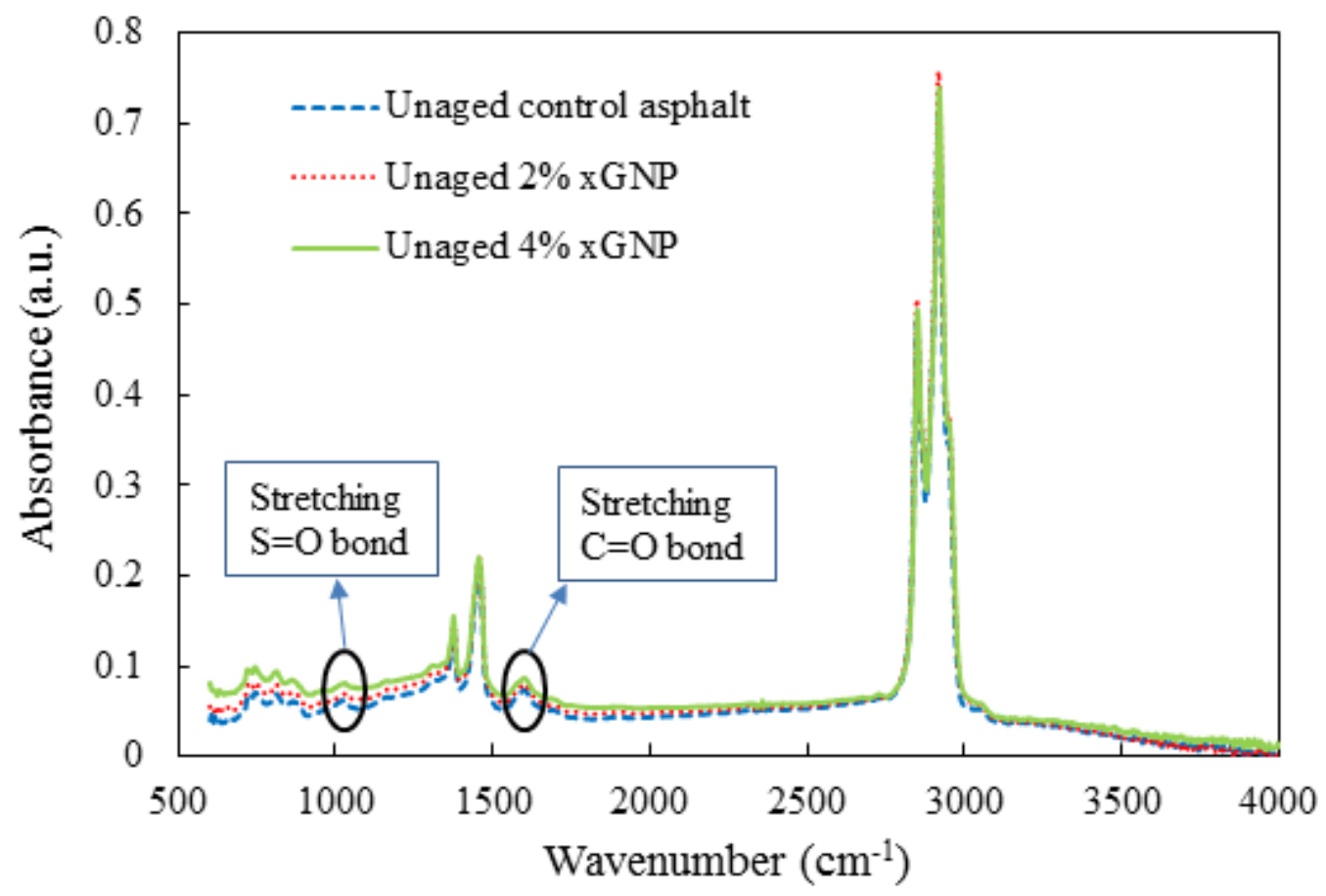

Figure 5. 15 FTIR results of unaged control and xGNP modified asphalt.

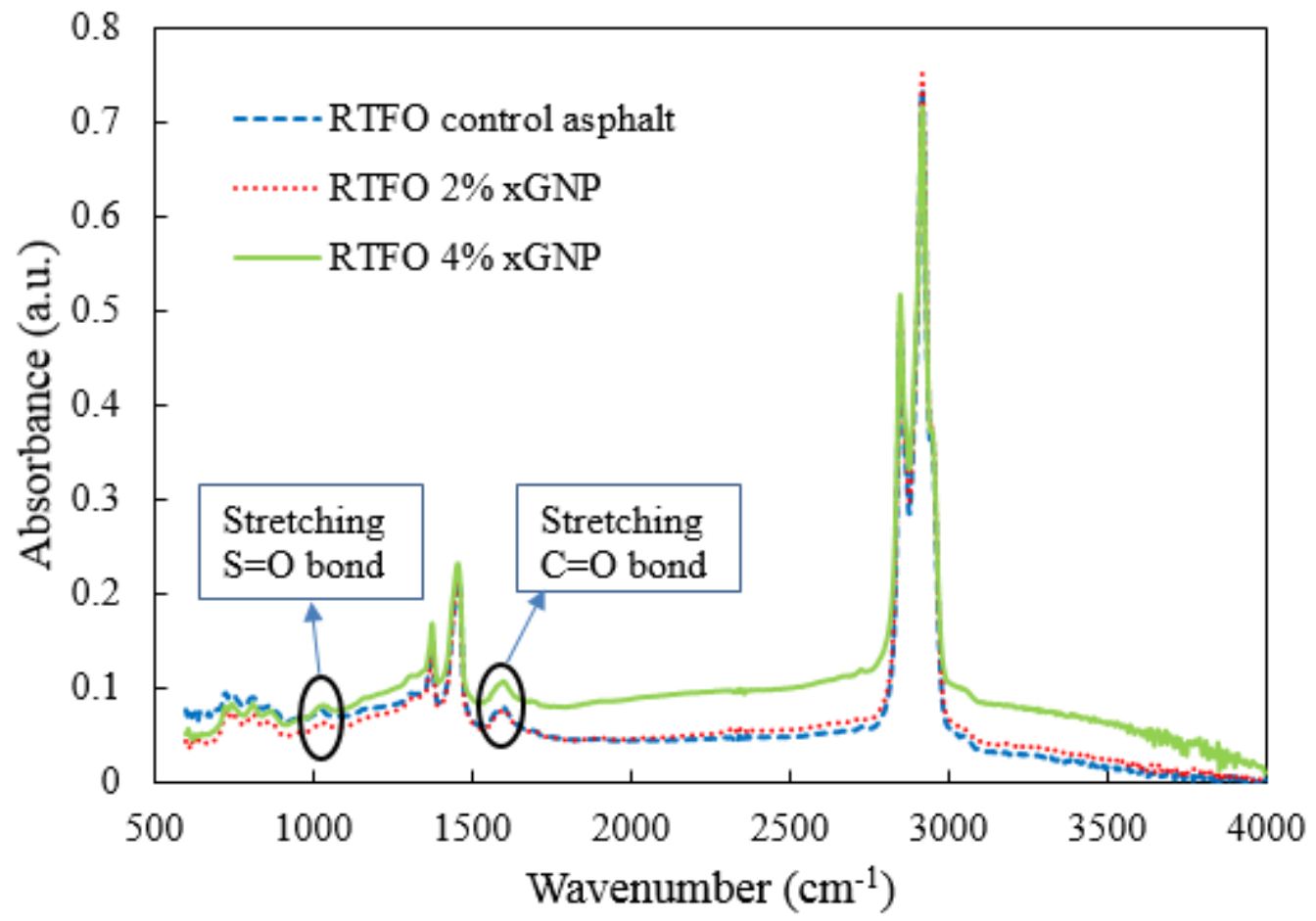

Figure 5. 16 FTIR results of RTFO control and xGNP modified asphalt. 


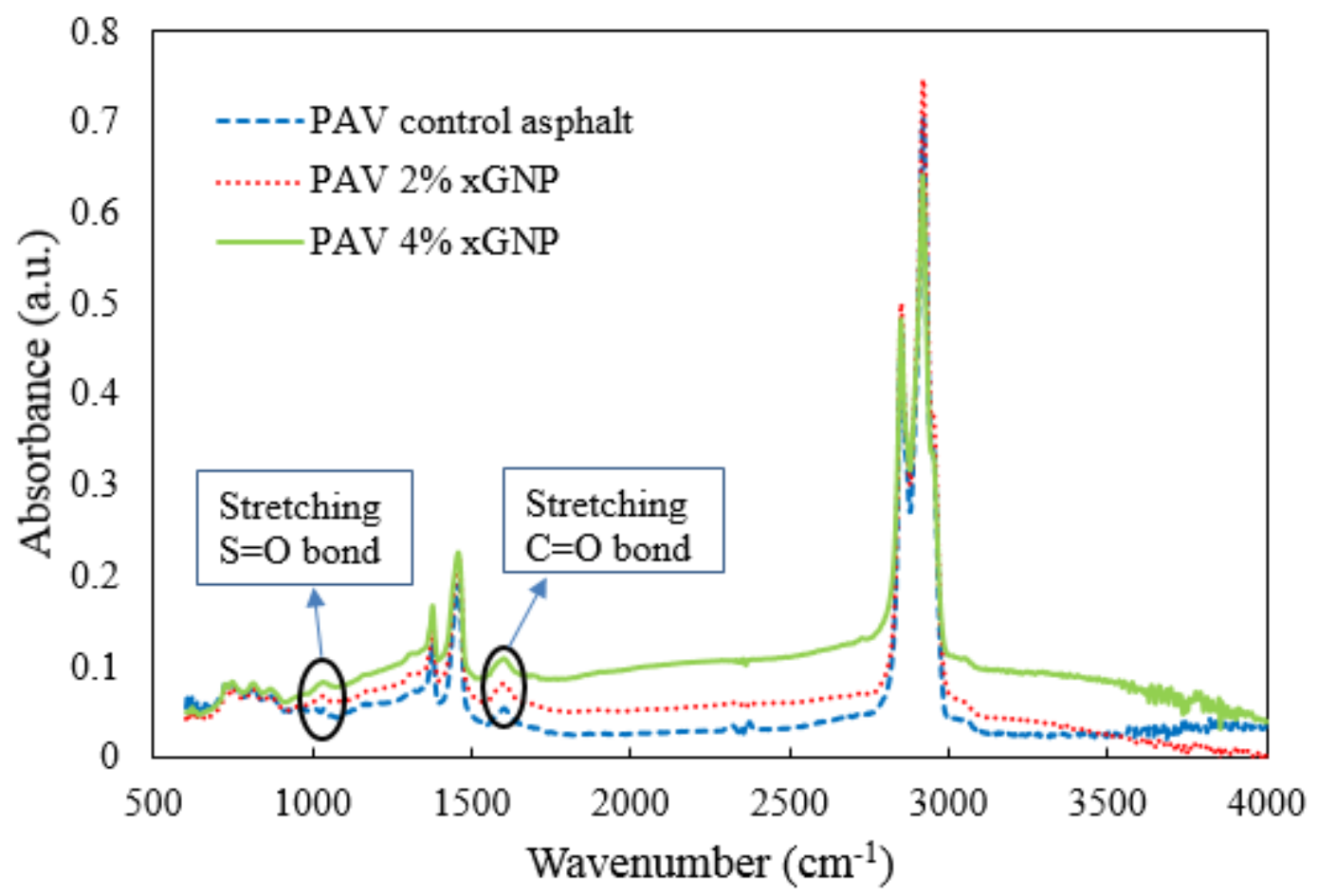

Figure 5. 17 FTIR results of PAV control and xGNP modified asphalt.

The area below the peak curve can be regarded as the relative amount of bonds in the asphalt. The reason is that high amount of carbonyl bonds and sulfoxide bonds result in high light absorbance of asphalt binder. Therefore, a ratio was introduced to calculate the relative amount of carbonyl and sulfoxide bonds existing in the asphalt binder, displayed in Equation (5-5) and (5-6).

$$
\begin{gathered}
R_{C=O}=\frac{A_{C=O}}{A_{T}} \\
R_{S=O}=\frac{A_{S=O}}{A_{T}}
\end{gathered}
$$

where $R_{C=O}$ and $R_{S=O}$ indicate the ratios of carbonyl and sulfoxide bonds. $A_{C=O}$ and $A_{S=0}$ denote the areas under the peak curves of carbonyl and sulfoxide bonds. In this 
study, the wavenumber of carbonyl peak was determined in the range of $1650 \mathrm{~cm}^{-1}$ to $1850 \mathrm{~cm}^{-1}$. The range of sulfoxide peak was $960 \mathrm{~cm}^{-1}$ to $1100 \mathrm{~cm}^{-1} . A_{T}$ is the total area under the curve of all the different bonds in the asphalt, which range was $600 \mathrm{~cm}^{-1}$ to $200 \mathrm{~cm}^{-1}$. Figure 5.18 shows the sulfoxide bond ratios of control and flake graphite modified asphalt. It is observed that the sulfoxide bond ratios increase with increasing of flake graphite contents of asphalt. In addition, the sulfoxide bond ratios increase with increasing of aging degree of the asphalt. Therefore, the flake graphite could increase the sulfoxide bond content of flake graphite modified asphalt binder. Figure 5.19 displays the carbonyl bond ratios of control and flake graphite modified asphalt. The carbonyl bond ratios increase with increasing of flake graphite contents and aging degree of the asphalt. Therefore, the flake graphite could increase the carbonyl bond content of flake graphite modified asphalt binder. The carbon in the flake graphite could react with the oxygen atoms to form the carbonyl bonds. Figure 5.20 and Figure 5.21 show the ratios of sulfoxide bond and carbonyl bond of control and xGNP modified asphalt, respectively. It is seen that both the ratios of sulfoxide bond and carbonyl bond increase with increasing of xGNP contents and aging degree of the asphalt. Hence, it is concluded that the graphite materials could increase the amount sulfoxide bond and carbonyl bond in the asphalt. The xGNP has the ability to promote the reaction of sulfur atoms and oxygen atoms andthe carbon in xGNP could react with the oxygen atoms to create the carbonyl bonds. Adding graphite material into asphalt is favorable to increase its aging degree and it is advantageous to improve the moisture sensitivity and rutting of asphalt mixture. 


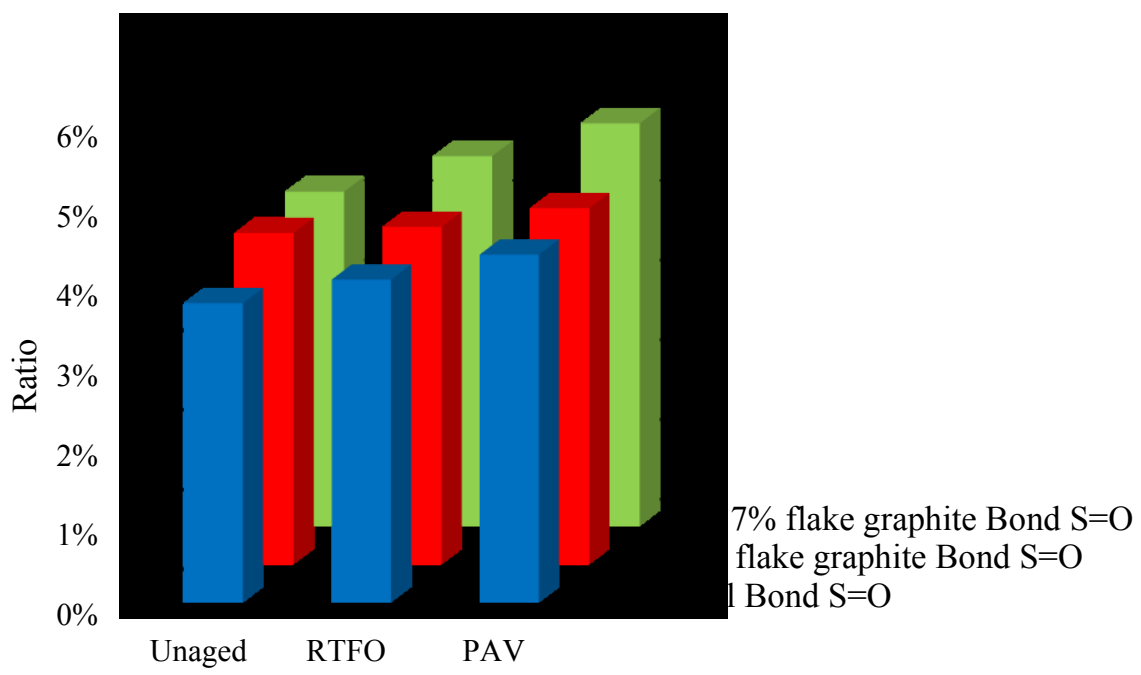

Figure 5. 18 The average ratios of sulfoxide groups in control and flake graphite modified asphalt.

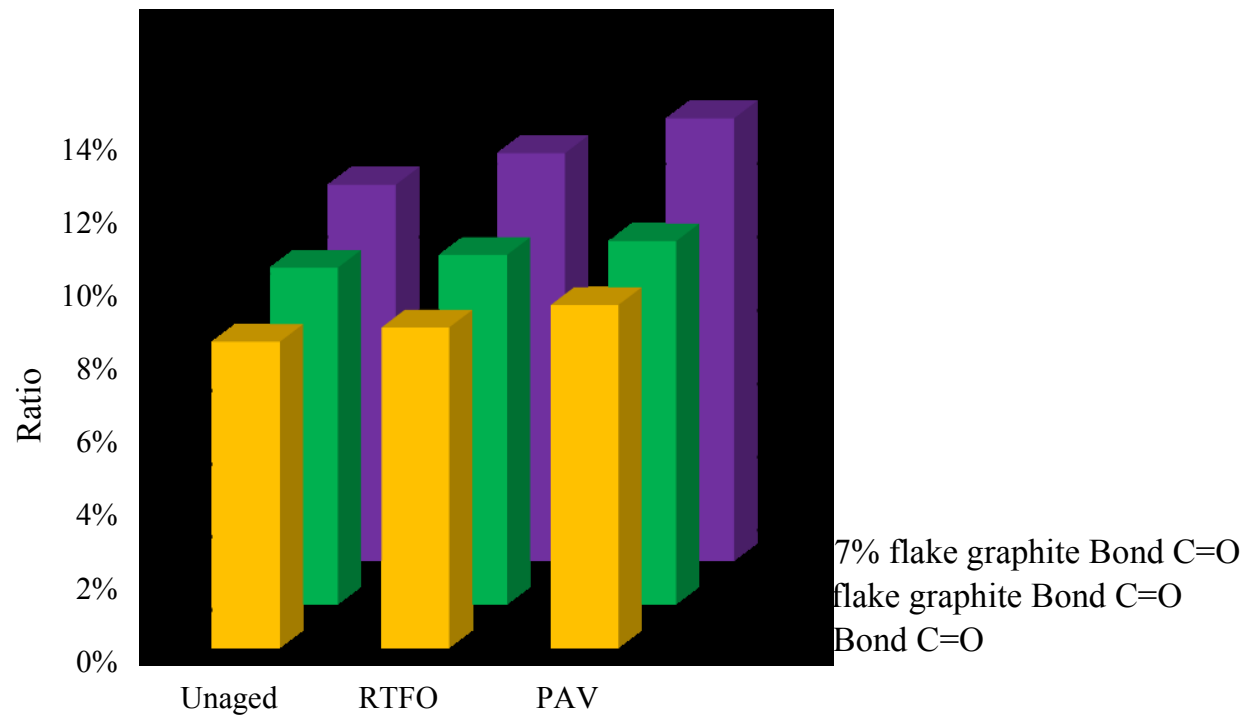

Figure 5. 19 The average ratios of carbonyl groups in control and flake graphite modified asphalt. 


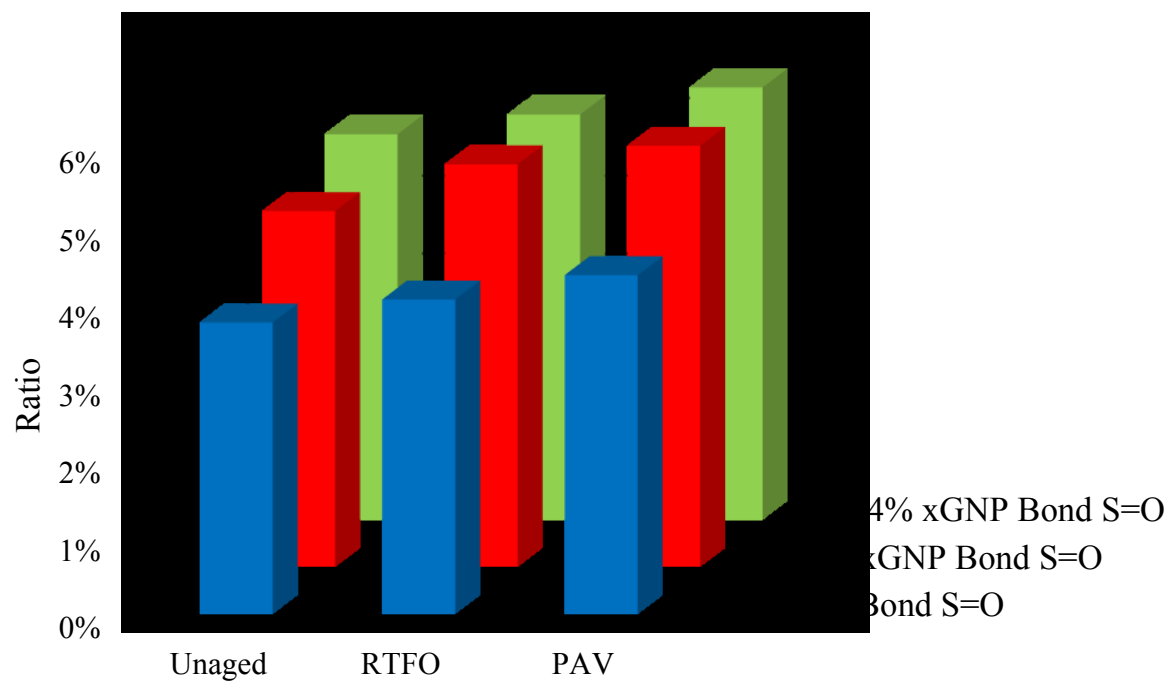

Figure 5. 20 The average ratios of sulfoxide groups in control and xGNP modified asphalt.

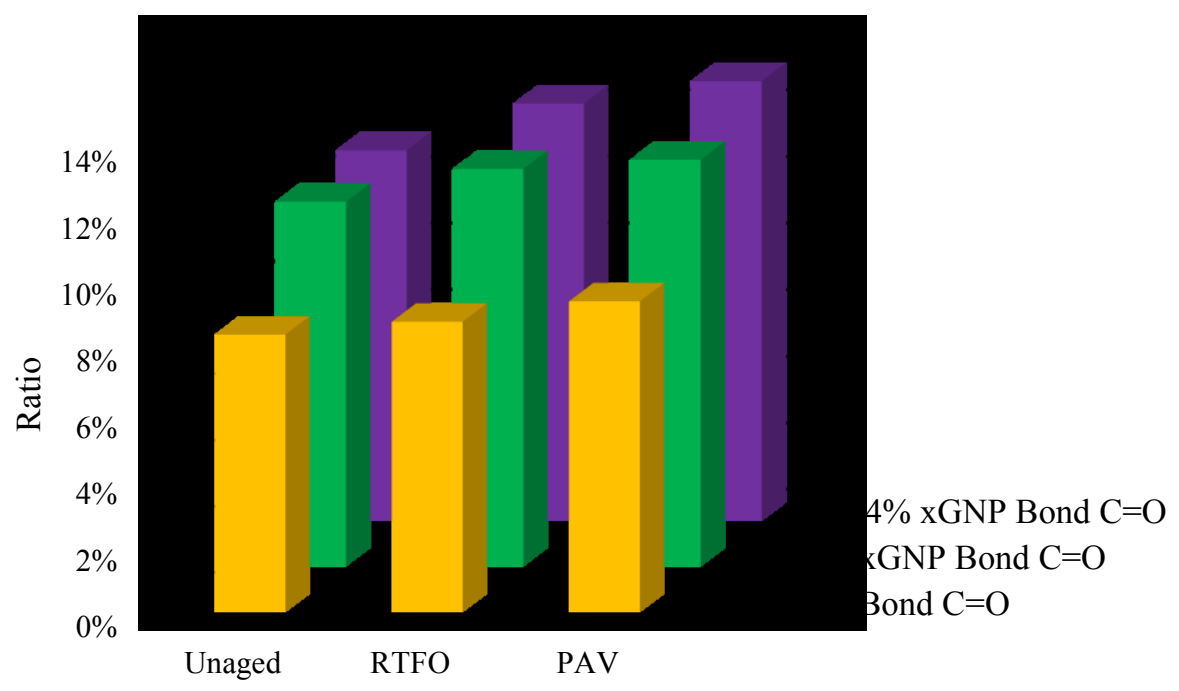

Figure 5. 21 The average ratios of carbonyl groups in control and xGNP modified asphalt. 


\subsubsection{Thermal conductivity measurement}

In this study, thermal conductivity values of asphalt samples were measured by a KD2 Pro thermal property analyzer from Decagon Devices Inc. based on transient line heal source methods[97, 98]. A large single needle TR-1 sensor (10 cm long, $2.4 \mathrm{~mm}$ diameter) was inserted into the asphalt sample. Then heat was generated by the device, forming temperature gradient along the needle probe. Afterwards, the sensor detected the temperature changes and recorded the data. The equations used to calculate thermal conductivity are shown in Equation (5-5) and (5-6)

$T=m_{0}+m_{1} t+m_{2} \ln t$

where $T$ indicates the recorded temperature, $t$ is time, $m_{0}$ is the environmental temperature, $m_{1}$ is the varying rate of the background temperature, $m_{2}$ denotes the temperature drifting of the studying material.

$k=\frac{q}{4 \pi m_{2}}$

where $k$ is the thermal conductivity, $q$ is the heat generated by the device. Five different types of asphalt samples were measured to evaluate the thermal performance at room temperature. They include control asphalt, 5\% and 7\% flake graphite modified asphalt, $2 \%$ and 4\% xGNP modified asphalt. The results of thermal conductivity measurement are exhibited in Figure 5.22. The thermal conductivity values of control asphalt, 5\% flake graphite modified asphalt, 7\% flake graphite modified asphalt, 2\% xGNP modified asphalt and 4\% xGNP modified asphalt ascends in turn. The thermal conductivity of 4\% xGNP modified asphalt is nearly 5 times that of the control asphalt. 
The significantly increased thermal conductivity indicates that the graphite modified binder can increase thermal transfer inside the asphalt mixture for promoting the light healing process.

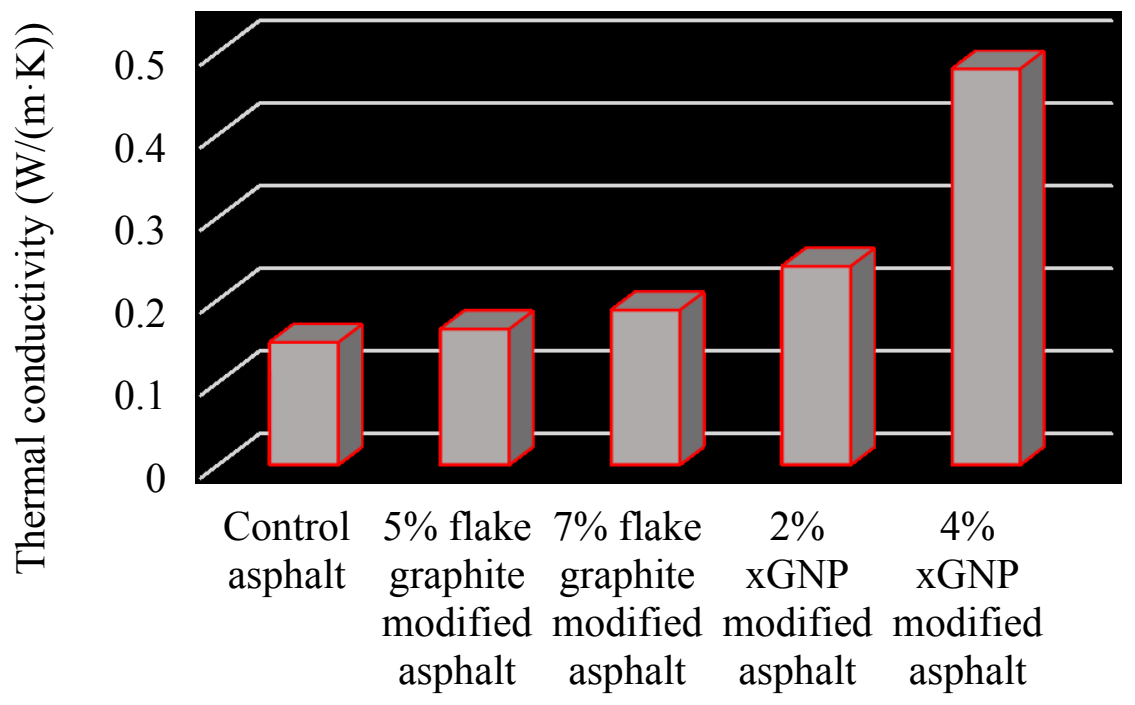

Figure 5. 22 Thermal conductivity of control asphalt, flake graphite modified (5\% and $7 \%$ ) asphalt and $\mathrm{xGNP}$ modified ( $2 \%$ and $4 \%$ ) asphalt.

\subsection{Summary and conclusions}

In this research, two graphite modifiers, flake graphite and xGNP were added into the asphalt mixture material. The viscosity test, visible/near infrared light absorption test, bending beam rheometer test, dynamic shear rheometer test, FTIR test and thermal conductivity test of control asphalt and graphite modified asphalt were conducted.

The viscosity measurement results of asphalt samples were utilized to calculate the activation energy. Both flake graphite and xGNP modified asphalt binder could decrease the activation energy of asphalt. It is concluded that the graphite modified asphalt has lower energy input for healing compared with pure asphalt binder. The 
results of the visible/near infrared light absorption test show that the graphite materials have capability to enhance the light absorption of asphalt, especially the infrared light absorption of asphalt. The effect of the 5\% flake graphite modified asphalt is better than that of the $2 \% \times$ GNP modified asphalt. The graphite material could decrease the low temperature property of asphalt through the bending beam rheometer. Additionally, the complex shear moduli of graphite modified asphalt increase compared with the control asphalt. The aging degree of asphalt increases by the graphite materials as well. The results of the thermal conductivity test reveal that added small portion of graphite can increase the thermal conductive property of control asphalt. 


\section{CHAPTER 6 PERFORMANCE TESTS ON GRAPHITE MODIFIED ASPHALT MIXTURE*}

\subsection{Introduction}

Asphalt mixture consist of asphalt, graded aggregates and air void [85]. Asphalt binder, regarded as a temperature-dependent material, behaves as viscoelastic solid at low temperature and viscous flow at high temperature [4]. The pavement's service life is to a great extent affected by the traffic loads and climatic conditions [52]. The main reason of pavement's service life shortened is the developing microcracks [99]. Many pavement distresses, like the raveling, moisture damage, rutting issue, fatigue cracking are induced by the microcracks in the asphalt mixture [124]. Therefore, the wearing course of the pavement is supposed to be repaired frequently.

Rutting is a primary traffic load-related distress in pavement[125]. The performance tests conducted to evaluate the rutting level of the asphalt mixture include the asphalt pavement analyzer (APA) test and Hamburg wheel tracking device (HWTD) test [24]. Zhao et al. [25] utilized APA and HWTD rutting tests to investigate rut depths of the warm mix asphalt and hot mix asphalt containing reclaimed asphalt pavement. Rushing et al. [126] studied the rutting susceptibility of HMA designed for high tire pressure aircraft.

Asphalt mixture dynamic modulus is one of the most important parameters for flexible pavement design [127]. The dynamic modulus was affected by asphalt

\footnotetext{
${ }^{*}$ Part of the text was accepted in Construction and Building materials - Wang, Z., Dai, Q., Guo, S. Wang, R., Ye, M., Yap, Y. "Experimental Investigation of Physical Properties and Accelerated Sunlight-Healing Performance of Flake Graphite and Exfoliated Graphite Nanoplatelet Modified Asphalt Materials.” (2016).
} 
stiffness and aggregate size distribution [26]. Clyne et al. [128] reported that the dynamic modulus of the mixture with softer asphalt was lower than those with stiffer asphalt. Birgisson et al. [27] proposed that the gradation of the aggregates had a crucial impact on the dynamic modulus of mixtures. A study by Chen et al. [129] presented that the asphalt mixtures using low percentages of flat and elongated aggregates resulted in a stable internal structure because of better developing stone-on-stone contact.

Graphite, as a good conductor, has attracted the interest of many researchers in civil engineering. Wu et al. [109] combine asphalt mixture with microcrystal graphite powders to collect solar energy for civil construction application. Chen et al. [110] found that the graphite powders could be used to resolve the snow problem of the pavement because of increasing the thermal conductivity of the asphalt mixture. A prediction model established by finite element method to study the thermal response of asphalt pavement with added graphite conductive media by Wang et. al [111].

The objective of this research is to evaluate the electrical, thermal and mechanical properties of graphite modified asphalt mixture, including the 5\% flake graphite modified and 2\% xGNP modified asphalt mixtures. Therefore, The electrical resistivity, thermal conductivity, rut depth and dynamic modulus of the graphite modified asphalt mixture were measured by 1864 Megohmmeter, KD2 thermal property analyzer, HWTD and UTM-100, respectively. 


\subsection{Asphalt mixture design and sample preparation}

\subsubsection{Control and graphite modified asphalt mixture design}

In this study, two types of graphite materials, flake graphite and xGNP, were added into the asphalt mixture to implement a series of performance tests. Hence, samples of the control asphalt mixture, flake graphite modified asphalt mixture and xGNP modified asphalt mixture were prepared. The flake graphite was purchased from Asbury Carbons with a density of $2.25 \mathrm{~g} / \mathrm{cm}^{3}$. The particles size of the flake graphite contains No.100 ( $75 \%$ by weight) and No.200 ( $25 \%$ by weight). The minimum layer is $0.11 \mathrm{~mm}$. The xGNP was offered by XG Sciences with a bulk density of 0.03-0.1 $\mathrm{g} / \mathrm{cm}^{3}$. The particle diameter is 25 microns and the average thickness is 15 nanometers. The asphalt binder was PG 58-28 with a density of $1.024 \mathrm{~g} / \mathrm{cm}^{3}$. The aggregates were obtained in Hancock, Michigan with an average density of $2.72 \mathrm{~g} / \mathrm{cm}^{3}$. The asphalt amount used was $5.2 \%$ of the asphalt mixture by weight, determined by the optimum asphalt content test due to the Superpave volumetric design guide. The flake graphite modified asphalt mixture contained 5\% flake graphite by weight of the mixture. The xGNP modified asphalt mixture contained $2 \% x$ GNP by weight of the mixture. The air void of all the samples was $4 \%$ of the asphalt mixture by volume.

\subsubsection{Mixture samples preparation}

Three different shapes of asphalt mixture samples were manufactured, including beam with a dimension of $95 \mathrm{~mm} \times 50 \mathrm{~mm} \times 69 \mathrm{~mm}$, small cylinder with diameter of $100 \mathrm{~mm}$, height of $150 \mathrm{~mm}$ for dynamic modulus test, big cylinder with diameter of 150 $\mathrm{mm}$, height of $60 \mathrm{~mm}$ for Hamburg Wheel Tracking Device (HWTD) test. The shapes 
of samples were based on the requirement of the performance tests. Table 6.1 shows the aggregate gradation of asphalt mixture beam samples for the electrical resistivity and thermal conductivity measurement. It is observed that $4.9 \mathrm{~g}$ of the No.100 and 1.6 g of the No.200 aggregates are replaced by the flake graphite for the flake graphite modified asphalt mixture to keep the mixture volume consistent. In the same way, $3 \mathrm{~g}$ of pan powder is replaced by xGNP due to its dimension.

Table 6. 1 Aggregate gradation of asphalt mixture beam samples.

\begin{tabular}{|c|c|c|c|}
\hline $\begin{array}{l}\text { Sieve } \\
\text { number }\end{array}$ & $\begin{array}{l}\text { Aggregate mass of } \\
\text { control asphalt } \\
\text { mixture (g) }\end{array}$ & $\begin{array}{l}\text { Aggregate mass of } \\
\text { flake graphite } \\
\text { modified asphalt } \\
\text { mixture (g) }\end{array}$ & $\begin{array}{l}\text { Aggregate mass of } \\
\text { xGNP modified } \\
\text { asphalt mixture }(\mathrm{g})\end{array}$ \\
\hline $1 / 2$ & 157.3 & 157.3 & 157.3 \\
\hline $3 / 8$ & 1476.3 & 1476.3 & 1476.3 \\
\hline No. 4 & 1778.9 & 1778.9 & 1778.9 \\
\hline No. 8 & 2468.6 & 2468.6 & 2468.6 \\
\hline No. 16 & 1851.5 & 1851.5 & 1851.5 \\
\hline No. 30 & 1282.7 & 1282.7 & 1282.7 \\
\hline No. 50 & 1306.9 & 1306.9 & 1306.9 \\
\hline No. 100 & 847.1 & 842.2 & 844.9 \\
\hline No. 200 & 278.3 & 276.7 & 277.6 \\
\hline Pan powder & 653.5 & 653.5 & 650.5 \\
\hline
\end{tabular}


Table 6.2 displays the aggregate gradation of asphalt mixture asphalt samples for HWTD test. $1.7 \mathrm{~g}$ of No.100 and $0.6 \mathrm{~g}$ of No.200 aggregates are replaced by flake graphite for flake graphite modified asphalt mixture and $0.9 \mathrm{~g}$ pan powder is replaced by $x$ GNP for $x$ GNP modified asphalt mixture. In addition, Table 6.3 shows the aggregate gradation of asphalt mixture dynamic modulus samples. $1.5 \mathrm{~g}$ of No.100 and $0.5 \mathrm{~g}$ of No.200 aggregates are replaced by flake graphite for flake graphite modified asphalt mixture. $0.7 \mathrm{~g}$ pan powder is replaced by $\mathrm{xGNP}$ for $\mathrm{xGNP}$ modified asphalt mixture. 
Table 6. 2 Aggregate gradation of asphalt mixture samples for HWTD test.

\begin{tabular}{|c|c|c|c|}
\hline $\begin{array}{l}\text { Sieve } \\
\text { number }\end{array}$ & $\begin{array}{l}\text { Aggregate mass of } \\
\text { control asphalt } \\
\text { mixture }(\mathrm{g})\end{array}$ & $\begin{array}{l}\text { Aggregate mass of } \\
\text { flake } \quad \text { graphite } \\
\text { modified asphalt } \\
\text { mixture (g) }\end{array}$ & $\begin{array}{l}\text { Aggregate mass of } \\
\text { xGNP modified } \\
\text { asphalt mixture }(\mathrm{g})\end{array}$ \\
\hline $1 / 2$ & 55.5 & 55.5 & 55.5 \\
\hline $3 / 8$ & 520.9 & 520.9 & 520.9 \\
\hline No. 4 & 627.6 & 627.6 & 627.6 \\
\hline No. 8 & 871.0 & 871.0 & 871.0 \\
\hline No. 16 & 653.3 & 653.3 & 653.3 \\
\hline No. 30 & 452.6 & 452.6 & 452.6 \\
\hline No. 50 & 461.1 & 461.1 & 461.1 \\
\hline No. 100 & 298.9 & 297.2 & 298.9 \\
\hline No. 200 & 98.2 & 97.6 & 98.2 \\
\hline $\begin{array}{l}\text { Pan } \\
\text { powder }\end{array}$ & 230.6 & 230.6 & 229.7 \\
\hline
\end{tabular}


Table 6. 3 Aggregate gradation of asphalt mixture dynamic modulus samples.

\begin{tabular}{|c|c|c|c|}
\hline $\begin{array}{l}\text { Sieve } \\
\text { number }\end{array}$ & $\begin{array}{l}\text { Aggregate mass of } \\
\text { control asphalt } \\
\text { mixture (g) }\end{array}$ & $\begin{array}{l}\text { Aggregate mass of } \\
\text { flake graphite } \\
\text { modified asphalt } \\
\text { mixture (g) }\end{array}$ & $\begin{array}{l}\text { Aggregate mass of } \\
\text { xGNP modified } \\
\text { asphalt mixture }(\mathrm{g})\end{array}$ \\
\hline $1 / 2$ & 43.1 & 43.1 & 43.1 \\
\hline $3 / 8$ & 404.5 & 404.5 & 404.5 \\
\hline No. 4 & 487.4 & 487.4 & 487.4 \\
\hline No. 8 & 676.4 & 676.4 & 676.4 \\
\hline No. 16 & 507.3 & 507.3 & 507.3 \\
\hline No. 30 & 351.5 & 351.5 & 351.5 \\
\hline No. 50 & 358.1 & 358.1 & 358.1 \\
\hline No. 100 & 232.1 & 230.8 & 232.1 \\
\hline No. 200 & 76.3 & 75.8 & 76.3 \\
\hline Pan powder & 179.1 & 179.1 & 178.4 \\
\hline
\end{tabular}

\subsection{Performance tests of asphalt mixture}

In this section, performance tests were conducted to investigate the properties of the control, 5\% flake graphite modified, and 2\% xGNP modified asphalt mixture samples. The electrical resistivity and thermal conductivity of the control and graphite modified asphalt mixture were measured by asphalt mixture beam samples. The rutting depth of the control and graphite modified asphalt mixture was determined by HWTD, 
using big cylinder samples. Additionally, the dynamic modulus of the control and graphite modified asphalt mixture was measured by UTM-100, using small cylinder samples.

\subsubsection{Electrical resistivity measurement of asphalt mixture beams}

The electrical resistivity of the control, $5 \%$ flake graphite modified and $2 \%$ xGNP modified asphalt mixture beam samples were measured by 1864 Megohmmeter at room temperature, shown in Figure 6.1 (a). Two copper electrodes were placed on two sides of the measured beam sample. Then the electrical resistance was read through the device. The electrical resistivity was calculated by Equation (6-1):

$\rho=\frac{R \square}{L}$

where $\rho$ is the electrical resistivity ( $\Omega \square$ ), $R$ denotes the measured electrical resistance $(\Omega), S$ is the cross-sectional area and $L$ is the length of the beam samples. Figure 6.1 (b) displays the electrical resistivity values of the control, 5\% flake graphite modified and $2 \%$ xGNP modified asphalt mixture beams. The average electrical resistivity of the control asphalt mixture beams is $37.25 \Omega \square$. The average electrical resistivity of the flake graphite and xGNP modified asphalt mixture beams are 25.99 $\Omega \square$ and $20.07 \Omega \square$, respectively. Hence, the flake graphite and xGNP both could decrease the electrical resistivity of asphalt mixture beam samples. 


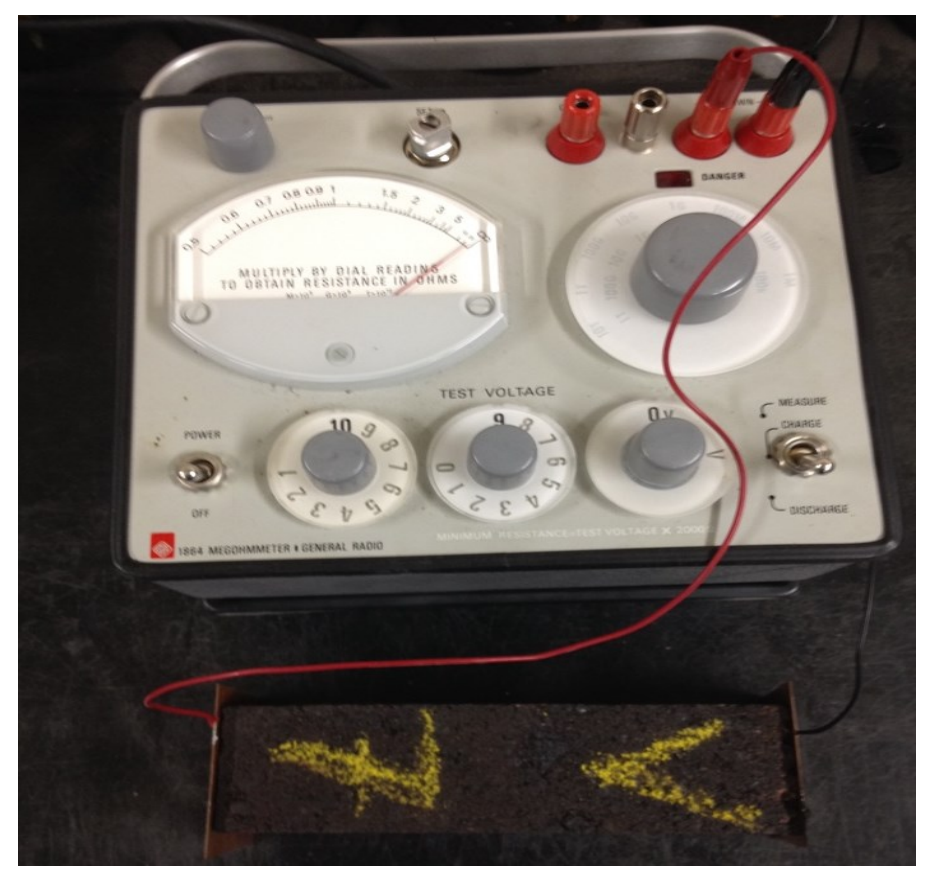

(a)

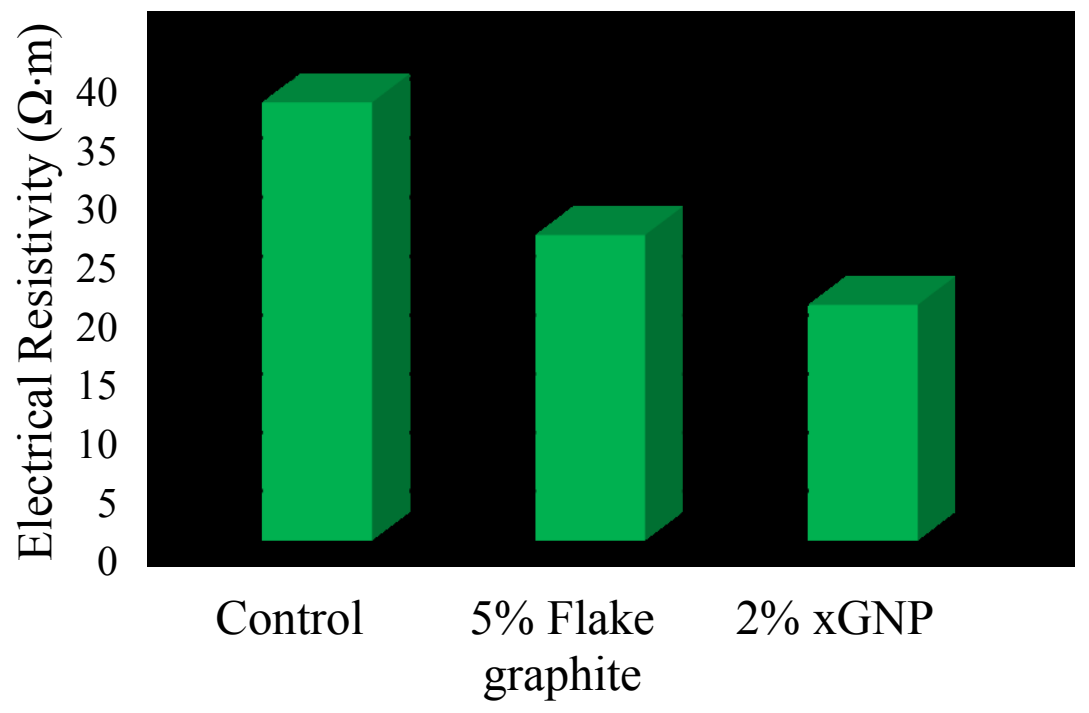

(b)

Figure 6. 1 Electrical resistivity data of non-fractured asphalt mixture beams. 


\subsubsection{Thermal conductivity of asphalt mixture beams}

The thermal conductivity of the control, $5 \%$ flake graphite modified and $2 \%$ xGNP modified asphalt mixture beam samples were measured by a KD2 thermal property analyzer from Decagon Devices Inc.. The device used the transient line heal source methods[97, 98], shown in Figure 6.2 (a). The measured sample was drilled a hole, inserted by a needle TR-1 sensor with a dimension of length of $10 \mathrm{~cm}$, diameter of $2.4 \mathrm{~mm}$. The gradient temperature produced by the sensor inside the sample could be detected and recorded. The thermal conductivity was calculated by Equation (6-2) and (6-3):

$T=m_{0}+m_{1} t+m_{2} \ln t$

where $T$ is the recorded temperature, $m_{0}$ is the environmental temperature, $m_{1}$ is the varying rate of the background temperature, $m_{2}$ indicates the temperature drifting of the tested material, $t$ is the testing time.

$k=\frac{q}{4 \pi m_{2}}$

where $k$ is the thermal conductivity $(\mathrm{W} /(\mathrm{m} \cdot \mathrm{K})), q$ is the heat generated by the device. Figure 6.2 shows the thermal conductivity of the control, $5 \%$ flake graphite modified and $2 \%$ xGNP modified asphalt mixture beams. The thermal conductivity of the control asphalt mixture is $1.58 \mathrm{~W} /(\mathrm{m} \cdot \mathrm{K})$. The thermal conductivity of the flake graphite and xGNP modified asphalt mixture are $2.08 \mathrm{~W} /(\mathrm{m} \cdot \mathrm{K})$ and $1.69 \mathrm{~W} /(\mathrm{m} \cdot \mathrm{K})$, respectively. Therefore, the flake graphite and xGNP both could increase the thermal conductivity of the asphalt mixture. Normally, the thermal conductivity of the xGNP is 
much higher than the flake graphite. However, the thermal conductivity is based on the direction between the graphite particles. If two particles are parallel to each other, the thermal conductivity could be very high. If they are perpendicular to each other, the thermal conductivity could be very low. In addition, the flake graphite modified asphalt mixture contains more graphite particles than the xGNP modified asphalt mixture. Therefore, the thermal conductivity of the flake graphite modified asphalt mixture samples is higher than the $\mathrm{xGNP}$ modified asphalt mixture samples.

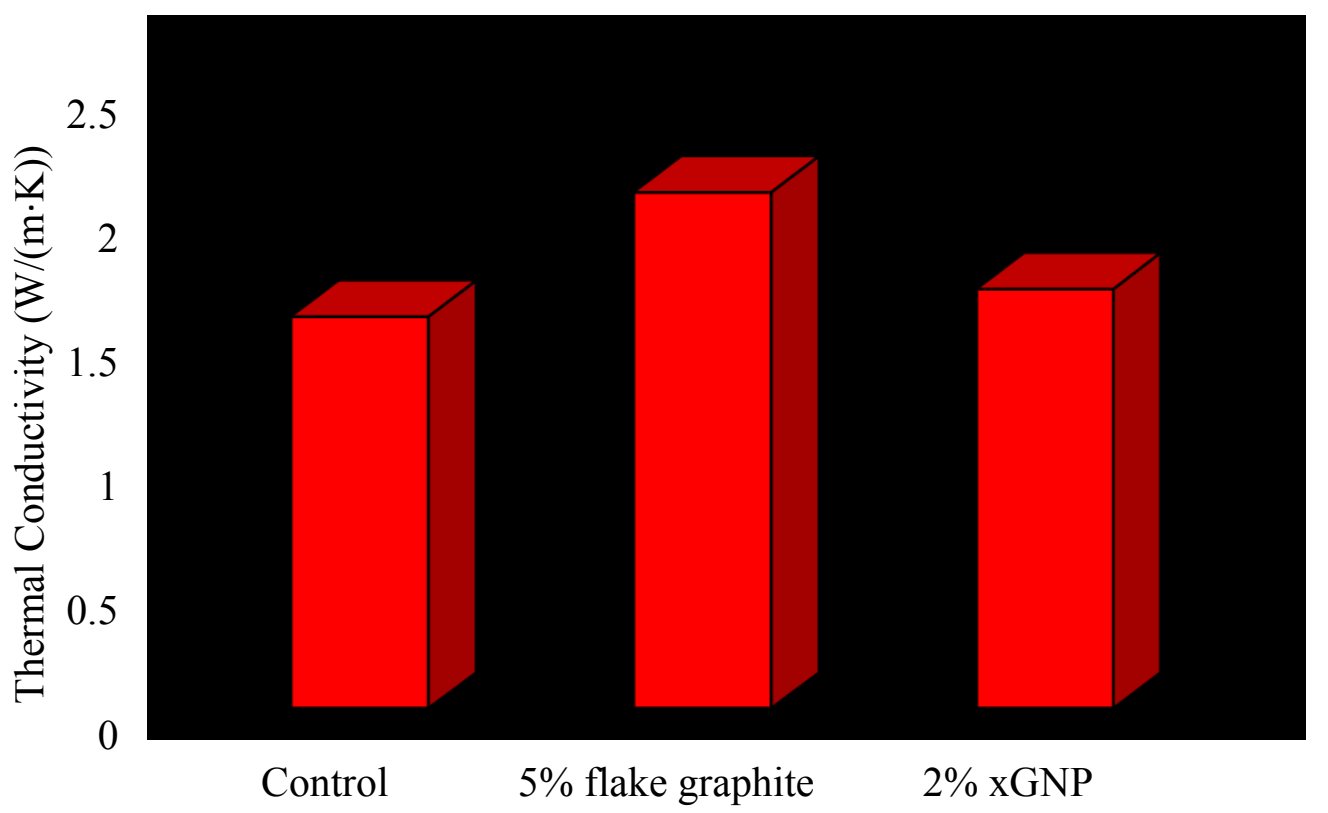

Figure 6. 2 Thermal conductivity data of non-fractured asphalt mixture beams.

\subsubsection{Hamburg wheel tracking device (HWTD) test of asphalt mixture samples}

The rutting susceptibility of the control, 5\% flake graphite modified and 2\% xGNP modified asphalt mixture samples was evaluated by the Hamburg wheel tracking device based on AASHTO T324. The steel wheel load of HWTD was 705 N. The maximum displacement of the wheel load that the transducer could measure was 25 
$\mathrm{mm}$. The samples were placed in the water tub for 30 minutes with a temperature of 50 ${ }^{\circ} \mathrm{C}$ before conducting the test. Then the rut depths were captured during the test with setup 5000 passes. Figure 6.3 displays the HWTD test results of the control, 5\% flake graphite modified and $2 \% \times \mathrm{xGNP}$ modified asphalt mixture samples. The test results indicated that the graphite materials decreased the rut depth of the asphalt mixture. After 5000 passes, the rut depths of the xGNP and flake graphite modified asphalt mixture samples were $66 \%$ and $48 \%$ of the control asphalt mixture samples. The effect of the $5 \%$ flake graphite modified asphalt mixture is better than the $2 \%$ xGNP modified asphalt mixture on the reduction of rut depth.

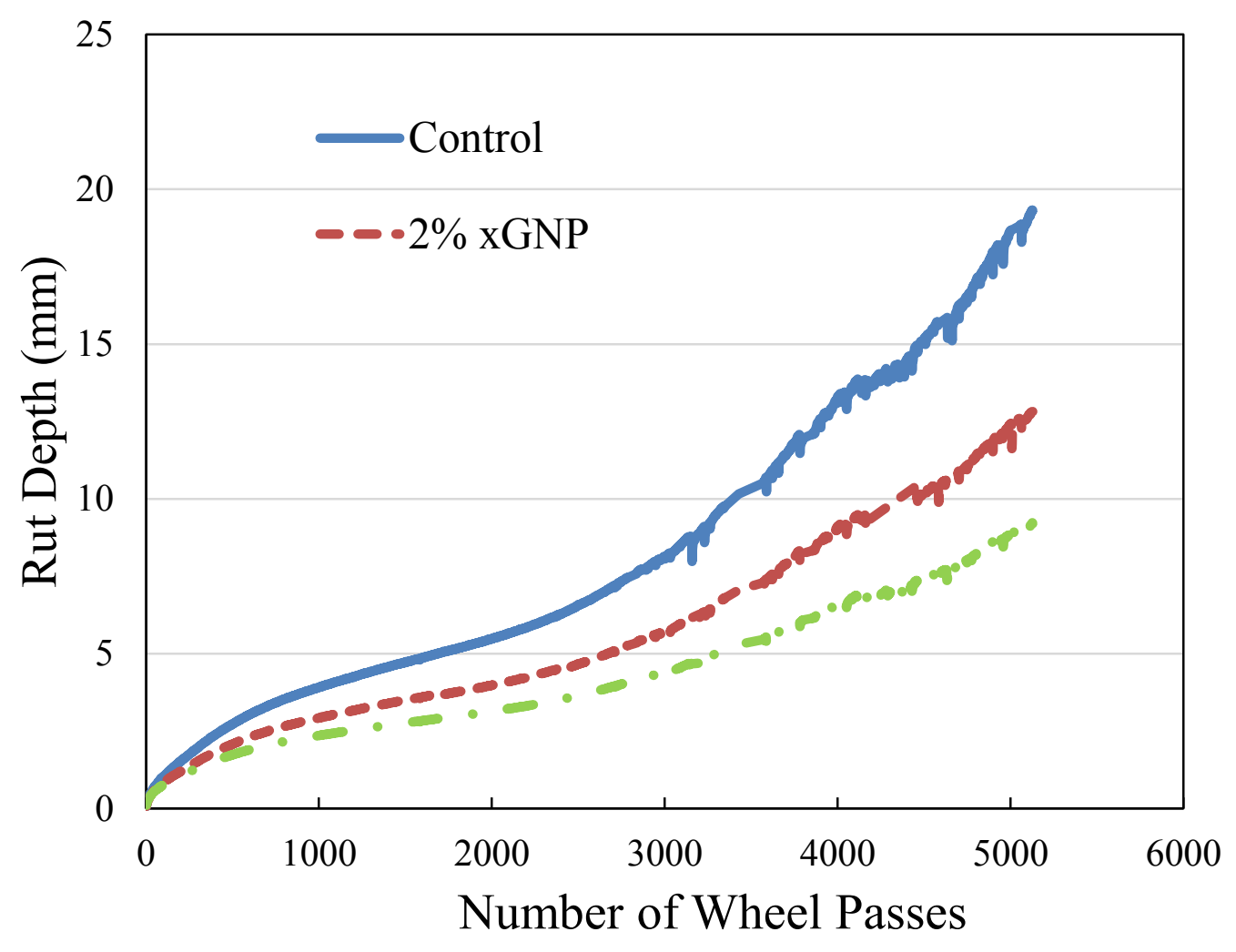

Figure 6. 3 Hamburg Wheel Tracking Device test data of control, 5\% flake graphite and $2 \% x$ xNP modified asphalt mixture samples. 


\subsubsection{Dynamic modulus measurement of asphalt mixture samples}

The dynamic modulus was utilized to investigate the compact resistance of the control, $5 \%$ flake graphite modified and 2\% xGNP modified asphalt mixture samples by UTM-100 machine. The definition of the dynamic modulus is the ratio of the stress amplitude to the strain amplitude that responses for a given frequency in a steady state. In this research, three samples were tested to compute the dynamic modulus over a range of loading frequencies $(0.1 \mathrm{~Hz}, 0.5 \mathrm{~Hz}, 1 \mathrm{~Hz}, 5 \mathrm{~Hz}, 10 \mathrm{~Hz}$ and $25 \mathrm{~Hz})$ and testing temperatures $\left(-10{ }^{\circ} \mathrm{C}, 4{ }^{\circ} \mathrm{C}, 21.3{ }^{\circ} \mathrm{C}\right.$ and $\left.39.4{ }^{\circ} \mathrm{C}\right)$. Figure 6.4 shows the dynamic modulus master curves of the control, $5 \%$ flake graphite modified and $2 \%$ xGNP modified asphalt mixture samples. The reference temperature is $-10^{\circ} \mathrm{C}$. It is observed that the moduli of the graphite modified asphalt mixture samples are higher compared to the control asphalt mixture sample. The dynamic modulus of the $5 \%$ flake graphite modified asphalt mixture sample is higher than the $2 \% \mathrm{xGNP}$ modified asphalt mixture sample. The two graphite materials both have the ability to increase the dynamic modulus of the asphalt mixture. 


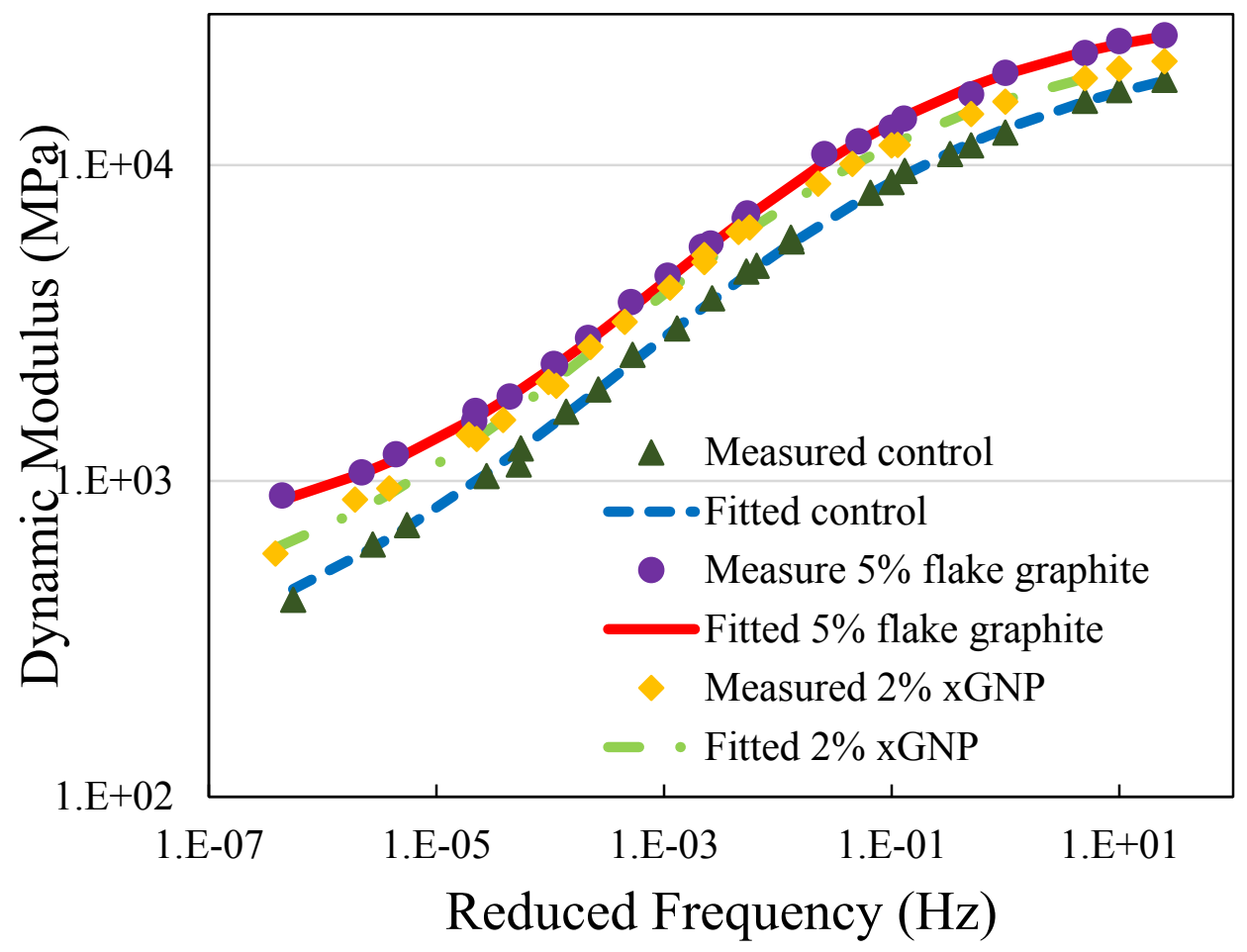

Figure 6. 4 Dynamic modulus master curves of control, 5\% flake graphite and 2\% xGNP modified asphalt mixture.

\subsection{Conclusion}

In this research, the performance tests of the graphite (5\% flake graphite and $2 \%$ xGNP) modified asphalt mixture were conducted, including the electrical resistivity measurement, thermal conductivity measurement, Hamburg wheel tracking device test and dynamic modulus test. The electrical resistivity measurement results showed that the graphite materials, as a good electrical conductor, could decrease the electrical resistivity of asphalt mixture. In addition, thermal conductivity of asphalt mixture increased with added graphite materials. The HWTD test data indicated that the rut depths of the graphite modified asphalt mixture decreased compared with the control asphalt mixture. The graphite materials could improve the high temperature rutting 
issue of the asphalt mixture. The graphite materials have the ability to increase the dynamic modulus of the asphalt mixture as well to improve the mechanical property of the pavement. 


\section{CHAPTER 7 FRACTURE-LIGHT HEALING TESTS ON GRAPHITE MODIFIED ASPHALT MIXTURE BEAM SAMPLES*}

\subsection{Introduction}

The asphalt mixture could self-heal its damage during the service life of pavement [64]. This self-healing process are affected by the environmental temperature and rest period $[33,87]$. The key point of the healing is the external energy is observed by the pavement system [88]. In addition, the healing behavior was a complex process, combined with capillary flow, molecules wetting and intermolecular diffusion [12].

Graphite, as a high thermal conductive material, was studied by researchers. Wu et al. [109]employed the microcrystal graphite powders to collect solar energy. The graphite could increase the thermal conductivity and diffusivity of asphalt binder[111]. Chen et al. [110]found that graphite powders could increase the thermal conductivity of asphalt mixture.

The microwave was used to combine with asphalt and mixture in the past few years. For instance, the aggregates could observe the microwave energy more easily than the asphalt binder[130]. The microwave was employed to heat the asphalt mixture within steel wool to heal the microcracks by Gallego et al. [131].

The objective of this study is to investigate the light healing performance of the control and graphite modified asphalt mixture beams. The graphite modified asphalt mixture beams ( $5 \%$ flake graphite and $2 \% \mathrm{xGNP})$ were prepared and used for cyclic

\footnotetext{
* Part of the text was accepted in Construction and Building materials-Wang, Z., Dai, Q., Guo, S. Wang, R., Ye, M., Yap, Y. "Experimental Investigation of Physical Properties and Accelerated Sunlight-Healing Performance of Flake Graphite and Exfoliated Graphite Nanoplatelet Modified Asphalt Materials.” (2016).
} 
fracture-light healing tests. The measured recovered strength after each cycle was used to evaluate the healing performance of both graphite modified and control samples. In addition, during the light healing process, the temperature distribution of tested beams was analyzed by capturing the infrared images. The DIC was utilized to evaluate the displacements of pixels in the fractured zone inside the sample, containing the average, maximum and median displacements.

\subsection{Asphalt mixture design and sample preparation}

Three types of asphalt mixture beams were prepared as the tested samples: control asphalt mixture, flake graphite modified asphalt mixture and xGNP modified asphalt mixture samples, respectively.

\subsubsection{Control asphalt mixture design}

The aggregates used in the asphalt mixture were from a local source in Hancock, Michigan with an average density of $2.72 \mathrm{~g} / \mathrm{cm}^{3}$ and the selected asphalt binder was PG 58-28 with a density of $1.024 \mathrm{~g} / \mathrm{cm}^{3}$. The amount of asphalt used for all the beams was $5.2 \%$ by weight of the mixture determined through employing the test of the optimum asphalt content based on the Superpave volumetric mixture design standard. The aggregate gradation for the control asphalt mixture sample is shown in Table 7.1. 
Table 7. 1 Aggregate gradation of control asphalt mixture.

\begin{tabular}{|l|l|l|l|}
\hline Sieve number & Sieve size $(\mathrm{mm})$ & Retained (\%) & Mass (g) \\
\hline $1 / 2$ & 12.5 & 6 & 157.3 \\
\hline $3 / 8$ & 9.5 & 7.7 & 1476.3 \\
\hline No. 4 & 4.75 & 18.1 & 1778.9 \\
\hline No. 8 & 2.36 & 19 & 2468.6 \\
\hline No. 16 & 1.18 & 10.8 & 1851.5 \\
\hline No. 30 & 0.6 & 10.6 & 1282.7 \\
\hline No. 50 & 0.3 & 12.8 & 1306.9 \\
\hline No. 100 & 0.15 & 8.3 & 847.1 \\
\hline No. 200 & 0.075 & 2.2 & 278.3 \\
\hline Pan powder & $<0.075$ & 4.5 & 653.5 \\
\hline
\end{tabular}

\subsubsection{Flake graphite modified asphalt mixture design}

The prepared flake graphite binder was used for preparation of the mixture sample preparation. The flake graphite amount was $5 \%$ of the asphalt by weight. Based on the Superpave volumetric design guide, the added flake graphite powders were treated as the fine aggregates to keep the volume consistent for the preparation of the sample. In the mixture design, flake graphite with a surface dimension of $0.15 \mathrm{~mm}(75 \%), 0.075$ mm (25\%) was used to replace the No. 100 and No. 200 fine aggregates. The detailed aggregate gradation of flake graphite modified mixtures was listed in Table 7.2. It is seen that the masses of No.100 aggregate and No.200 aggregate decrease. The reason is 
that $4.9 \mathrm{~g}$ of No.100 aggregate and $1.6 \mathrm{~g}$ of No.200 aggregate are replaced by added flake graphite particles.

Table 7. 2 Aggregate gradation of flake graphite modified asphalt mixture.

\begin{tabular}{|l|l|l|l|}
\hline Sieve number & Sieve size $(\mathrm{mm})$ & Retained (\%) & Mass $(\mathrm{g})$ \\
\hline $1 / 2$ & 12.5 & 6 & 157.3 \\
\hline $3 / 8$ & 9.5 & 7.7 & 1476.3 \\
\hline No. 4 & 4.75 & 18.1 & 1778.9 \\
\hline No. 8 & 2.36 & 19 & 2468.6 \\
\hline No. 16 & 1.18 & 10.8 & 1851.5 \\
\hline No. 30 & 0.6 & 10.6 & 1282.7 \\
\hline No. 50 & 0.3 & 12.8 & 1306.9 \\
\hline No. 100 & 0.15 & 8.3 & 842.2 \\
\hline No. 200 & 0.075 & 2.2 & 276.7 \\
\hline Pan powder & $<0.075$ & 4.5 & 653.5 \\
\hline
\end{tabular}

\subsubsection{Exfoliated graphite nanoplatelet (xGNP) asphalt modified mixture design}

The prepared exfoliated graphite nanoplatelet binder described in section 2 was used. The XGNP with a surface dimension of 25 microns, similarly, were also used to replace the fine aggregates, pan powder $(<0.075 \mathrm{~mm})$. The $\mathrm{xGNP}$ used in the asphalt mixture was about $2 \%$ of the binder by weight. The aggregate gradation of the $\mathrm{xGNP}$ modified asphalt mixture is listed in Table 7.3. About $2.4 \mathrm{~g}$ of pan powder is replaced by $x$ GNP compared with the aggregate gradation of the control asphalt mixture. 
Table 7. 3 Aggregate gradation of xGNP modified asphalt mixture.

\begin{tabular}{|l|l|l|l|}
\hline Sieve number & Sieve size $(\mathrm{mm})$ & Retained (\%) & Mass (g) \\
\hline $1 / 2$ & 12.5 & 6 & 157.3 \\
\hline $3 / 8$ & 9.5 & 7.7 & 1476.3 \\
\hline No. 4 & 4.75 & 18.1 & 1778.9 \\
\hline No. 8 & 2.36 & 19 & 2468.6 \\
\hline No. 16 & 1.18 & 10.8 & 1851.5 \\
\hline No. 30 & 0.6 & 10.6 & 1282.7 \\
\hline No. 50 & 0.3 & 12.8 & 1306.9 \\
\hline No. 100 & 0.15 & 8.3 & 847.1 \\
\hline No. 200 & 0.075 & 2.2 & 278.3 \\
\hline Pan powder & $<0.075$ & 4.5 & 651.1 \\
\hline
\end{tabular}

\subsubsection{Mixture beam sample preparation}

The asphalt mixture beam samples were used in this study. All of the asphalt mixtures were first compacted by a slab kneading compactor to obtain a mixture slab. Then the slab was cut into six beams with a length of $190 \mathrm{~mm}$, width of $50 \mathrm{~mm}$ and height of $69 \mathrm{~mm}$ due to the size of the mold. In addition, a $23 \mathrm{~mm}$ deep, $3 \mathrm{~mm}$ wide notch was sawn in the center of the beams to control the initial cracking position. Consequently, 5 beam samples were prepared for each mixture type, including 2 beam samples for the three-point beam bending test and 3 beam samples for the cyclic fracture-light healing test, respectively. Therefore, 15 beam samples were produced in 
total. For each beam sample, two knife edges were glued on the top notch for measuring the crack tip opening displacement by a clip-on gauge.

\subsection{Fracture-light healing investigation of asphalt mixture samples}

\subsubsection{Accelerated light healing mechanism}

The asphalt mixtures were heated at the pavement surface layer with the light absorption ability. The added graphite particles can promote the near-field infrared light absorption abilities. Then the heat is transferred to the deeper layer of the pavement based on the thermal conductivity of control and modified asphalt mixtures. In this heat transfer process, the asphalt as a temperature-dependent material behaves as Newtonian flow to fill the existing cracks in the pavement. The crack healing process is a combination of capillary flow caused by surface tension force, gravity of liquid asphalt filled in the crack and friction between the flowing asphalt and aggregate particles. The recovered strength was based on two factors. One is the diffusion of asphalt molecules. The other is the rebinding of asphalt and aggregate particles. The mechanism of accelerated light healing of the asphalt mixture material is shown in Figure 7.1. Hence, absorption ability and thermal conductivity of asphalt can affect the accelerated light healing greatly. In this study, a small percentage of flake graphite and xGNP was added into asphalt to improve the ability of light absorption and the thermal conductivity of the asphalt mixture. The light healing performance of the control and modified asphalt mixtures were described in the following sections. 


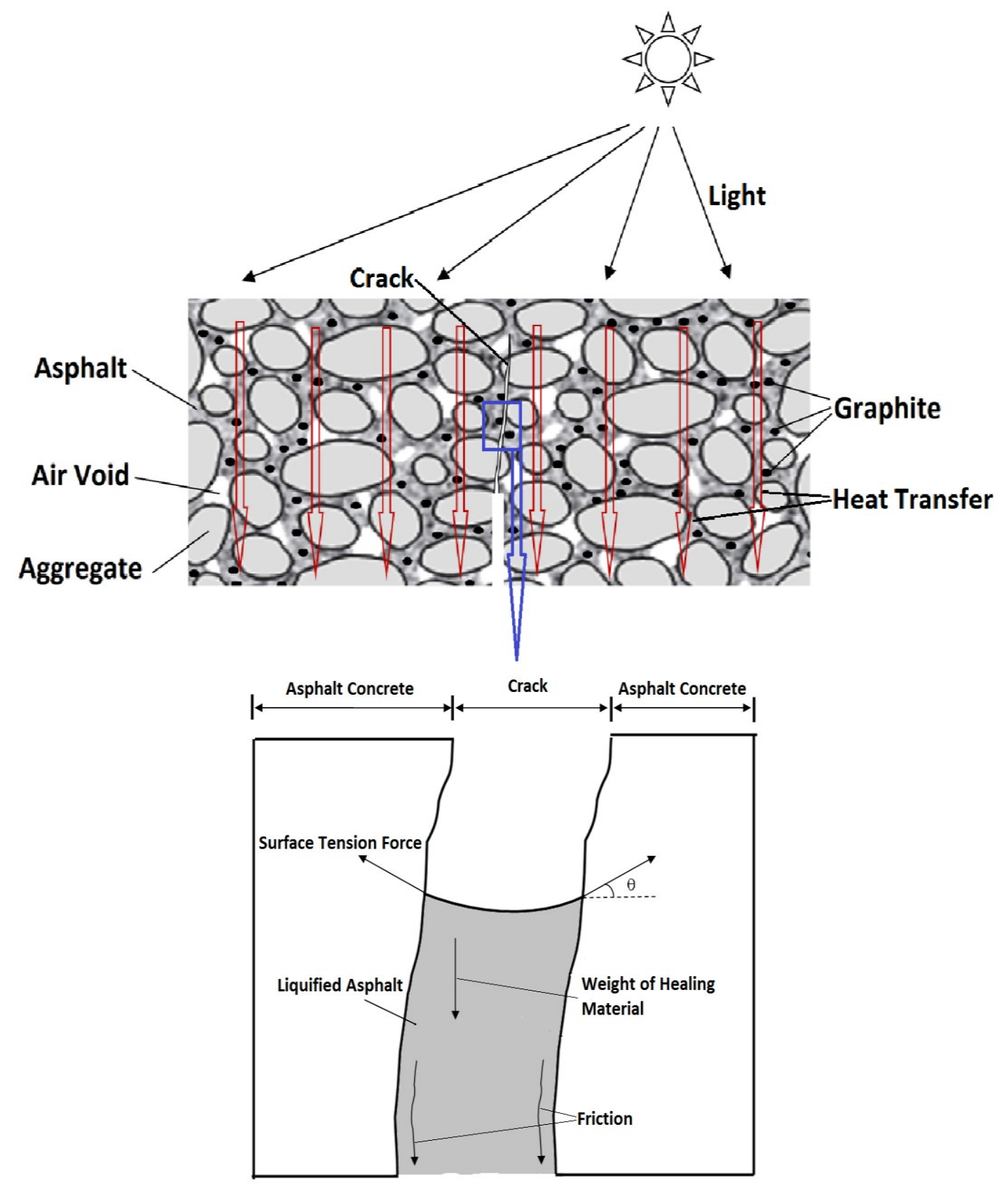

Figure 7. 1 Schematic demonstration of light healing mechanism for asphalt mixture within graphite material.

\subsubsection{Cyclic fracture-light healing test of asphalt mixture samples}

The cyclic fracture-light healing test was used to verify the light healing effect of the graphite modified asphalt mixture. It encompasses two processes, the sample 
fractured part and sample light healing part. In the sample fracture part, all of the beams were placed in a freezer for 6 hours to guarantee an internal temperature of -10 ${ }^{\circ} \mathrm{C}$. Subsequently, the beam was located on a modified elastic foundation instead of the regular three-point support, as shown in Figure 7.2. The purpose was to decrease the cracking speed of a beam compared to that of a beam implemented by the traditional three-point bending test and avoid overly damaged samples. The crack along the vertical direction of the tested beam was generated by applying a controlled load by a load cell with a decreasing speed of $0.5 \mathrm{~mm} / \mathrm{min}$. During the test, the loading machine was paused manually as long as the applying load increased to the maximum value (peak load) recorded in Table 7.4. Afterwards, the testing beam was laid in the air environment for about an hour until its temperature increased to room temperature for the whole light healing process. 
Table 7. 4 Peak loads (N) of control samples, flake graphite modified beams and xGNP modified beams under fracture-light healing cycles.

\begin{tabular}{|c|c|c|c|c|c|}
\hline Sample & $\begin{array}{l}\text { 1st } \\
\text { loading }\end{array}$ & $\begin{array}{l}\text { 2nd } \\
\text { loading }\end{array}$ & $\begin{array}{l}\text { 3th } \\
\text { loading }\end{array}$ & $\begin{array}{l}\text { 4th } \\
\text { loading }\end{array}$ & $\begin{array}{l}\text { 5th } \\
\text { loading }\end{array}$ \\
\hline Control No.1 & 4024.2 & 3450.8 & 1857.1 & 1832.9 & 1104.5 \\
\hline Control No.2 & 3492.6 & 1576.5 & 1324.7 & 1259.1 & 1167.2 \\
\hline Control No.3 & 4324.6 & 1689.7 & 1592.6 & 1519.9 & 1378.4 \\
\hline $\begin{array}{l}\text { Average of control } \\
\text { samples }\end{array}$ & 3947.1 & 2239.0 & 1591.5 & 1537.3 & 1216.7 \\
\hline $\begin{array}{l}\text { Flake graphite } \\
\text { No.1 }\end{array}$ & 4018.9 & 3505.6 & 3116.4 & 3046.1 & 2509.4 \\
\hline $\begin{array}{l}\text { Flake graphite } \\
\text { No.2 }\end{array}$ & 4645.0 & 4476.6 & 4378.2 & 3529.9 & 3258.1 \\
\hline $\begin{array}{l}\text { Flake graphite } \\
\text { No.3 }\end{array}$ & 3808.5 & 3807.8 & 2966.2 & 2773.9 & 2482.3 \\
\hline $\begin{array}{l}\text { Average of flake } \\
\text { graphite samples }\end{array}$ & 4157.5 & 3930.0 & 3486.9 & 3116.6 & 2749.9 \\
\hline xGNP No.1 & 4018.4 & 3428.8 & 3047.4 & 2640.7 & 2228.3 \\
\hline xGNP No. 2 & 3829.0 & 2516.5 & 2514.3 & 2373.3 & 1839.7 \\
\hline xGNP No.3 & 3750.0 & 2540.4 & 2459.4 & 2378.4 & 2190.7 \\
\hline $\begin{array}{l}\text { Average of } \mathrm{xGNP} \\
\text { samples }\end{array}$ & 3865.8 & 2828.6 & 2673.7 & 2464.1 & 2086.2 \\
\hline
\end{tabular}




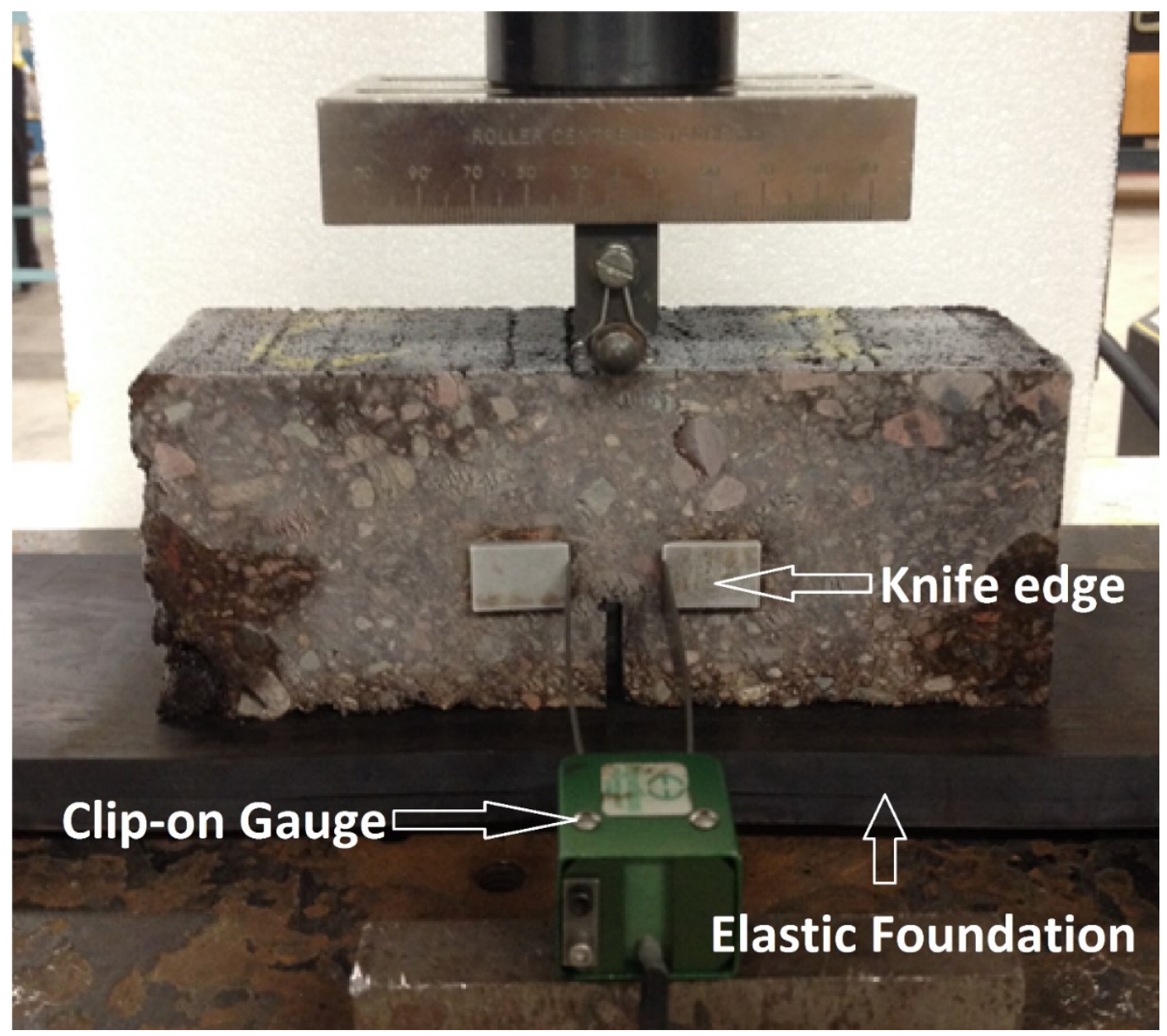

Figure 7.2 Demonstration of modified bending test of asphalt mixture beam with elastic foundation.

During the sample light healing process, the fractured sample was settled under a $300 \mathrm{w}$ infrared lamp with a distance of $10 \mathrm{~cm}$ between the top of the sample and bottom of the bulb shown in Fig. 7. The selected healing time was about several minutes. Later, the lamp was turned off and the sample kept being healed for around 30 minutes until its temperature decreased to room temperature. Then the healed sample was placed into the freezer for 6 hours and the controlled load was applied again. This repeated procedure was called cyclic fracture-light healing tests. In this research, five 
cycles of fracture-light healing tests were conducted to investigate the light healing effect of control, flake graphite and xGNP modified asphalt mixtures.

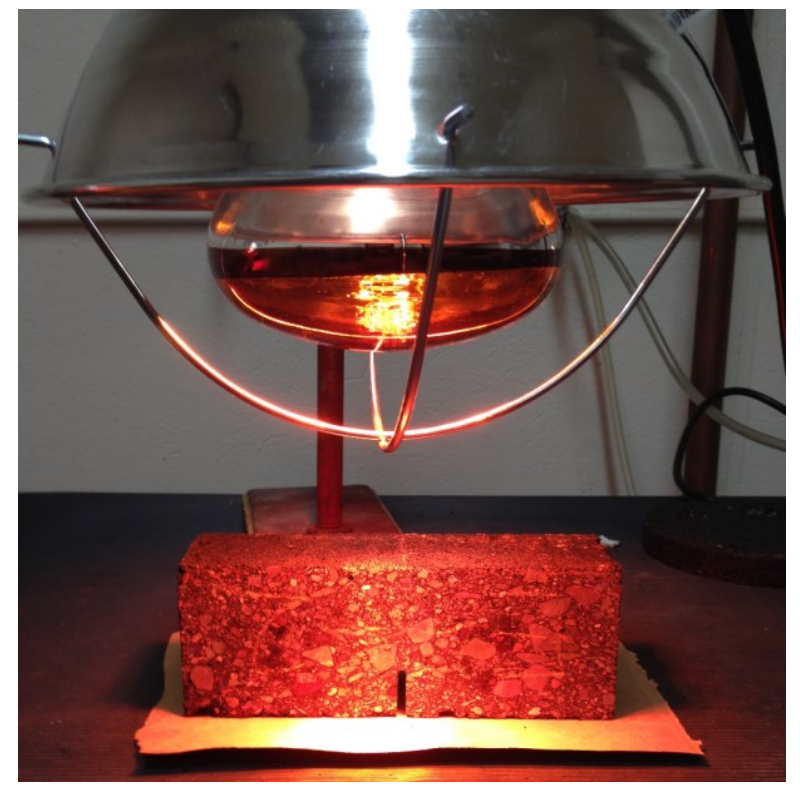

Figure 7. 3 Light healing system with $300 \mathrm{w}$ lamp.

\subsubsection{Temperature distribution of light-heated asphalt mixture samples}

During the light healing process with the selected healing period, the highest top surface temperature of the control asphalt mixture sample was in the range of $80{ }^{\circ} \mathrm{C}$ to $90{ }^{\circ} \mathrm{C}$. The highest top surface temperature of flake graphite modified asphalt mixture sample was in the range of $105^{\circ} \mathrm{C}$ to $110^{\circ} \mathrm{C}$. And the highest top surface temperature of xGNP modified asphalt mixture sample was in the range of $100{ }^{\circ} \mathrm{C}$ to $105{ }^{\circ} \mathrm{C}$. An infrared thermal camera (FLIR ThermaCAM ${ }_{\mathrm{TM}}$ SC640) was employed to capture the images of temperature distribution of three types of asphalt mixture samples. Figure 7.3 reveals the temperature distribution of the three types of asphalt mixture beam close to the end of light healing. The color bar represents the temperature variation in the samples. The yellow color and dark blue color indicate a high temperature and low 
temperature, respectively. It is observed that near the end of light healing, the highest temperatures appeared on the top sample surface of the control asphalt mixture sample, flake graphite modified asphalt mixture sample and xGNP modified asphalt mixture sample were $62.1{ }^{\circ} \mathrm{C}, 109{ }^{\circ} \mathrm{C}$ and $100{ }^{\circ} \mathrm{C}$, respectively. Meanwhile, the area of the yellow region in the thermal image of the flake graphite modified asphalt mixture beam is bigger than that of xGNP modified asphalt mixture beam. The area of the yellow region in the thermal image of the control asphalt mixture beam is smaller than the other two types of asphalt mixture beams. Therefore, the graphite materials have the capability to better absorb the light energy and to transfer the heat to the bottom of the samples faster. It is concluded that the light healing effect of the $5 \%$ flake graphite modified asphalt mixture sample is better than that of the control asphalt mixture sample and $2 \%$ xGNP modified asphalt mixture sample. The reason is that the asphalt around the crack of the flake graphite modified asphalt mixture sample can obtain more energy to flow and to possibly fill microcracks for healing process. 


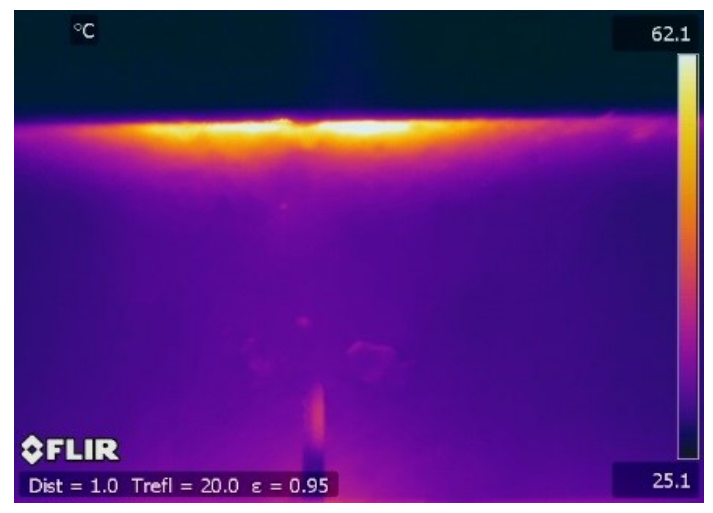

(a)

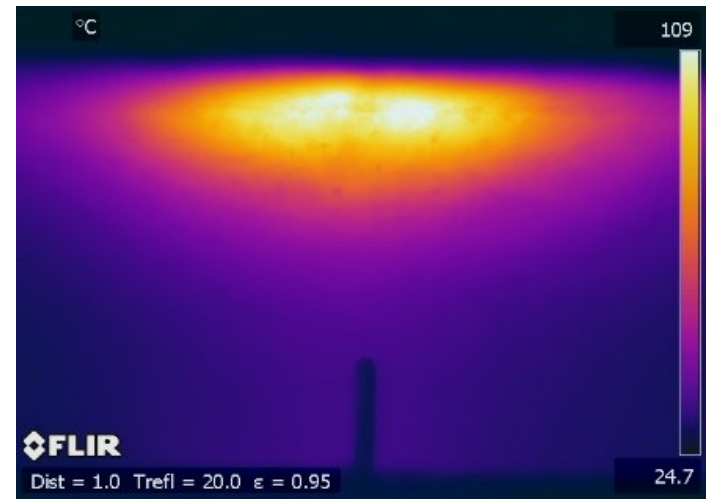

(b)

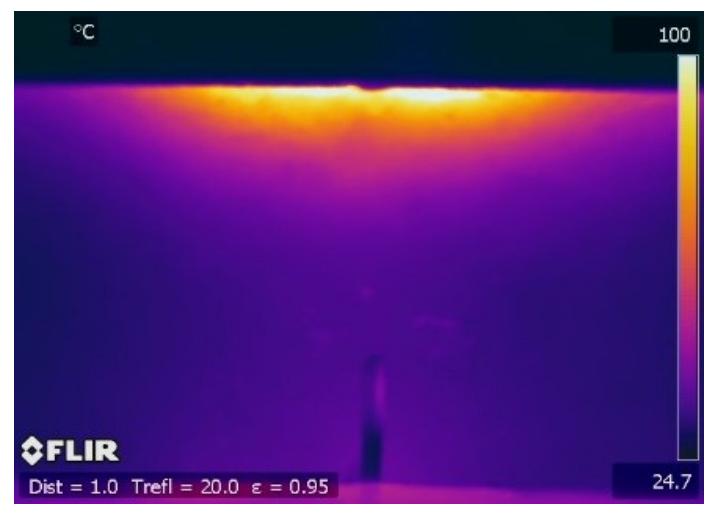

(c)

Figure 7. 4 Infrared images of temperature distribution in asphalt mixture samples after 8 minutes of light healing: (a) control asphalt mixture beam; (b) flake graphite modified asphalt mixture beam; (c) xGNP modified asphalt mixture beam. 201 


\subsubsection{DIC evaluation of the local healing strains changes with healing cycles}

In this study, for the fracture zone displacement analysis during light healing cycles, a MATLAB image toolbox DIC algorithm was used [132]. Initially, several control points (pixels) were selected in the reference image, and a size-adjustable subset of pixels was produced around each control point. Afterwards, the program searched the same pixels in the corresponding subset of the deformed image by a normalized cross-correlation coefficient, $C$ shown in Equation (7-1) [133]

$$
C\left(u^{\prime}, v^{\prime}\right)=\frac{\Sigma_{x^{\prime},}\left[\left(r\left(x^{\prime}, y^{\prime}\right)-\bar{r}_{u^{\prime}, v^{\prime}}\right)\left(d\left(x^{\prime}-u^{\prime}, y^{\prime}-v^{\prime}\right)-\bar{d}\right)\right]}{\left.\left\{\Sigma_{x, y}\left[\left(r\left(x^{\prime}, y^{\prime}\right)-\bar{r}_{u^{\prime}, v^{\prime}}\right)^{2}\right] \Sigma_{x^{\prime}, y}\left[d\left(x^{\prime}-u^{\prime}, y^{\prime}-v^{\prime}\right)-\bar{d}\right)^{2}\right]\right\}^{1 / 2}}
$$

where $C$ is the normalized cross-correlation coefficient, $r$ is the greyscale values of the pixels in the subset of the reference image, $d$ is the greyscale values of the pixels in the subset of the deformed image, $\left(x, y^{\prime}\right)$ are local coordinates of the subset center, and $\left(u^{\prime}, v^{\prime}\right)$ are the displacements between a pixel and the subset center. If the normalized cross-correlation coefficient of a pixel in the subset of the deformed image exceeded the threshold (typically 0.5), this pixel was regarded as the same pixel in the reference image. This process was called the DIC. Then displacements (pixels) of this point between the reference image and the deformed image were computed.

In this study, three tested samples, including a control asphalt mixture beam, a flake graphite modified asphalt mixture beam and an xGNP modified mixture beam were analyzed by DIC for three cycles of the light healing process. About 400 points (pixels) were chosen to be analyzed by DIC in each reference image of three different samples. Then the displacements of each selected point between the reference image 
and the deformed image for each cycle of the light healing process were computed. Figure 7.4 (a)-(c) presents three sets of local images of the control asphalt mixture beam. Each set has two images representing the crack width of the beam sample before and after light healing and a pixel displacement vector plot as a result of DIC analysis. The vectors indicate both the direction and the magnitude of a selected pixel (sample particle) displacement. Figure 7.5 (a)-(c) exhibits three sets of local images of the flake graphite modified asphalt mixture beam. Figure 7.6 (a)-(c) displays the similar pattern of local images of the xGNP modified asphalt mixture beam. It is observed that the cracks of three different asphalt mixture samples can all be healed at different degrees over cycles. The detailed results are listed in Table 7.5, including average, maximum and median pixel displacements of three tested samples before and after three cycles of light healing. It is observed that the average, maximum and median displacements of all the selected pixels decrease with light healing cycles. The light healing effect decreases with light healing cycles for all the samples. 
Table 7.5 Average, maximum, and median displacements (pixels) of control asphalt mixture sample, flake graphite modified asphalt mixture sample and xGNP modified asphalt mixture sample under cyclic light healing process by DIC analysis.

\begin{tabular}{|c|c|c|c|c|c|c|c|c|c|}
\hline \multirow{2}{*}{$\begin{array}{l}\text { Sampl } \\
\mathrm{e} \\
\text { Cycle }\end{array}$} & \multicolumn{3}{|c|}{ Control } & \multicolumn{3}{|c|}{$\begin{array}{ll}\text { Flake } & \text { graphite } \\
\text { Modified } & \end{array}$} & \multicolumn{3}{|c|}{ xGNP Modified } \\
\hline & $\begin{array}{l}\text { Cycle } \\
1\end{array}$ & $\begin{array}{l}\text { Cycle } \\
2\end{array}$ & $\begin{array}{l}\text { Cycle } \\
3\end{array}$ & $\begin{array}{l}\text { Cycle } \\
1\end{array}$ & $\begin{array}{l}\text { Cycle } \\
2\end{array}$ & $\begin{array}{l}\text { Cycle } \\
3\end{array}$ & $\begin{array}{l}\text { Cycle } \\
1\end{array}$ & $\begin{array}{l}\text { Cycle } \\
2\end{array}$ & $\begin{array}{l}\text { Cycle } \\
3\end{array}$ \\
\hline $\begin{array}{l}\text { Avera } \\
\text { ge } \\
\text { disp. }\end{array}$ & 7.91 & 7.86 & 5.60 & 2.69 & 2.54 & 1.52 & 5.27 & 350 & 347 \\
\hline $\begin{array}{l}\text { Maxi } \\
\text { mum } \\
\text { disp. }\end{array}$ & 10.47 & 10.48 & 8.94 & 5.88 & 4.33 & 2.46 & 7.11 & 7.05 & 6.90 \\
\hline $\begin{array}{l}\text { Media } \\
\text { n } \\
\text { disp. }\end{array}$ & 7.99 & 7.95 & 4.62 & 2.49 & 2.27 & 1.69 & 5.34 & 3.52 & 3.54 \\
\hline
\end{tabular}



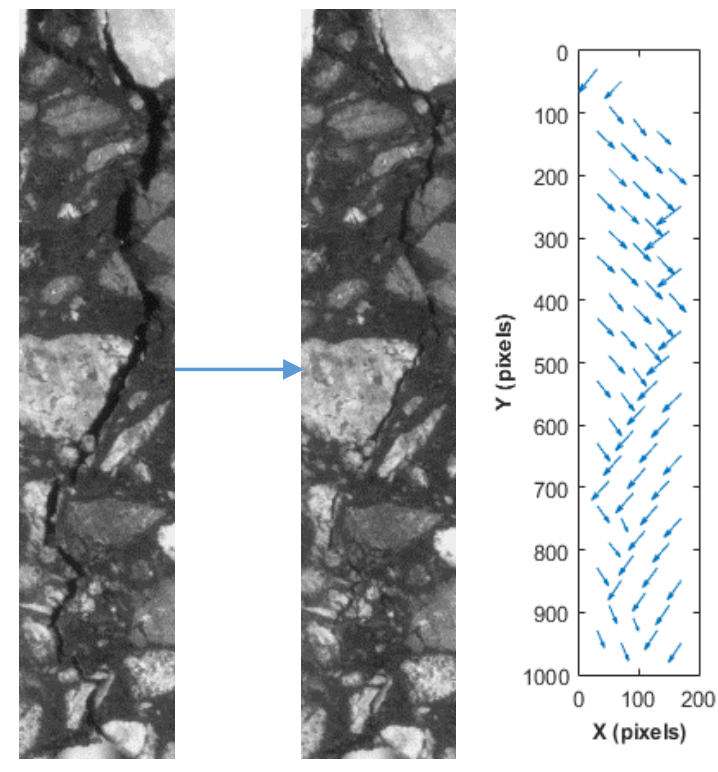

(a)
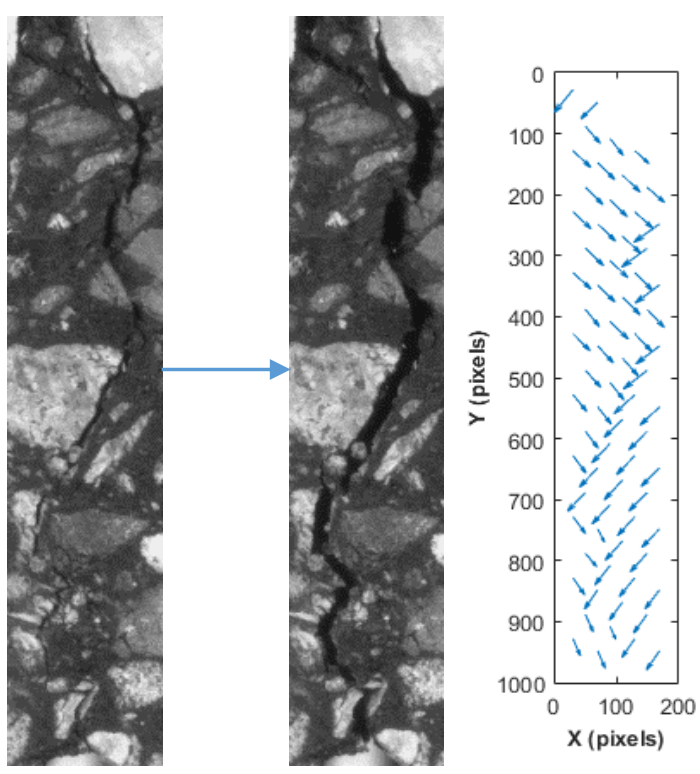

(b) 

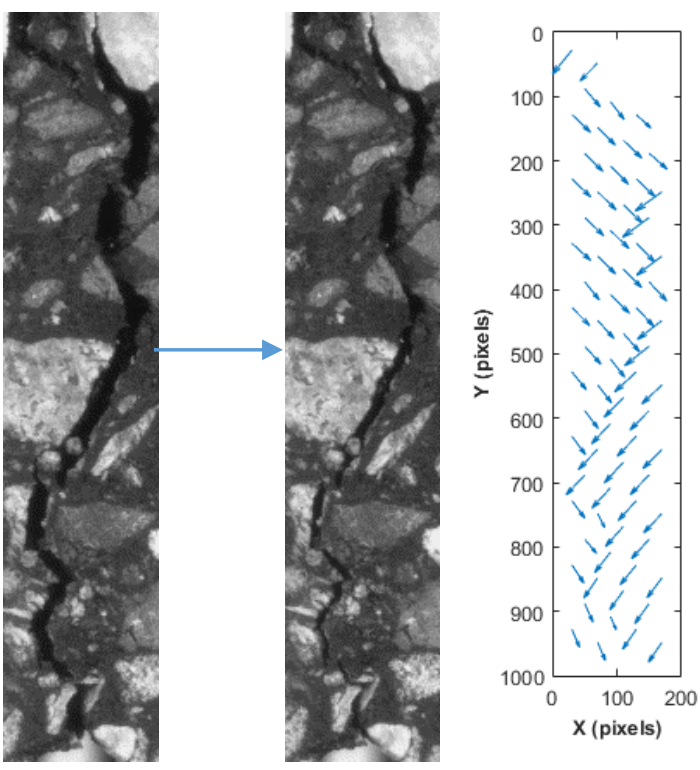

(c)

Figure 7. 5 Demonstration of DIC analysis of local No.1 control asphalt mixture sample on cyclic fracture-light healing tests, before light healing (reference image), after light healing (deformed image) and a vector plot of the displacement field for each set of images: (a) first light healing process; (b) second light healing process; (c) third light healing process. 

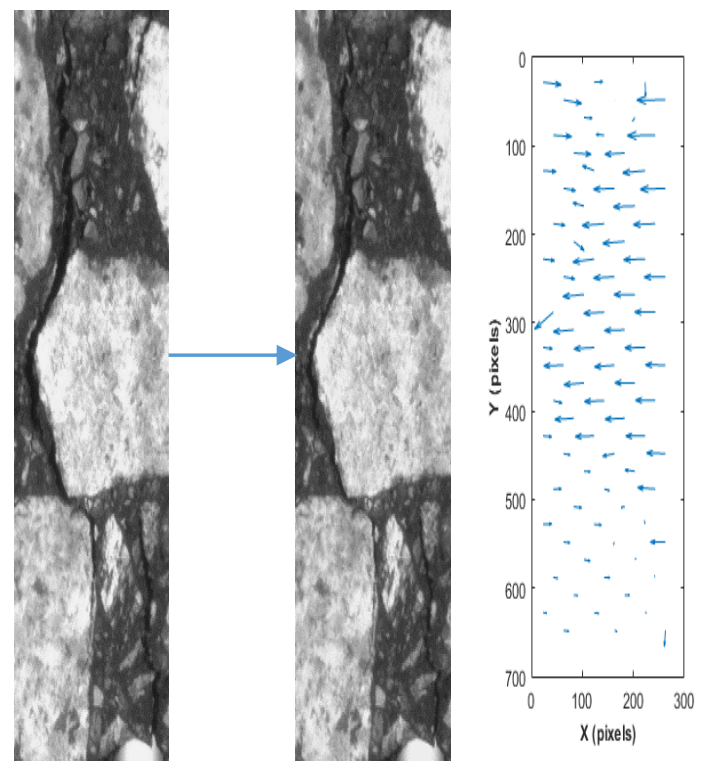

(a)
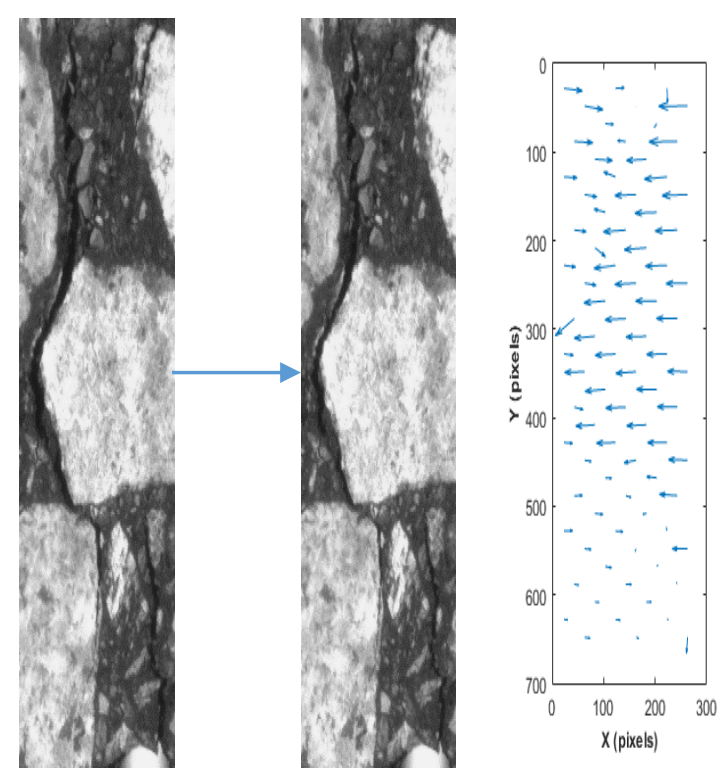

(b) 

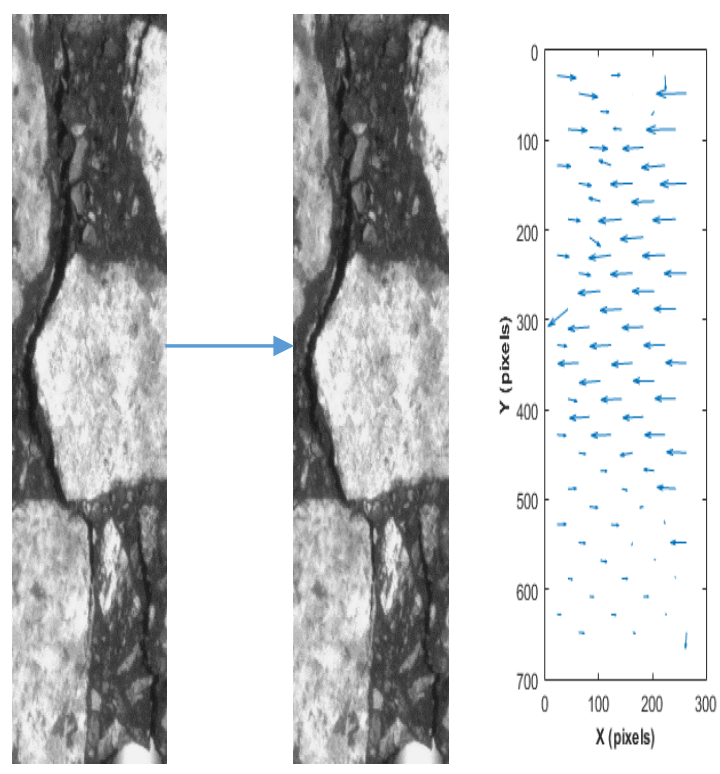

(c)

Figure 7. 6 Demonstration of DIC analysis of local No.1 flake graphite modified mixture sample on cyclic fracture-light healing tests, before light healing (reference image), after light healing (deformed image) and a vector plot of the displacement field for each set of images: (a) first light healing process; (b) second light healing process; (c) third light healing process. 


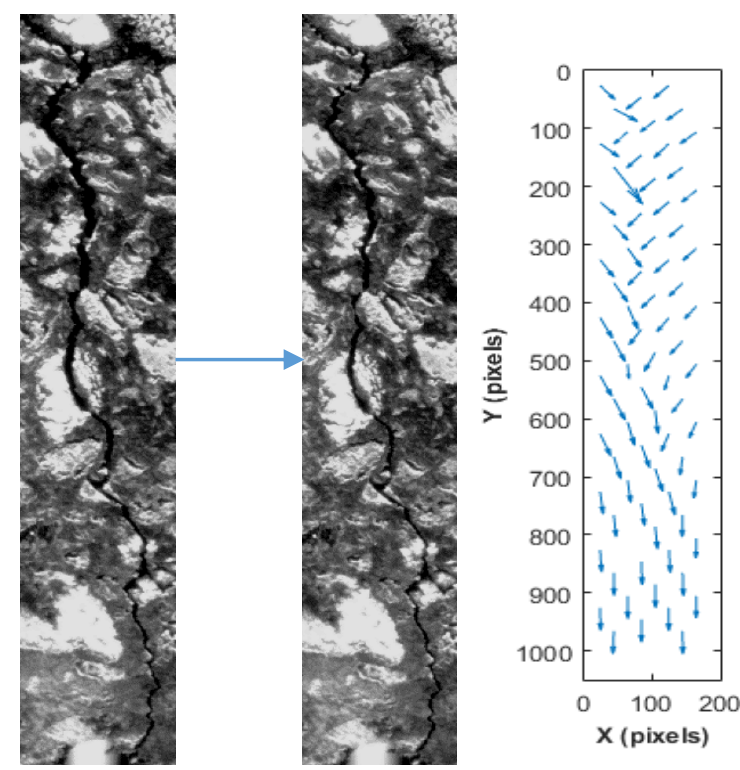

(a)
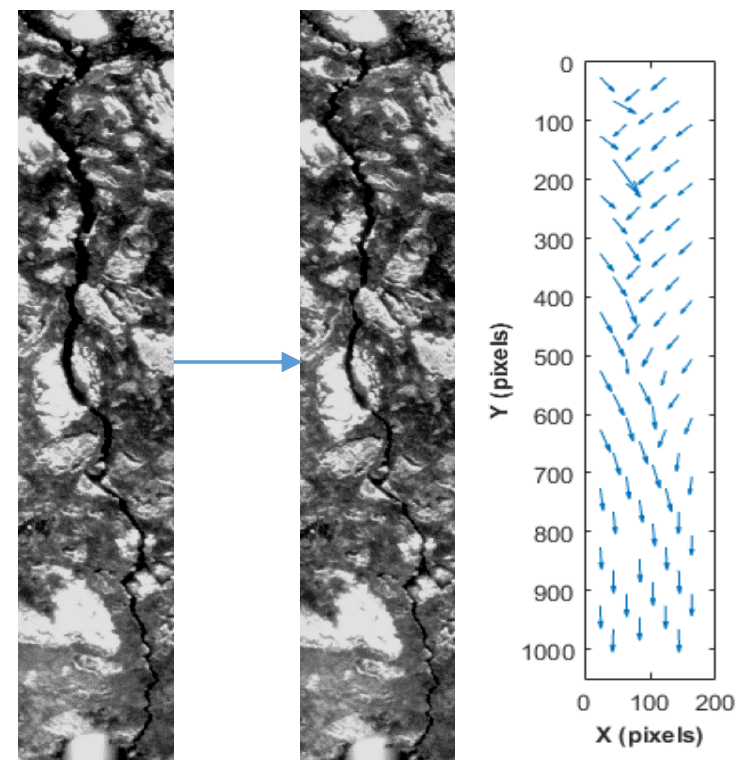

(b) 

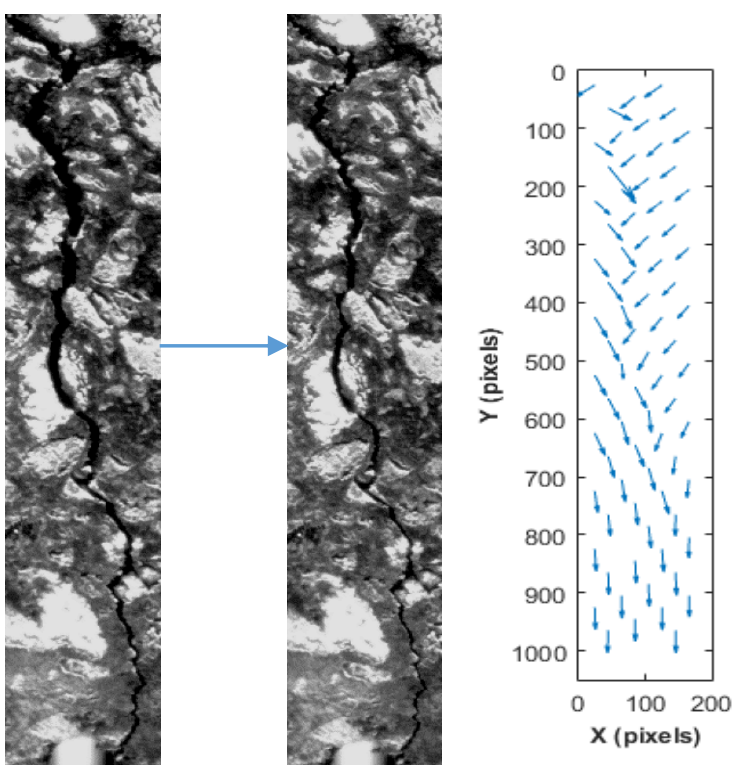

(c)

Figure 7. 7 Demonstration of DIC analysis of local No.1 xGNP modified mixture sample on cyclic fracture-light healing tests, before light healing (reference image), after light healing (deformed image) and a vector plot of the displacement field for each set of images: (a) first light healing process; (b) second light healing process; (c) third light healing process.

\subsection{Cyclic fracture-light healing test results of asphalt mixture samples}

In this research, the recovered peak loads of all the samples were obtained from cyclic fracture-light healing tests. And the results were used to verify the effect of light healing recorded in Table 7.4. It is observed that the range of original peak loads is from $3400 \mathrm{~N}$ to $4700 \mathrm{~N}$.

Figure 7.7-7.9 exhibit the fracture-light healing tests data of three control asphalt mixture samples, three flake graphite modified asphalt mixture samples and three xGNP modified asphalt mixture samples, respectively. The $\mathrm{x}$-axis represents the 
CTOD and the y-axis represents the loads. In Figure 7, the original peak loads are in the range of $3400 \mathrm{~N}$ to $4400 \mathrm{~N}$, and are reduced to the range of $1100 \mathrm{~N}$ to $1300 \mathrm{~N}$ after five fracture-light healing cycles. Table 7.6 lists the ratio of recovered peak loads (recovered peak load/original peak load) of asphalt mixture samples after each fracturelight healing cycles. The average ratio of recovered peak loads after the second cycle remains $56.7 \%$ and reduces to $40.3 \%, 39.0 \%$ and $30.9 \%$ constantly. Figure 7.8 demonstrates the fracture-light healing data of three flake graphite modified asphalt mixture samples. The range of original peak loads is from $3800 \mathrm{~N}$ to $4700 \mathrm{~N}$. The average ratio of recovered peak loads is $94.5 \%$ after the second fracture-light healing cycle and still remains $65.9 \%$ even after five cycles, displayed in Table 7.6. The original peak loads of three xGNP modified asphalt mixture samples are in the range of $3700 \mathrm{~N}$ to $4100 \mathrm{~N}$ presented in Figure 7.9. The mean original ratio of recovered peak loads is $72.9 \%$ and then gradually decreases to $69.0 \%, 63.7 \%$ and $54.0 \%$. Accordingly, the light healing performance of flake graphite modified asphalt mixture samples is better than that of xGNP modified asphalt mixture samples. The light healing performance of the control asphalt mixture sample is lower than that of the other two types of graphite-modified asphalt mixture samples. The experimental results showed that both the added flake graphite and xGNP have the ability to enhance the light healing performance of asphalt mixture material. This study demonstrate the promising light healing technique with graphite-modified asphalt mixtures. 
Table 7. 6 Ratio (\%) of recovered peak loads (RPL) of control samples, flake graphite modified beams and xGNP modified beams.

\begin{tabular}{|c|c|c|c|c|}
\hline Sample & $\begin{array}{l}\text { 2nd loading } \\
\text { after } 1 \text { cycle }\end{array}$ & $\begin{array}{l}3^{\text {rd }} \text { loading } \\
\text { after } 2 \text { cycles }\end{array}$ & $\begin{array}{l}4^{\text {th }} \text { loading } \\
\text { after } 3 \text { cycles }\end{array}$ & $\begin{array}{l}5 \text { th loading } \\
\text { after } 4 \text { cycles }\end{array}$ \\
\hline Control No.1 & $85.8 \%$ & $46.2 \%$ & $45.6 \%$ & $27.5 \%$ \\
\hline Control No.2 & $45.1 \%$ & $37.9 \%$ & $36.1 \%$ & $33.4 \%$ \\
\hline Control No.3 & $39.1 \%$ & $36.8 \%$ & $35.2 \%$ & $31.9 \%$ \\
\hline $\begin{array}{l}\text { Average of } \\
\text { control samples }\end{array}$ & $56.7 \%$ & $40.3 \%$ & $39.0 \%$ & $30.9 \%$ \\
\hline $\begin{array}{l}\text { Flake graphite } \\
\text { No.1 }\end{array}$ & $87.2 \%$ & $77.5 \%$ & $75.8 \%$ & $62.4 \%$ \\
\hline $\begin{array}{l}\text { Flake graphite } \\
\text { No.2 }\end{array}$ & $96.4 \%$ & $94.3 \%$ & $76.0 \%$ & $70.1 \%$ \\
\hline $\begin{array}{l}\text { Flake graphite } \\
\text { No.3 }\end{array}$ & $100.0 \%$ & $77.9 \%$ & $72.8 \%$ & $65.2 \%$ \\
\hline $\begin{array}{l}\text { Average of flake } \\
\text { graphite samples }\end{array}$ & $94.5 \%$ & $83.2 \%$ & $74.9 \%$ & $65.9 \%$ \\
\hline xGNP No.1 & $85.3 \%$ & $75.8 \%$ & $65.7 \%$ & $55.5 \%$ \\
\hline xGNP No.2 & $65.7 \%$ & $65.7 \%$ & $62.0 \%$ & $48.1 \%$ \\
\hline xGNP No.3 & $67.7 \%$ & $65.6 \%$ & $63.4 \%$ & $58.4 \%$ \\
\hline $\begin{array}{l}\text { Average of } \\
\text { xGNP samples }\end{array}$ & $72.9 \%$ & $69.0 \%$ & $63.7 \%$ & $54.0 \%$ \\
\hline
\end{tabular}




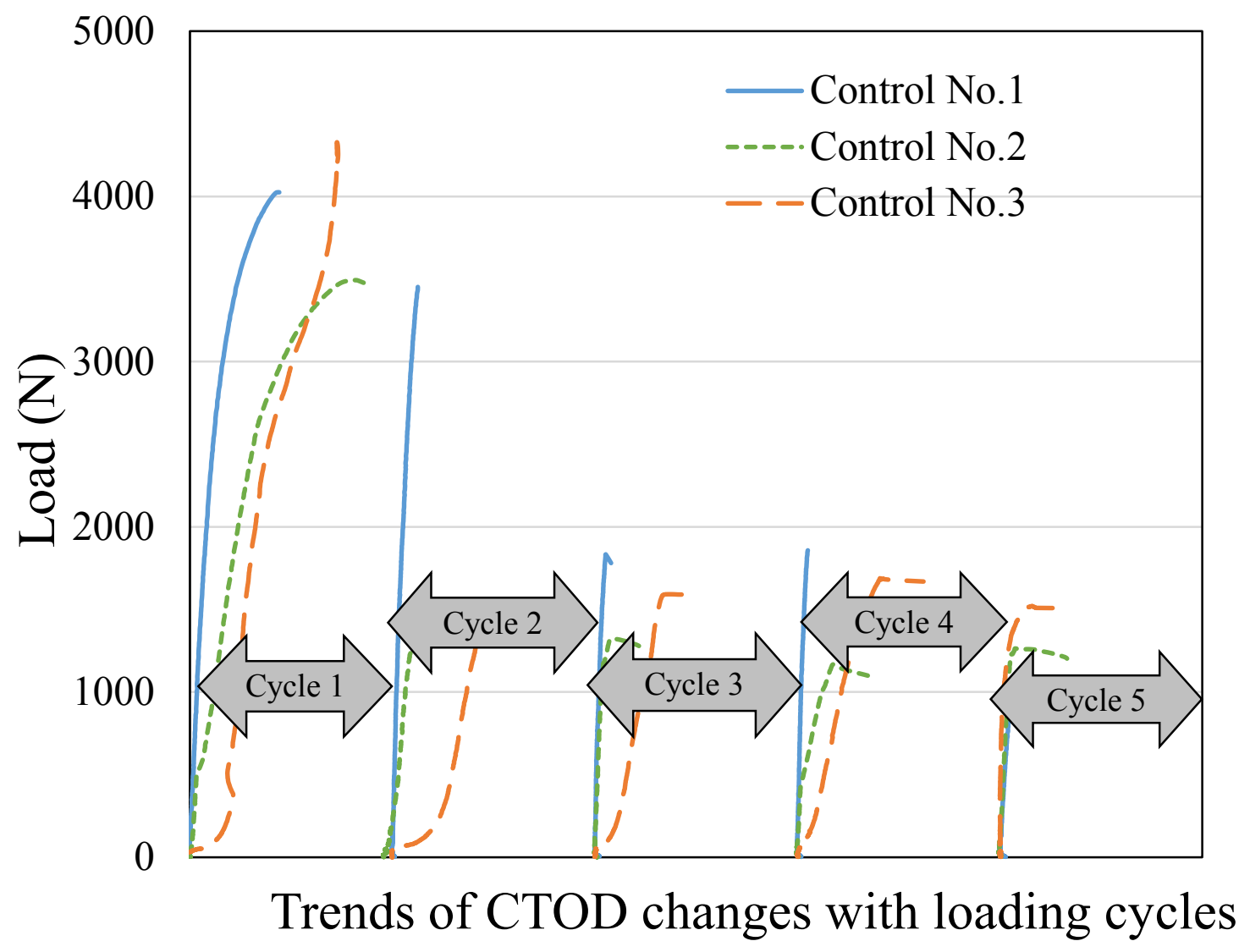

Figure 7. 8 Fracture-light healing test data of control asphalt mixture samples. 


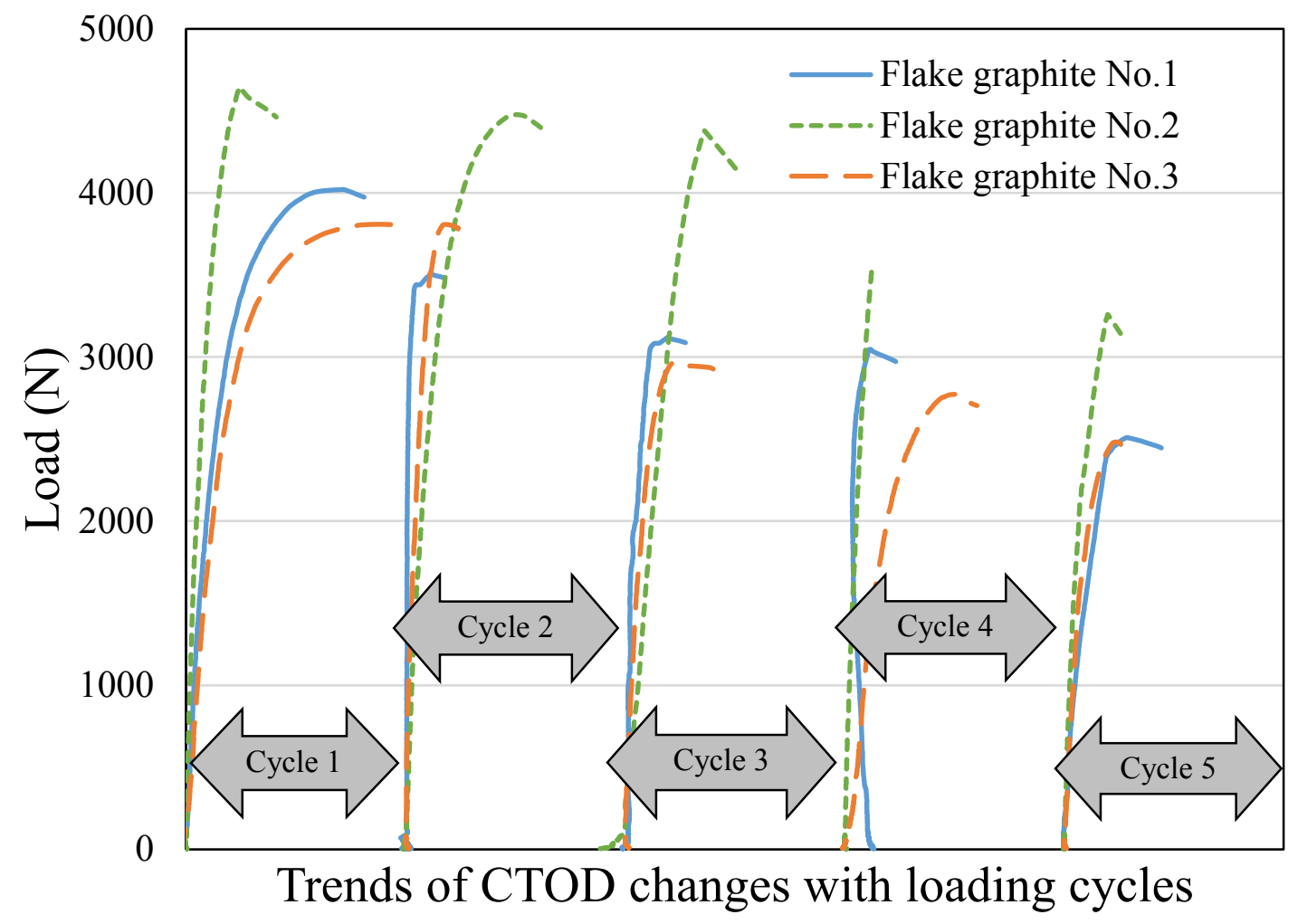

Figure 7.9 Fracture-light healing test data of asphalt mixture samples within flake graphite. 


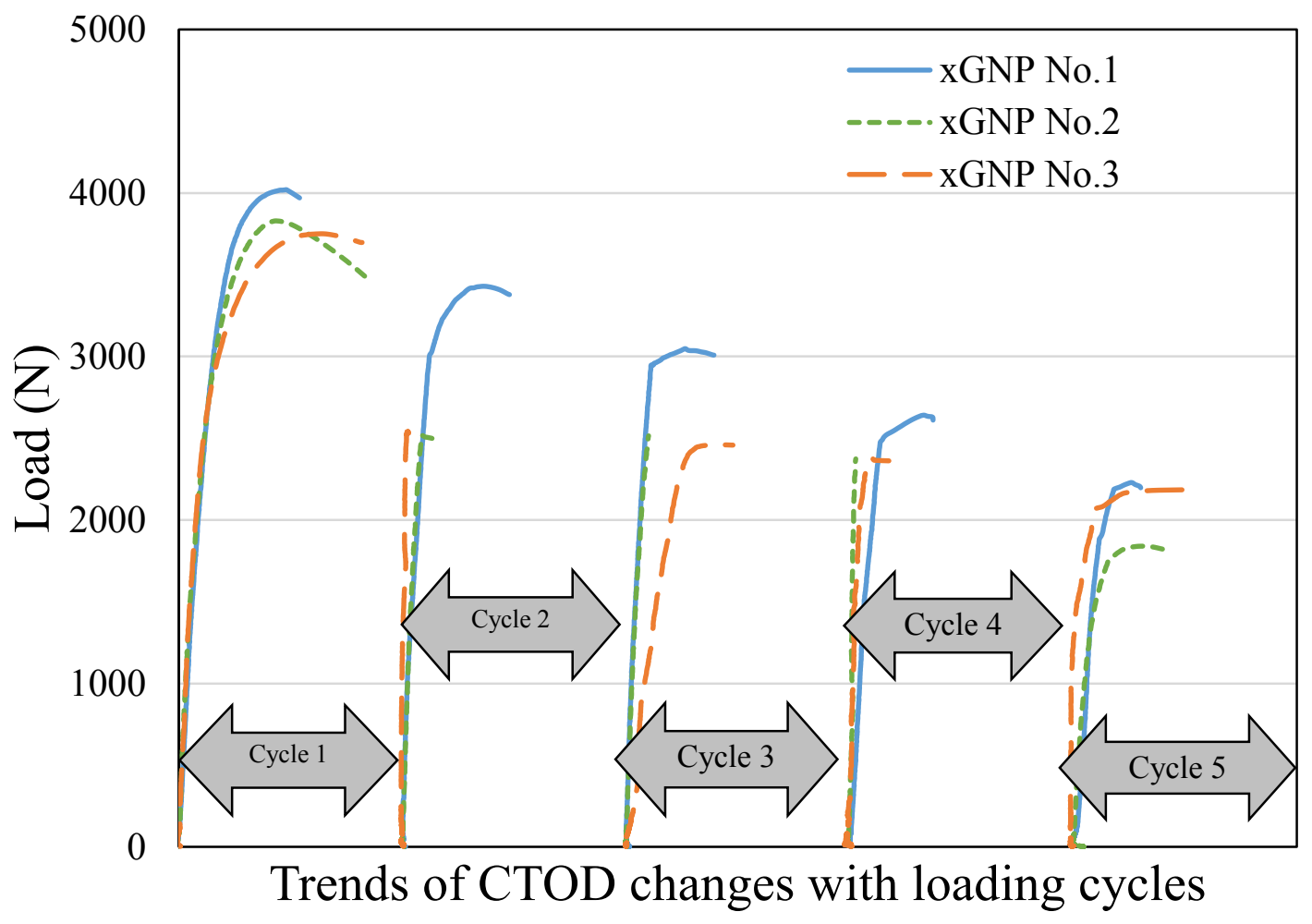

Figure 7.10 Fracture-light healing test data of asphalt mixture samples within xGNP.

\subsection{Summary and conclusions}

In this research, the light healing effect of control, $5 \%$ flake graphite modified and $2 \% \mathrm{xGNP}$ modified asphalt mixture samples was investigated. The infrared images of asphalt mixture samples conclude that both the 5\% flake graphite and 2\% xGNP modified asphalt mixtures could better absorb the light energy and transfer the heat from top to bottom than the control asphalt mixtures. The DIC analysis results of pixel displacements in the light healing processes indicates that the visible/infrared light is an effective way to heal the fractured asphalt mixture sample. The healing effect decreases with light healing cycles. The recovered peak loads from the cyclic fracturelight healing tests showed that both the 5\% flake graphite and 2\% xGNP modified 
asphalt mixtures have improved light healing performance compared with the control asphalt mixture. The $5 \%$ flake graphite modified asphalt mixtures have better healing performance than the $2 \%$ xGNP modified asphalt mixtures. 


\title{
CHAPTER 8 FRACTURE MODEL DEVELOPMENT FOR GRAPHITE MODIFIED MIXTURE SAMPLES WITH DIGITAL IMAGE CORRELATION
}

\begin{abstract}
ANALYSIS*
\end{abstract}

\subsection{Introduction}

Asphalt mixture consists of asphalt, graded aggregates and air voids [85]. The temperature-dependent asphalt binder behaves as viscous flow at high temperatures and as viscoelastic solid at low temperatures [4]. In the United States, $94 \%$ of the pavement's surface was constructed with asphalt mixtures [1]. Increasing traffic loads and changing climatic conditions challenge the pavement's durability and service life. In addition, the pavement performance can be quickly weakened with initial microcrack developments followed by combined pavement distresses [52].

The asphalt mixture has the self-healing ability to repair the micro-cracks caused by traffic loads and variable temperature [64]. This self-healing behavior is mainly limited by two main factors, rest period and pavement temperature [33, 87]. The asphalt begins to fill the existing micro-cracks in the asphalt mixture once the external energy is input. If the external energy or the rest period is adequate, the cracks can be healed almost completely [64]. The mixture self-healing process mainly involves with asphalt Newtonian flow [41]. The prerequisite of initiating this process is to increase the asphalt's temperature to exceed the transition temperature. Afterwards, the asphalt binder can behave as Newtonian fluid. The composites and components of

* Text was submitted to Journal of Materials in Civil Engineering —Wang, Z., Dai, Q "Evaluation of Recovered Fracture Strength after Light Healing of Graphite Modified Asphalt Mixtures with Integrated Computational-Experimental Approach.” (2016). 
asphalt affect the transition temperature in $30{ }^{\circ} \mathrm{C}$ to $70{ }^{\circ} \mathrm{C}$ range [100-103]. Shen et al. [12] studied that the healing behavior related to loading and environmental conditions was regarded as a complex process, incorporating activation energy, capillary flow, intermolecular diffusion and molecules wetting. Additionally, the self-healing behavior was affected by the crack size, material type and modification $[11,14,41]$.

The visible/near-field infrared lights considered as an easily obtained solar energy could be utilized to heal the micro-cracks in pavement surface. However, the light absorption (specifically the near-field infrared light absorption) and thermal conductivity of asphalt mixture are relatively low [104, 105]. Therefore, graphite materials that have the ability to increase the light absorbance and thermal conductivity of composites are necessary to be combined with asphalt mixture to promote the light healing process [134]. Liu et al. [107] found that manufactured flake graphite had high thermal conductivity between graphite layers. Kim et al. [106] proposed that exfoliated graphite nanoplatelets had the ability to increase the material's thermal conductivity. Asphalt mixture added in microcrystal graphite powders was used to collect solar energy for adjusting building's and pavement's temperature by Wu et al. [109]. Chen et al. [110] applied graphite powders to improve the thermal conductivity of asphalt mixture for melting snow. Pan et al. [112] proposed a model to describe thermal conductivity and diffusivity of graphite modified asphalt changed based on the ratio of graphite amount.

Cohesive zone model (CZM) was widely applied for fracture simulation of different materials $[71,72,135]$ after the pioneer research by Prandtl [136]. The CZM 
techniques defined the relation between surface traction and crack opening displacement [137], such as bilinear model [72] and exponential model [138]. To date, the CZM techniques have been employed to simulate both the homogeneous and heterogeneous materials. Fractures in civil engineering materials have been studied over the past decade [139-141]. The implementation of CZM techniques needed the inputs of model parameters including fracture energy and material strength determined from fracture tests such as three-point beam bending test $[71,88,142]$.

Digital image correlation (DIC) method is a technique used to measure the pixel displacement or deformation between two relative images [113]. One is the reference image and the other is the deformed image. The DIC algorithm could detect the grayscale value of a pixel between the reference image and then find the location of that pixel in the deformed image by matching the grayscale value [114]. This technique has been applied to study the fracture behavior through monitoring crack open displacement. Kuntz et al. [115] measured the displacement of a shear crack in a concrete beam during the loading test by digital image cross-correlation. Rastiello et al. [117] developed a relation between crack surface and mid-height crack opening displacement by the DIC method.

The main objective of this study is to use a cohesive zone model and finite element method to numerically investigate the recovered fracture strength of asphalt mixture beams during the cyclic fracture-light healing tests. Firstly, the cohesive zone finite element model was applied to predict the fracture behavior of the original beam samples. The fracture energy of the samples were measured with the three-point 
bending test. The fracture simulation was conducted by using the cross-section image of one single-edged notched control beam. Both fracture behavior and crack path development were compared with experimental data. Secondly, for the samples after fracture-light healing cycles, the DIC analysis was used to calculate the relative strain ratios by considering the crack displacement changes after healing and reloading. Two key input parameters, calibrated fracture energy and peak separation stress, were used to simulate the cyclic fracture-light healing tests based on DIC analysis. Finally, the predicted peak loads from both original and healed beam samples were compared with the corresponding experimental peak loads. The cohesive zone fracture simulation has very reasonable prediction on the recovered fracture strength of asphalt mixture beam.

\subsection{Asphalt mixture sample preparation and fracture-light healing tests results}

\subsubsection{Asphalt mixture beam preparation}

The materials used in this research were asphalt binder, aggregates, flake graphite and exfoliated graphite nanoplatelets (xGNP). The asphalt binder was PG 58-28 with a density of $1.024 \mathrm{~g} / \mathrm{cm}^{3}$. The aggregates were purchased in Hancock, MI with a density of $2.72 \mathrm{~g} / \mathrm{cm}^{3}$. The flake graphite was attained from Asbury Carbons with a density of $2.25 \mathrm{~g} / \mathrm{cm}^{3}$. Its particle sizes distribution is described as: about $75 \%$ of the No.100 and $25 \%$ of the No.200 sizes. The minimum layer thickness of the flake graphite was 0.11

$\mathrm{mm}$. The $\mathrm{xGNP}$ was offered by XG Sciences with a bulk density of $0.03-0.1 \mathrm{~g} / \mathrm{cm}^{3}$. The particle diameter was 25 microns and the average thickness was approximately 15 nanometers. The untreated graphite materials, flake graphite and xGNP, were added separately to asphalt, blended by a high speed mixer for about one hour at $120^{\circ} \mathrm{C}$. The 
amounts of graphite materials used were $5 \%$ for flake graphite and $2 \%$ for $\mathrm{xGNP}$ by weight of asphalt. Then three types of the asphalt mixture samples were produced, including the control, flake graphite modified and xGNP modified asphalt mixture samples. The aggregate gradations of the control, flake graphite modified and xGNP modified asphalt mixtures are listed in Table 8.1. Based on the Superpave volumetric design guide, the added graphite powders were regarded as the fine aggregates to keep volumetric consistent for the preparation of the graphite modified asphalt mixture samples. Therefore, it is observed that about $4.9 \mathrm{~g}$ of the No.100 aggregates and $1.6 \mathrm{~g}$ of the No.200 aggregates were replaced by the flake graphite. In a similar way, nearly $2.4 \mathrm{~g}$ of the pan powder was replaced by the xGNP. The ratio of the asphalt used was $5.2 \%$ by weight of asphalt mixture for all the samples. The asphalt mixture samples used were beams with a dimension of $190 \mathrm{~mm} \times 50 \mathrm{~mm} \times 69 \mathrm{~mm}$. A $3 \mathrm{~mm}$ wide, 23 mm deep notch was sawn in the center of the beams to limit the initial fracture position. Two knife edges with a distance of $20 \mathrm{~mm}$ were glued on the top notch of each beam sample to measure the crack opening tip displacement (CTOD) by a clip-on gauge discussed in the following sections. 
Table 8. 1 Aggregate gradation of control, flake graphite modified and xGNP modified asphalt mixture.

\begin{tabular}{|c|c|c|c|}
\hline $\begin{array}{l}\text { Sieve } \\
\text { number }\end{array}$ & $\begin{array}{l}\text { Aggregate mass of } \\
\text { control asphalt } \\
\text { mixture (g) }\end{array}$ & $\begin{array}{l}\text { Aggregate mass of } \\
\text { flake graphite } \\
\text { modified asphalt } \\
\text { mixture (g) }\end{array}$ & $\begin{array}{l}\text { Aggregate mass of } \\
\text { xGNP modified } \\
\text { asphalt mixture }(\mathrm{g})\end{array}$ \\
\hline $1 / 2$ & 157.3 & 157.3 & 157.3 \\
\hline $3 / 8$ & 1476.3 & 1476.3 & 1476.3 \\
\hline No. 4 & 1778.9 & 1778.9 & 1778.9 \\
\hline No. 8 & 2468.6 & 2468.6 & 2468.6 \\
\hline No. 16 & 1851.5 & 1851.5 & 1851.5 \\
\hline No. 30 & 1282.7 & 1282.7 & 1282.7 \\
\hline No. 50 & 1306.9 & 1306.9 & 1306.9 \\
\hline $\begin{array}{l}\text { No. } \\
100\end{array}$ & 847.1 & 842.2 & 844.9 \\
\hline $\begin{array}{l}\text { No. } \\
200\end{array}$ & 278.3 & 276.7 & 277.6 \\
\hline $\begin{array}{l}\text { Pan } \\
\text { powder }\end{array}$ & 653.5 & 653.5 & 650.5 \\
\hline
\end{tabular}




\subsubsection{Results of cyclic fracture-light healing tests}

The cyclic fracture-light healing tests were conducted to evaluate the light healing performance of graphite modified asphalt mixture materials. Firstly, a tested beam was placed on an elastic foundation at $-10{ }^{\circ} \mathrm{C}$. An impact roller applied the load on the beam with descending speed of $0.5 \mathrm{~mm} / \mathrm{min}$, shown in Figure $8-1$ (a). When the load increased to the peak value, the loading machine was ceased manually to avoid overly damaging the sample. After the temperature of the fractured beam increased to $20{ }^{\circ} \mathrm{C}$, it was heated by a $300 \mathrm{w}$ lamp with a distance of $10 \mathrm{~cm}$ between the bottom of the bulb and the top of the beam for several minutes, displayed in Figure 8.1 (b). Then the fractured beam was rested and self-healed for about $30 \mathrm{~min}$ until the temperature decreased to $20{ }^{\circ} \mathrm{C}$. This repeated procedure was called cyclic fracture-light healing tests. Five cycles was conducted for all the three types of samples in this study. The peak loads of all the samples were utilized to investigate the recovered strength, listed in Table 8.2. These data were compared with the simulation results discussed in the following sections. 
Table 8. 2 Peak loads (N) of control samples, flake graphite samples and xGNP samples under fracture-light healing cycles.

\begin{tabular}{|l|l|l|l|l|l|}
\hline Specimen & 1st & 2nd & 3th & 4 th & th \\
& loading & loading & loading & loading & loading \\
\hline Control No.1 & 4024.2 & 3450.8 & 1857.1 & 1832.9 & 1104.5 \\
\hline Control No.2 & 3492.6 & 1576.5 & 1324.7 & 1259.1 & 1167.2 \\
\hline Control No.3 & 4324.6 & 1689.7 & 1592.6 & 1519.9 & 1378.4 \\
\hline Average of control & 3947.1 & 2239.0 & 1591.5 & 1537.3 & 1216.7 \\
\hline samples & & & & & \\
\hline Flake graphite No.1 & 4018.9 & 3505.6 & 3116.4 & 3046.1 & 2509.4 \\
\hline Flake graphite No.2 & 4645.0 & 4476.6 & 4378.2 & 3529.9 & 3258.1 \\
\hline Flake graphite No.3 & 3808.5 & 3807.8 & 2966.2 & 2773.9 & 2482.3 \\
\hline Average of flake & 4157.5 & 3930.0 & 3486.9 & 3116.6 & 2749.9 \\
\hline graphite samples & & & & & \\
\hline xGNP No.1 & & & & & \\
\hline xGNP No.2 & 3818.4 & 3428.8 & 3047.4 & 2640.7 & 2228.3 \\
\hline
\end{tabular}




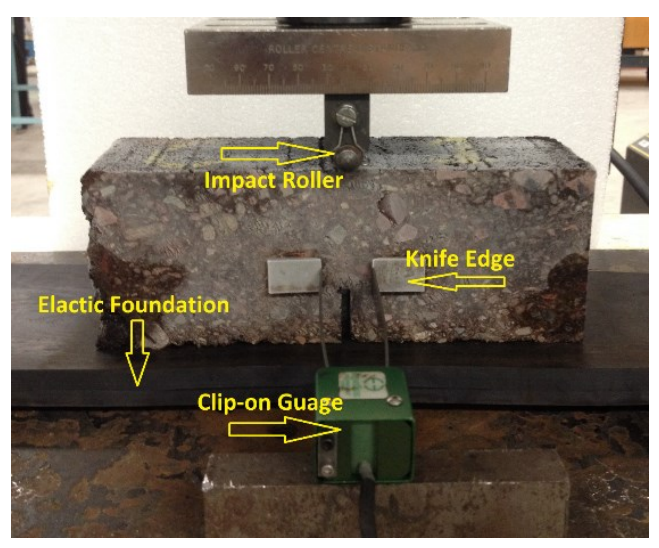

(a)

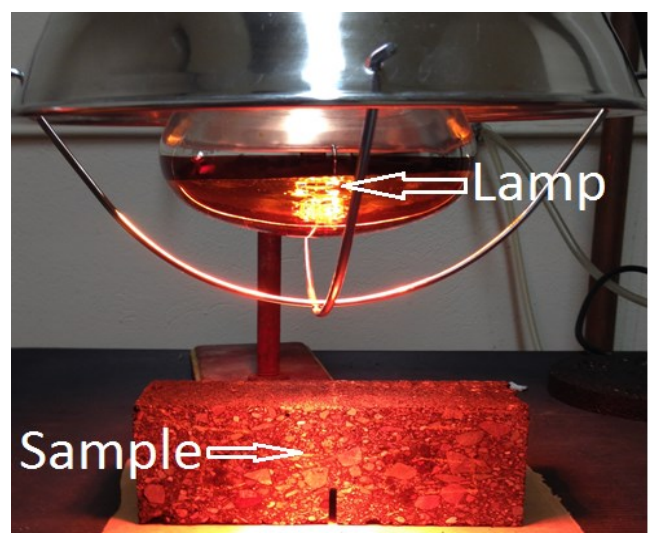

(b)

Figure 8. 1 Demonstration of fracture-light healing test: (a) modified bending test of asphalt mixture.

In addition, the peak separation stresses of all the tested samples during the cyclic fracture-light healing tests were calculated by Equation (8-1):

$$
\sigma_{\max }=\frac{3 \cdot F \cdot L}{2 \cdot B \cdot H^{2}}
$$

where $F$ is the applied force, $L$ indicates the span, $B$ represents the beam thickness and $H$ is the height of the middle sectional-area of the beam. The span was assumed as the half length of the beam sample $(190 / 2=95 \mathrm{~mm})$ because the support was an elastic rubber belt instead of the regular rollers. The thickness of the beam was $50 \mathrm{~mm}$ and the height of the middle sectional-area was two thirds of the height of the beam (69 $\times 2 / 3=46 \mathrm{~mm})$. Consequently, the peak separation stresses of nine tested samples including the control, flake graphite modified and xGNP modified asphalt mixture samples for four cycles of the fracture tests were calculated, listed in Table 8.3. These peak stress data were used to simulate the fracture behavior of the samples discussed in the following sections. 
Table 8. 3 Peak separation stress (MPa) of asphalt mixture samples.

\begin{tabular}{|l|r|r|r|r|}
\hline Specimen & 1st loading & 2nd loading & 3rd loading & 4th loading \\
\hline Control No.1 & 5.392 & 4.624 & 2.489 & 2.456 \\
\hline Control No.2 & 4.680 & 2.113 & 1.775 & 1.687 \\
\hline Control No.3 & 5.795 & 2.264 & 2.134 & 2.037 \\
\hline Flake graphite & & & & \\
No.1 & 5.385 & 4.698 & 4.176 & 4.082 \\
\hline Flake graphite & & & & \\
No.2 & 6.224 & 5.999 & 5.867 & 4.730 \\
\hline Flake graphite & 5.103 & 5.102 & 3.975 & 3.717 \\
No.3 & 5.385 & 4.595 & 4.084 & 3.539 \\
\hline xGNP No.1 & 5.131 & 3.372 & 3.369 & 3.180 \\
\hline xGNP No.2 & 5.025 & 3.404 & 3.296 & 3.187 \\
\hline xGNP No.3 & & & & \\
\hline
\end{tabular}

\subsection{Fracture simulation of original asphalt mixture samples}

\subsubsection{Determination of measured fracture energy of asphalt mixture samples}

In this research, the measured fracture energy of the control, flake graphite modified and xGNP modified asphalt mixture samples was determined for the beam fracture simulation by implementing the standard three-point bending test. A beam sample was located on the support and was loaded by an impact roller with a descending speed of $3 \mathrm{~mm} / \mathrm{min}$. The distance between the two support rollers was 140 
mm. A clip-on gauge was adopted to measure the crack tip opening displacement (CTOD) during the sample fracturing process with the sample temperature of $-10^{\circ} \mathrm{C}$. Meanwhile, the load, CTOD and time were recorded. Subsequently, the measured fracture energy was determined by calculating the area under the CTOD-load curve divided by the cross-sectional area of the tested sample [84]. The test results showed that the average measured fracture energy of the control asphalt mixture was 382.30 $\mathrm{J} / \mathrm{m}^{2}$ which was lower than those of the flake graphite modified asphalt mixture $\left(453.21 \mathrm{~J} / \mathrm{m}^{2}\right)$ and the $x G N P$ modified asphalt mixture $\left(490.03 \mathrm{~J} / \mathrm{m}^{2}\right)$. The average measured fracture energy of the xGNP modified asphalt mixture was higher than that of the flake graphite modified asphalt mixture. Consequently, both the added flake graphite and xGNP could increase the measured fracture energy of the asphalt mixture beams.

\subsubsection{Bilinear cohesive fracture modeling}

The CZM was widely used to simulate the fracture zone ahead of crack tip. The essential cohesive laws can be expressed with the traction, displacement jump along the crack for simulating fracture behavior, including nucleation, crack initiation and propagation [84]. The traction is zero on the crack tip and is maximum value on the cohesive zone tip. This would indicate the crack tip experiences the total failure while the cohesive zone tip goes through the highest cohesive bonding. The cohesive zone where fracture occurs is defined as the area between the crack tip and the cohesive zone tip. When the traction caused by external force increases to peak value and then decays to zero monotonically, the corresponding displacement jump increases 
constantly. The peak separation stress, failure displacement, and fracture energy are considered the key parameters that affect the facture behavior. Different cohesive laws were applied to develop CZM techniques, in particular, exponential cohesive law and bilinear cohesive law $[84,138]$. In this research, the bilinear cohesive law was applied to establish the cohesive fracture zone model. The characteristic of the bilinear cohesive law is the relations between the traction and displacement on the traction increasing and decreasing phases are both linear during the fracture process if there is no shear sliding displacement, shown in Figure 8.2. $\delta_{c}$ and $\delta_{s}$ represent the critical displacement and shear sliding, respectively. If the shear sliding is considered when the fracture behavior occurs, the relation between the traction and displacement follows the curve as shown in the figure. The fracture energy is defined as the area under the traction-displacement curve shown in Equation (8-2):

$G=\frac{1}{2} \sigma_{p} \times \delta_{f}$

where $G$ is the cohesive fracture energy, $\sigma_{p}$ indicates the peak separation stress, $\delta_{f}$ denotes the failure displacement where the separation stress is zero. The ABAQUS user-defined element (UEL) subroutine $[84,143]$ was applied to carry out the CZM for fracture behavior research. In this study, the three-node interface elements along the crack path were employed by combining with cohesive elements to simulate the fracture behavior. The fracture simulation and crack propagation were discussed in the following sections. 


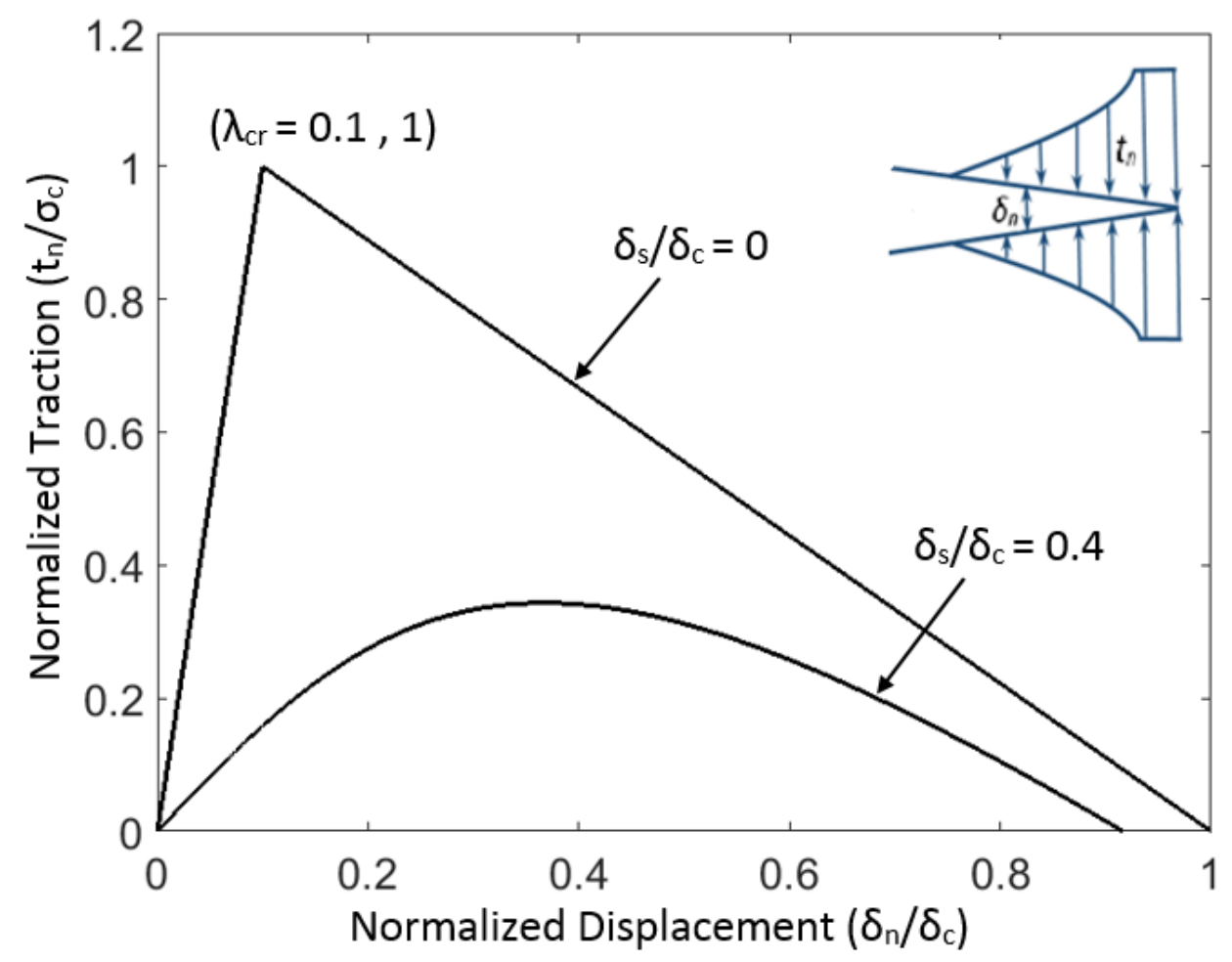

Figure 8. 2 A cohesive law in accordance with normalized traction and normalized displacement jump with or without shear sliding.

\subsubsection{Fracture simulation of original asphalt mixture beam with digital imaging analysis}

In this section, the crack path propagated at the first loading of the No.1 control asphalt mixture sample was used to establish the cohesive zone model, shown in Figure 8.3. First, the image of the fractured beam after first loading was captured by a Point Grey high resolution camera, presented in Figure 8.3 (a). Then a local area of the image with the crack path was selected by ImageJ, displayed in Figure 8.3 (b). Subsequently, all the pixels in the local area of the image were transferred to nodes used to constitute 
the three-node triangle elements. The crack path was set up as the common boundaries of those elements locating along the both sides of the crack. Eventually, the four-node interface cohesive elements were defined along the crack path. In addition, the elastic foundation was simulated by setting up spring elements to connect with the nodes on the bottom of the beam model. The spring modulus were setup as $9.28 \mathrm{MPa}$, obtained from the rubber layer loading experiment. The completed 2D fractured asphalt mixture beam model is shown in Figure 8.3 (c). Figure 8.3 (d) displays the magnified details of the crack path in the highlighted region. In this section, the fracture simulation of the original asphalt mixture samples was conducted using two input parameters, the measured fracture energies and the peak separation stresses obtained from the first loading. Hence, $382.30 \mathrm{~J} / \mathrm{m}^{2}$ was used to simulate the original fracture of the three control asphalt mixture samples. Similarly, $453.21 \mathrm{~J} / \mathrm{m}^{2}$ and $490.03 \mathrm{~J} / \mathrm{m}^{2}$ were for simulating the flake graphite and the xGNP modified asphalt mixture samples. The numerically predicted CTOD-load curves including the peak loads were obtained from the cohesive zone beam model after inputted those parameters. Figure 8.3 (e) compares the measured and predicted CTOD-load curves of the No.1 control asphalt mixture sample from the first loading. For other original beam samples, the comparison (relative difference) of the measured and predicted fracture strength is listed in the 1st loading column of Table 8.5. These results indicated the finite element CZM can predict the original beam fracture behavior with measured fracture energy and peak separation stress. 


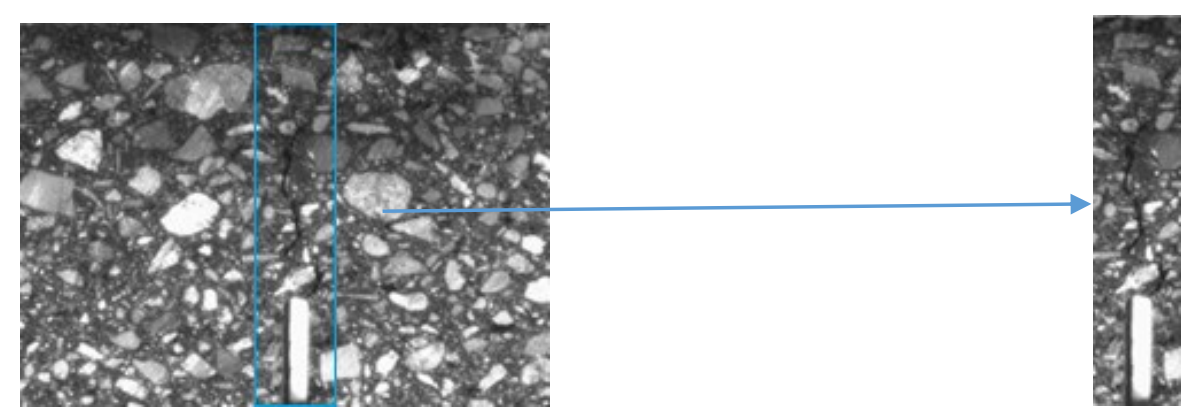

(a)

(b)

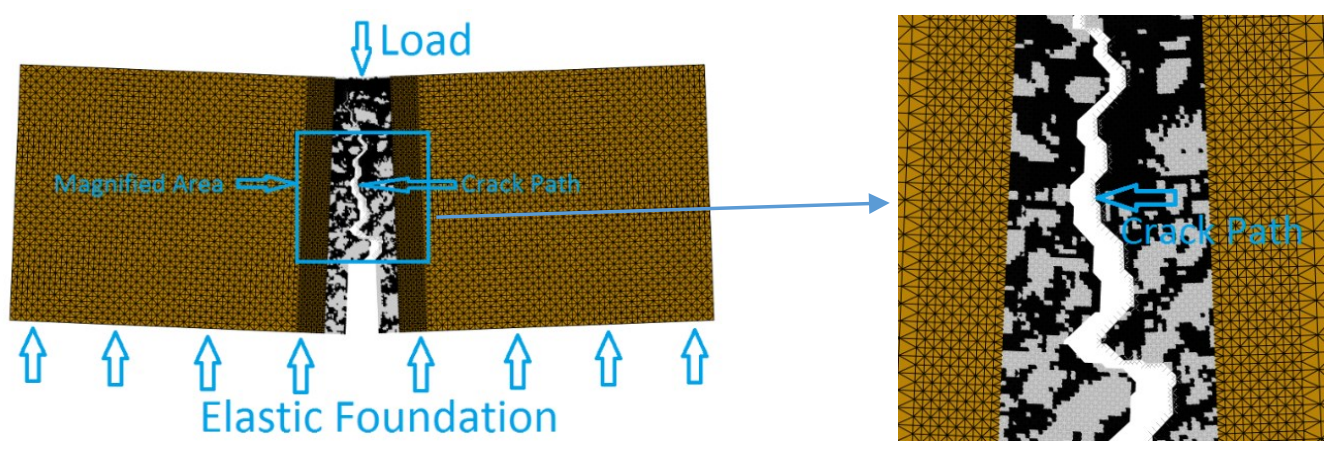

(c)

(d)

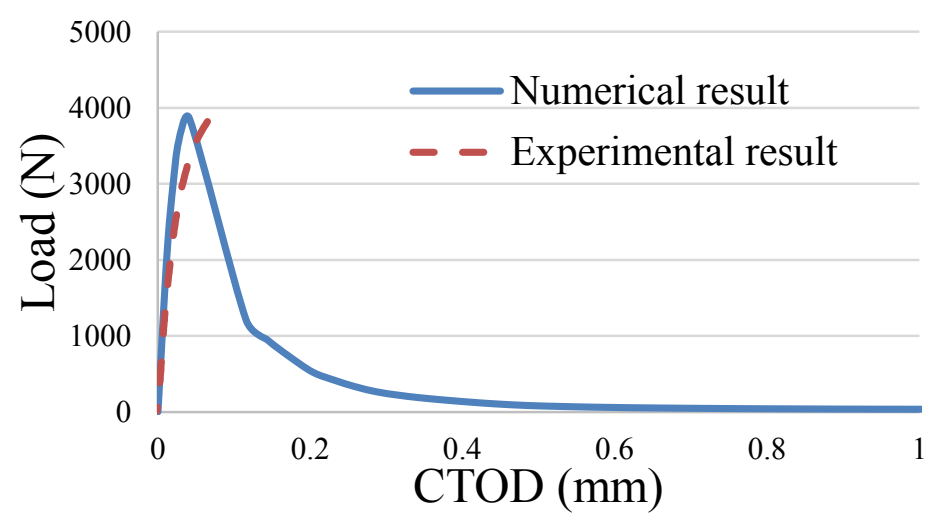

(e)

Figure 8. 3 Schematic fracture simulation of original No.1 control asphalt mixture beam: (a) global crack path area; (b)local crack path; (c) cracking mesh configuration and mesh detail of crack path; (d) magnified mesh with detailed crack path and 
indicated material phases (dark grey-aggregate and light grey-mastic); (e) numerical and experimental CTOD-load curves.

\subsection{Fracture simulation of recovered strength healed beam samples with DIC analysis}

\subsubsection{DIC analysis of cyclic fracture-light healing processes}

The digital image correlation (DIC) is an effective optical technique that measures the full-field surface deformation of samples [113]. Essentially, two digital images are compared by the DIC, one is the reference image regarded as the undeformed case and the other is the deformed image. The DIC program could find the two locations of one selected pixel in the reference image and in the deformed image by matching the gray value of that pixel. Afterwards, the displacement (pixels) of the selected pixel moving in the two images can be calculated [114].

In this research, the DIC MATLAB image toolbox [132] was used to analyze the displacements of asphalt mixture particles during the fracture-light healing cycles. Figure 8.4 (a)-(d) present a set of images of the No.2 control asphalt mixture sample during the cyclic fracture-light healing tests. Figure 8.4 (a) shows the crack displacement variation of the sample before and after the first loading, which demonstrates the initial crack development of the sample. Figure 8.4 (b) displays the crack displacement variation of the sample after the first light healing and the second loading. Likewise, Figure 8.4 (c) and (d) are the images that demonstrate fractured samples after the second or third light healing and the third or forth loading, respectively. The crack open displacement were recorded with ten red points along the 
crack path. Each red point is adjacent with two blue points horizontally, regarded as one set. The DIC analysis were conducted to obtain displacements of 10 sets of pixels in the image between the non-fractured and fractured sample images. The displacements of the two blue points were utilized to investigate the crack displacement changes during the cyclic fracture-light healing tests. 

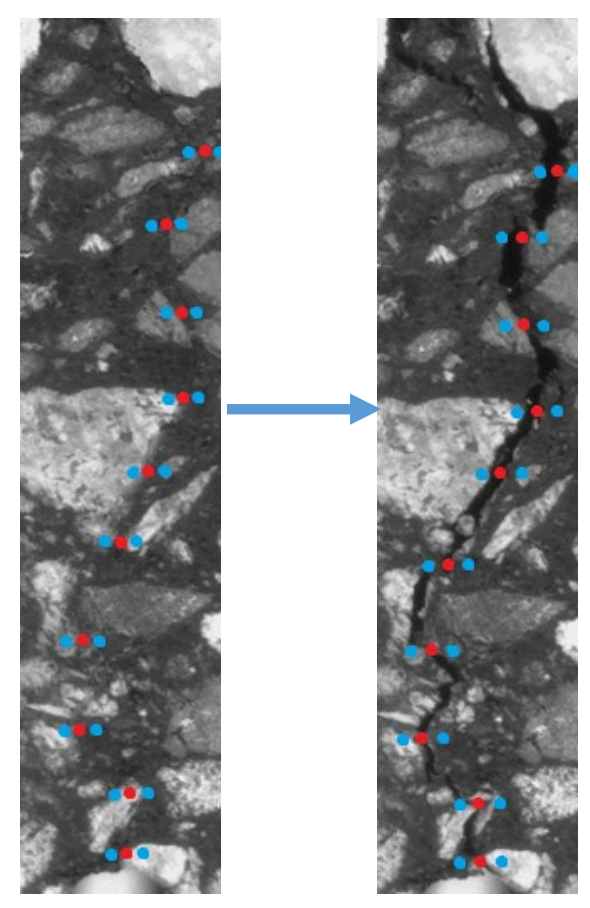

(a)

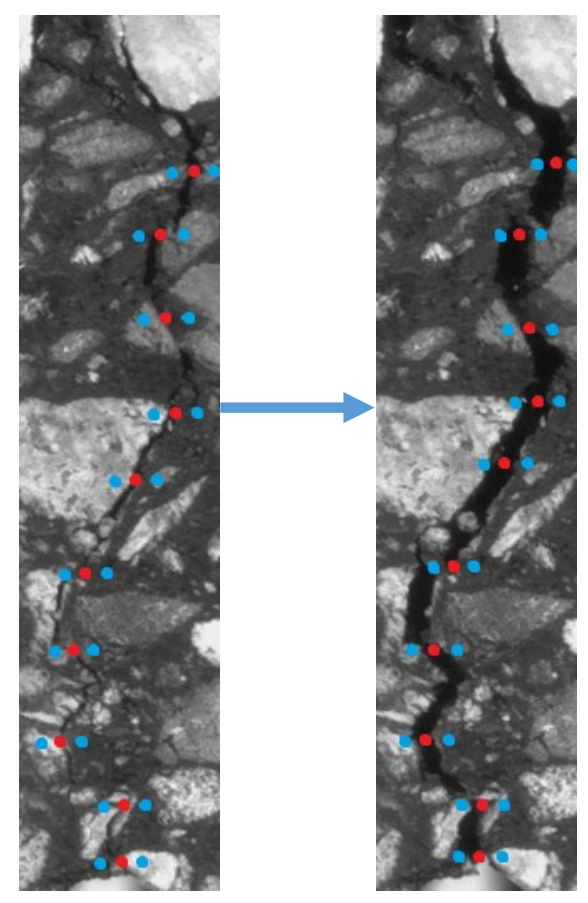

(c)

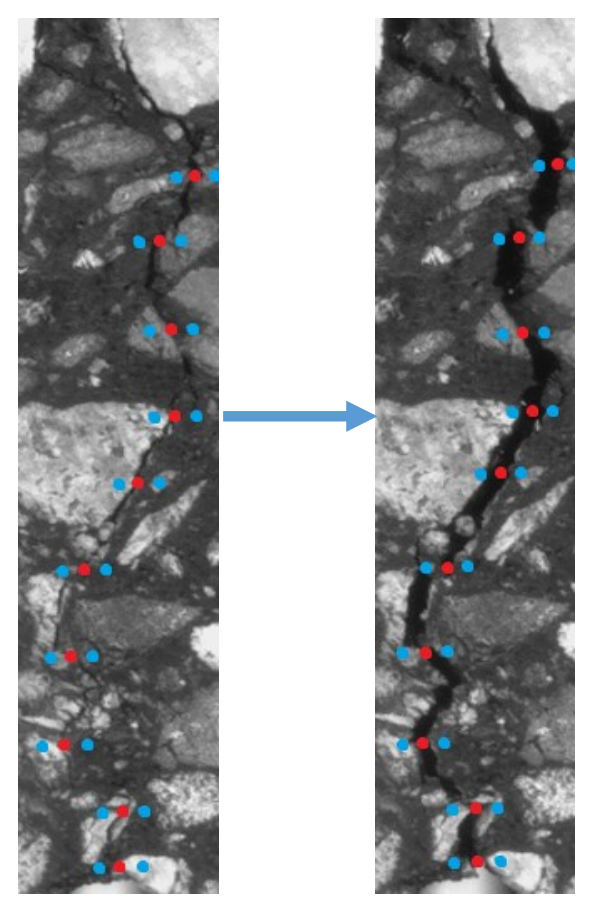

(b)

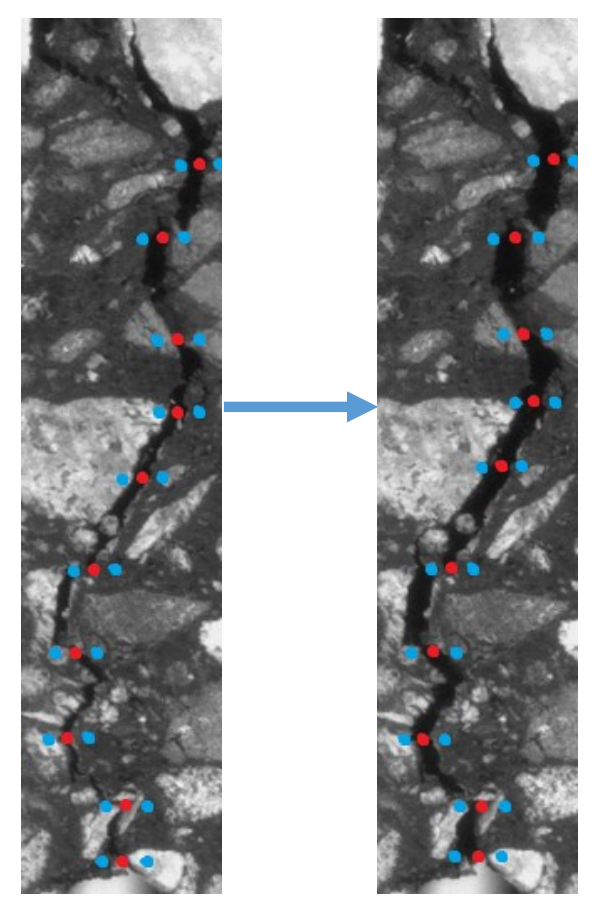

(d) 
Figure 8. 4 Demonstration of DIC analysis of No.2 control asphalt mixture beam on cyclic fracture-light healing tests: (a) crack variation at the first loading; (b) crack variation at the second loading; (c) crack variation at the third loading; (d) crack variation at the forth loading. (The red points indicate the crack locations for DIC analysis. The blue points display the locations for strain ratio calculation.)

In this study, the relative strain ratio was incorporated to analyze the crack displacement variation, defined as the healed crack strain divided by the fracture strain, shown in Equation (8-3):

$$
R_{S}^{i}=\frac{\varepsilon_{H}^{i}}{\varepsilon_{F}^{i}}
$$

where $R_{S}$ indicates the relative strain ratio, $\varepsilon_{H}$ is the healed crack strain, $\varepsilon_{F}$ denotes the fracture strain, superscript $i$ is the No. of the pixel set $(i=1,2,3, \ldots, 10)$. The healed crack strain was described as the displacement $\left(\delta_{H}\right)$ of the two blue points in one set before and after the light healing process divided by the original distance $\left(\delta_{o}\right)$ between the same two blue points on the non-fractured sample, exhibited in Equation $(8-4)$ :

$\varepsilon_{H}^{i}=\frac{\delta_{H}^{i}}{\delta_{o}}$

where $\delta_{H}$ indicates the displacement of the blue points in one set before and after the light healing process, $\delta_{o}$ denotes the original distance of the same blue points in the image of the non-fractured sample. The fracture strain was interpreted as the 
displacement between the two blue points in each set divided by the original distance of those two blue points in the image of the non-fractured sample, exhibited in Equation (8-5):

$$
\varepsilon_{F}^{i}=\frac{\delta_{F}^{i}}{\delta_{o}}
$$

where $\delta_{F}$ indicates the displacement of the blue points in one set before and after the loading. The displacements of the blue points in ten sets for the calculation of the healed crack strain and fracture strain were obtained by running the DIC code. Afterwards, the relative strain ratio for each red point was attained. Subsequently, the average relative strain ratio for ten red points was calculated by Equation (8-6):

$$
\overline{R_{S}}=\frac{1}{10} \sum_{i=1}^{10} R_{S}{ }^{i}
$$

The DIC analysis and relative strain ratios calculation were conducted on No. 2 control, No. 2 flake graphite modified and No.2 xGNP modified asphalt mixture samples. The calculations consist of the relative strain ratios after the first, second and third time of the loading and light healing, respectively. The healed crack strain before and after the first light healing of the No.2 control asphalt mixture sample was obtained by comparing the second image in Figure 8.4 (a) and the first image in Figure 8.4 (b). The fracture strain before and after the first loading was obtained by comparing the two images in Figure 8.4 (a). The average relative strain ratio of the No. 2 control asphalt mixture sample by using the first light healing and first loading was calculated as 0.651 by Equation (8-6). Similarly, the healed crack strain of the No. 2 control asphalt 
mixture sample before and after the second light healing was obtained by comparing the second image in Figure 8.4 (b) and the first image in Figure 8.4 (c). The fracture strain before and after the second loading was obtained by comparing the two images in Figure 8.4 (b). The average relative strain ratio by using the second light healing and second loading was 0.577 . Likewise, the healed crack strain before and after the third light healing was obtained from the second image in Figure 8.4 (c) and the first image in Figure 8.4 (d). The fracture strain before and after the third loading was obtained by comparing the two images in Figure 8.4 (c). Then the average relative strain ratio by using the third light healing and third loading was calculated as 0.503 . Briefly, the average relative strain ratios of the No.2 control asphalt mixture sample were 0.651 , 0.577 and 0.503 before and after the first, second and third time of the light healing and the loading, separately. Figure 8.5 shows four sets of images of the No. 2 flake graphite modified asphalt mixture sample during the cyclic fracture-light healing tests. The average relative strain ratios before and after the first, second and third time of the light healing and the loading were $0.822,0.696$ and 0.617 , respectively. Similarly, the crack variation of the No. 2 xGNP modified asphalt mixture sample are shown in Figure 8.6. The average relative strain ratios before and after the first, second and third time of the light healing and the loading were $0.736,0.642$ and 0.535 using the same method of analysis and calculation. The relative strain ratios were employed to determine the recovered fracture energy discussed in the following section. 


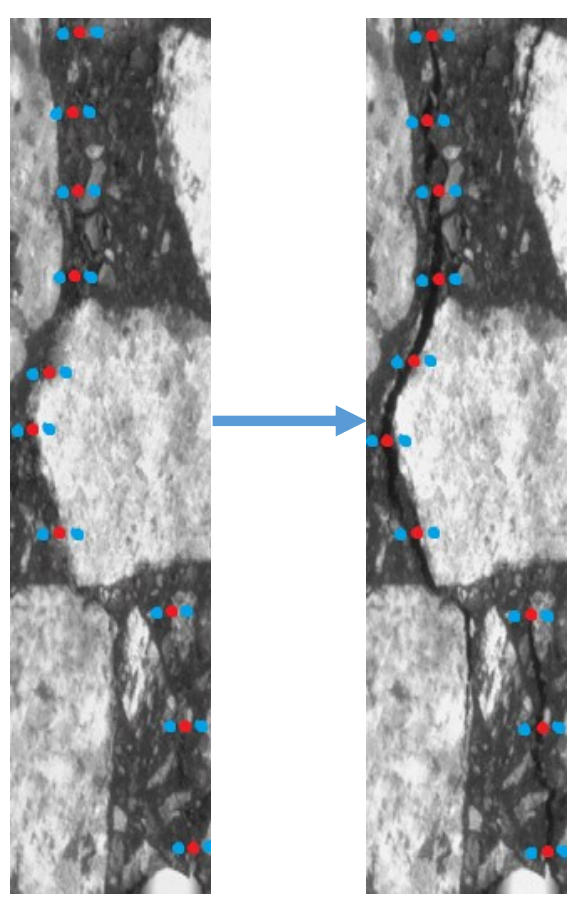

(a)

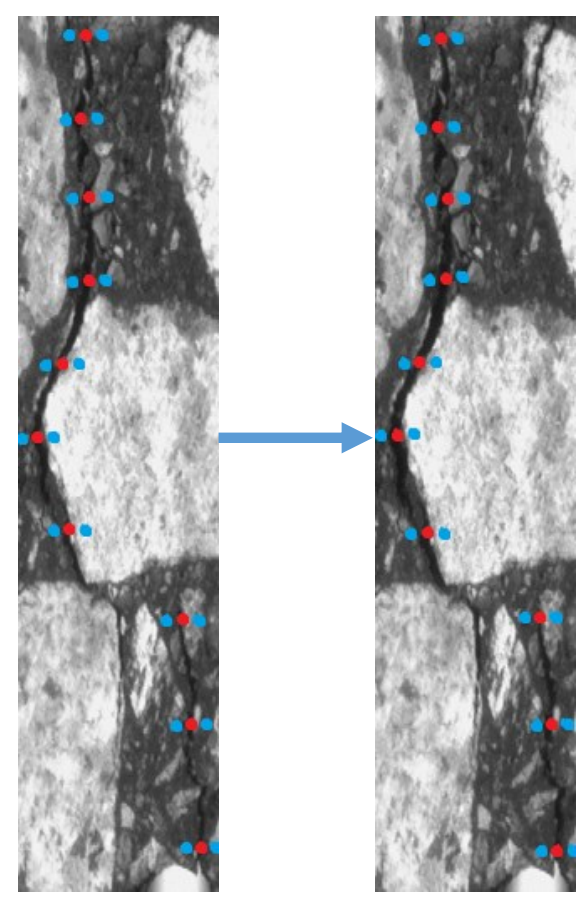

(c)

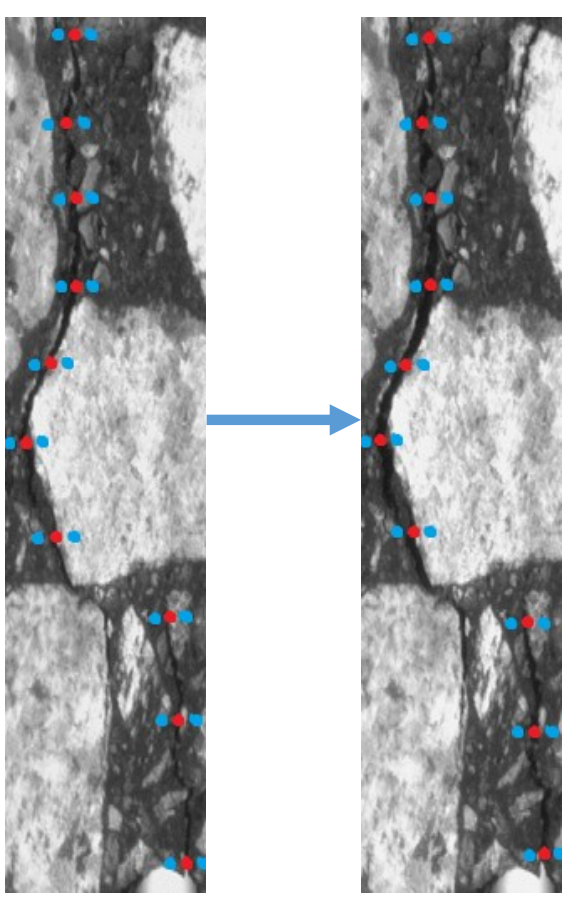

(b)

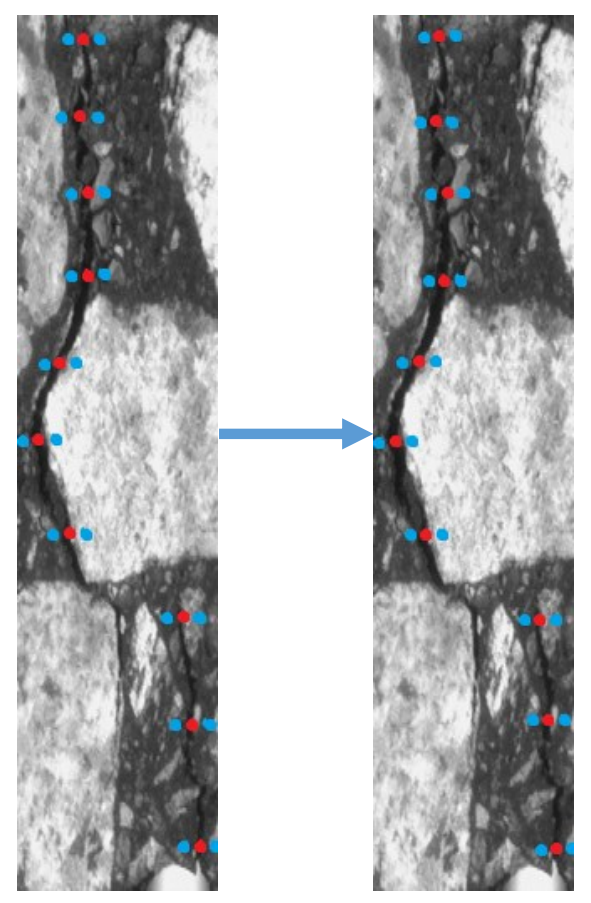

(d) 
Figure 8. 5 Demonstration of DIC analysis of No.2 flake graphite modified asphalt mixture beam on cyclic fracture-light healing tests: (a) crack variation at the first loading; (b) crack variation at the second loading; (c) crack variation at the third loading; (d) crack variation at the forth loading. (The red points indicate the crack locations for DIC analysis. The blue points display the locations for strain ratio calculation.) 


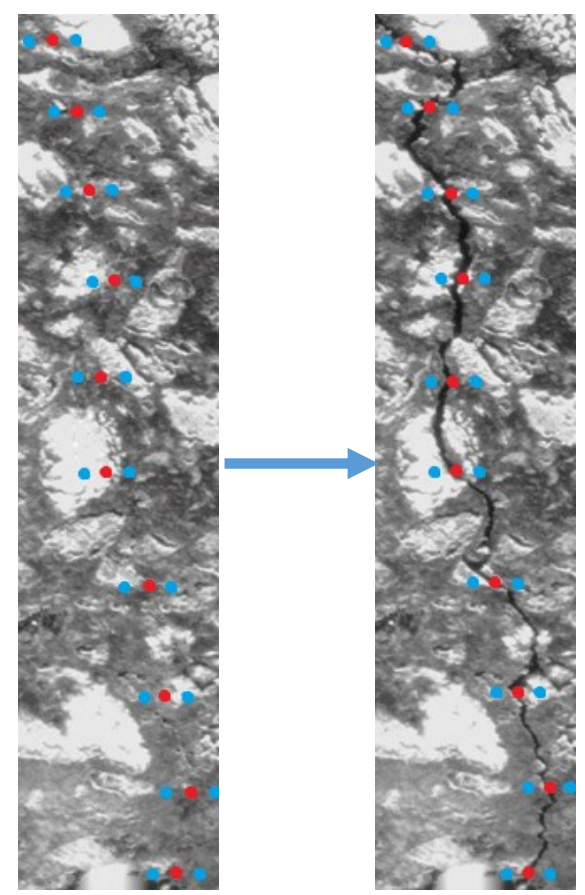

(a)

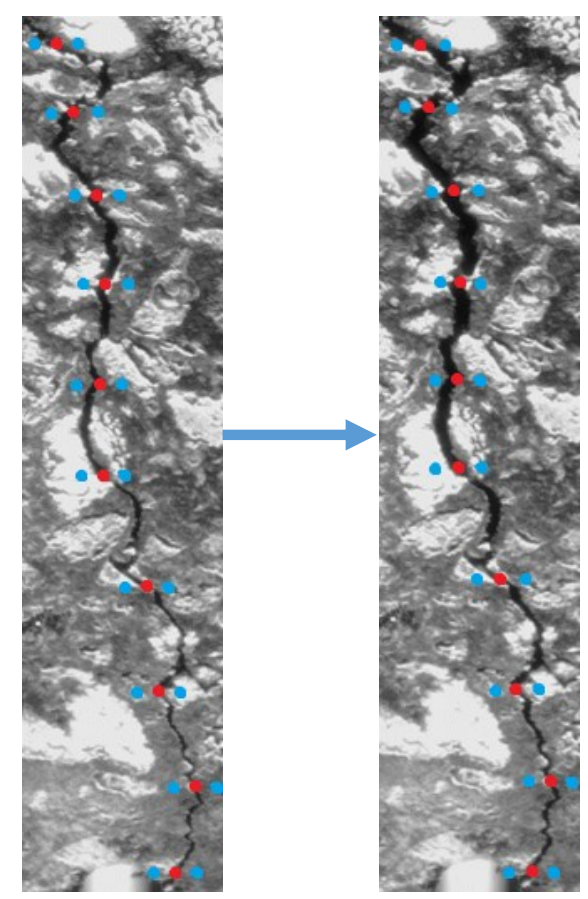

(c)

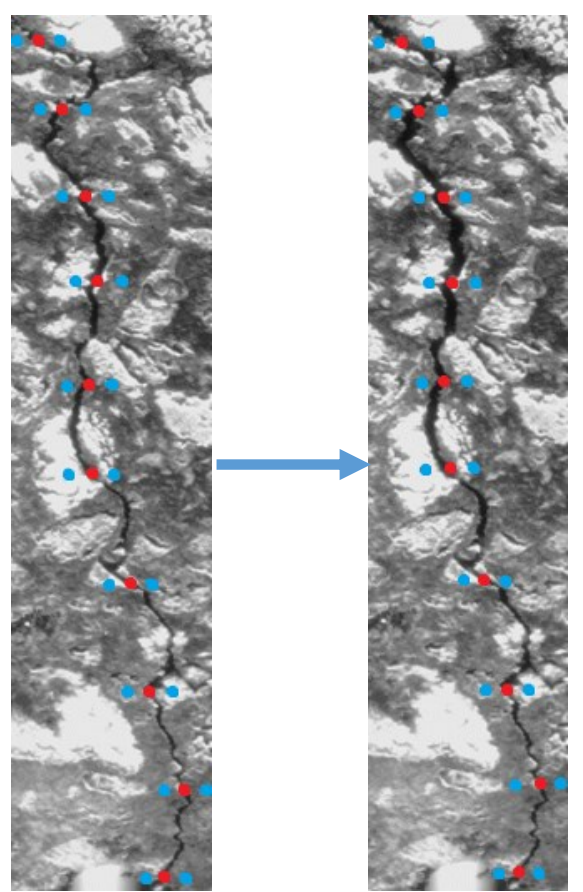

(b)

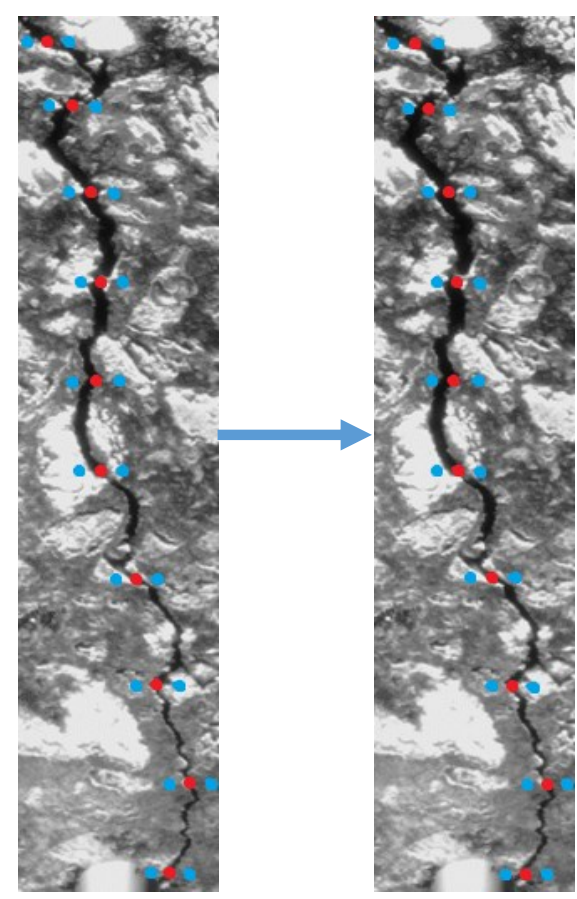

(d) 
Figure 8. 6 Demonstration of DIC analysis of No.2 xGNP modified asphalt mixture beam on cyclic fracture-light healing tests: (a) crack variation at the first loading; (b) crack variation at the second loading; (c) crack variation at the third loading; (d) crack variation at the forth loading. (The red points indicate the crack locations for DIC analysis. The blue points display the locations for strain ratio calculation.)

\subsubsection{Fracture simulation of strength recovered asphalt mixture samples}

In this study, the recovered strengths of the asphalt mixture samples were simulated using the cohesive model with defined crack path. Two major input parameters, the peak separation stress and the recovered fracture energy were used to complete the simulation of all the samples. The peak separation stresses were obtained from the peak loads of experiments listed in Table 8.2. The recovered fracture energy was calculated by Equation (8-7):

$$
E_{R}=\frac{1}{2} \sigma \square \square
$$

where $E_{R}$ indicates the recovered fracture energy, $\sigma$ is the peak separation stress, $\delta$ is the original failure displacement, $\bar{R}_{S}$ denotes the average relative strain ratio. Figure 8.7 represents the relation between the traction and displacement of the control asphalt mixture sample on the cohesive zone. This figure includes four triangles whose areas correspond to the measured fracture energy for the fracture simulation of the original asphalt mixture beam samples and three recovered fracture energies for the fracture simulation of strength recovered healed asphalt mixture beam samples. According to Equation (8-1), the original failure displacement for each sample was expressed as 
doubling the original fracture energy divided by the original peak separation stress. Taking the No.1 control asphalt mixture sample as an example, the original fracture energy for the control asphalt mixture samples was $382.30 \mathrm{~J} / \mathrm{m}^{2}$ and the peak separation stress was 5.392 MPa. Therefore, the original failure displacement was $2 \times$ $382.30 / 5.392 / 1000=0.142 \mathrm{~mm}$. Then the recovered failure displacement for the second loading was calculated as the original failure displacement timed by the relative strain ratio for the first loading, namely, $0.142 \times 0.651=0.0924 \mathrm{~mm}$. Hence, the recovered fracture energy of the sample for the second loading was computed as $0.5 \times$ $4.624 \times 0.0924 \times 1000=213.42 \mathrm{~J} / \mathrm{m}^{2}$. In the same way, the recovered failure displacements of the sample for the third loading and forth loading were calculated as $0.142 \times 0.577=0.0819 \mathrm{~mm}$ and $0.142 \times 0.503=0.0714 \mathrm{~mm}$, respectively. The recovered fracture energies of the sample for the third and forth loading were $0.5 \times$ $2.489 \times 0.0819=101.80 \mathrm{~J} / \mathrm{m}^{2}, 0.5 \times 2.456 \times 0.0714=87.59 \mathrm{~J} / \mathrm{m}^{2}$, separately. The recovered fracture energies of No. 2 and No. 3 control asphalt mixture samples were calculated by the same method based on their peak separation stresses. The recovered fracture energies of the No. 1, 2, 3 flake graphite and the No. 1, 2, 3 xGNP modified asphalt mixture samples were calculated with their own measured fracture energies, relative strain ratios and peak separation stresses. Table 8.4 lists all the values of the measured fracture energies (first loading) and the recovered fracture energies (second, third and forth loading) for the fracture simulation of the control, flake graphite modified and xGNP modified asphalt mixture samples. 
Table 8. 4 Input measured fracture energy $\left(\mathrm{J} / \mathrm{m}^{2}\right)$ and recovered fracture energy $\left(\mathrm{J} / \mathrm{m}^{2}\right)$ for simulation model of asphalt mixture samples.

\begin{tabular}{|l|l|l|l|l|}
\hline Specimen & 1st loading & 2nd loading & 3rd loading & 4th loading \\
\hline Control No.1 & 382.30 & 213.42 & 101.80 & 87.59 \\
\hline Control No.2 & 382.30 & 112.34 & 83.67 & 69.32 \\
\hline Control No.3 & 382.30 & 97.24 & 81.23 & 67.58 \\
\hline $\begin{array}{l}\text { Flake graphite } \\
\text { No.1 graphite }\end{array}$ & 453.21 & 324.96 & 244.60 & 211.94 \\
\hline $\begin{array}{l}\text { Flake No.2 graphite } \\
\text { Flake }\end{array}$ & 453.21 & 359.03 & 297.32 & 212.50 \\
No.3 & 453.21 & 372.47 & 245.67 & 203.67 \\
\hline xGNP No.1 & 490.03 & 307.74 & 238.58 & 172.28 \\
\hline xGNP No.2 & 490.03 & 237.03 & 206.58 & 162.50 \\
\hline xGNP No.3 & 490.03 & 244.33 & 206.33 & 166.28 \\
\hline
\end{tabular}




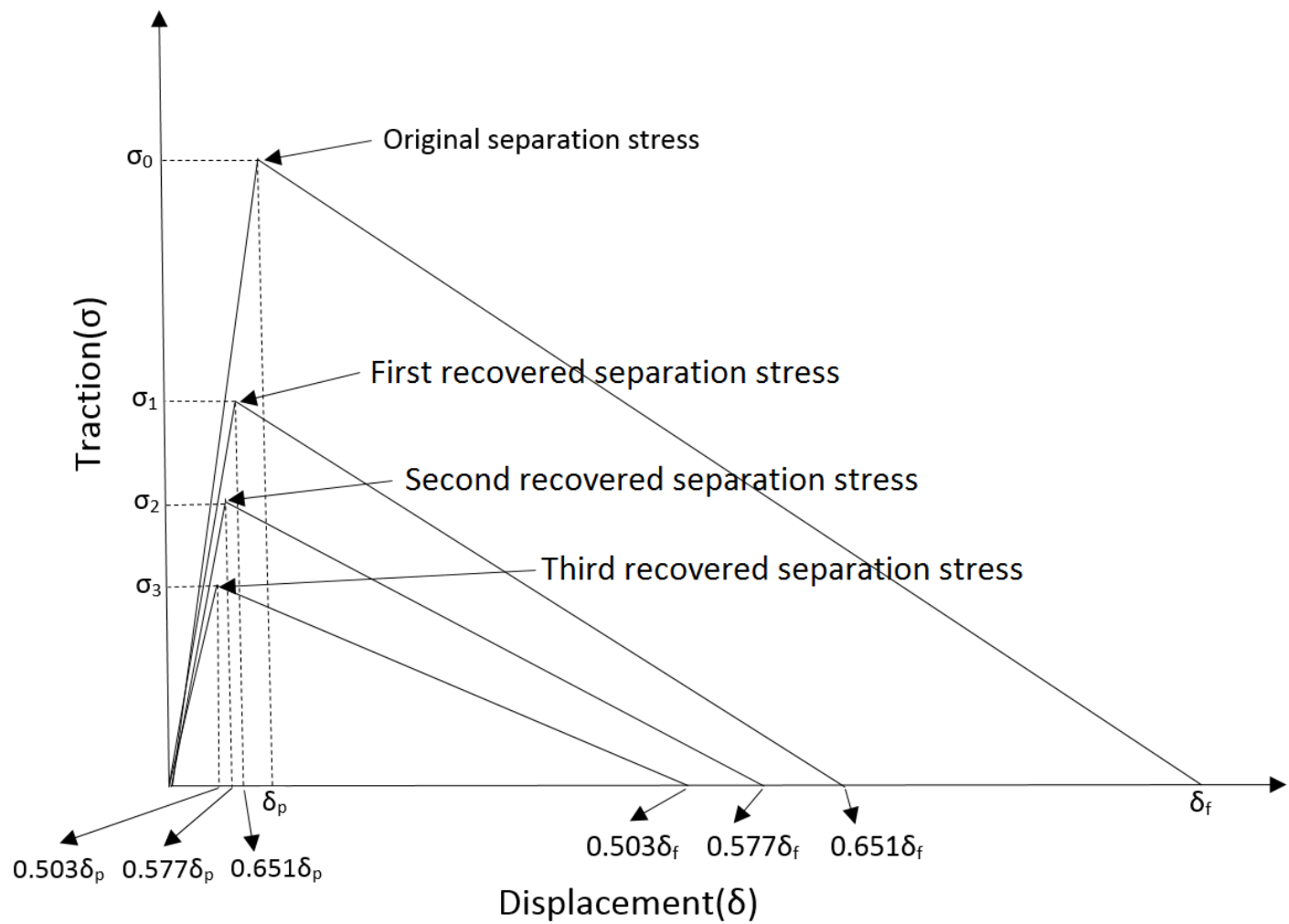

Figure 8. 7 Illustration of relation between traction and displacement on four times loading of control asphalt mixture sample.

\subsection{Comparison of predicted and measured fracture strength of original and healed beam samples}

All the peak separation stresses and fracture energies (original and recovered) were inputted to the cohesive zone model to obtain the numerical CTOD-load curves. Figure 8.8 shows the numerical CTOD-load curves of the No.1, 2 and 3 control asphalt mixture samples. Additionally, the numerical CTOD-load curves of the No.1, 2 and 3 flake graphite modified and the No.1, 2 and 3 xGNP modified asphalt mixture samples are displayed in Figure 8.9 and Figure 8.10. In this study, the relative difference was used to compare the numerical and experimental peak loads. It was defined as the 
absolute value of experimental value subtracted by numerical value divided by experimental value. The relative differences of the peak loads between the experimental data and numerical data are recorded in Table 8.5. The average relative difference of the control asphalt mixture samples was $4.98 \%$. Similarly, the average relative differences of the flake graphite and the xGNP modified asphalt mixture samples were $8.49 \%$ and $3.88 \%$, respectively. Since the average relative differences of all the asphalt mixture samples were adequately low, the finite element CZM simulation of original and healed beam fracture behavior with input model parameters can favorably predict the beam fracture strength. The relative strain ratio measured by DIC was reliable for predicting the recovered fracture energy of the asphalt mixture samples for the model simulation. 
Table 8. 5 Relative difference (\%) between experimental results and numerical results.

\begin{tabular}{|c|c|c|c|c|}
\hline Specimen & 1st loading & 2nd loading & 3rd loading & 4th loading \\
\hline Control No.1 & $6.89 \%$ & $11.04 \%$ & $3.83 \%$ & $5.33 \%$ \\
\hline Control No.2 & $2.53 \%$ & $2.55 \%$ & $3.68 \%$ & $1.81 \%$ \\
\hline Control No.3 & $8.96 \%$ & $1.26 \%$ & $2.84 \%$ & $3.90 \%$ \\
\hline $\begin{array}{l}\text { Flake graphite } \\
\text { No.1 }\end{array}$ & $4.28 \%$ & $5.23 \%$ & $6.15 \%$ & $8.82 \%$ \\
\hline $\begin{array}{l}\text { Flake graphite } \\
\text { No.2 }\end{array}$ & $9.13 \%$ & $11.72 \%$ & $13.82 \%$ & $16.50 \%$ \\
\hline $\begin{array}{l}\text { Flake graphite } \\
\text { No.3 }\end{array}$ & $2.71 \%$ & $10.79 \%$ & $7.69 \%$ & $5.09 \%$ \\
\hline xGNP No.1 & $3.02 \%$ & $5.14 \%$ & $5.98 \%$ & $7.65 \%$ \\
\hline xGNP No.2 & $1.59 \%$ & $0.41 \%$ & $1.86 \%$ & $9.94 \%$ \\
\hline xGNP No.3 & $0.97 \%$ & $0.61 \%$ & $1.30 \%$ & $8.06 \%$ \\
\hline
\end{tabular}




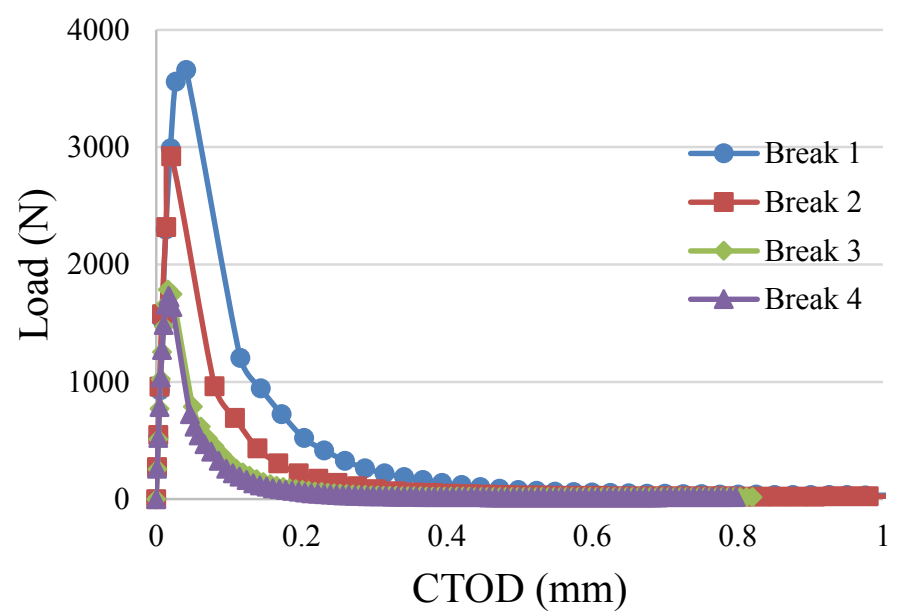

(a)

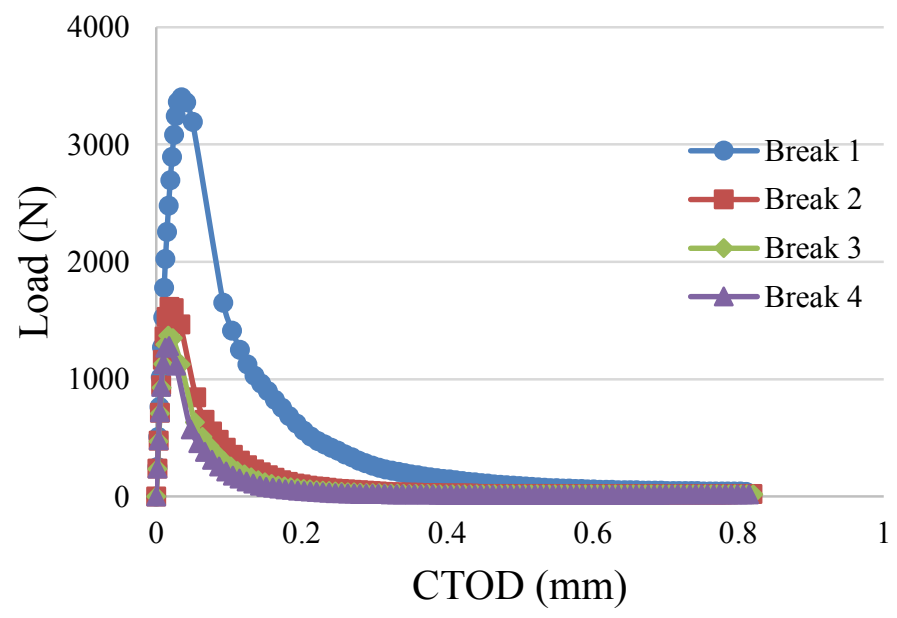

(b) 


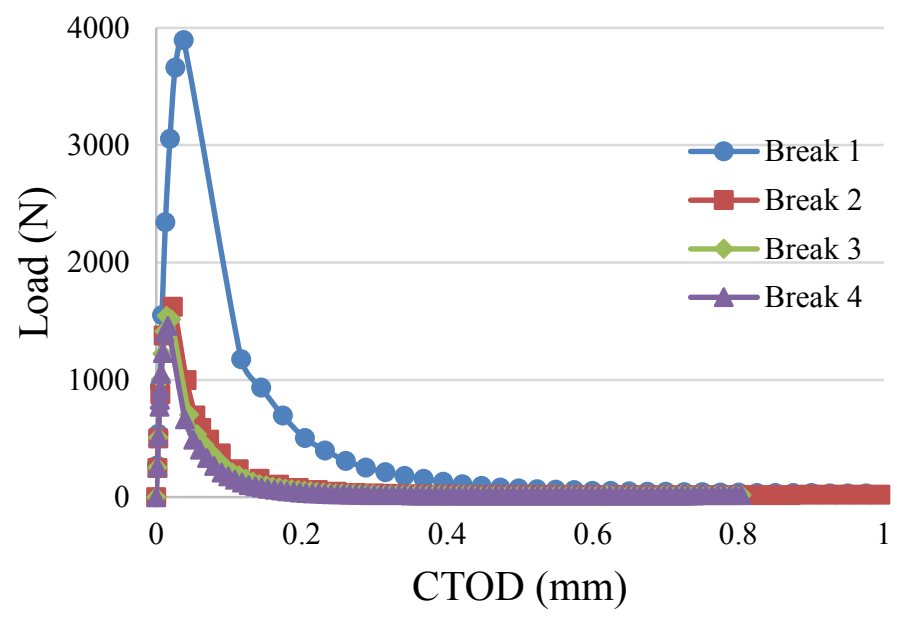

(c)

Figure 8. 8 Numerical results of control asphalt mixture samples: (a) sample No.1; (b) sample No.2; and (c) sample No.3. 


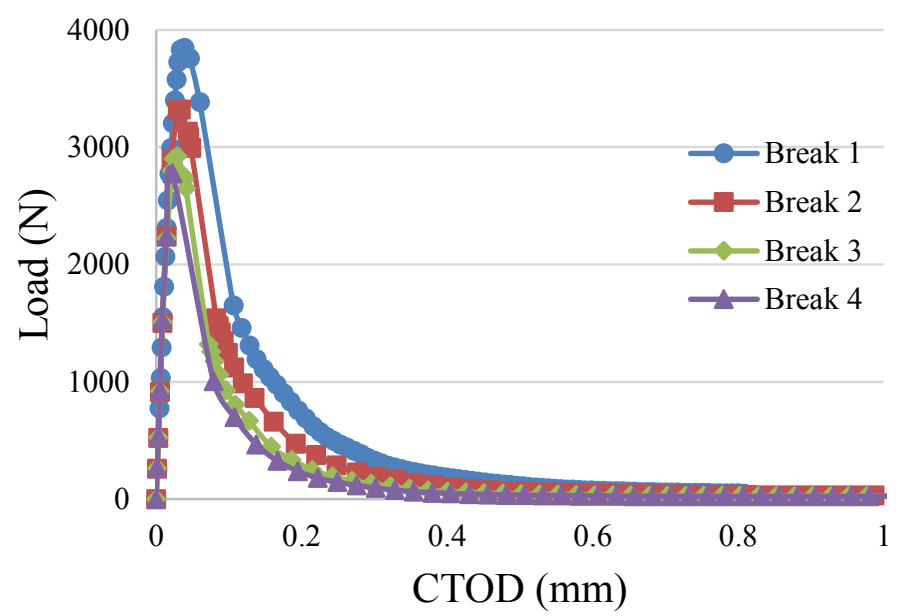

(a)

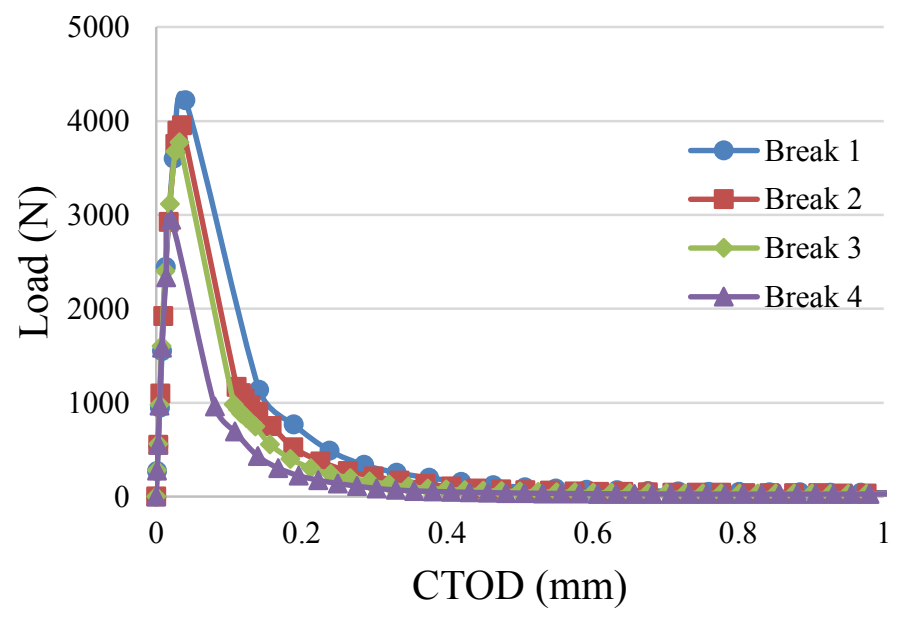

(b) 


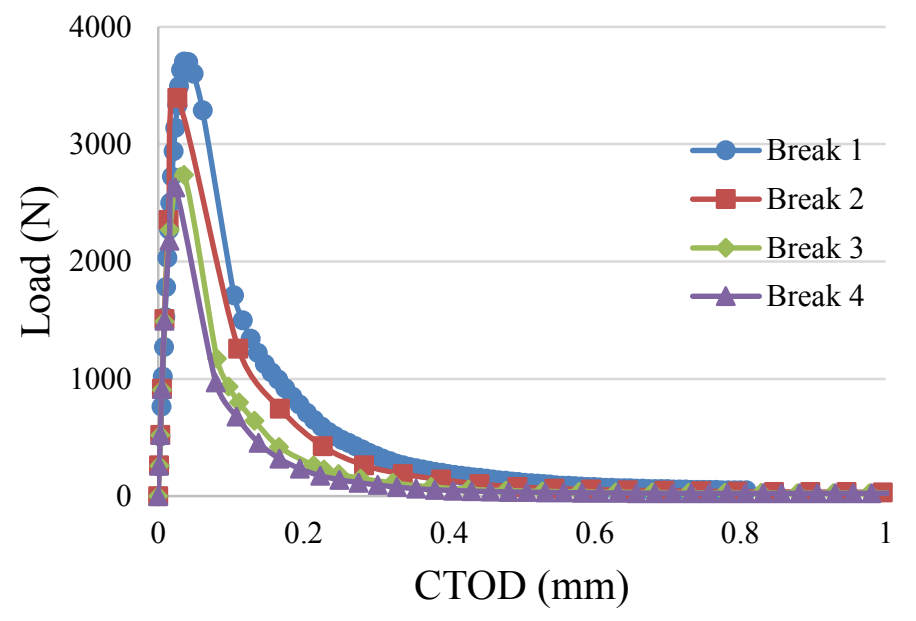

(c)

Figure 8.9 Numerical results of flake graphite modified asphalt mixture samples: (a) sample No.1; (b) sample No.2; and (c) sample No.3. 


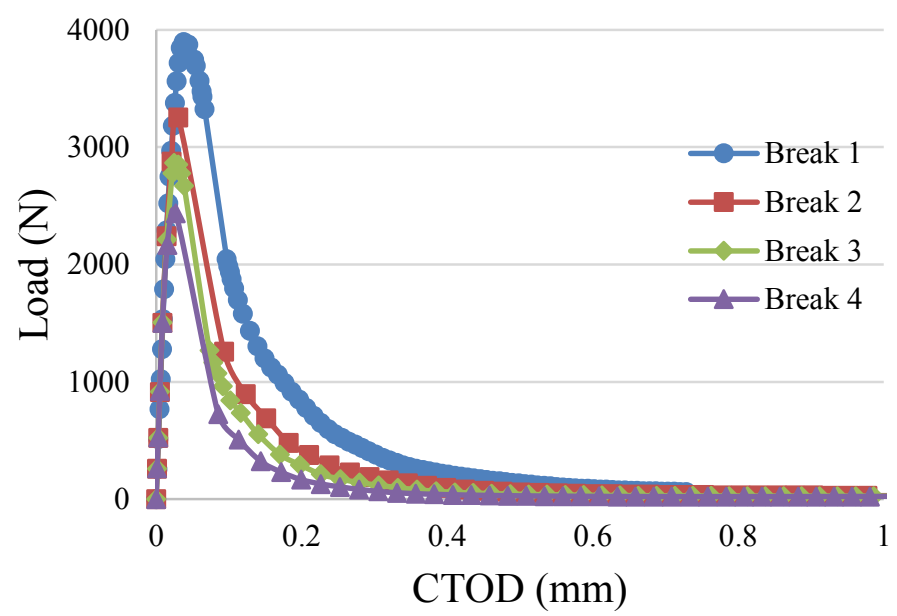

(a)

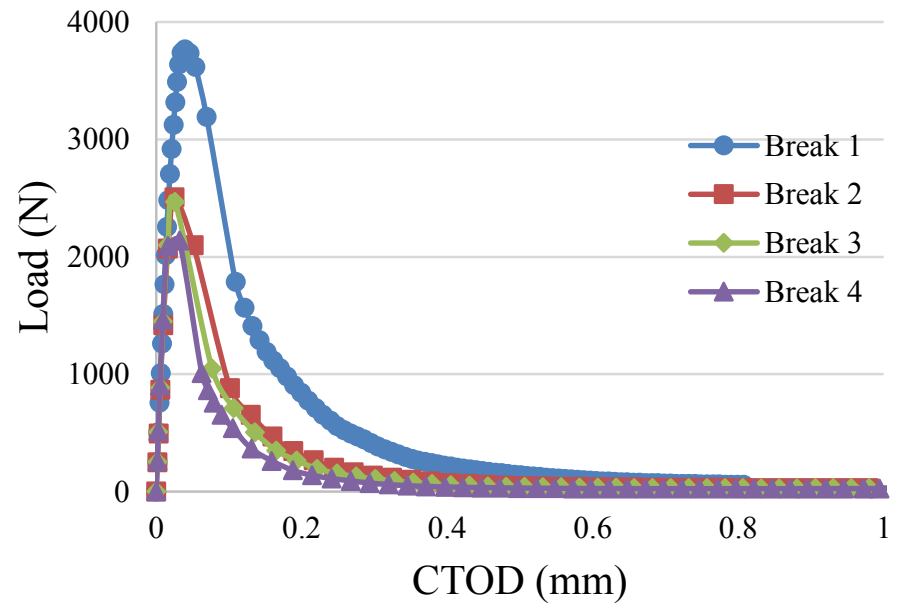

(b) 


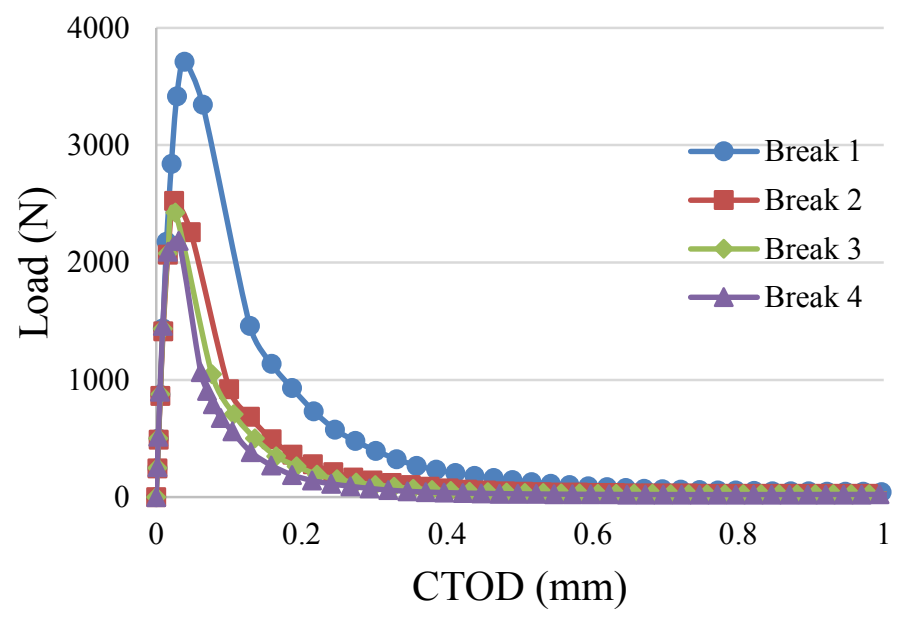

(c)

Figure 8. 10 Numerical results of xGNP modified asphalt mixture samples: (a) sample No.1; (b) sample No.2; and (c) sample No.3.

\subsection{Conclusions}

In this paper, the finite element CZM with measured or calibrated fracture energy and peak separation stress were used to predict the original and recovered fracture strength of the control, flake graphite modified and xGNP modified asphalt mixture samples during the cyclic fracture-light healing tests. The DIC techniques were applied to calculate the relative strain ratios during the fracture-light healing cycles for calibration of recovered fracture energy of samples. For the original beam samples, the measured fracture energy of the control, flake graphite modified and xGNP modified beams were obtained with the three-point bending tests. Both flake graphite and xGNP have the ability to increase the fracture energy of the asphalt mixture beam samples. The finite element CZM was used to simulate the beam crack propagation and original fracture strength under elastic-support beam bending loading. The simulation results 
from the micromechanical beam cross-section model showed the close prediction for both the original fracture strength and crack propagation on the beam samples. For the healed beam samples, the DIC technique provides a useful approach to analyze the crack displacement variation of the asphalt mixture samples during the cyclic fracturelight healing processes. The recovered fracture energies were calculated based on the peak separation stresses, the originally measured fracture energies and the relative strain ratios of the tested samples. The numerical peak loads of all the samples have a favorable agreement with the experimental results due to the low relative differences. This comparison indicates that the combined triangle-shaped finite elements and the user-defined cohesive zone interface elements can be used to simulate the fracture behavior of the asphalt mixture beam. In addition, the recovered fracture energies of the asphalt mixture samples can be calculated using the measured peak separation stress and the DIC calibrated relative strain ratios. In the future work, the other performance of light-healed asphalt mixture samples will be studied further to explore the field application. 


\section{CHAPTER 9 CYCLIC FRACTURE-MICROWAVE HEALING TESTS ON GRAPHITE MODIFIED MIXTURE DISK-SHAPED COMPACT TENSION (DCT) SAMPLES}

\subsection{Introduction}

Asphalt mixture has the capability to repair the pavement distresses during the service life, called self-healing [64]. The environmental temperature and rest periods both can have an impact on the healing process $[33,87]$. The mechanism of the healing is the pavement system is input with external energy to induce the asphalt flow[141]. Shen et al. [12] proposed that the healing behavior was a complex process, involving with capillary flow, molecules wetting and intermolecular diffusion. Additionally, the self-healing process could be affected by the crack size and material type $[11,14,41]$.

Graphite was studied with asphalt materials by many researchers. Wu et al. [109] utilized microcrystal graphite powders to collect solar energy for heating the pavement. Pan et al. [111] proposed that the graphite could increase the thermal conductivity and diffusivity of asphalt binder. Chen et al. [110] found that graphite powder had the ability to increase the thermal conductivity of asphalt mixture.

Some scientists utilized microwave to study the asphalt mixture or the carbon material properties. The microwave absorption of aggregates was easier than the asphalt [130]. Gallego et al. used the microwave to heat the asphalt mixture with steel wool to improve its self-healing capability. Menendez et al. [131] proposed that the carbon materials were good microwave absorbers with reduction of energy consumption. 
The objective of this research is to investigate the fracture energy and microwave healing performance of the graphite materials modified asphalt mixture. First, the control, $5 \%$ flake graphite modified and 2\% xGNP modified asphalt mixture samples were produced for the DCT machine. Then the fracture energy values of the control, flake graphite modified and xGNP modified asphalt mixture were measured. Afterwards, the cyclic fracture-microwave healing test and fracture-non microwave healing test were conducted to evaluate the microwave healing performance of the control and flake graphite modified asphalt mixture DCT samples.

\subsection{Asphalt mixture design and DCT sample preparation}

\subsubsection{Asphalt mixture design}

In this research, two types of graphite materials, flake graphite and xGNP, were utilized to improve the asphalt mixture properties. Three types of mixture samples were prepared for the test, including the control asphalt mixture, flake graphite modified asphalt mixture and xGNP modified asphalt mixture. The aggregates in the mixture came from Hancock, Michigan with an average density of $2.72 \mathrm{~g} / \mathrm{cm}^{3}$. The asphalt binder was PG 58-28 with a density of $1.024 \mathrm{~g} / \mathrm{cm}^{3}$. The asphalt amount used was $5.2 \%$ of the asphalt mixture by weight, determined by conducting the optimum asphalt content test based on the Superpave volumetric design guide. Table 9.1 shows the aggregate gradation of control asphalt mixture. 
Table 9. 1 Aggregate gradation of control asphalt mixture DCT samples.

\begin{tabular}{|l|l|l|l|}
\hline Sieve number & Sieve size $(\mathrm{mm})$ & Retained (\%) & Mass (g) \\
\hline $1 / 2$ & 12.5 & 6 & 76.4 \\
\hline $3 / 8$ & 9.5 & 7.7 & 717.0 \\
\hline No. 4 & 4.75 & 18.1 & 864.0 \\
\hline No. 8 & 2.36 & 19 & 1199.0 \\
\hline No. 16 & 1.18 & 10.8 & 899.3 \\
\hline No. 30 & 0.6 & 10.6 & 623.0 \\
\hline No. 50 & 0.3 & 12.8 & 634.8 \\
\hline No. 100 & 0.15 & 8.3 & 411.4 \\
\hline No. 200 & 0.075 & 2.2 & 135.2 \\
\hline Pan powder & $<0.075$ & 4.5 & 317.4 \\
\hline
\end{tabular}

The flake graphite modified asphalt mixture samples were prepared by the aggregate gradation, shown in Table 9.2. The added flake graphite powders $(5 \%$ of the asphalt binder by weight) were treated as fine aggregates to keep the volume consistent of the mixture samples. In addition, the mesh of flake graphite was $0.15 \mathrm{~mm}(75 \%)$ and $0.075 \mathrm{~mm}(25 \%)$. Therefore, it is observed that the $2.3 \mathrm{~g}$ of No.100 aggregate and $0.8 \mathrm{~g}$ of No.200 aggregate are replaced by flake graphite material compared with the control aggregate gradation. 
Table 9. 2 Aggregate gradation of flake graphite modified asphalt mixture DCT samples.

\begin{tabular}{|l|l|l|l|}
\hline Sieve number & Sieve size $(\mathrm{mm})$ & Retained (\%) & Mass $(\mathrm{g})$ \\
\hline $1 / 2$ & 12.5 & 6 & 76.4 \\
\hline $3 / 8$ & 9.5 & 7.7 & 717.0 \\
\hline No. 4 & 4.75 & 18.1 & 864.0 \\
\hline No. 8 & 2.36 & 19 & 1199.0 \\
\hline No. 16 & 1.18 & 10.8 & 899.3 \\
\hline No. 30 & 0.6 & 10.6 & 623.0 \\
\hline No. 50 & 0.3 & 12.8 & 634.8 \\
\hline No. 100 & 0.15 & 8.3 & 409.1 \\
\hline No. 200 & 0.075 & 2.2 & 134.4 \\
\hline Pan powder & $<0.075$ & 4.5 & 317.4 \\
\hline
\end{tabular}

The $x$ GNP powders with a surface dimension of 25 microns were another material added into the asphalt mixture. The amount of used xGNP was $2 \%$ of the asphalt binder by weight. Similarly, part of the fine aggregates, the pan powder, were replaced by the xGNP. Table 9.3 displays the aggregate gradation of xGNP modified asphalt mixture. It is seen that $1.2 \mathrm{~g}$ of pan powder is replaced by $\mathrm{xGNP}$ compared with the aggregate gradation of the control asphalt mixture. 
Table 9.3 Aggregate gradation of xGNP modified asphalt mixture DCT samples.

\begin{tabular}{|l|l|l|l|}
\hline Sieve number & Sieve size $(\mathrm{mm})$ & Retained $(\%)$ & Mass $(\mathrm{g})$ \\
\hline $1 / 2$ & 12.5 & 6 & 76.4 \\
\hline $3 / 8$ & 9.5 & 7.7 & 717.0 \\
\hline No. 4 & 4.75 & 18.1 & 864.0 \\
\hline No. 8 & 2.36 & 19 & 1199.0 \\
\hline No. 16 & 1.18 & 10.8 & 899.3 \\
\hline No. 30 & 0.6 & 10.6 & 623.0 \\
\hline No. 50 & 0.3 & 12.8 & 634.8 \\
\hline No. 100 & 0.15 & 8.3 & 411.4 \\
\hline No. 200 & 0.075 & 2.2 & 135.2 \\
\hline Pan powder & $<0.075$ & 4.5 & 316.2 \\
\hline
\end{tabular}




\subsubsection{DCT sample preparation}

The sample used in this research was for the disk-shaped compact tension (DCT) test. First, the asphalt mixture was cast in a cylinder mold based on the asphalt amount, graphite amount and aggregate gradation. Then the big cylinder asphalt mixture sample was cut to small cylinder samples with a thickness of $50 \mathrm{~mm}$. Afterwards, the small cylinder sample was further cut to the particular shape that meets the specification of DCT test, shown in Figure 9.1. Consequently, 3 DCT samples for each type of asphalt mixture were used to measure the fracture energies by crack mouth opening displacement (CMOD) method. 3 flake graphite modified asphalt mixture DCT samples and three control asphalt mixture DCT sample were used to conduct the cyclic fracture-microwave healing tests. Another 2 control asphalt mixture samples were employed to do the cyclic fracture-non healing tests. Therefore, 9 control asphalt mixture DCT samples, 6 flake graphite modified asphalt mixture DCT samples, and 3 xGNP modified asphalt mixture DCT samples were prepared for the whole tests. 


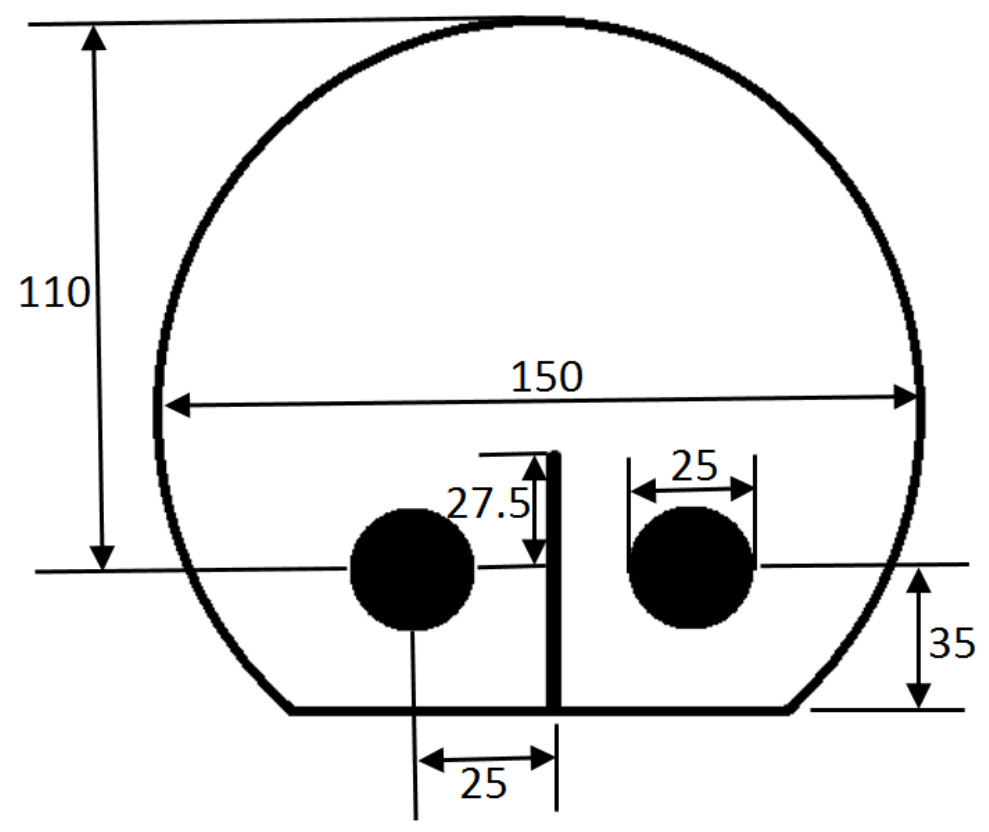

Figure 9. 1 Geometry (unit: $\mathrm{mm}$ ) of asphalt mixture DCT samples.

\subsection{Fracture-microwave healing investigation of asphalt mixture samples}

\subsubsection{Accelerated microwave healing mechanism}

The graphite materials have the ability to absorb the energy when locating in the microwave field. The temperature of graphite increases when absorbing the microwave energy. Then the heat is transferred to the asphalt binder and aggregate particles. During this process, the asphalt considered as temperature-dependent material behaves as Newtonian flow to fill the microcracks in the mixture. The crack healing process is regarded as a combination of gravity of liquid asphalt, the capillary flow resulted from surface tension force, and friction effect between the aggregates and flowing asphalt. The recovered strength of the asphalt mixture is mainly from the molecules diffusion and the rebinding of asphalt binder and aggregates. Figure 9.2 show the mechanism of microwave healing for asphalt mixture material. 


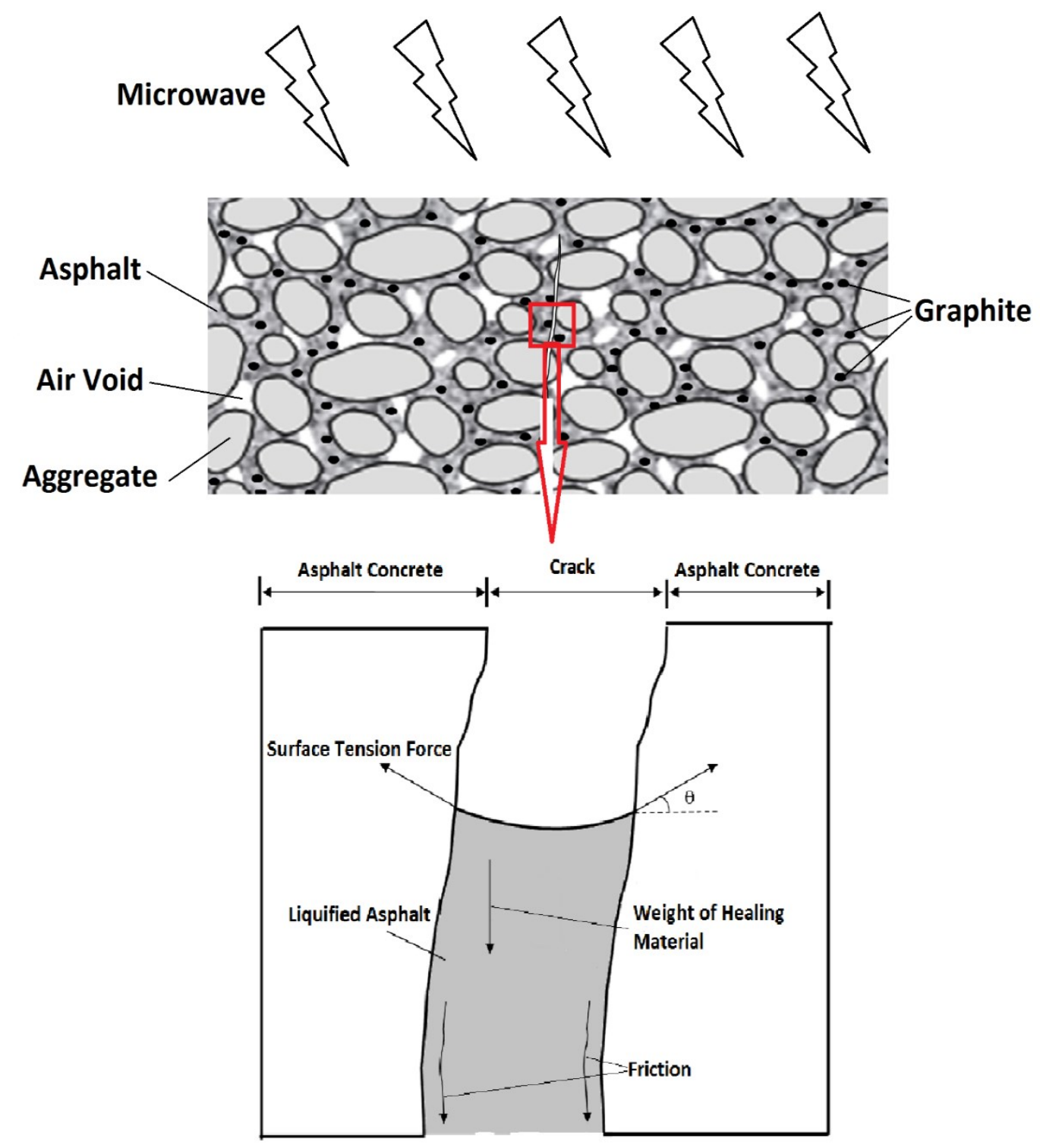

Figure 9. 2 Schematic demonstration of microwave healing mechanism for graphite modified asphalt mixture.

\subsubsection{Determination of measured fracture energy of asphalt mixture samples}

In this research, the fracture energy of the control, flake graphite modified and xGNP modified asphalt samples was determined by implementing the standard diskshaped compact tension test, ASTM E399 standard method. First, two knife edges were 
glued on a DCT sample with a distance of $5 \mathrm{~mm}$. Then the DCT sample was installed on the frictionless loading pins in a temperature controlled chamber. Figure 9.3 shows the experimental setup with the loading fixture, sample, clip-on gauge and crack detection wire. The test temperature was selected as $-20{ }^{\circ} \mathrm{C}$. The loading pins separated with a speed of $0.02 \mathrm{~mm} / \mathrm{s}$ while the CMOD and load were recorded. Subsequently, the fracture energy was determined by calculating the area under the CMOD-load curve divided by the cross-sectional area of the tested sample [144]. The average fracture energy values of each type asphalt mixture samples were calculated, including the control, 5\% flake graphite modified and 2\% xGNP modified asphalt mixture samples. The average fracture energy of the control asphalt mixture samples was $391.64 \mathrm{~J} / \mathrm{m}^{2}$ which was lower than that of the 5\% flake graphite modified asphalt mixture samples $\left(448.52 \mathrm{~J} / \mathrm{m}^{2}\right)$ and $2 \% \mathrm{xGNP}$ modified asphalt mixture samples $\left(496.98 \mathrm{~J} / \mathrm{m}^{2}\right)$. The average fracture energy of the $2 \% \mathrm{xGNP}$ modified asphalt mixture samples was higher than the 5\% flake graphite modified asphalt mixture samples. Therefore, both the added flake graphite and xGNP are capable of increasing the fracture energy of the asphalt mixture DCT samples. 


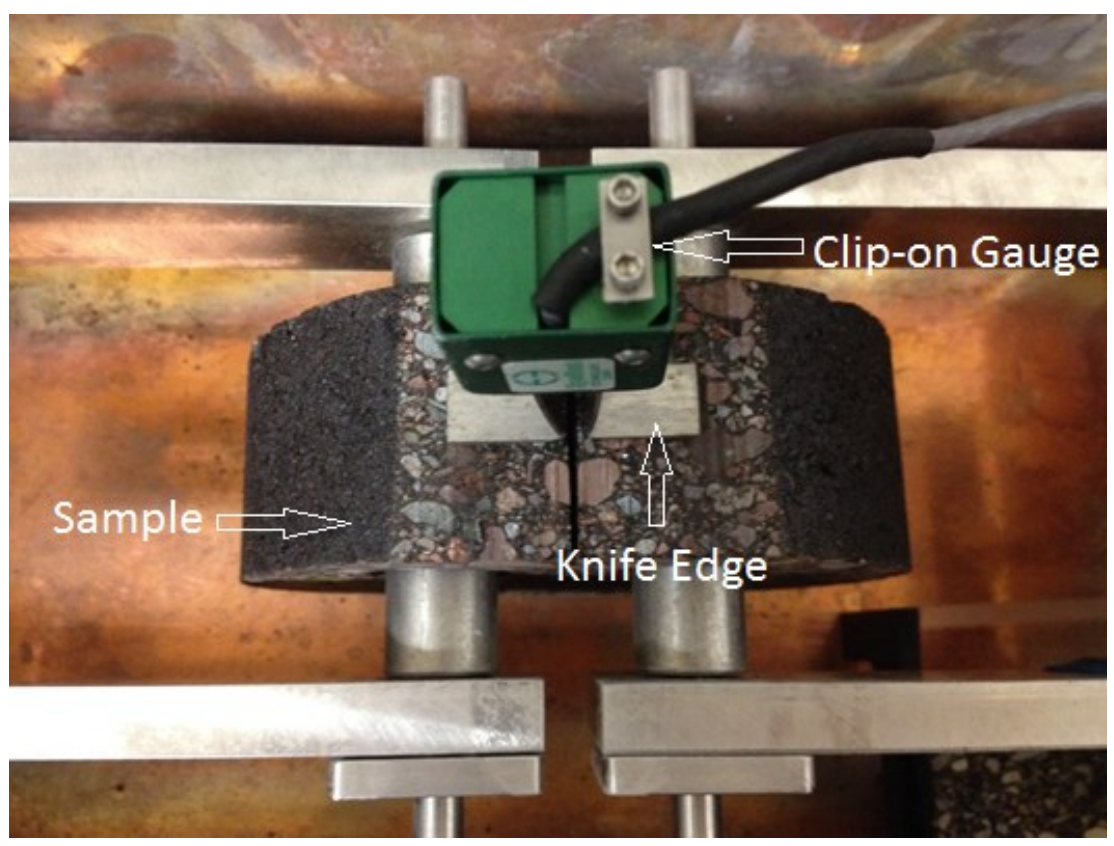

Figure 9. 3 Demonstration of disk-shaped compact tension test of asphalt mixture sample.

\subsubsection{Cyclic fracture-microwave healing tests of asphalt mixture samples}

The healing performance of the flake graphite and xGNP were investigated by the cyclic fracture-microwave healing tests, consisting of two parts, the sample fractured test and the sample microwave healed process. In the sample fractured test, the DCT sample was first installed on the loading pins with a testing temperature of $-20{ }^{\circ} \mathrm{C}$. Then the sample was pulling separately by the loading pins with a speed of $0.01 \mathrm{~mm} / \mathrm{s}$. Afterwards, the loading pins were stopped manually as long as the applying load increased to the maximum value (peak load). Meanwhile, the peak load, CMOD and testing time were recorded automatically. Subsequently, the fractured sample was taken out of the chamber for an hour until its temperature went up to the room temperature. In this research, three control asphalt mixture DCT samples and three 5\% flake 
graphite modified asphalt mixture DCT samples were investigated by the cyclic fracture-microwave healing tests.

In the sample microwave healed process, the fractured sample with room temperature was placed in a $1100 \mathrm{w}$ microwave oven, heating for 2 minutes, shown in Figure 9.4. The samples absorbed the microwave energy to heal the crack. The surface temperature of the control asphalt mixture samples could go up to $90{ }^{\circ} \mathrm{C}$ compared to the $5 \%$ flake graphite modified asphalt mixture samples with surface temperature increasing to $100{ }^{\circ} \mathrm{C}$. After that, the sample was taken out, being healed for about 30 minutes until its temperature went down to the room temperature. Then the microwave healed sample was put in the temperature controlled chamber for 2 hours and installed on the loading pins, pulled separately again. This repeated procedure was called cyclic fracture-microwave healing tests. Six cycles were implemented to evaluate the microwave healing performance of the asphalt mixture DCT samples. 


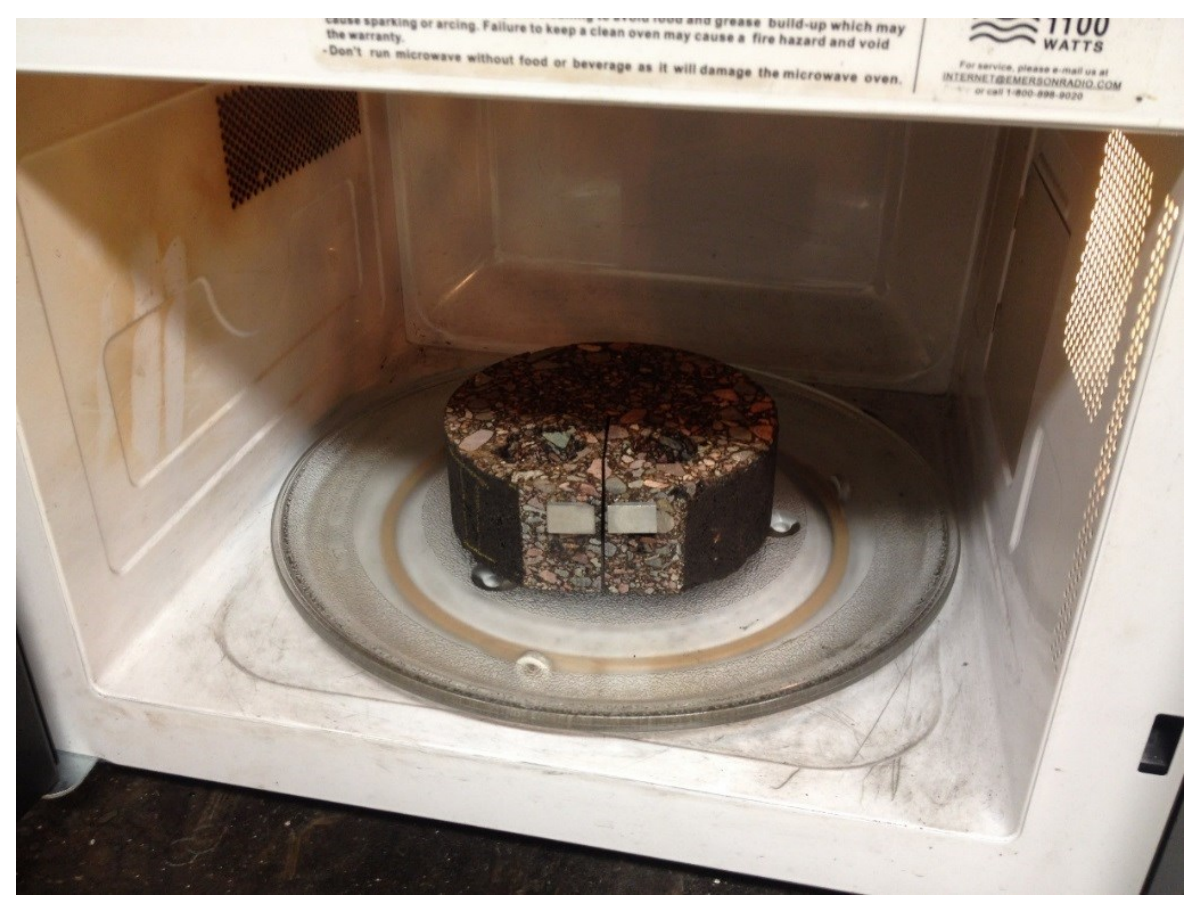

Figure 9. 4 Microwave healing of asphalt mixture sample.

\subsubsection{Fracture-microwave healing test results of asphalt mixture samples}

The recovered strength (recovered peak loads) were utilized to evaluate the microwave healing performance of the control and flake graphite modified asphalt mixture samples. Table 9.4 shows the peak loads of six asphalt mixture DCT samples during seven cycles of fracture-microwave healing tests. Then the ratios of recovered strength (recovered peak loads divided by original peak loads) are listed in Table 9.5. Figure 9.5 shows the seven cycles of fracture-microwave healing tests results of the three control asphalt mixture samples. It is observed that the range of original peak loads is from 3.3 to $3.7 \mathrm{kN}$, reducing to the range of $1.7 \mathrm{kN}$ to $2.2 \mathrm{kN}$ after seven fracture-microwave healing cycles. The average ratio of recovered peak loads after the first cycle remains $83.27 \%$, reducing to $76.57 \%, 66.85 \%, 63.07 \%, 60.21 \%$, and $56.37 \%$ cycle by cycle. 
Table 9. 4 Peak loads $(\mathrm{kN})$ of control samples and flake graphite modified samples under fracture-microwave healing cycles.

\begin{tabular}{|c|c|c|c|c|c|c|c|}
\hline Sample & $\begin{array}{l}1 \text { st } \\
\text { loading }\end{array}$ & $\begin{array}{l}\text { 2nd } \\
\text { loading }\end{array}$ & $\begin{array}{l}\text { 3rd } \\
\text { loading }\end{array}$ & $\begin{array}{l}\text { 4th } \\
\text { loading }\end{array}$ & $\begin{array}{l}\text { 5th } \\
\text { loading }\end{array}$ & $\begin{array}{l}\text { 6th } \\
\text { loading }\end{array}$ & $\begin{array}{l}\text { 7th } \\
\text { loading }\end{array}$ \\
\hline $\begin{array}{l}\text { Control } \\
1\end{array}$ & 3.538 & 3.214 & 2.949 & 2.752 & 2.471 & 2.261 & 1.981 \\
\hline $\begin{array}{l}\text { Control } \\
2\end{array}$ & 3.647 & 2.802 & 2.623 & 2.306 & 2.263 & 2.261 & 2.193 \\
\hline $\begin{array}{l}\text { Control } \\
3\end{array}$ & 3.314 & 2.722 & 2.467 & 1.973 & 1.9 & 1.813 & 1.756 \\
\hline $\begin{array}{l}\text { Flake } \\
\text { graphite } \\
1\end{array}$ & 3.516 & 2.772 & 2.867 & 2.819 & 2.828 & 2.824 & 2.793 \\
\hline $\begin{array}{l}\text { Flake } \\
\text { graphite } \\
2\end{array}$ & 3.537 & 2.969 & 2.671 & 2.569 & 2.547 & 2.511 & 2.422 \\
\hline $\begin{array}{l}\text { Flake } \\
\text { graphite } \\
3\end{array}$ & 3.416 & 2.818 & 2.607 & 2.577 & 2.489 & 2.437 & 2.398 \\
\hline
\end{tabular}


Table 9. 5 Ratios (\%) of recovered peak loads (RPL) of control samples, flake graphite modified samples.

\begin{tabular}{|c|c|c|c|c|c|c|}
\hline Sample & $\begin{array}{l}\text { 2nd } \\
\text { loading } \\
\text { after } 1 \\
\text { cycle }\end{array}$ & $\begin{array}{l}\text { 3rd } \\
\text { loading } \\
\text { after } 2 \\
\text { cycles }\end{array}$ & $\begin{array}{l}\text { 4th } \\
\text { loading } \\
\text { after } 3 \\
\text { cycles }\end{array}$ & $\begin{array}{l}\text { 5th } \\
\text { loading } \\
\text { after } 4 \\
\text { cycles }\end{array}$ & $\begin{array}{l}\text { 6th } \\
\text { loading } \\
\text { after } 5 \\
\text { cycles }\end{array}$ & $\begin{array}{l}\text { 7th } \\
\text { loading } \\
\text { after } 6 \\
\text { cycles }\end{array}$ \\
\hline $\begin{array}{l}\text { Control } \\
1\end{array}$ & $90.84 \%$ & $83.35 \%$ & $77.78 \%$ & $69.84 \%$ & $63.91 \%$ & $55.99 \%$ \\
\hline $\begin{array}{l}\text { Control } \\
2\end{array}$ & $76.83 \%$ & $71.92 \%$ & $63.23 \%$ & $62.05 \%$ & $62.00 \%$ & $60.13 \%$ \\
\hline $\begin{array}{l}\text { Control } \\
3\end{array}$ & $82.14 \%$ & $74.44 \%$ & $59.54 \%$ & $57.33 \%$ & $54.71 \%$ & $52.99 \%$ \\
\hline $\begin{array}{l}\text { Average } \\
\text { of } \\
\text { control } \\
\text { samples }\end{array}$ & $83.27 \%$ & $76.57 \%$ & $66.85 \%$ & $63.07 \%$ & $60.21 \%$ & $56.37 \%$ \\
\hline $\begin{array}{l}\text { Flake } \\
\text { graphite } \\
1\end{array}$ & $78.84 \%$ & $81.54 \%$ & $80.18 \%$ & $80.43 \%$ & $80.32 \%$ & $79.44 \%$ \\
\hline $\begin{array}{l}\text { Flake } \\
\text { graphite } \\
2\end{array}$ & $83.94 \%$ & $75.52 \%$ & $72.63 \%$ & $72.01 \%$ & $70.99 \%$ & $68.48 \%$ \\
\hline
\end{tabular}




\begin{tabular}{|c|c|c|c|c|c|c|}
\hline $\begin{array}{l}\text { Flake } \\
\text { graphite } \\
3\end{array}$ & $82.49 \%$ & $76.32 \%$ & $75.44 \%$ & $72.86 \%$ & $71.34 \%$ & $70.20 \%$ \\
\hline $\begin{array}{l}\text { Average } \\
\text { of } 5 \% \\
\text { flake } \\
\text { graphite } \\
\text { samples }\end{array}$ & $81.76 \%$ & $77.79 \%$ & $76.08 \%$ & $75.10 \%$ & $74.22 \%$ & $72.71 \%$ \\
\hline
\end{tabular}

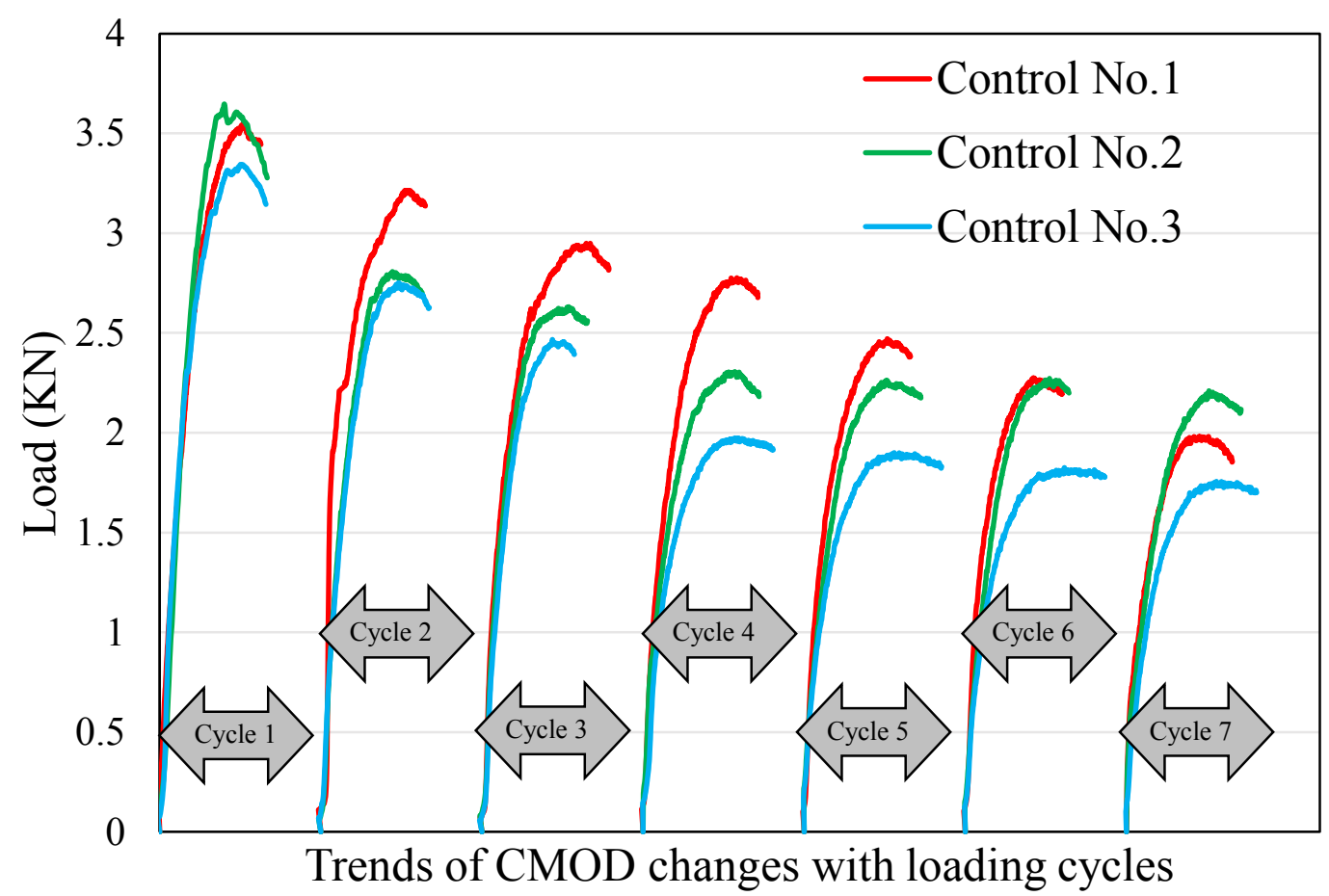

Figure 9. 5 Fracture-microwave healing test data of control asphalt mixture DCT samples. 
Figure 9.6 displays the fracture-microwave healing test results of the $5 \%$ flake graphite modified asphalt mixture samples. The original peak loads are in the range of $3.4 \mathrm{kN}$ to $3.6 \mathrm{kN}$, decreasing to the range of $2.3 \mathrm{kN}$ to $2.8 \mathrm{kN}$ at the seventh loading. The average ratios of the recovered peak loads decrease from $81.76 \%, 77.79 \%, 76.08 \%$, $75.10 \%, 74.22 \%$, to $72.71 \%$ during six cycles.

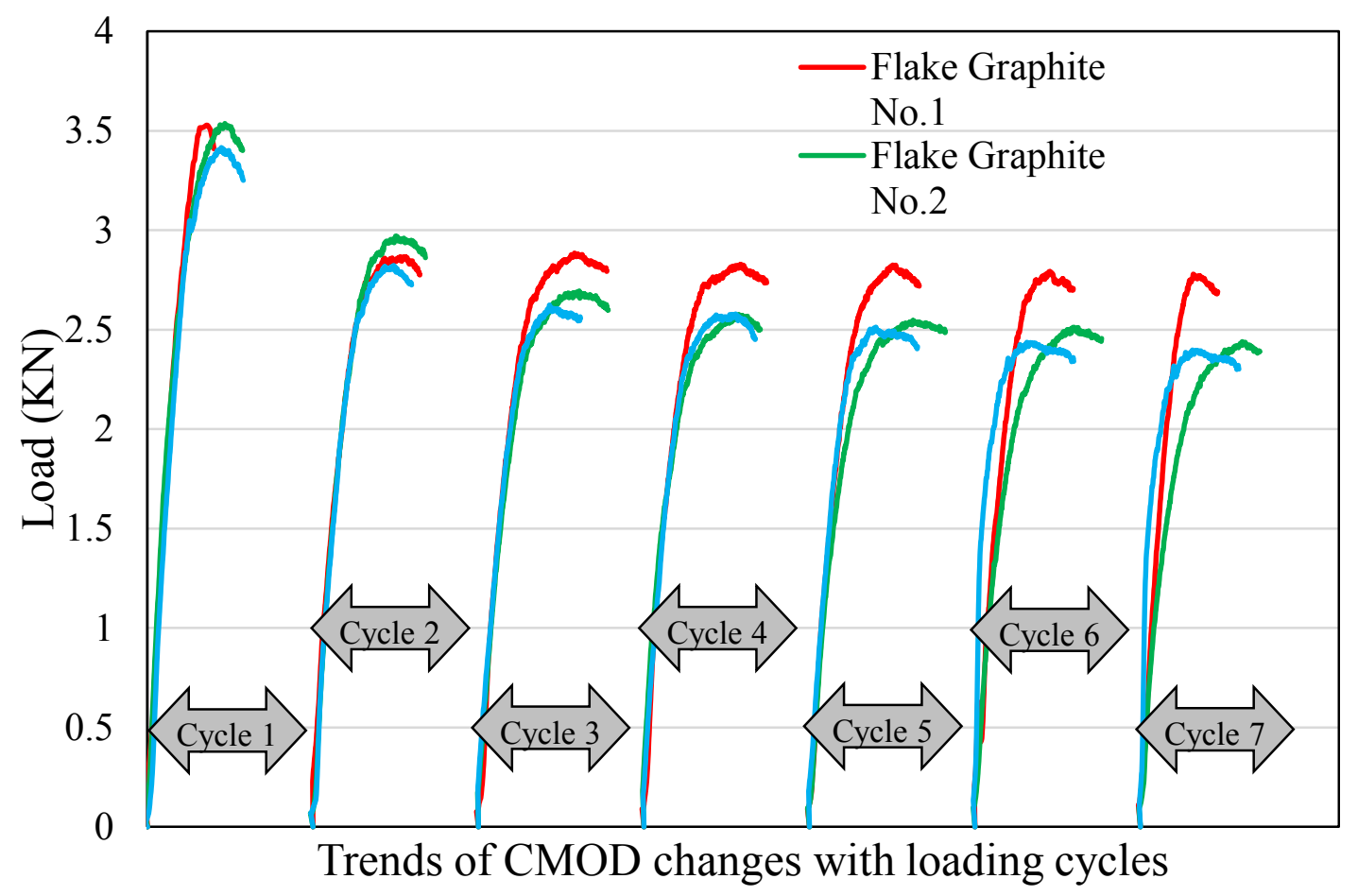

Figure 9. 6 Fracture-microwave healing test data of flake graphite modified asphalt mixture DCT samples.

In this study, three asphalt mixture DCT samples without flake graphite called non-microwave healing samples were conducted by fracture-non microwave healing test. These three samples had the same aggregate gradation and asphalt content compared with control asphalt mixture DCT samples. First, the three non-microwave 
healing samples were fractured by the loading pins, taken out of the chamber without microwave healing process. After a few hours, the samples with room temperature were installed on the loading pins and fractured again. Table 9.6 exhibits the peak loads of three non-microwave healing asphalt mixture samples conducted by the fracture-non microwave healing test. Figure 9.7 shows the fracture-non microwave healing test results. The original peak loads are from $3.2 \mathrm{kN}$ to $3.7 \mathrm{kN}$. Then the peaks loads decrease to $0.3 \mathrm{kN}$ to $0.5 \mathrm{kN}$ at the second loading. Therefore, the microwave healing process is effective to increase the recovered strength of asphalt mixture DCT samples.

Table 9. 6 Peak loads (KN) of asphalt mixture samples without flake graphite under the cycleic fracture-non microwave healing tests.

\begin{tabular}{|l|l|l|}
\hline Sample & 1st loading & 2nd loading \\
\hline Non-microwave & 3.659 & 0.364 \\
\hline Non-microwave & 3.481 & 0.409 \\
\hline healing 2 & & \\
\hline Non-microwave & 3.271 & 0.478 \\
healing 3 & & \\
\hline
\end{tabular}




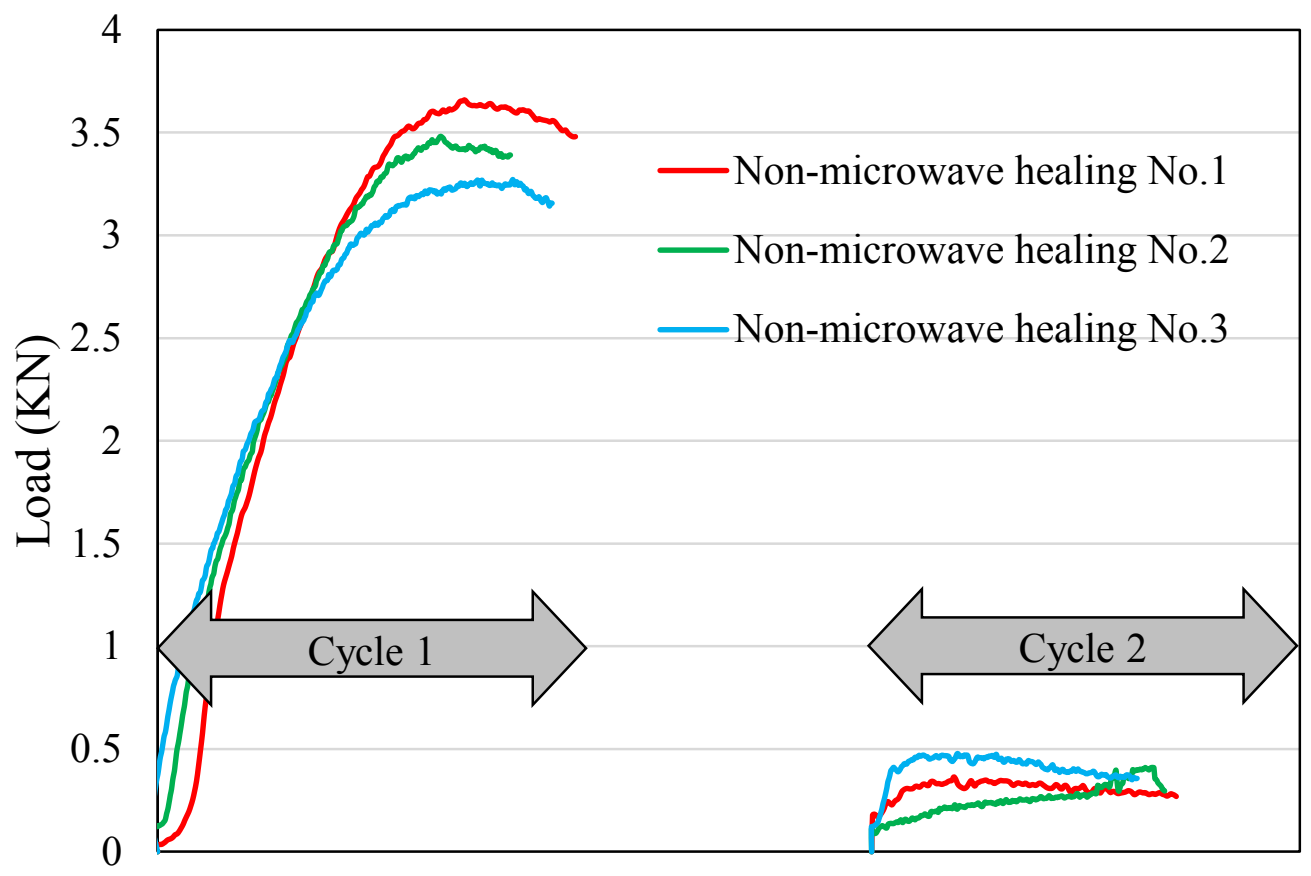

Trends of CMOD changes with loading cycles

Figure 9. 7 Fracture-non microwave healing test data of asphalt mixture DCT samples without flake graphite.

\subsection{Summary and conclusions}

In this research, two graphite materials, flake graphite and xGNP were added to the asphalt mixture. Both the flake graphite and xGNP could increase the fracture energy of the asphalt mixture DCT samples. In addition, the fracture-non microwave healing test proved that the microwave healing process is effective to increase the recovered strength of the asphalt mixture. Moreover, it is concluded from the cyclic fracture-microwave healing tests that the microwave has the ability to increase the temperature of asphalt mixture and graphite. The graphite could further reinforce the 
microwave healing performance on asphalt mixture because of more absorbed microwave energy. 


\section{CHAPTER 10 SUMMARY AND CONCLUSION}

\subsection{Summary}

In this research, the materials, steel wool, carbon fiber and graphite were added to the asphalt to modify the properties of the asphalt binder and mixture. A series of performance tests were conducted to evaluate the electrical resistivity, thermal conductivity, viscosity, mechanical property of the modified asphalt and mixture. The electromagnetic energy was utilized to accelerate the self-healing process of asphalt binder by evaluating the recovered strength of the asphalt mixtures.

The asphalt mixture within steel wool fibers was investigate the self-healing performance of conductive asphalt materials through cyclic peak-to-peak fracture and induction healing tests, and to evaluate the influence of different temperatures of induction heating on the healing capability of dense-graded asphalt materials. The mastic and concrete samples were prepared by adding Type 1 steel wool fibers with an approximate length of $6.5 \mathrm{~mm}$. These prepared samples were then tested under fracture-healing cycles by using the three-point bending loading and modified threepoint bending loading tests (with an elastic foundation support) for the asphalt mastic and concrete beam samples, respectively. The healing performances of samples were evaluated with recovered peak load under fracture-healing cycles. In addition, the simulation model using cohesive zone theory and finite element method was adapted to simulate the crack path of asphalt concrete beam using digital imaging analysis. Then standard three-point bending test was conducted to validate the cohesive fracture model by comparing the experimental results with numerical simulation. Afterwards, the 
fracture properties including the peak separation stress and fracture energy were proposed for fracture-healing cyclic simulation to predict the loading-displacement curves for different cycles. Finally, the cohesive model simulation with proposed fracture properties have favorable prediction on the recovered fracture strength by comparing the difference between the experimental and numerical results.

The carbon fibers modified asphalt composites were investigated with thermal property, electrical property and microwave healing effect of the carbon fiber modified asphalt mixture. First, two types of carbon fiber, HexTow IM8 and AS4 were added to the asphalt mixture to produce the beam samples. Then, the thermal conductivity and electrical resistivity of the samples were measured and calculated, respectively. Moreover, the cyclic fracture-microwave healing tests were implemented to evaluate the healing effect of the samples.

Two graphite modifiers, flake graphite and xGNP were added into the asphalt mixture material. The viscosity test, visible/near infrared light absorption test, bending beam rheometer test, dynamic shear rheometer test, FTIR test and thermal conductivity test of control asphalt and graphite modified asphalt were conducted. The performance tests of the graphite (5\% flake graphite and $2 \% \mathrm{xGNP})$ modified asphalt mixture were conducted, including the electrical resistivity measurement, thermal conductivity measurement, Hamburg wheel tracking device test and dynamic modulus test. The light healing effect of control, 5\% flake graphite modified and 2\% xGNP modified asphalt mixture samples was investigated. The infrared images of asphalt mixture samples conclude that both the 5\% flake graphite and 2\% xGNP modified asphalt 
mixtures could better absorb the light energy and transfer the heat from top to bottom than the control asphalt mixtures. The control, $5 \%$ flake graphite modified and $2 \%$ xGNP modified asphalt mixture samples were produced for the DCT machine. Then the fracture energy values of the control, flake graphite modified and xGNP modified asphalt mixture were measured. The cyclic fracture-microwave healing test and fracture-non microwave healing test were conducted to evaluate the microwave healing performance of the control and flake graphite modified asphalt mixture DCT samples.

The finite element CZM with measured or calibrated fracture energy and peak separation stress were used to predict the original and recovered fracture strength of the control, flake graphite modified and xGNP modified asphalt mixture samples during the cyclic fracture-light healing tests. The DIC techniques were applied to calculate the relative strain ratios during the fracture-light healing cycles for calibration of recovered fracture energy of samples. For the original beam samples, the measured fracture energy of the control, flake graphite modified and xGNP modified beams were obtained with the three-point bending tests. Both flake graphite and xGNP have the ability to increase the fracture energy of the asphalt mixture beam samples. The finite element CZM was used to simulate the beam crack propagation and original fracture strength under elastic-support beam bending loading. The simulation results from the micromechanical beam cross-section model showed the close prediction for both the original fracture strength and crack propagation on the beam samples. For the healed beam samples, the DIC technique provides a useful approach to analyze the crack displacement variation of the asphalt mixture samples during the cyclic fracture-light 
healing processes. The recovered fracture energies were calculated based on the peak separation stresses, the originally measured fracture energies and the relative strain ratios of the tested samples. The numerical peak loads of all the samples have a favorable agreement with the experimental results due to the low relative differences.

\subsection{Conclusion}

The induction healing performance of prepared asphalt mastic and asphalt concrete samples were investigated through fracture-healing test. The test data of asphalt mastic samples indicate that micro-cracks in the mastic samples can be effectively healed at the heating temperature of $60^{\circ} \mathrm{C}$. The sample fracture strength was improved because the binder filled the notched cracks at the bottom of the samples at the heating temperatures of $80^{\circ} \mathrm{C}$ and $100^{\circ} \mathrm{C}$. From the test data of asphalt concrete samples, it was determined that the $100^{\circ} \mathrm{C}$ heating temperature could be the optimum option for the induction healing because the recovered peak load values were higher than the other two temperatures after several fracture-healing cycles. Besides, the cohesive fracture simulation were conducted with scaled fracture energy and peak separation stress from experimental data to predict the recovered peak loads after each fracture-healing cycle. The predicted peak loads have a good agreement with the experimental results. The average relative difference between the predicted peak load and the experimental peak load was low as $1.75 \%$. These favorable comparison indicated that numerical simulation using finite element method and cohesive zone model is capable to predict the fracture recovered strength after fracture-healing cycles. This result could offer great help on highway maintenance if the field sample is 
obtained. Then the cohesive zone model with defined crack based on the sample could be employed to evaluate the pavement performance and to decide the maintenance method.

The measurement results of the thermal conductivity of the carbon fibers modified asphalt of the samples indicated that the carbon fiber, as a modifier, could increase the thermal conductivity of the asphalt mixture. On the other hand, the carbon fiber has the ability to decrease the electrical resistivity. Finally, the results of the cyclic fracturemicrowave healing test indicated that the carbon fibers, containing IM8 and AS4, could increase the microwave healing effect. However, too many carbon fibers may affect the Newtonian flow of asphalt and the microwave healing effect could be decreased.

The viscosity measurement results of graphite modified asphalt samples were utilized to calculate the activation energy. Both flake graphite and xGNP modified asphalt binder could decrease the activation energy of asphalt. It is concluded that the graphite modified asphalt has lower energy input for healing compared with pure asphalt binder. The results of the visible/near infrared light absorption test show that the graphite materials have capability to enhance the light absorption of asphalt, especially the infrared light absorption of asphalt. The effect of the 5\% flake graphite modified asphalt is better than that of the $2 \% \mathrm{xGNP}$ modified asphalt. The graphite material could decrease the low temperature property of asphalt through the bending beam rheometer. Additionally, the complex shear moduli of graphite modified asphalt increase compared with the control asphalt. The aging degree of asphalt increases by the graphite materials as well. The results of the thermal conductivity test reveal that 
added small portion of graphite can increase the thermal conductive property of control asphalt. The electrical resistivity measurement of the graphite modified asphalt mixture results showed that the graphite materials, as a good electrical conductor, could decrease the electrical resistivity of asphalt mixture. In addition, thermal conductivity of asphalt mixture increased with added graphite materials. The HWTD test data indicated that the rut depths of the graphite modified asphalt mixture decreased compared with the control asphalt mixture. The graphite materials could improve the high temperature rutting issue of the asphalt mixture. The graphite materials have the ability to increase the dynamic modulus of the asphalt mixture as well to improve the mechanical property of the pavement. The DIC analysis results of pixel displacements in the light healing processes indicates that the visible/infrared light is an effective way to heal the fractured asphalt mixture sample. The healing effect decreases with light healing cycles. The recovered peak loads from the cyclic fracture-light healing tests showed that both the 5\% flake graphite and $2 \%$ xGNP modified asphalt mixtures have improved light healing performance compared with the control asphalt mixture. The 5\% flake graphite modified asphalt mixtures have better healing performance than the $2 \%$ xGNP modified asphalt mixtures. Both the flake graphite and xGNP could increase the fracture energy of the asphalt mixture DCT samples. In addition, the fracture-non microwave healing test proved that the microwave healing process is effective to increase the recovered strength of the asphalt mixture. Moreover, it is concluded from the cyclic fracture-microwave healing tests that the microwave has the ability to increase the temperature of asphalt mixture and graphite. The graphite could further 
reinforce the microwave healing performance on asphalt mixture because of more absorbed microwave energy.

The comparison of the experimental and numerical results of the graphite modified asphalt mixture indicates that the combined triangle-shaped finite elements and the user-defined cohesive zone interface elements can be used to simulate the fracture behavior of the asphalt mixture beam. In addition, the recovered fracture energies of the asphalt mixture samples can be calculated using the measured peak separation stress and the DIC calibrated relative strain ratios. In the future work, the other performance of light-healed asphalt mixture samples will be studied further to explore the field application. 


\section{REFERENCE}

1. FHWA, Highway Statistics 2000. 2001, Office of Highway Policy Information, Federal Highway Administration: Washington, D.C.

2. Yao, H., et al., Rheological properties and chemical analysis of nanoclay and carbon microfiber modified asphalt with Fourier transform infrared spectroscopy. Construction and Building Materials, 2013. 38: p. 327-337.

3. Shashidhar, N. and K. Gopalakrishnan, Evaluating the aggregate structure in hot-mix asphalt using three-dimensional computer modeling and particle packing simulations. Canadian Journal of Civil Engineering, 2006. 33(8): p. 945-954.

4. Dai, Q., Z. Wang, and M.R.M. Hasan, Investigation of induction healing effects on electrically conductive asphalt mastic and asphalt concrete beams through fracture-healing tests. Construction and Building Materials, 2013. 49: p. 729737.

5. Arambula, E., E. Masad, and A.E. Martin, Influence of air void distribution on the moisture susceptibility of asphalt mixes. Journal of materials in civil engineering, 2007. 19(8): p. 655-664.

6. Seo, Y., et al., Air void models for the dynamic modulus, fatigue cracking, and rutting of asphalt concrete. Journal of Materials in Civil Engineering, 2007. 19(10): p. 874-883.

7. Hager, M.D., et al., Self-Healing Materials. Advanced Materials, 2010. 22(47): p. 5424-5430.

8. White, S.R., et al., Autonomic healing of polymer composites. Nature, 2001. 409(6822): p. 794-797.

9. Raithby, K. and A. Sterling. THE EFFECT OF REST PERIODS ON THE FATIGUE PERFORMANCE OF A HOT-ROLLED ASPHALT UNDER REVERSED AXIAL LOADING AND DISCUSSION. in Association of Asphalt Paving Technologists Proc. 1970.

10. Bazin, P. and J. Saunier. Deformability, fatigue and healing properties of asphalt mixes. in Intl Conf Struct Design Asphalt Pvmts. 1967.

11. Qiu, J., et al., Evaluating self healing capability of bituminous mastics. Experimental mechanics, 2012. 52(8): p. 1163-1171.

12. Shen, S., H.-M. Chiu, and H. Huang, Characterization of fatigue and healing in asphalt binders. Journal of Materials in Civil Engineering, 2010. 22(9): p. 846852.

13. Castro, M. and J.A. Sánchez, Fatigue and healing of asphalt mixtures: discriminate analysis of fatigue curves. Journal of transportation engineering, 2006. 132(2): p. 168-174.

14. Bhasin, A., et al., Use of molecular dynamics to investigate self-healing mechanisms in asphalt binders. Journal of Materials in Civil Engineering, 2010. 23(4): p. 485-492.

15. Kringos, N., et al., Towards an understanding of the self-healing capacity of asphaltic mixtures. Heron, 2011. 56(1/2): p. 45. 
16. García, Á., et al., Optimization of composition and mixing process of a selfhealing porous asphalt. Construction and Building Materials, 2012. 30: p. 5965.

17. Akisetty, C.K., S.-J. Lee, and S.N. Amirkhanian, High temperature properties of rubberized binders containing warm asphalt additives. Construction and Building Materials, 2009. 23(1): p. 565-573.

18. Bommavaram, R., A. Bhasin, and D. Little, Determining intrinsic healing properties of asphalt binders: role of dynamic shear rheometer. Transportation Research Record: Journal of the Transportation Research Board, 2009(2126): p. 47-54.

19. Xiao, F., A.N. Amirkhanian, and S.N. Amirkhanian, Influence of carbon nanoparticles on the rheological characteristics of short-term aged asphalt binders. Journal of Materials in Civil Engineering, 2010. 23(4): p. 423-431.

20. Yu, J.-Y., et al., Effect of organo-montmorillonite on aging properties of asphalt. Construction and Building Materials, 2009. 23(7): p. 2636-2640.

21. You, Z., et al., Nanoclay-modified asphalt materials: Preparation and characterization. Construction and Building Materials, 2011. 25(2): p. 10721078.

22. Velasquez, R., et al., Bending beam rheometer testing of asphalt mixtures. International Journal of Pavement Engineering, 2011. 12(5): p. 461-474.

23. Xiang, L., J. Cheng, and G. Que, Microstructure and performance of crumb rubber modified asphalt. Construction and Building Materials, 2009. 23(12): p. 3586-3590.

24. Williams, R. and B. Prowell, Comparison of laboratory wheel-tracking test results with Wes Track performance. Transportation Research Record: Journal of the Transportation Research Board, 1999(1681): p. 121-128.

25. Zhao, S., et al., Comparative evaluation of warm mix asphalt containing high percentages of reclaimed asphalt pavement. Construction and Building Materials, 2013. 44: p. 92-100.

26. Kim, Y., H.D. Lee, and M. Heitzman, Dynamic modulus and repeated load tests of cold in-place recycling mixtures using foamed asphalt. Journal of Materials in Civil Engineering, 2009. 21(6): p. 279-285.

27. Birgisson, B., et al., The use of complex modulus to characterize the performance of asphalt mixtures and pavements in Florida. 2004.

28. Poulikakos, L. and M. Partl, Micro scale tensile behaviour of thin bitumen films. Experimental mechanics, 2011. 51(7): p. 1171-1183.

29. Brown, E., S. White, and N. Sottos, Retardation and repair of fatigue cracks in a microcapsule toughened epoxy composite-Part II: In situ self-healing. Composites Science and Technology, 2005. 65(15): p. 2474-2480.

30. Schmets, A.J., G. van der Zaken, and S. van der Zwaag, Self healing materials: an alternative approach to 20 centuries of materials science. Vol. 100. 2007: Springer. 
31. Little, D.N. and A. Bhasin, Exploring Mechanism of Healing in Asphalt Mixtures and Quantifying its Impact. Springer Series in Materials Science, 2007. 100: p. 205.

32. Williams, D., et al., Microdamage healing in asphalt and asphalt concrete, volume II: Laboratory and field testing to assess and evaluate microdamage and microdamage healing. 2001.

33. Kim, Y.-R., D. Little, and R. Lytton, Fatigue and healing characterization of asphalt mixtures. Journal of Materials in Civil Engineering, 2003. 15(1): p. 7583.

34. Song, I., et al., Comprehensive Evaluation of Damage in Asphalt Mastics Using $X$-ray CT, Continuum Mechanics, and Micromechanics (With Discussion). Journal of the association of asphalt paving technologists, 2005. 74.

35. Bahia, H., et al., Non-linear viscoelastic and fatigue properties of asphalt binders. Journal of the Association of Asphalt Paving Technologists, 1999. 68.

36. Bhasin, A., S. Palvadi, and D.N. Little, Influence of aging and temperature on intrinsic healing of asphalt binders. Transportation Research Record: Journal of the Transportation Research Board, 2011. 2207(1): p. 70-78.

37. Shan, L., et al., Application of thixotropy to analyze fatigue and healing characteristics of asphalt binder. Transportation Research Record: Journal of the Transportation Research Board, 2010. 2179(1): p. 85-92.

38. Phillips, M. Multi-step models for fatigue and healing, and binder properties involved in healing. in Eurobitume workshop on performance related properties for bituminous binders, Luxembourg. 1998.

39. Bhasin, A., et al., A framework to quantify the effect of healing in bituminous materials using material properties. Road Materials and Pavement Design, 2008. 9(sup1): p. 219-242.

40. Qiu, J., et al., Investigating self healing behaviour of pure bitumen using Dynamic Shear Rheometer. Fuel, 2011. 90(8): p. 2710-2720.

41. García, Á., Self-healing of open cracks in asphalt mastic. Fuel, 2012. 93: p. 264-272.

42. Kim, B. and R. Roque, Evaluation of healing property of asphalt mixtures. Transportation Research Record: Journal of the Transportation Research Board, 2006. 1970(1): p. 84-91.

43. Kim, Y.R., D.N. Little, and F.C. Benson, CHEMICAL AND MECHANICAL EVALUATION ON HEALING MECHANISM OF ASPHALT CONCRETE (WITH DISCUSSION). Journal of the Association of Asphalt Paving Technologists, 1990. 59.

44. Bommavaram, R.R., Evaluation of healing in asphalt binders using dynamic shear rheometer and molecular modeling techniques. 2013.

45. Bonnaure, F., A. Huibers, and A. Boonders, A laboratory investigation of the influence of rest periods on the fatigue characteristics of bituminous mixes. Journal of the Association of Asphalt Paving Technologists, 1982. 51: p. 104128. 
46. Daniel, J.S. and Y.R. Kim, Laboratory evaluation of fatigue damage and healing of asphalt mixtures. Journal of Materials in Civil Engineering, 2001. 13(6): p. 434-440.

47. García, Á., et al., Electrical conductivity of asphalt mortar containing conductive fibers and fillers. Construction and Building Materials, 2009. 23(10): p. $3175-3181$.

48. Lee, S.J., et al., Fatigue cracking resistance of fiber-reinforced asphalt concrete. Textile Research Journal, 2005. 75(2): p. 123-128.

49. Dai, Q., Z. Wang, and M.R. Mohd Hasan, Investigation of induction healing effects on electrically conductive asphalt mastic and asphalt concrete beams through fracture-healing tests. Construction and Building Materials, 2013. 49: p. 729-737.

50. Liu, Q., et al., Induction healing of asphalt mastic and porous asphalt concrete. Construction and Building Materials, 2011. 25(9): p. 3746-3752.

51. Liu, Q., et al., Optimization of steel fiber used for induction heating in porous asphalt concrete. Traffic and transportation studies, 2010: p. 1320-1330.

52. García, Á., et al., Induction heating of mastic containing conductive fibers and fillers. Materials and structures, 2011. 44(2): p. 499-508.

53. Kneepkens, A., et al. DEVELOPMENT OF VIA-RAL FOR POROUS ASPHALT: MORE THAN JUST RESEARCH, MORE PRAGMATISM. 2004.

54. Liu, Q., et al., Evaluation of the induction healing effect of porous asphalt concrete through four point bending fatigue test. Construction and Building Materials, 2012. 29: p. 403-409.

55. Shen, S., H.M. Chiu, and H. Huang, Characterization of fatigue and healing in asphalt binders. Journal of Materials in Civil Engineering, 2010. 22: p. 846.

56. Alvaro, G., Self-healing of open cracks in asphalt mastic. Fuel, 2012. 93: p. 264-272.

57. Daniel, J.S. and Y.R. Kim, Laboratory evaluation of fatigue damage and healing of asphalt mixtures. Journal of Materials in Civil Engineering, 2001. 13: p. 434.

58. Lytton, R., C. Chen, and D. Little, Microdamage Healing in Asphalt and Asphalt Concrete, Volume IV: A Viscoelastic Continuum Damage Fatigue Model of Asphalt Concrete with Microdamage Healing. 2001.

59. Kim, Y.R., Fatigue and healing characterization of asphalt mixtures. Journal of Materials in Civil Engineering, 2003. 15: p. 75.

60. Bhasin, A., et al., Use of molecular dynamics to investigate self-healing mechanisms in asphalt binders. Journal of Materials in Civil Engineering, 2011. 23: p. 485.

61. Qiu, J., et al., Evaluating Self Healing Capability of Bituminous Mastics. Experimental Mechanics, 2011: p. 1-9.

62. Little, D. and A. Bhasin, Exploring Mechanism of H ealing in Asphalt Mixtures and Quantifying its Impact. Self healing materials, 2008: p. 205-218. 
63. Bhasin, A., S. Palvadi, and D.N. Little, Influence of aging and temperature on intrinsic healing of asphalt binders. Transportation Research Record, 2011(2207): p. 70-78.

64. García, Á., et al., A simple model to define induction heating in asphalt mastic. Construction and Building Materials, 2012. 31: p. 38-46.

65. Liu, Q., et al., Induction heating of electrically conductive porous asphalt concrete. Construction and Building Materials, 2010. 24(7): p. 1207-1213.

66. Garcia, A., et al., Crack repair of asphalt concrete with induction energy. Heron, 2011. 56(1-2): p. 37-48.

67. Liu, Q., et al., Induction healing of asphalt mastic and porous asphalt concrete. Construction and Building Materials, 2011. 25(9): p. 3746-3752.

68. Liu, Q., et al. Optimization of steel fiber used for induction heating in porous asphalt concrete. in 7th International Conference on Traffic and Transportation Studies, (ICTTS 2010), August 3, 2010 - August 5, 2010. 2010. Kunming, China: American Society of Civil Engineers.

69. García, A., Self-healing of open cracks in asphalt mastic. Fuel, 2012. 93: p. 264-272.

70. Paulino, G.H., S.H. Song, and W.G. Buttlar, Cohesive Zone Modeling of Fracture in Asphalt Concrete, in 5th International RILEM Conference 2004, RILEM Publication: Limoges, France. p. 63-70.

71. Roesler, J., et al., Concrete fracture prediction using bilinear softening. Cement and Concrete Composites, 2007. 29(4): p. 300-312.

72. Song, S.H., G.H. Paulino, and W.G. Buttlar, A bilinear cohesive zone model tailored for fracture of asphalt concrete considering viscoelastic bulk material. Engineering Fracture Mechanics, 2006. 73(18): p. 2829-2848.

73. Spring, D.W., Cohesive Zone Modeling of Fracture of Sustainable and Functionally Graded Concrete, in Civil Engineering. 2011, University of Illinois at Urbana-Champaign: Urbana, Illinois.

74. Prandtl, L., Ein Gedankenmodell für den Zerreißvorgang spröder Körper. ZAMM - Journal of Applied Mathematics and Mechanics / Zeitschrift für Angewandte Mathematik und Mechanik, 1933. 13(2): p. 129-133.

75. Barenblatt, G.I., The mathematical theory of equilibrium cracks in brittle fracture. Advances in applied mechanics, 1962. 7(1): p. 55-129.

76. Xu, X.P. and A. Needleman, Numerical simulations of fast crack growth in brittle solids. Journal of the Mechanics and Physics of Solids, 1994. 42(9): p. 1397-1434.

77. Shet, C. and N. Chandra, Analysis of energy balance when using cohesive zone models to simulate fracture processes. Journal of engineering materials and technology, 2002. 124(4): p. 440-450.

78. Zhang, Z., Cohesive Zone Modeling of Dynamic Failure in Homogeneous and Functionally Graded Materials, in Civil and Environmental Engineering. 2003, University of Illinois at Urbana-Champaign: Urbana, Illinois. 
79. Klein, P.A., et al., Physics-based modeling of brittle fracture: cohesive formulations and the application of meshfree methods. Theoretical and Applied Fracture Mechanics, 2001. 37(1-3): p. 99-166.

80. Anderson, T.L., Fracture Mechanics: Fundamentals and Applications. 2nd ed. 1995: C.R.C Press, Inc.

81. Kim, Y.-R., D.H. Allen, and D.N. Little, Computational Constitutive Model for Predicting Nonlinear Viscoelastic Damage and Fracture Failure of Asphalt Concrete Mixtures. International Journal of Geomechanics, 2007. 7(2): p. 102110.

82. Kim, Y.-R., D.H. Allen, and D.N. Little, Damage-Induced Modeling of Asphalt Mixtures through Computational Micromechanics and Cohesive Zone Fracture. Journal of Materials in Civil Engineering, 2005. 17(5): p. 477-484.

83. Rosselló, C., M. Elices, and G.V. Guinea, Fracture of model concrete: 2. Fracture energy and characteristic length. Cement and Concrete Research, 2006. 36(7): p. 1345-1353.

84. Song, S.H., G.H. Paulino, and W.G. Buttlar, Simulation of Crack Propagation in Asphalt Concrete Using an Intrinsic Cohesive Zone Model. Journal of Engineering Mechanics, 2006. 132(11): p. 1215-1223.

85. Yao, H., et al., Performance of asphalt binder blended with non-modified and polymer-modified nanoclay. Construction and Building Materials, 2012. 35: p. 159-170.

86. Livneh, M., Deterioration modeling for unlaid and overlaid pavements. Transportation Research Record: Journal of the Transportation Research Board, 1996(1524): p. 177-184.

87. García, Á., et al., Optimization of composition and mixing process of a selfhealing porous asphalt. Construction and Building Materials, 2012. 30: p. 5965 .

88. Wang, Z., Q. Dai, and X. Yang, Integrated Computational-Experimental Approach for Evaluating Recovered Fracture Strength after Induction Healing of Asphalt Concrete Beam Samples. Construction and Building Materials, accepted, 2016.

89. Yang, T., et al., Experimental study on carbon fiber tape-based deicing technology. Journal of Cold Regions Engineering, 2011. 26(2): p. 55-70.

90. Liu, X., et al., Self-monitoring application of asphalt concrete containing graphite and carbon fibers. Journal of Wuhan University of Technology-Mater. Sci. Ed., 2008. 23(2): p. 268-271.

91. Liu, X. and S. Wu, Study on the graphite and carbon fiber modified asphalt concrete. Construction and Building Materials, 2011. 25(4): p. 1807-1811.

92. Khattak, M.J., et al., The impact of carbon nano-fiber modification on asphalt binder rheology. Construction and Building Materials, 2012. 30: p. 257-264.

93. Qing, Y., et al., Electromagnetic and microwave absorption properties of carbonyl iron and carbon fiber filled epoxy/silicone resin coatings. Applied Physics A, 2010. 100(4): p. 1177-1181. 
94. Zhao, N., et al., Microwave absorbing properties of activated carbon-fiber felt screens (vertical-arranged carbon fibers)/epoxy resin composites. Materials Science and Engineering: B, 2006. 127(2): p. 207-211.

95. Hashisho, Z., et al., Role of functional groups on the microwave attenuation and electric resistivity of activated carbon fiber cloth. Carbon, 2009. 47(7): p. 1814-1823.

96. Cao, M.-S., et al., The effects of temperature and frequency on the dielectric properties, electromagnetic interference shielding and microwave-absorption of short carbon fiber/silica composites. Carbon, 2010. 48(3): p. 788-796.

97. D5334-14, A., Standard Test Method for Determination of Thermal Conductivity of Soil and Soft Rock by Thermal Needle Probe Procedure. 2014, ASTM.

98. Vacquier, V., The measurement of thermal conductivity of solids with a transient linear heat source on the plane surface of a poorly conducting body. Earth and planetary science letters, 1985. 74(2): p. 275-279.

99. Kneepkens, A., S.H. van Hoof Th, and W. van Keulen, VIA-RAL ${ }^{\circledR}$ for porous asphalt: a result of research and development, but most of all of implementation. Wegbouwkundige Werkdagen, 2004.

100. Zhao, Y. and H.G. Machel. Determination of the Viscosities of Grosmont Reservoir Bitumen, Alberta, Canada. in CSP CSEG CWLS Convention. Calgary, Canada. 2009.

101. Carpenter, S. and S. Shen, Dissipated energy approach to study hot-mix asphalt healing in fatigue. Transportation Research Record: Journal of the Transportation Research Board, 2006(1970): p. 178-185.

102. Ukwuoma, O. and B. Ademodi, The effects of temperature and shear rate on the apparent viscosity of Nigerian oil sand bitumen. Fuel processing technology, 1999. 60(2): p. 95-101.

103. Sybilski, D., Non-Newtonian viscosity of polymer-modified bitumens. Materials and Structures, 1993. 26(1): p. 15-23.

104. Mamlouk, M.S., et al., Determination of thermal properties of asphalt mixtures. Journal of Testing and Evaluation, 2005. 33(2): p. 1-9.

105. Feng, D., J. Yi, and D. Wang, Performance and thermal evaluation of incorporating waste ceramic aggregates in wearing layer of asphalt pavement. Journal of Materials in Civil Engineering, 2013. 25(7): p. 857-863.

106. Kim, S. and L.T. Drzal, High latent heat storage and high thermal conductive phase change materials using exfoliated graphite nanoplatelets. Solar Energy Materials and Solar Cells, 2009. 93(1): p. 136-142.

107. Liu, Z., et al., Graphite blocks with high thermal conductivity derived from natural graphite flake. Carbon, 2008. 46(3): p. 414-421.

108. Luo, T. and J.R. Lloyd, Enhancement of thermal energy transport across graphene/graphite and polymer interfaces: a molecular dynamics study. Advanced Functional Materials, 2012. 22(12): p. 2495-2502. 
109. Wu, S.-p., et al., Laboratory study on solar collector of thermal conductive asphalt concrete. International Journal of Pavement Research and Technology, 2009. 2(4): p. 130-136.

110. Chen, M., et al., Study of ice and snow melting process on conductive asphalt solar collector. Solar Energy Materials and Solar Cells, 2011. 95(12): p. 32413250 .

111. Wang, H., et al., Numerical simulation on the thermal response of heatconducting asphalt pavements. Physica Scripta, 2010. 2010(T139): p. 014041.

112. Pan, P., et al., Influence of graphite on the thermal characteristics and antiageing properties of asphalt binder. Construction and Building Materials, 2014. 68: p. 220-226.

113. Dally, J.-R., WF (2005):" Experimental stress analysis" College House Enterprises LLC, Glen Cove Dr. Knoxville (4th Edition), 2005.

114. Shen, B. and G. Paulino, Direct extraction of cohesive fracture properties from digital image correlation: a hybrid inverse technique. Experimental Mechanics, 2011. 51(2): p. 143-163.

115. Küntz, M., et al., Digital image correlation analysis of crack behavior in a reinforced concrete beam during a load test. Canadian Journal of Civil Engineering, 2006. 33(11): p. 1418-1425.

116. Chehab, G.R., Y. Seo, and Y.R. Kim, Viscoelastoplastic damage characterization of asphalt-aggregate mixtures using digital image correlation. International Journal of Geomechanics, 2007.

117. Rastiello, G., et al., Real-time water permeability evolution of a localized crack in concrete under loading. Cement and Concrete Research, 2014. 56: p. 20-28.

118. Eyring, H., Viscosity, plasticity, and diffusion as examples of absolute reaction rates. The Journal of chemical physics, 1936. 4(4): p. 283-291.

119. Salomon, D. and H. Zhai. Asphalt binder flow activation energy and its significance for compaction effort. in Proc., 3rd Eurasphalt \& Eurobitume Congress. 2004.

120. Arrhenius, S., Über die Dissociationswärme und den Einfluss der Temperatur auf den Dissociationsgrad der Elektrolyte. 1889: Wilhelm Engelmann.

121. Huang, S.-C., et al., Impact of lime modification of asphalt and freeze-thaw cycling on the asphalt-aggregate interaction and moisture resistance to moisture damage. Journal of materials in civil engineering, 2005. 17(6): p. 711718.

122. Petersen, J.C., A review of the fundamentals of asphalt oxidation: chemical, physicochemical, physical property, and durability relationships.

Transportation Research E-Circular, 2009(E-C140).

123. Silverstein, R.M., G.C. Bassler, and T.C. Morrill, Spectrometric identification of organic compounds. 1974.

124. Wang, H., Z. Chen, and L. Sun, Image preprocessing methods to identify micro-cracks of road pavement. Optics and Photonics Journal, 2013. 3(02): p. 99. 
125. $\mathrm{Xu}, \mathrm{T}$. and $\mathrm{X}$. Huang, Investigation into causes of in-place rutting in asphalt pavement. Construction and Building Materials, 2012. 28(1): p. 525-530.

126. Rushing, J., D. Little, and N. Garg, Asphalt pavement analyzer used to assess rutting susceptibility of hot-mix asphalt designed for high tire pressure aircraft. Transportation Research Record: Journal of the Transportation Research Board, 2012(2296): p. 97-105.

127. Wang, H., et al., Three-dimensional modeling and simulation of asphalt concrete mixtures based on X-ray CT microstructure images. Journal of Traffic and Transportation Engineering (English Edition), 2014. 1(1): p. 55-61.

128. Clyne, T., et al., Dynamic Modulus and Resilient Modulus of Mn/DOT Asphalt Mixtures. II Minnesota Department of Transportation. 2003, MN/RC-2003-09.

129. Chen, J.S., S.Y. Wong, and K.Y. Lin, Quantification of movements of flat and elongated particles in hot mix asphalt subject to wheel load test. Materials and Structures. 38(3): p. 395-402.

130. Silva, H.M., J.R. Oliveira, and C.M. Jesus, Are totally recycled hot mix asphalts a sustainable alternative for road paving? Resources, Conservation and Recycling, 2012. 60: p. 38-48.

131. Menéndez, J., et al., Microwave heating processes involving carbon materials. Fuel Processing Technology, 2010. 91(1): p. 1-8.

132. Jones, E., Documentation for Matlab-based DIC code. University or Illinois, 2013.

133. Mathworks, Normalized 2-D cross-correlation (normxcorr2). 2012.

134. Wang, Z., et al., Experimental Investigation of Physical Properties and Accelerated Sunlight-Healing Performance of Flake Graphite and Exfoliated Graphite Nanoplatelet Modified Asphalt Materials. Construction and Building Materials, submitted, 2016.

135. Paulino, G.H., S.H. Song, and W.G. Buttlar. Cohesive zone modeling of fracture in asphalt concrete. in Proceedings of the 5th International RILEM Conference-Cracking in Pavements: Mitigation, Risk Assessment, and Preservation. 2004. Limoges, France.

136. Prandtl, L., Ein Gedankenmodell für den Zerreißvorgang spröder Körper. ZAMM-Journal of Applied Mathematics and Mechanics/Zeitschrift für Angewandte Mathematik und Mechanik, 1933. 13(2): p. 129-133.

137. Spring, D.W., Cohesive zone modeling of fracture of sustainable and functionally graded concrete. 2011.

138. Xu, X.-P. and A. Needleman, Numerical simulations of fast crack growth in brittle solids. Journal of the Mechanics and Physics of Solids, 1994. 42(9): p. 1397-1434.

139. Kim, Y.-R., D. Allen, and D. Little, Computational constitutive model for predicting nonlinear viscoelastic damage and fracture failure of asphalt concrete mixtures. International Journal of Geomechanics, 2007. 7(2): p. 102110. 
140. Kim, Y.-R., D. Allen, and D. Little, Damage-induced modeling of asphalt mixtures through computational micromechanics and cohesive zone fracture. Journal of Materials in Civil Engineering, 2005.

141. Yang, X., et al., Integrated Experimental-Numerical Approach for Estimating Asphalt Mixture Induction Healing Level through Discrete Element Modeling of a Single-Edge Notched Beam Test. Journal of Materials in Civil Engineering, 2014.

142. Rosselló, C., M. Elices, and G. Guinea, Fracture of model concrete: 2.

Fracture energy and characteristic length. Cement and Concrete research, 2006. 36(7): p. 1345-1353.

143. Version, A., 6.7 User's manual. Inc. and Dassault systemes, 2007.

144. Wagnoner, M., W. Buttlar, and G. Paulino, Disk-shaped compact tension test for asphalt concrete fracture. Experimental Mechanics, 2005. 45(3): p. 270-277. 


\section{APPENDIX: COPYRIGHT CLEARANCE}

Article 1: Copyright clearance of the journal paper "Investigation of Induction Healing Effects on Electrically Conductive Asphalt Mastic and Asphalt Concrete Beams Through Fracture-healing Tests", 2013, Construction and Building Materials. The full article is used in Chapter 2 of this dissertation. The permission of reuse this article is as below. 
Copyright

Clearance

Center

\section{RightsLink}

Title:

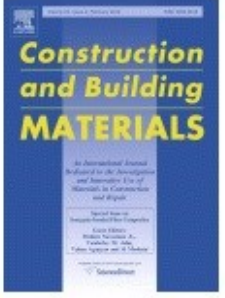

asphalt mastic and asphalt concrete beams through fracture-healing tests

Author: $\quad$ Qingli Dai,Zigeng Wang,Mohd Rosli Mohd Hasan

Publication: Construction and Building Materials

Publisher: Elsevier

Date: December 2013

Copyright (s) 2013 Elsevier Ltd. All rights reserved.

\section{Custom Permission Request}

Review the details below and click 'Submit Request'.

Elsevier will review and respond within ten business days.

\begin{tabular}{|c|c|}
\hline $\begin{array}{l}\text { Licensed content } \\
\text { publisher }\end{array}$ & Elsevier \\
\hline $\begin{array}{l}\text { Licensed content } \\
\text { publication }\end{array}$ & Construction and Building Materials \\
\hline Licensed content title & $\begin{array}{l}\text { Investigation of induction healing effects on electrically conductive asphalt mastic and asphalt } \\
\text { concrete beams through fracture-healing tests }\end{array}$ \\
\hline Licensed content author & Qingli Dai,Zigeng Wang,Mohd Rosli Mohd Hasan \\
\hline Licensed content date & December 2013 \\
\hline $\begin{array}{l}\text { Licensed content } \\
\text { volume number }\end{array}$ & 49 \\
\hline $\begin{array}{l}\text { Licensed content issue } \\
\text { number }\end{array}$ & $\mathrm{n} / \mathrm{a}$ \\
\hline Number of pages & 9 \\
\hline Type of Use & reuse in a thesis/dissertation \\
\hline Portion & cover image \\
\hline Quantity & 1 \\
\hline Format & electronic \\
\hline $\begin{array}{l}\text { Are you the author of } \\
\text { this Elsevier article? }\end{array}$ & Yes \\
\hline Will you be translating? & No \\
\hline $\begin{array}{l}\text { Title of your } \\
\text { thesis/dissertation }\end{array}$ & $\begin{array}{l}\text { INTEGRATED COMPUTATIONAL AND EXPERIMENTAL EVALUATION OF ELECTROMAGNETIC } \\
\text { ENERGY-INDUCED SELF-HEALING PERFORMANCE OF ASPHALT COMPOSITES }\end{array}$ \\
\hline $\begin{array}{l}\text { Expected completion } \\
\text { date }\end{array}$ & Jun 2016 \\
\hline $\begin{array}{l}\text { Estimated size (number } \\
\text { of pages) }\end{array}$ & 250 \\
\hline Elsevier VAT number & GB 494627212 \\
\hline Permissions price & Not Available \\
\hline VAT/Local Sales Tax & Not Available \\
\hline Total & Not Available \\
\hline
\end{tabular}

Edit Order Details 
Article 2: Copyright clearance of the journal paper "Integrated Computationalexperimental Approach for Evaluating Recovered Fracture Strength after Induction Healing of Asphalt Concrete Beam Samples", 2016, Construction and Building Materials. The full article is used in Chapter 3 of this dissertation. The permission of reuse this article is as below. 
Copyright

Clearance

Center

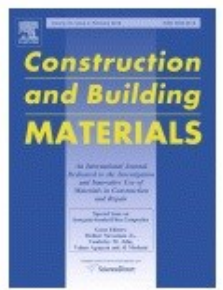

Logged in as:

zigeng wang

Account \#:

3001010591

evaluating recovered fracture

strength after induction healing

of asphalt concrete beam

samples

LOGOUT

Author: Zigeng Wang, Qingli Dai, Xu Yang

Publication: Construction and Building

Materials

Publisher: Elsevier

Date: 1 March 2016

Copyright (c) 2015 Elsevier Ltd. All rights reserved.

Permission Request Submitted

Your request is now under review.

You will be notified of the decision via email.

Please print this request for your records.

Get the printable order details.

\begin{tabular}{|c|c|}
\hline Order Number & 501129516 \\
\hline Order Date & Apr 08, 2016 \\
\hline Licensed content publisher & Elsevier \\
\hline Licensed content publication & Construction and Building Materials \\
\hline Licensed content title & $\begin{array}{l}\text { Integrated computational-experimental approach for } \\
\text { evaluating recovered fracture strength after induction healing } \\
\text { of asphalt concrete beam samples }\end{array}$ \\
\hline Licensed content author & Zigeng Wang,Qingli Dai,Xu Yang \\
\hline Licensed content date & 1 March 2016 \\
\hline $\begin{array}{l}\text { Licensed content volume } \\
\text { number }\end{array}$ & 106 \\
\hline \multicolumn{2}{|c|}{ Licensed content issue number $\mathrm{n} / \mathrm{a}$} \\
\hline Number of pages & 11 \\
\hline Type of Use & reuse in a thesis/dissertation \\
\hline Portion & cover image \\
\hline Quantity & 1 \\
\hline Format & electronic \\
\hline $\begin{array}{l}\text { Are you the author of this } \\
\text { Elsevier article? }\end{array}$ & Yes \\
\hline Will you be translating? & No \\
\hline $\begin{array}{l}\text { Title of your } \\
\text { thesis/dissertation }\end{array}$ & $\begin{array}{l}\text { INTEGRATED COMPUTATIONAL AND EXPERIMENTAL } \\
\text { EVALUATION OF ELECTROMAGNETIC ENERGY-INDUCED } \\
\text { SELF-HEALING PERFORMANCE OF ASPHALT COMPOSITES }\end{array}$ \\
\hline Expected completion date & Jun 2016 \\
\hline Elsevier VAT number & GB 494627212 \\
\hline Permissions price & Not Available \\
\hline VAT/Local Sales Tax & Not Available \\
\hline Total & Not Available \\
\hline
\end{tabular}

ORDER MORE... CLOSE WINDOW

Copyright (c) 2016 Copyright Clearance Center, Inc, All Rights Reserved. Privacy statement. Terms and Conditions.

Comments? We would like to hear from you. E-mail us at customercare@copyriaht.com 